\title{
Gradients in myocardial blood flow, metabolism and mechanics across the ischemic left ventricular wall
}

Citation for published version (APA):

Prinzen, F. W. (1982). Gradients in myocardial blood flow, metabolism and mechanics across the ischemic left ventricular wall. [Doctoral Thesis, Maastricht University]. Rijksuniversiteit Limburg. https://doi.org/10.26481/dis.19820611fp

Document status and date:

Published: 01/01/1982

DOI:

10.26481/dis.19820611fp

Document Version:

Publisher's PDF, also known as Version of record

\section{Please check the document version of this publication:}

- A submitted manuscript is the version of the article upon submission and before peer-review. There can be important differences between the submitted version and the official published version of record.

People interested in the research are advised to contact the author for the final version of the publication, or visit the DOI to the publisher's website.

- The final author version and the galley proof are versions of the publication after peer review.

- The final published version features the final layout of the paper including the volume, issue and page numbers.

Link to publication

\footnotetext{
General rights rights.

- You may freely distribute the URL identifying the publication in the public portal. please follow below link for the End User Agreement:

www.umlib.nl/taverne-license

Take down policy

If you believe that this document breaches copyright please contact us at:

repository@maastrichtuniversity.nl

providing details and we will investigate your claim.
}

Copyright and moral rights for the publications made accessible in the public portal are retained by the authors and/or other copyright owners and it is a condition of accessing publications that users recognise and abide by the legal requirements associated with these

- Users may download and print one copy of any publication from the public portal for the purpose of private study or research.

- You may not further distribute the material or use it for any profit-making activity or commercial gain

If the publication is distributed under the terms of Article $25 \mathrm{fa}$ of the Dutch Copyright Act, indicated by the "Taverne" license above, 

gradients in myocardial blood flow, metabolism and mechanics across the ischemic left ventricular wall 



\section{gradients in myocardial blood flow. metabolism and mechanics across the ischemic left ventricular wall}

\section{Proefschrift}

ter verkrijging van de graad van doctor in de geneeskunde aan de Rijksuniversiteit Limburg te Mastricht op gezag van de rectar magnificus, prof. dr. H.C. Hemker volgens besluit van het College van Dekanen in het openbaar te verdedigen in de Aula van dle Universiteit op vrijdag 11 juni 1982 des namiddags om 4.00 uur.

doar

\section{Frederik Willem Prinzen}

geboren te Hilversum. 
Promotores: Prof. dr. R.S. Reneman, University of Limburg, Mastricht, The Netherlands Prof. dr. H.R. Scholte, Erasmus Uniwersity, Rotterdam, The Netherlands

Co-promotores: dr. T. Arts, University of Limburg, Mastricht, The Netherlands dr. G.J. van der Vusse, University of Limburg, Maastricht, The Netherlands

Referentes: M.I.M. Noble, M.D., Ph.D., Midhurst Medical Research Institute, Midhurst, Sussex, England Prof. dr. G. Elzinga, Free University, Ansterdam, The Netherlands Prof. dr. F. ten Hoor, University of Limburg, Maastricht, The Netherlands

This investigation was supported by the Foundation for Medical Research FUNGO, which is subsidized by the Netherlands Organization for the Advancement of Pure Research (ZWO)

The publication of this thesis was also made possible by support of the Dutch Heart Foundation

cover designed by Sieg Sweeris 
Voor Mieke

Lenneke

en Brusje 



\section{CONTENTS}

List of symbols and abbreviations

1. General introduction

2. Survey of the literature 6

2.1 Mechanics 6

2.1.1 Global mechanics of the left ventricle and its 6 transmural distribution

2.1.2 Failure of mechanical activity during oxygen deprivation 7

2.1.3 Measurement of regional mechanical variables 10

2.1.4 Measurement of epicardial deformation 11

2.2 Energetics 12

2.2.1 Myocardial heat production 12

2.2.2 Energy-rich phosphate metabolism 12

2. 3 Substrate metabolism 13

2.3.1 Global substrate metabolism under normoxic circumstances 13

2.3.2 Transmural differences im metabolism during normoxia is

2.3.3 Substrate metabolism during ischemia 16

2.4 Myocardial blood flow 18

2.4.1 Myocardial blood flow and its transmural distribution 18

2.4.2 Measurement of regional myocardial blood flow 20

3. Methods 21

3.1 Experimental set-up 21

3.1 .1 Choice of the animal model 21

$\begin{array}{ll}3.1 .2 \text { Anesthesia } & 21\end{array}$

3.1.3 Instrumentation $\quad 22$

3.1.4 Stenasis system 24

3.1 .5 Technique of blood sampling 25

3.1 .6 Techniques of tissue sampling 26

3.1.7 Anti-coagulation $\quad 27$

3.2 Hemodynamic measurements 28

3.2.1 Introduction 28

3.2 .2 Blood pressures and derived parameters 29

3.2.3 Bilood flaw (electromagnetically measured) 30

3.2 .4 Cardiac output 30

3.2 .4 .1 Introduction 30

3.2.4.2 Instrumentation 31

3.2.4.3 Calculation of cardiac output 31

3.2.4.4 Accuracy of the cardiac output determination 32

3.3 Regional mechanical function 33

3.3.1 Introduction 33

3.3.2 Epicardial deformation 33

3.3.2.1 Principles and instrumentation 33

3.3.2.2 Assessment of epi and subendocardial fiber 35 shortening

3.3.3 Transmural differences in deformation 37

$\begin{array}{ll}3.3 .3 .1 \text { Principles } & 37\end{array}$

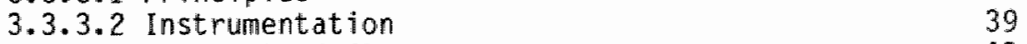

3.4 Regional myocardial blood flow 40

3.4.1 Introduction 40

3.4.2 Choice of the type of microspheres 40 
3.4.3 Checks before experimental use

3.4.4 Experimental use of microspheres

3.4 .5 Calculation of regional blood flow

3.4.6 Accuracy of the method

3.4.7 Comparison between 34 and NEN microspheres

3.5 Detemination of chemical substances in blood

3.5.1 Introduction

3.5.2 Blood gases and blood pH

3.5.3 Hemoglobine, oxygen saturation and oxygen content

3.5.4 Glucose, lactate, inorganic phosphate and potassium

3.5 .5 Non-esterified fatty acids

3.5.6 Triacylglycerol

3.6 Determination of chemical substances in myocardial tissue 60

3.6 .1 Introduction

3.6.2 Handling of the tissue samples

60

3.6.3 ATP, creatine phosphate and glycogen

3.6.4 Fatty acids

60

60

62

3.7 Assessment of myocardial metabolism

3.8 Relation between blood flow, metabolism and mechanics

4. Investigation on the homogeneity in time and space of myocardial mechanical performance, biood flow and metabolism in the nomally perfused left ventricle: evaluation of the experimental mode1

4.1 Introduction

4.2 Stability of the preparation during two hours of normia $1 \quad 68$ perfusion

4.2.1 Protocol

66

4.2.2 Results

4.2.2.1 Hemodynamic variables

4.2.2.2 Biochemical variables in blood

4.2.2.3 Biochemical variables in myocardial tissue

4.2.2.4 Mechanical variables

4.2.2.5 Myocardial blood flow

4.2 .3 Discussion

4.3 Regional differences in left ventricular blood flow and metabolism during normal perfuston

4.3.1 Protocol

4.3.1.1 Blochemical variables in myocardial tissue

4.3.1.2 Myocardial blood flow

4.3 .2 Results

4.3.2.1 Biochemical variables in myocardial tissue 76

4.3.2.1 Myocardial blood flow

4.3.3 Discussion

4.3.3.1 Biochemical variables in myocardial tissue

4.4 Conclusions

4.3.3.2 Myocardial blood flow

68

68

68

70

70

70

72

72

74

74

74

74

76

76

76

76

79

81

5. Prediction of fiber shortening in the inner layers of the left

ventricular wall from epicardial deformation measurements

during normoxia and ischemia

5.1 Introduction

82

5.2 Experimental design 
5.2.2 Data analysis $\quad 85$

5.3 Results 85

5.3.1 Epicardial defomation (group I) 85

5.3.2 Transmural deformation (group [I) 89

5.4 Discussion 91

5.4.1 Reliability of the assessment of the transmural course
of fiber shortening from epicardial deformation

5.4.2 Transmural differences in the changes of shortening 95 along the approximate fiber direction

5.4.3 Comparison of measured and predicted transmural 96

5.5 Conclusions deformation

6. Relationship between fiber shortening, myocardial blood flow

and metabolism in the various layers of the left ventricular wall within 5 minutes after coronary artery stenosis

6.1 Introduction

6.2 Experimental design 98

6.2.1 Protocal 98

6.2.2 Data analysis $\quad 99$

6.3 Results 101

6.3.1 Inducement of stenosis 101

6.3.2 Time course of regional mechanical variables 101

6.3.3 Time course of regional myocardial blood flow 103

6.3.4 Time course of regional metabolic variables 103

6.3.5 Estimation of ATP utilization in the inner and outer 105

1 ayers during normoxica and ischemia

6.3.6 Time course of hemodymamic variables 108

6.4 Discussion 108

6.4.1 Effects of ischemia on general hemodynamics 108

6.4.2 Effects of ischemia on myocardial blood flow 108

6.4.3 Effects of ischemia on myocardial metabolism 109

6.4.4 Relation between cessation of shortening and 111 myocardial blood flow and metabolism

6.4.5 Changes of mechanical activity in the left ventricular 113

6.5 Conclusions wall during ischemi

7. Time course of changes in blood flow, local mechanics and metabolism in myocardial tissue during $120 \mathrm{~min}$ of ischenia with special reference to accumulation of NEFA

7.1 Introduction 117

7.2 Experimental design 117

$\begin{array}{ll}7.2 .1 \text { Protocal } & 117\end{array}$

$\begin{array}{ll}7.2 .2 \text { Data analysis } & 120\end{array}$

7. 3 Results

7.3.1 Time course of hemodynamic variables during 2. hours 1.20 of regional ischemila

7.3.2 Time course of regional myocardial blood flaw 122

7.3.3 Time course of fatty acid contents during ischemia 122

7.3.4 Time course of myocardial content of ATP, creatine 1.26 phosphate and glycogen during ischemia

7.3.5 Time course of biochemical variables in the blood 126

7.3.6 Time course of regional mechanical variables 128 
7.3.7 The relation between NEFA content and the blood flow 130 and ATP content in myocardial tissue

7.4 Discussion

7.4.1 Effect of ischemia on global and regional myocardial 130 function

7.4.2 Effect of ischemia on myocardial blood flow 132

7.4.3 Effect of ischemia on myocardial metabolism 133

7.4.4 Effect of ischemia on myocardial content of fatty acids 134

7.4.5 Possible sources of NEFA accumulation in the outer 135 layers after 60 minutes of ischemia

7.4.6 Possible sources of NEFA accumulation in the inner 137 layers

7.4.7 Discussion on the harmful effects of MEFA accumulation 138

7.5 Conclusions

8. The effect of elevated arterial non-esterified fatty acid concentrations on hernodynamics and myocardial blood flow and metabolism during ischemia

8.1 Introduction

8.2 Experimental design

8.2.1 Protocol

140

8.2.2 Data analysis

142

8.3 Results

142

8.3. I Hemodynamic variables

8.3.2 Regional myocardial blood flow

8.3.3 Biochemical variables

8.3.4 In vitro effect of intralipid on hemoglobin ( $\mathrm{Hb}$ ) measurements

8.4 Discussion

8.4. I Artificial elevation of arterial NEFA concentrations

8.4.2 Effect of elevated arterial NEFA concentrations on myocardial blood fllow

8.4.3 Effect of elevated arterfal NEFA concentration on myocardial metabolism

8.4.4 Effect of elevated arterial NEFA concentration on hernodynamics

8.5 Conclusions 
ATP

AV (difference)

$B_{\min }$

$B_{\min , \text { endo }}$

$\gamma$

$d p_{\prod v} / d t \max$

ECG

endo/epi ratio

$e_{c}$

endo

$\mathrm{e}_{\max }$

$\mathrm{e}_{\max , \text { endo }}$

emin

emin,endo

$e_{z}$

endo

epi

i.m.

i.v.

LAICA

LCCA

MFGC

MBF

meso

$\mathrm{n}$

NEFA

$p_{a 0}$

$\mathrm{P}_{\text {cor }}$

$p_{T V}$

$p_{\text {Ived }}$ adenosine triphosphate

arterio-local venous difference (mol. $1^{-1}$ )

angle of epicardial minimal shortening with the circumference (rad)

angle of minimal shortening in the inner layers with the circumference (rad)

shear angle (rad)

maximal first positive derivative of left ventricular pressure $\left(\mathrm{kPa} . \mathrm{s}^{-1}\right.$ )

electrocardiogram

endo/epicardial blood flow ratio

circumferential shortening $(\%)$

shortening in the inner layers in the direction of (epicardial) $e_{\min }(x)$

maximal shortening on the epicardium $(\%)$

maximal shortening in the inner layers (\%)

minimal shortening on the epicardiun $(\%)$

minimal shortening in the inner layers $(\%)$

base-to-apex shortening ( $\%)$

inner layers $(1 / 3)$ of the left ventricular wall

outer layers $(1 / 3)$ of the left ventricular wall

intramuscular

intravenous

left anterior interventricular coronary artery

left circumflex coronary artery

magnetic field generating coil

myocardial blood flow

middle layers (1/3) of the left ventricular wall

number of observations

non-esterified fatty acids

aortic pressure

coronary artery pressure distal to the site of stenosis

left ventricular pressure

end-diastolic left ventricular pressure 
$\mathrm{pH}$

$\mathrm{PCO}_{\mathrm{C}}$

$\mathrm{PO} 2$

5

SC negative logarithm of hydrogen fon concentration partial carbondioxide tension partial oxygen tension

second $(s)$

sensor colit

Tissue contents of the various substances are expressed as mol. $\mathrm{g}^{-1}$ wet wellght, unless explicitely mentioned otherwise. 


\section{GENERAL INTRODUCTION}

It is well known that myocardial ischemia as a result of narrowing (stenosis) of a coronary artery is most pronounced in the subendocardial (or inner) layers of the heart muscle. The greater vulnerability of the inner layers is demonstrated not only by the significantly lower blood flow in these layers during ischemia as compared with the other layers of the myocardium (Jageneau et a1, 1975; Reneman et a), 1975; Bache et a1, 1977; Nakamura et a1, 1977; Schamhardt et al, 1979), but also by the bjochemical changes in the different layers under these circumstances. A significantly higher lactate content has been found in the inner than in the outer layers after coronary artery stenosis or acclusion. Al so a mare pronounced decrease of giycogen and creatine phosphate in the inner than in the outer layers has been shown (Griggs et al, 1972; Opie et al, 1975; Opie and Owen, 1976; Higuchi et al, 1981). However, assessment of tissue ATP contents showed contradictory results. Griggs et al (1972) found that after coronary artery stenosis the decrease and the transmural differences in ATP content were not statistically significant. In contrast, Opie and Owen (1976) found a distinct decrease (90\% or more) im ATP concentration in the inner layers and a moderate decrease (only 30\%) in the outer layers. This discrepancy may result from differences in experimental set-up and/or sample interval after the onset of ischemia. A time course of tissue contents of ATP, creatine phosphate as well as of inorganic phosphate in the venous effluence has been found (Opie et al, 1972), while Higuchi et al (1981) showed that the decrease and the transmural gradient of ATP content were dependent on the degree of ischemia.

Beside changes in blood flow and metabolism, changes in regional mechanical activity do occur following the inducement of myocardial ischemta tTennant and Wiggers, 1935; Hood et al, 1969; Van der Meer et a1, 1973; Banka and He1fant, 1974; Theroux et all, 1976). These studies, however, do not provide data on differences in mechanical activity between ininer and outer layers under these circumstances. Consequently, it is not known whether there is a relation between the decrease in blood flow and mechanical activity and the metabolic changes in the various layers of the myocardium. Diminution or cessation of mechanical activity could be directly related to factors inhibiting this activity like high cellular concentrations af hydrogen lons (Katz and Hecht, 1969; Poole Wilson and Langer, 1976), inarganic phosphate (Kuebier and Katz, 1977) or fatty acids (Katz and Messineo, 1981), or depletion of energy- 
rich phosphates (Gudbjarnason et a1, 1970; Hearse, 1979) or glycogen (Rovetto. 1979 ).

Horeover, it is important to know the time course of mechanical activity during the whole period of ischemia. A time-dependent decrease in local mechanical activity during this period could be responsible for the decrease in arterio-venous differences for potasstum, lactate and inorganic phosphate as observed during: stenosis of a coronary artery (Owen et a1, 1970; 0pie et a1, 1972; Van der Vusse et a1, 1980).

Energy for processes is achieved from the residual aerobic metabolism and anderobic glycolysis. Because of the low oxygen uptake and the inefficient ATP production from anaerobic glycolysis under these circumstances, insufficlent energy may be delivered to maintain cell viability during ischemia. Beside low ATP concentrations, depletion of glycogen stores and accumulation of lactate have been mentioned to coincide irreversable damage (Reimer et al, 1973, 1981; Jennings et a1, 1981).

Abnormaltties in lipid metabolism may be involved in cell death. Although during ischemia fatty acid combustion is impaired (shug et al, 1978), fatty acids are still taken up from the blood (Opie et al, 1973). This could lead to increased tissue contents of triacylglycerol or non-esterified fatty acids (NEFA) (Lochner et a1, 1978). NEFA accumulation could also origin from breakdown of phospholipids which are present in cellular membranes (Vasdev et all, 1980). The few data on this subject presented in 7iterature are contradictory. No signifficant (Regan et a1, 1972; Haider et al, 1977) and elevated NEFA contents (Weishaar et a1, 1977, 1979; Van der Vusse et al, 1982) have been described following oxygen deficiency. Moreover, no clear information is avaliable about the time course of this elevation during ischemia, and NEFA contents reported in these studies vary greatly in the normoxic as well as in the ischemic situation.

High NEFA contents are thought to be harmful for the ischemic myocardium. In vitro experiments with isolated enzymes and subcellular fractions have shown that high NEFA concentrations can inhiblit enzyme activities and mitachondrial energy production (Katz and Messineo, 1981). Elevated plasma NEFA concentrations are related to ventricular arrhythmias (Kurien and 01iver, 1966). It is not known whether this noxious effect also originates from increased intracellular NEFA contents under these circumstances or from a direct effect of the high plasma NEFA concentrations on membrames.

knowledge about the relation between blood flow, metabolism and mechani- 
cal activity in the various myocardial layers during ischemia is important.

- Firstly, to get insight into the mechanism(s) inwolved in the cessation of mechanical activity during ischemia.

- Secondly, this relation has never been studied extensively.

- Thirdly, it is known that without impaiment of the coronary circulation, generated energy as well as blood flow per unit of tissue volume in the different layers of the myocardial wall depends on the hemodynamic load (Buckberg et al, 1972; Vipintsoi et al, 1973; Arts, 1978) and treatment of ischemic heart failure is generally employed by changing preload or afterload

- Fourthly, the metabolism of fatty acids during ischemia is important because accumulation of NEFA can either be a cause or a result of irreversible damage, as well as a cause of detrimental events for the whole heart.

The relation between blood flow, metabolism and mechanical activity in the various layers of the myocandium was investigated in an open-chest dog preparation. Regional ischemia was induced by narrowing the left anterior interventricular coronary artery was by an inflatable cuff. The degree of inflation of the cuff was controled by the post-stenotic coronary artery pressure, so that a reproducible degree of ischemia could be obtained. Blood flow within various layers of the normoxic and ischemic left ventricular myacardium was measured with the radioactive microsphere technique (reviewed by Heymann et al, 1977). Regional mechanical activity in the ischemic area was determined by measurement of epicardial surface deformation as described by Arts and Reneman (1980). Evidence will be shawm that this technique provides relevant infomation about the shortening along the subendocardial fiber direction in the inner and outer layers. Metabolism in the normoxic and ischemic tissue was assessed by measurement of concentrations of ATP, creatine phosphate, glycogen and fatty acids in tissue samples as well as by measurement of differences in the concentrations of oxygen, glucose, fatty acids, lactate, imarganic phosphate and potassium between arterial blood and blood sampled from a local vein, that drains the ischemic area. 


\section{SURVEY OF THE LITERATURE}

\subsection{Mechanics}

\subsubsection{Global mechanics of the left ventricle and its transmural mechanical distribution.}

The basic structure of the vertebrate heart muscle is characterized by muscie cells (fibers) arranged in collumns (Spiro and Sonnenblick, 1965). Light microscopic examination reveals these cells to be roughly cylindrical in

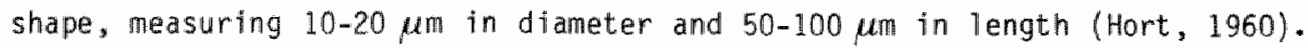
The myocardial wall is composed of a well ardened fiber-wound continum of interconnected muscle fibers. Studies in the dog (streeter et al, 1969) and macaque (Ross and streeter, 1975) have shown that the orientation of the fibers is nearly vertical (i.e. perpendicular to the circumferential direction) at both epicardial and endocardial surfaces. In moving through the ventricular wall, fiber direction undergoes a marked change such that the angle made with the circumferential direction is about $60^{\circ}$ for the fibers near the inner surface, about $0^{\circ}$ for the fibers in the middle of the wall and about $-60^{\circ}$ for the fibers near the epicardial surface. Studies of Torrent Guasp (1973) showed that the above-mentioned orientation, as established by sampling tissue from a certain area of the left ventricle, is a result of the course of strings of fibers through the wall: roughly a three-dimensional eight-shaped curve.

This architecture of the left ventricle not only results in a predaminant circumferential decrease of size during ejection, but also in rotation of the apex around the long axis of the ventricle with respect to the base during contraction. This movement, already observed by Leonardo da Vinci (Evans, 1936), is called torsion. Studies of Streeter et al (1970) showed the importance of the complex fiber orientation with respect to transmural fiber stress distribution. Moreover, Arts (1978) predicted from a mathematical model that fiber stress and fiber shortening (and therefore energy demand) are rather homogeneously distributed across the left ventricular wall. The latter homogeneity is enabled by the occurrence of torsion.

Attempts have been made to assess transmural distribution of workload from intramyocardial pressure measurements. Amour and Randall (1971) found a higher systolic pressure in the inner than in the outer layers but calculation of developed tension revealed that this tension was slightly lower in 
the inner layers due to the smaller diameter of the ventricle in the inner than for the outer layers. However, Marzilli et al (1980, 1981) concluded from their data, that the work load in the inner layers would be considerably higher than in the outer layers due to a higher systolic intramyocardial pressure $(200 \%)$, rate of rise of this pressure $(270 \%)$, and shortening velocity (190\%) as well as a more pronounced shortening in the inner layers. These results, however, should be interpretated with care, because measurement of intramyocardial pressure is subject to errors and generally the values are overestimated (see below), measured values of shortening highly depend on correct arientation of the ultrasonic crystals, e.g. parallel to the fiber direction, and last but not least, lacal workload is not related to intramyocardial pressure.

The above-mentioned findings seem to be in conflict with the findings that axygen consumption in the inner layers is only 1.3-1.6 times wigher than in the outer layers. (Holtz et al, 1977; Weiss et al, 1978). These values, which may even be overestimations of the real transmural gradient (see below), suggest only a moderate transmural difference in workload.

\subsubsection{Failure of mechanical activity during oxygen deprivation}

After the onset of acute ischemia or anoxia, myocardial mechanical function is impaired within seconds (Tennant and Wiggers, 1935; Theroux et al, 1976; Lab et a1, 1978; Hearse, 1979). Several hypotheses have been developed to explain this "early contractile fallure".

A. Oxygen deprivation induced changes in cardiac contractile proteins (Katz and Hecht, 1969). This hypothesis is not very likely because even after prolonged ischemia no irreversible damage could be detected in the contractile proteins (Kako and Bing, 1958; Barany et al, 1964; Katz and Maxwel1, 1964) or in the myofibrillar ATPase (Albert and Gordon, 1962).

B. Proton-induced changes in calcium homeostasis. The increased hydrogen ion concentration would interfere with the calclum binding to troponin (Katz and Hecht, 1969) or with mechanisms involved in the regulation of cytoplasmatic calcium concentrations (reviewed by Nayler et al, 1979). Several arguments have been raised against decreased $\mathrm{pH}$ as first responsible factor for the decline of contraction, such as:

a. the source of early praton production, if any, is not clear: neither carbondioxide nor anaerobic glycolysis are believed to cause a dramatic fall in $\mathrm{pH}$ in early ischemia (Opie, 1976; Gevers, 1977; Hearse, 1979). 
Moreover, proton consuning creatine phosphate breakdown in the first moments after oxygen deprivation would rather cause a transient alkalosis (Danforth, 1965; Gevers, 1977 ).

b. aithough tissue pH measurements may still be debatable, these determinations did not reveal an impressive decline in $\mathrm{pH}$ when mechanical function decreased during ischemia (Poole-wilson, 1975; Cobbe and PooleWil son, 1980).

c. comparing ischemia and hypoxia, Cobbe and Poole-wilson (1980) showed that under the former circumstances, aclidosis developped earlier and more severely, while the decline in tension development occurred at the same time in both cases.

C. Fatty acid induced changes in calclum homeostasis. Elevated concentrations of non-esterified fatty acids (NEFA), acyl-COA or acylcarnitine could interfere with calcium influx during electrical activation as may be concluded from in vitro experiments (reviewed by Katz and Messineo, 1981). Higher contents of the afore-mentioned fatty acid-esters, as in non-working hearts from diabetic rats, coincided with a faster rate of ventricular failure of these hearts as compared with hearts from normal rats (Feuvray et al, 1979). Extrapolation of in vitro results to the myocardial cell in situ should be done with caution, because addition of albumin, a NEFA-binding protein, can abolish or greatly depress in witro effects of NEFA (Borst et a1, 1962). Specific binding proteins are known to be present in the myocardial cell (Mishkin et al, 1972; Ockner et al, 1972; Glaster and Harris, 1977). If high cellular NEFA concentrations would be hamiful for the Ischemic myocardium, the proposed deleterious effects should be preceeded by a NEFA accumulation. In chapter 6 the time course of the decrease in mechanical performance will be studied and the NEFA accumulation in chapter 7 .

D. ATP depletion induced uncoupling of the excitation-contraction mechanism. After al1, sudden oxygen deprivation will cause a decrease in ATP concentration. However, this simple and attractive hypothesis has been dismissed on the basis of reports which showed sufficient quantities of ATP when the contractile activity was severely reduced (Braasch et a1, 1968; Katz, 1968; Williamson et al, 1976). Mevertheless, recently, arguments were found, which stress the importance of the degradation of energy-mich phosphates: 
a. relatively moderate decreases in ATP concentrations may al ready cause a reduction in contractility through the modulatory role of ATP in calcium movements (Kuebler and Katz, 1977).

b. a relatively small decline in energy-rich phosphates yields considerable amounts of inorganic phosphate when compared with the nomally occurring intracellular inorganic phosphate concentration. This could promote calcium precipitation, preventing calcium to react with the contractile proteins. Kuebler and Katz (1977) calculated an 8-fold increase in inorganic phosphate concentrations, while tissue contents have been shown to increase only 1.5 to 2-fold in the early phase of ischemia (Imai et a1, 1979; Higuchi et a), 1981). The difference between calculated and measured values might be due to the release of inorganic phosphate from the ischemic myocardium (Opie et a7, 1972; Van der vusse et al, 1979). Moreover, the observation that during hypoxia the inorganic phosphate content hardly increased while developed tension declined (Dhalla et al, 1972) further invalidates this "phosphate trap" theory.

c. ATP could exist in discrete cellular compiartments and depletion of one sma11 compartment, not detected by determination of the content in the whole biopsy, might be responsible for the decline in contractile energy (Gudbjarnason et al, 1970). These authors postulated inhibition of intracellular energy transfer in ischemic muscle by a breakdown of the unidirectional phosphocreatine energy shuttle. Also ATP compartments have been suggested to exist in the proximity of the contractile proteins (Yagi and Mase, 1965) and the cell membrane (Bricknell and Opie, 1978). Existence of ATP compartments has become more likely because of the observation that ATP is produced by glycolysis and not the total ATP content is inversely related to development of contracture during ischemia (Bricknell et al, 1981).

d. Recently, in a preliminary report Kammemeier and coinvestigators (1981) suggested that a reduction in the free energy from ATP hydrolysis could be responsible for the early mechanical failure. This free energy is dependent on the logarithm of the phosphorylation potential:

$$
\frac{\text { [ATP ] }}{[\text { ADP }]\left[P_{i}\right]}
$$

With impaired ATP synthesis and continuing energy consumption, even a small decrease in [ATP] will lead to increases in ADP ([ADP]) and even more in $[\mathrm{Pi}]$ by the rapid breakdown of creatine phosphate, and thus in 
a marked decrease in the phosphorylation potential. This decrease might reach levels below the free energy per mole $(\Delta G)$ needed by actomyosine ATPase for the reactions resulting in contraction. Indeed, Kammemeier et al (1981) showed that in the hypoxic non-working isolated perfused rat heart cessation of contraction paralleled the decline in the calculated free energy from ATP hydrolysis. In these calculations, they estimated the cytoplasmatic concentrations of the substances of interest as estimated by Giesen and Kamnermeier (1980). Also in the isolated guinea pig heart, the phosphorylation potential (as calculated from the tissue contents) dramatically falls within half a minute after onset of ischemia, synchronously with the decrease in mechanical perfomance (Imai et al, 1979). This theory will be difficult to prove, because the cytosolic phosphorylation potential will control contractile activity, but only total tissue contents can be measured with the techniques presently available.

\subsubsection{Measurement of regional mechanical variables}

Parameters related to regional cardiac mechanics are (a) local fiber stress (or generated mechanical power per unit of tissue volume), (b) velocity of sarcomere shortening, (c) intramyacardial pressure, and (d) epicardial deformation. Assessment of regional left ventricular mechanics is difficult because of limitations of the measuring techniques for these parameters:

- in spite of several attempts (Feigl et al, 1967; Burns et al, 1971; Mchale and Greenfield, 1973), direct determination of local wall stress remains difficult and unreliable because of artefacts like tissue injury at the site of measurement (Huisman et a1, 1980).

- sarcomere length (Yaran et al, 1973; Grimm et al, 1980) and fiber orientation (Streeter and Hanna, 1973) can only be measured in the post-mortem heart.

- measurement of intramyocardial pressure is difficult and probably unreliable because the techniques used until now induce damage or disalignment of the contractile fibers (Arts and Reneman, 1977). Damage will enlarge the fluid cavity in which the intramyocardial pressure is measured resulting in an underpressure within the cavity causing an underestimation of intramyocardial pressure. Disalignment will increase the pressure in this compartment as a consequence of La Place's law.

In the absence of a direct and accurate technique to measure transmural 
distribution of fiber stress and intramyocardial pressure, in the present study regional myocardial fiber mechanics are assessed from left ventricular wall deformation, as assessed on the epicardial surface.

\subsubsection{Measurement of epicardial deformation}

Detemination of epicardial defomation during systole is useful in study ing the process of cardiac contraction (Fenton et a1, 1978; Lab and Woollard, 1978; Arts, 1978; Arts et al, 1980 and 1982b). During ejection of the left ventricle, locally measured circumferential and axial strain detemine the decrease of the epicardial surface which is directly related to the contribution of local myocardial tissue to total pump function of the left ventricle (Arts et al, 1982b). Epicardial shear is related to torsion of the left ventricle which is defined as a rotation of the apex around the axis of the left ventricle with respect to the base. Analysis of the mechanics of the left ventricle during ejection in a mathematical model revealed that the transmural distribution of fiber shortening was related to the amount of torsion of the left ventricle. In vivo measurements of epicardial shear (Arts et al, 1982b) compared favorably with the calculated values of these parameters. Therefore, it is likely, that the amount of torsion af the left ventricle determines the transmural distribution of fiber shortening. Thus, indirectly, information can be obtained about the transmural contractile behavior by measuring strains and shear angle at the surface of the heart.

Techniques to measure segment length on the heart are: (a) the determination of the distance between opaque markers, implanted on the epicardial surface using $x$-ray film or video recording techniques (Carlsson, 1969; Fenton et al, 1978), and (b) measurement of epicardial segment length by strain gauges (Lab and Woollard, 1978), inductive coils (Irisawa et a1, 1959; Wilson et al, 1963; Guntheroth, 1969; Hinds et al, 1969), or a pair of piezoelectric crystals, measuring the transit time of ultrasound which is proportianal to the distance between the crystals (Rushmer et al, 1956; Stegal et a), 1967).

Recently. Arts and Reneman (1980) described a new method for the assessment of epicardial deformation, which is basically an inductive technique. Advantages of this technique are low noise, high sensitivity and good stability. Matural strains were derived electronically from changes in the amplitude of the signals induced in sensor coils. Moreover, application in openchest experiments is easy because the inductive coils are simply sucked on 
the epicardium.

\subsection{Energetics}

\subsubsection{Myocardial heat production}

This subject has been extensively reviewed by Gibos (1978). The mechanical energy performed by the left ventricle is a result of metabolic processes in which the first law of themodynamics is applicable. The total energy produced by the heart can thus be assessed by investigating the sum of external power and heat production. Global ventricular heat production can be reliably estimated through calculation of the product of coronary blood flow and the arterio-venous temperature difference while correcting for the fraction of heat that is not carried away by the coronary blood but dissipated to ventricular cavities, mediastinum and lungs as well as the small fraction that is last through endothermic reactions in the coronary blood (Bui-Monghung et al, 1981; Ten Velden et a1, 1982).

For the purpose of the present study, measurement of local heat production within 3 layers of the ventricular wall is required. During the initial phase of the study we were confrontated with the problems encountered by $d r$. G.H.M." Ten Velden and his colleagues in using heat production as a measure of myocardial work. We are grateful to them showing us their original experimental results, far before they were published. Ten velden (1982) concluded from his study that the possibility to detect differences in metabolic activity from local heat production seems to be limited due to geometric factors at a certain location (such as wall thickness and irregullar wall surface) and by the possible dependency on blood flow direction. It is to be expected that

inducement of ischemia results in an even more complex situation by the inhomogeneity of nyocardial blood flow.

Regarding these problems, it was concluded that determination of lacal heat production would give little valid information about myocardial energetics during ischemia in relation to blood flaw and metabolism in different layers of the left ventricle.

\subsubsection{Energy-rich phosphate metabol ism}

In situ the rate of degradation and resynthesis of ATP is difficult to measure (Glbbs, 1978; Vary et al, 1981). The absolute contents of ATP and creatine phosphate in myocardial tissue only give information about the 
availability of these substances at a certain tine. This is in agreement with the finding that during normal perfusion, no relation exists between myocardial blood flow and ATP content (Kleinert and Weiss, 1981). Therefore, although most authors found a lower content of ATP and creatine phosphate in the inner layers (Boerth et a1, 1969; Dunn and Griggs, 1975; Ichihara and Abiko, 1975; Allison et al, 1978) but not by others (Griggs et a1, 1972; opie, 1976), this cannot be used as evidence for a higher energy demand of these layers.

In the present study, ATP and creatine phosphate contents have been determined to assess the amounts of these substances present under ischemic conditions. Decreased contents of these substances have been mentioned to be related to impaired mechanical actiwity and irreversible cell damage (Gudbjarnason et a1, 1970; Jennings et al, 1978; Hearse, 1979; Reimer et al, 1981). The time course of the breakdown of energy-rich phosphates was also assessed by measuring the release of inorganic phosphate into the local venous blood draining the ischemic area.

\subsection{Substrate metabolism}

\subsubsection{Global substrate metabolism under nomoxic cilrcumstances}

Cardiac energy metabolism is highly oxygen-dependent. Even at reduced axygen supply, oxidative metabolism remains the predominant source (over 90\%) of residual ATP production (Neely et al, 1975; Opie, 1976). Myocardial tissue is able to extract almost all oxygen from the blood. Under nommoxic conditions, the extraction of oxygen from the arterial content is 60-70\% (Van der vusse et al, 1979; 1981a) which favors the hypothesis that myocardial blood flow is directly related to the oxygen consumption of the blood (Mohrman and Feligl, 1978). During ischemia, up to 90\% of the arterial oxygen content is extracted (Van der Vusse et al, 1979); *

of the variety of fuels avallable to the aerobic heart, the major substrates are NEFA, lactate, glucose and triacylglyceral. Their rates of incorporation and utilization are dependent on their respective concentrations in blood, the availability of hormones (like insulin, catecholamines) and the metabolic rate of oxidative phosphorylation as determined by the mechanical activity of the heart.

Historically, the incorporation and utilization of glucose as a cardiac substrate has received the greatest attention and detailed knowledge of its 
regulation is avallable.

The nomal rates of glucose utillization are low and NEFA and lactate are preferentially utillzed when present. Uptake of glucose by the myocytes is carrier mediated, not dependent on energy but highly dependent on the presence of insulin.

Uptake of lactate by normoxic myocardium has been described extensively. At high arteriall concentrations, lactate may be responsible for up to $87 \%$ of tatal $\mathrm{CO}_{2}$ production or axygen consumption (Drake et a1, 1980; De Jong, 1977a) The mechanism of lactate uptake, however, is poorly understood. Chiong (1973) has communicated a myocardium-arterial blood gradient of lactate under normoxic conditions so that an active transport mechanism in the myocardium may be responsible for the uptake of this substrate. This is in agreement with the findings of apie and Mansford (1971) in the isolated heart preparation.

NEFA are oxidized in preference to carbohydrates and in aerobic hearts nomally account for more than half the substrates utilized for axidative metabolism. About half of the NEFA taken up from the blood is oleic acid (Rothling and Bing, 1961; Van der Vusse et a1, 1982). Serum triacylglycerol fatty acids are a potential source of substrates for myocardial tisue. However, uptake of these fatty acids from the blood is only possible in the presence of lipoprotein lipase on the endothelial cells (Jansen, 1975) an enzyme released by heparin. Also triacylglycerol uptake may be dependent on anesthesia and manipulation of the heart (Van der Vusse et a , 1981a).

Under simillar conditions, the sum of the oxygen equivalences of the four substrates mentioned above is lower than the measured oxygen uptake by the heart (Van der Vusse et a1, 1981a). This indicates that other substrates are extracted or that endogenous stores of triacylglycerol and/or glycogen are used. This would imply that no steady state is reached under these experimental conditions. However, in chapter 4, it will be shown that under normoxic conditions the myocardial glycogen content does not change within a periad of 2 hours. The metabolism of these endogenous substrate stores has been reviewed recently by Van der Vusse and Reneman (1982).

\subsubsection{Transmural differences in metabolism during normoxia}

Because of the supposed higher workload in the inner than in the outer layers of the left ventricular wall, much attention has been payed to metabolic differences between these layers, especially since differences in 
workload itsellf cannot be measured adequately.

Glycogen content has been shown to be higher in the inmer than in the outer layers in dog as well as in ox hearts Jedeikin, 1964; Ichihara and Abiko, 1975; Allison et al, 1977). Carefully performed dissection studies revealed that especially the conductive tissue (i.e. buinde of His and Purkinje fibers) contained large amounts of glycogen (Jedeikin, 1964) which was substantiated by an electronmicroscopic study of Crass and Sterrett (1975).

Triacylglycerol contents have been found to be about 2.5 times higher in the outer than in the middle and inner layers of the left ventricle (crass and Sterrett, 1975; Jesmok et al, 1978; Van der Vusse et al, 1982). However, since fat is macroscapically visible in the perivascular epicardial regions, the observed transmural gradient of triacylglycerol does not necessarily imply a difference in content of fat in the myocytes of the various myocardial layers.

No information could be found about transmural differences in glucose content. NEFA contents in the inner, middle and outer layers are not significantly different (Van der Vusse et $a 1,1981 b ; 1982$ ). Contents of lactate and pyruvate in the inner layers have been found to be 1-1.5 times the contents in the outer layers, the difference being not significant for lactate in 2 out of 5 and for pyruwate in 1 aut of 2 studies (Griggs et al, 1972; Dunn and Griggs, 1975; Ichihara and Abiko, 1975; Opie, 1976; A11ison et a1, 1977). G1 ucose-6-phosphate has been shown to be 1.5 times higher in the inner than in the outer layers (Ichihara and Abiko, 1975). The higher glycolytic activity in the inner layers as suggested by these results is in agreement with the findings of Lundsgaard-Hansen et al (1967) who reported higher contents of 4 glycolytic enzymes (including lactate hydrogenase) in the inner layers. However, transmural gradients of the latter enzmme were not found in more recent investigations (Dowel1, 1978; Visser et al, 1981). One should realize that these data only refer to the content of substances and emzymes at a certain monent and do not give direct information about the actual glycolytic flux in vivo.

axygen extraction in the various layers has been measured by microspectrophotometric observations of small regional arteries and veins. Under normoxic conditions, oxygen extraction was higher in the inner than in the outer layers. Multiplication of these values with those of regional myocardial bload flow resulted in 1.3 and 1.6 times higher oxygen uptake values in the inner layers than in the outer layers (Holtz et a1, 1977; Weiss et a1, 1978). 
These values might be an overestimation of the actual transmural gradient in oxygen uptake since the employed technique for the measurement of regional myocardial blood flow in these studies (e.g. radiaactive microspheres) likelly owerestimates blood flow in the inner layers (section 3.4.2). These results imply that the energy demand of the inner layers exceeds that of the outer layers but not as much as has been suggested by calculation of this demand from measured intramyocardial pressure (Marzilli et al, 1980; 1981). In fact, the differences in oxygen consumption between the inner and auter layers might be small, which is in keeping with the predicted equal workload for these layers from a mathematical model (Arts, 1978).

\subsubsection{Substrate metabolism during ischemia}

A decrease in blood flow causes oxygen extraction to increase up to $90 \%$ of the arterial content (Van der Vusse et a1, 1979). Under ischemic conditions, glycolysis is stimulated by restrictions in coronary flow (Neely et a1, 1975) due to the activation of hexokinase and phosphofructokinase. The increased transport of glucose, as found during anoxia (Morgan et al, 1959) might also play a role during ischemia. Anaerobic glycolysis causes a release of lactate during ischemia, in contrast to lactate uptake during nomoxia. Lactate extraction or production have been used to assess the presence or absence of myocardial ischemia in humans (Williamsom, 1966). However, this assessment is complicated by the facts that lactate extraction is dependent on arterial NEFA concentrations (Gertz et al, 1980) and lactate release from ischemic tissue is dependent on the time interval after onset of ischemia and is not Iinearly related to the degree and the amount of ischemia (Apstein et al, 1979).

Beside the increase in glucose uptake from the blood, glycogenolysis is stimulated which may ultimately lead to depletion of these stores after prolonged ischemia (reviewed by Van der Vusse and Reneman, 1982).

Fatty acid oxidation is greatly depressed under ischemic conditions, mainly due to inhibition of beta-oxidation which is demonstrated by mitachondrial accumulation of long-chain acyl-COA and cytosolic acylcarnitine (Idell-Wenger et al, 1978). Besides, NEFA uptake from the blood is continued during ischemia (Opie et al, 1973; Van der Vusse et a1, 1982). The NEFA taken up in excess of residual combustion can be accumulated as NEFA or as triacylglycerol. Accumulation of the latter substance has been reported (Evans, 1964). Controversely other investigators found increased release of NEFA and glyce- 
rol from endogeneous triacylglycerol stores (Opie et al, 1973; Vik-Mo et al, $1979)$.

Accumulation of NEFA in the ischemic myocardium is shown by Weishaar et al (1977, 1979) and Van der Vusse et al (1982), but not by Regan et al (1972) and Haider et al (1977). Increased myocardial NEFA contents are of interest because several harmful effects have been ascribed to elevated cellular NEFA concentrations. In vitro studies showed that NEFA concentrations, in the same order of magnitude as found during ischemia (Van der Vusse et al, 1982), inhibit glycolytic enzymes and uncouple mitochondrial ATP production, but that addition of albumin, simulating specific NEFA binding proteins (section 2.1.2), abolished or greatly depressed these deleterious effects (Borst et a1, 1962; Randle et al, 1964; Lea and Weber, 1968; Ramadoss et a1, 1976).

During ischemia, increased acyl-COA and acylcainitine comcentrations may have a detergent action on mitachondrial membranes (Feuvray and plouet, 1981). Also elevated acyl-COA and acylicarnitine seemed to be related to early mechanical failure after onset of ischemia (Pitts et al, 1978; Feuvray et al. 1979). Recent reviews on this subject were published by Katz and Messineo (1981), Liedtke (1981), Vik-Mo and Mjos (1981) and Van der Vusse (1982).

It has to be questioned whether the NEFA accumulation, as shown by Van der vusse et al (1982), has deleterious effects on the ischemic myacardium. There are several arguments which make a positive answer doubtful.

Comparisons of the harmful NEFA concentrations in vitro and the NEFA contents as measured in myocardial biopsies should be carefully made, since the biopsies contain 5-10\% blood in which the NEFA content is considerably higher than in the tissue itself. Nomoxic NEFA concentrations in myocytes have been calculated to be 10 mmol. $\mathrm{g}^{-1}$ as compared to $30 \mathrm{nmol} . \mathrm{g}^{-1}$ in biopsies (Van der vusse et al, 1981b, 1982).

Increased cellular concentrations of linoleic and arachidonic acid (Vam der Vusse et a1, 1982, during ischemia and chapter 7 of this thesis) may result in an increased biosynthesis of prostaglandins in ischemic myocardial tissue. Enhanced prostaglandin $F_{2 \alpha}$ synthesis and increased release of this substance from regional ischemic dog hearts have been reported (Berger et al, 1976). Protective effects of this prostaglandin have been described in animals after coronary artery occlusion (Goldfarb and Glenn, 1974).

In the present study the time course of NEFA accumulation has been compared with that of the changes in blood flow, metabolism and mechanical performance in the ischemic myocardium (chapter 7), which may indicate, 
whether the increase in myocardia! NEFA content preceeds inhibition of proposed affected processes.

\subsection{Myocardial blood flow}

\subsubsection{Myocardfal blood flow and its transmural distribution}

The myocardium is supplied with blood through epicardial coronary arteries that divide on the surface and send off tributaries at approximately right angles into the myocardium. There are indications that the epicardial and middle layers are perfused by other branches than the endocardial layers (Estes et al, 1966). The endocardial branches subdivide into anastomosing arcades, forming a large subendocardial plexus.

Under physiolagical conditions regulation of myocardial blaod flow is mainly achieved by modifying the smoath muscle tone, and hence the diameter, of the arterioles. Although coronary vessels are innervated by sympathetic (Feigl, 1975a) and parasympathetic nerves (Feigl, 1975b), it is likely that the regulation of myocardial blood flow is dominated by myocardial metabolism because coronary blood flow is directly related to the oxygen consumption of the myocardium (Allella et al, 1955; Mohrman and Feigl, 1978). Such factors as $\mathrm{P}_{02}, \mathrm{P}_{\mathrm{CO} 2}, \mathrm{H}^{+}, \mathrm{K}^{+}$, adenosine, lactate, osmolarity, prostaglandins and serotonine have been proposed as candidates for linking metabolic activity and arteriolar tone, but the best documented hypothesis for this feedback control is that adenosine is the mediator substance (Berne, 1963; Rubio and Berne, 1969). It is likely that in autoregulation of coronary blood flow, defined as the tendency to maintain blood flow constant despite changes in perfusion pressure, changes in pressure across the vessel wall play a part in the changes in arteriolar diameter. In various tissues, after all, a decrease in this pressure is followed by dilation of the arterioles (Bouskela and Wiederhielm, 1979; Burrows and Johnson, 1981), even when venous pressure is elevated simultaneously (Reneman et al, 1980), while an increase in pressure across the vessel wall induces arteriolar constriction (Boushkela and Wiederhelm, 1979).

Myocardial blood flow is impeded by ventricular contraction. This has been explained by the formation of vascular water falls (Downey and Kirk, 1975) or by the existence of an intramyocardial pump (Arts, 1978; Spaan et a1, 1981). The reduction of myocardial blood flow by extravascular compression is not unifom across the ventricular wall and is determined by intra-myocardial 
pressure $\left(p_{i m}\right)$. This quantity can be defined as the pressure in the weak incompressible material surrounding the contractile fiber structure. None of the methods developed to measure $p_{i m}$ is reliable (Arts and Reneman, 1977) because of the induced damage and/or disaligment of the contractile fibers. The transmural course of $p_{i m}$ can be predicted from a madel of the mechanics of the left ventricle in which myacardial material is assumed to be anisotropic and rotation of the apex relative to the base around the axis of the ventricle is allowed (Arts and Renemam, 1977; Arts et al, 1979). In the left ventricle, $p_{i m}$ is higher in systole than in diastole, and higher in the inner than in the outer layers. In the inner most layers, pim equals the pressure in the left ventricular cavity and in the outer most layers, it is zero. The equality of endocardial $p_{i m}$ to left ventricular cavity pressure is a boundary condition. The described pressure relationships imply that blood flow to the wall of the left ventricle mainly accurs during diastole, when the difference between aortic pressure and $p_{i m}$ is greatest. In systole, bload flows mainly to the outer layers. Since mean transmural blood flow in the left ventricle is approximately uniform (Buckberg et al, 1972) (chapter 4), the gradient in the distribution of flow during systole must be compensated by a similar but reversed gradient during diastale. The latter idea is supported by the finding that the conductance is higher in the subendocardial than in the subepicardial vessels (Rouleau et a1, 1979; Wuesten et a1, 1977), but in disagreement with the finding that left ventricular transmural blood flow is uniform during diastole (Hess and Bache, 1979).

Recently, it has been suggested that diastolic $p_{i m}$ might be higher than generally accepted and even exceed diastolic pressure in the left ventricular cavity (Hoffman, 1978; Rouleau et a1, 1979). This idea was derived from the finding that extrapolation of the diastolic coronary pressure-flow relation down to zero flow resulted in an intercept on the pressure axis at pressures between 2.7 and $7.2 \mathrm{kPa}$. This zero flow pressure, however, does not necessarily relate to $p_{i m}$ alone. In skeletal muscle experiments, capillary blood flow was found to stop at a perfusion pressure (arterilal minus venous pressure) of about $3.3 \mathrm{kPa}$ in the presence of an intramuscular pressure of approximately $0.75 \mathrm{kPa}$ (Reneman et a1, 1980), indicating that other (rheological) factors may be involved in inducing this zero-flow pressure.

Decreased blood flow due to partial or total coronary artery occlusion and reduced coronary artery pressure results in relative underperfusion of the subendocardial layers (Domenech et a1, 1969; Rivas et al, 1976; Bishop et al, 
1976). Even when blood flow in the inner layers was severely affected, vessells in the outer layers proved to be not yet fully dilated (Gould et al, 1975). This underperfustion of the inner layers of the left ventricular wall is caused by the higher $p_{i m}$ in these layers (Hoffman, 1979) and is the major cause of the greater susceptabllity of these layers for impedement of coronary flow, since a higher energy demand of the inner layers is disputable (see above).

\subsubsection{Measurement of regional myocardial blood flow}

Myocardial blood flow can be detemined with such techniques as: electromagnetic and Doppler, differential pressure, continuous themodilution, local heat and gas clearance $\left(\mathrm{H}_{2}, \mathrm{~N}_{2} \mathrm{O}, \mathrm{He}, \mathrm{Xe}{ }^{133}, \mathrm{Kr}{ }^{85}\right)$, diffusable tracer $\left(\mathrm{K}^{43}\right.$, $\mathrm{Rb}^{81}$, $\mathrm{Cr}^{131}$, Th201, I-ant ipyrine) and microspheres.

With regard to the aim of the present study (chapter 1), blood flow has to be measured: (a) in different layers of the myocardium, (b) at various time intervals within each experiment, (c) in the entire free wall of the left ventricle, enabling localization of the ischemic area in the myocardium, and (d) with acceptable accuracy, to make the comparison between myocardial blood flow and local mechanical performance and metabolism meaningful.

Most flow measuring methods are unsuitable because they faile to give information about the transmural distribution of myacardial blood flow. Unlabeled microspheres (as determined light microscopically) can be used only once in each experiment. Using local inert gasses or heat clearance, the ischemic area cannat be lacalized properly. The use of diffusable tracers to detect myocardial blood flow in more than one area requires elaborate equipment. With diffusable tracers, this localization is possible when a scanning camera is used. This method, however, is very expensive, more elaborate and hardly reaches the resolution of the microsphere method. With the latter technique, a satisfactory resolution in transmural direction as well as localization of the ischemic area can be reached by adaptation of the sample size. Besides, measurements can be performed several times in each experiment and the method has a good accuracy if the number of microspheres per sample is adequate (section 3.4). Moreover, application of the technique is relatively simple, though its limitations should be considered. 


\subsection{Experimental set-up}

\subsubsection{Choice of the animal model}

Measurement of mechanical perfomance, blood flow and metabolism selectively in the perfusion area of one coronary artery requires hearts of at least 150 gram, detemines the minimal size of the experimental animal. For these types of experiments, one generally uses the pig or the dog. The former species is preferred by some investigators because of the presumed similarity between pig and human heart (De wong and Goldstein, 1974; Liedtke et al, 1975; Verdouw et a1, 1978, 1979). Indeed both man and pig have a dominant right coronary artery or left anterior interventricular coronary artery. However, the number and type of collaterals (epi-or endocardial, and size) in the human heart is about in between those of the dog and the pig heart (Schaper, 1971a,b; Gregg, 1974). The use of the dog was preferred in the present study because (a) the dog is the most widely used experimental animal in heart research allowing the comparison with results abtained by other investigators; (b) pigs suffer from a high incidence of cardiac arrhythmias and ventricular fibrillation, especially during ischemia (Verdauw et al, 1978). This may be beneficial for the investigation of anti-arrhythic drugs but it is undesired in the present study; (c) the dominance of the left circumflex coronary artery in the dog is not crucial in interpreting the results of the present investigation.

Heart function and metabolism of the heart should be studied in a condition similar to the nomal situation. Therefore, the in situ preparation is superior to any isolated heart preparation. Of course an awake closed-chest animal is the best model, because anesthetics and opened chest influence the performance of the heart. However, the application of so many techniques at the same time requires the heart to be in reach. For that reason, an openchest preparation was used in which accurate limftation of coronary blood flow was possible (section 3.1 .4 ), which made the use of a separate coronary artery perfusion 1ine (Liedtke et al, 1978; Weintraub et a1, 1981) superfluant.

\subsubsection{Anesthesia}

The experiments were perfomed om mongrel dogs of either sex and unknown 
age, ranging in weight from $18-50 \mathrm{~kg}$. The animals were premedicated with Hypnorm (1 m. $\mathrm{kg}^{-1}$ body weight $\left.1 . \mathrm{m}.\right)$ as described by Marsboom et al (1964). One ml Hypnom contains $10 \mathrm{mg}$ fluanisone and $0.315 \mathrm{mg}$ fentanyl citrate. Anesthesia was induced with sodiun pentobarbital $110 \mathrm{mg} . \mathrm{kg}^{-1}$ body weight 1.v.) and after endotracheal intubation, was maintained with oxygen/nitrous oxide and a continuous infusion of sodium pentobarbital ( $2 \mathrm{mg} \cdot \mathrm{kg}^{-1} \cdot$ hour $^{-1}$ i.v.). Ventilation was kept constant during the experiments with a positive pressure resplrator (Pulmonat).

Decrease of body temperature of the animal was prevented by heating and humidifying the inhalated air with a Draeger air humidifier as well as by a heating matrass, placed underneath the animal.

During thoracotomy, succinylcholine $\left(2 \mathrm{mg} \cdot \mathrm{kg}^{-1} 1 . \mathrm{m.}\right)$ was injected to prevent muscle movement caused by electrocoagulation. The chest was opened through the left fifth intercostal space and the pericardium was incised over the antero-lateral aspect of the heart.

\subsubsection{Instrumentation}

ECG was recorded from the limb leads. Signals were amplified by a Schwarzer EC 553 ECG-amplifier. Aortic pressure was measured through a polyethylene catheter, connected to an external pressure transducer (section 3.2.2), which was $p l a c e d$ in the aortic arch. Left ventricular pressure $\left(p_{1 v}\right)$ was measured with a Millar catheter-tip micromanometer, inserted through the left brachial artery (section 3.2.2). The rate of change of left ventricular pressure and left ventricular end-diastolic pressure were also determined (section 3.2.2). A small polyethylene catheter (P.E.50, Clay Adams) was placed in a small side branch of the left anterior interventricular coronary artery for determination of the arterial pressure (Van der Meer and Reneman, 1972) distal to the partial occlusion (or: stenosis) (fig 3.1, section 3.1.4). An electromagnetic flowprobe was placed around the ascending aorta for the measurement of phasic aortic flow (section 3.2.3). Cardiac output was measured by themodilution using a digital analyzing technique (Snoeckx et al, 1976). Through a branch of the left jugular vein, a $7 \mathrm{~F}$ Swan-Ganz balloon guided thermistor catheter was placed in the pulmonary artery. For the injection of saline at room temperature, a separate injection catheter (8F NIH, USCI) was inserted through another side branch of the jugular vein and advanced till the transition of the superior caval vein into the right atrium. Both catheters were placed in position under fluoroscopic control. 


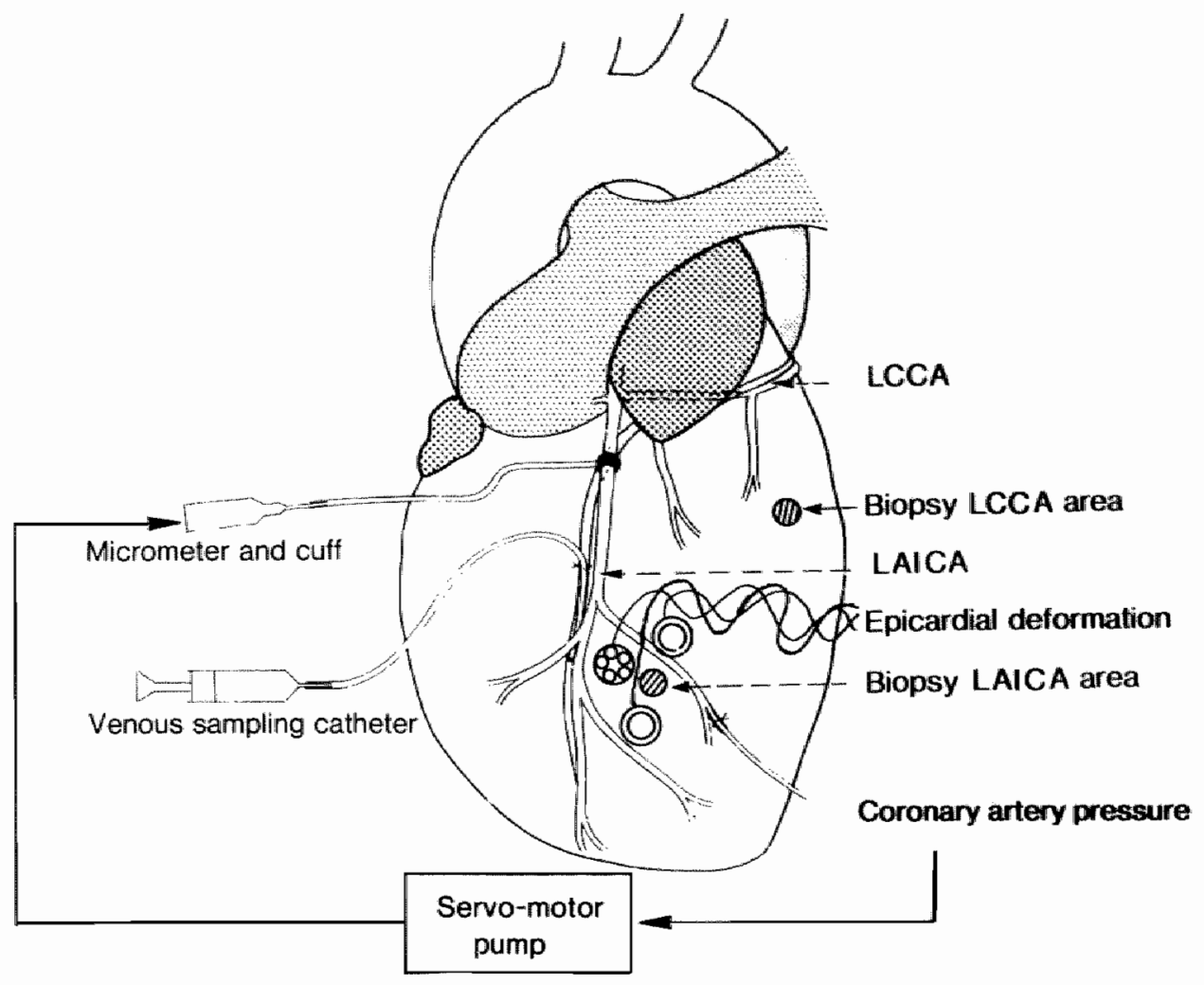

Fig 3.1 Experimental set-up. In the open-chest preparation, an occluder was placed around the left anterior interventricular coronary artery (LAICA). During ischemia, post-stenotic coronary artery pressure was kept constant using an autoregulating feedback system. Coronary artery pressure was measured through a catheter inserted into a small side branch of the LAICA, distal to the site of stenosis. Local venous blood was sampled through a catheter inserted into the left anterior interventricular coronary vein. Regional epicardial surface deformation was measured with three colls, sucked on the epicardium in the LAICA perfusion area. For the determination of substances in the perfusion area of the LAICA and the left circumflex coronary artery (LCCA), small blopsies were taken for ATP, creatine phosphate and glycogen detemination and large biopsies for fatty acid detemination. 
A polyethylene catheter (P.E.60. Clay Adams) was inserted into the left anterior interventricular vein with a seldinger technique to obtain venous blood from the area distal to the site of stenosis (fig 3.1).

To inject radioactive microspheres for the assesment of regional myocardial blood flow (section 3.4), a silastic catheter was placed in the left atrium. A polyethylene catheter was inserted inta the right brachial artery to obtain bload for the arterial reference sample, required for the calculation of regional blood flow (section 3.4).

For the measurement of epicardial deformation according to Arts and Reneman (1980) (section 3.3), three colls were attached to the epicardium (fig 3.1). The field-generating coill was placed on the free wall of the left ventricle, in the perfusion area of the left anterior interwentricular coronary artery (LAICA). The two sensor coils were placed in the same area, both at a distance of about $15 \mathrm{~mm}$ from the magnetic field-generating coil. The three colls were placed so that they formed an approximately rightangled triangle with the field generating cail at the rightangled corner and the sides containing the right angle, parallel to the circumferential and baseto-apex direction, respectively. In this way, shortening in circumferential and base-to-apex direction could be measured as well as shear deformation (section 3.3). The coils were attached to the epicardium by suction (underpressure approximately $-25 \mathrm{kPa})$.

Al1 hemodynamic variables as well as those from the measurement of epicardial defomation were recorded continuously on a multichannel Schwarzer recorder (upper frequency response $280 \mathrm{~Hz},-3 \mathrm{~dB}$ ) at a speed of $1.25 \mathrm{~mm}^{-\mathrm{s}^{-1}}$ and at the sample times at speeds of 50 and $200 \mathrm{~mm} \cdot \mathrm{s}^{-1}$.

\subsubsection{Stenosis system}

Partial occlusion (stenosis) of the LAICA was induced with an inflatable cuff which was placed around this artery just distal to the diagonal branch (fig 3.1 ).

The cuff was through silastic tubing connected to a micrometer. The whole system was filled with distilled water so that the cuff could be inflated carefully until the desired degree of stenosis was obtained. This degree of stenosis could be malntained during the experimental period, using a servo motorpump with an autoregulating feedback system controlled by the mean coronary artery pressure $\left(p_{\text {cor }}\right)$ (fig 3.1 ).

In the present study, mean $p_{c o r}$ as measured distal to the stenosis in a 
small side branch of the LAICA rather than the reduction of mean flow in this artery was used to estimate the degree of ischemia. Under these circumistances, the determination of pressure is easier and more accurate (Van der Meer and Reneman, 1972). Moreover, during ischemia flow in the coronary microvasculature is related to the perfusion pressure in that bed and less related to arterial inflow because of an unknown amount of collateral inflow. At last, the servacontrol corrects for possible movements of the cuff along the vessel, which may cause changes in the degree of stenosis.

Despite the similarity of mean $p_{\text {cor }}$ values distal to the stenosis, interindividual variations were seen in regional blaod flow, mechanical performance and metabolism during ischemia. This may be due to interindividual differences in coronary resistance, collateral circulation or aortic pressure. The latter factor increases myocardial energy requirement, so at a certain reduced flowlevel, ischemia will be more pronounced at higher aortic pressure.

The occlusion of the side branch caused a small area of underperfusion distall to the catheter, as could be shown by detemination of regional myocardial blood flow (section 3.4). However, this occlusion had no deleterious effect on the experiments. General cardiac function was not influenced by this procedure and cardiac arrhythmias due to the acclusion were not observed. For the calculation of total regional blood flow in the ischemic zone, this area of underperfusion was excluded because of possible artefacts due to the pre-existing ischemic tissue.

In the study dealing with total coronary artery occlusion (chapter 5) the cuff was fully inflated, whereafter the tubing was closed with a stopcock.

\subsubsection{Technique of blood sampling}

Arterial blood samples were collected through the catheter used for aortic pressure measurements. Local venous blood samples were obtained through the catheter in the left anterior interventricular coronary vein (fig. 3.1). Blood $(0.6 \mathrm{ml})$ was carefully sucked into a syringe filled with $0.2 \mathrm{ml}$ heparin $\left(5000\right.$ I.U. $\left.\mathrm{mi}^{-1}\right)$ and used for determination of blood gases and blood $\mathrm{pH}$ whlch were determined immediately after sampling (section 3.5). To reduce gas exchange with the enwironment between sampling and determination, the syringle was locked by stainless steel syringe caps. From the syringe with bload for the bload gas determination, $40 \mu$ was taken with a heparinized capillary and entered into a hemoxymeter to determine oxygen content of the blood (section 
3.5.3). Another 4-6 ml blood (for other chemical determinations) were rapidly centrifuged for 1 min in a Eppendorf centrifuge. The supernatants of these samples were quickly frozen and stored at $-80^{\circ} \mathrm{C}$ for biochemical analysis. The time from sampling to freezing varied in most cases from 2 to 5 min.

When the lacal venous catheter was not closed by a stopcock, in most cases blood dripped out of the catheter, although too slow for sampling purposes. Therefore, blood was sucked using 1 or $2 \mathrm{ml}$ syringes. A critique to this technique is that it cannot be excluded that blood is also sampled from adjacent vascular beds via venous collaterals. Especially during ischemia, this could be a problem in interpreting the results because of admixture of blood from normoxic tissue with that from ischemic tissue. However, measurement of regional myocardial blood flow, revealed that in an ischemic zone of about 20 9. which is a common figure in our model, a flow of $4 \mathrm{ml}^{\mathrm{min}} \mathrm{m}^{-1}$ is present. When venous blood samples are drawn, 4-6 ml of blood are withdrawn in the course of a few minutes. This implies that the volume of venous blood sampled over a certain period does not exceed the arterial inflow. Moreover, in the present study the ischemic area is relatively large as compared with experiments of Owen et a1. (1970), who created ischemic areas of 7-8 g. Therefore, in our study, the contribution of blood from the borders of the ischemic area or from outside this area will be small as compared with the study of Owen and co-investigators (1970). If admixture through venous collaterals occurs, changes due to ischemia will be underestimated. It should be emphasized that it is not clear whether the venous blood samples reflect the average of transmural venous blood or that mainly blood is obtained from one particular layer.

\subsubsection{Techniques of tissue sampling}

In this study two types of samples were taken from the left ventricular myocardium: samples for determination of the content of: (a) ATP, creatine phosphate, and glycogen; (b) fatty acids.

a. Biopsies for the determination of energy-rich phosphates and glycogen were taken with a pressured air driven drillbare (Schrader) on which drills were mounted with a length of $4 \mathrm{~cm}$ and an inner diameter of $4 \mathrm{~mm}$. The wet. weight of the biopsies ranged from 50 to $70 \mathrm{mg}$. Because of the deleterious effects of tissue sampling on regional blood flow and mechanics, shown in chapter 4, it was decided to stop the experiment after taking two biopsies. At first a transmural biopsy was taken from the area perfused by the 
LAICA. An assistant put his finger on the hole to prevent bleeding as much as possible. Subsequently, within 1-2 min, a blopsy was taken from the left circumflex coronary artery (LCCA) perfusion area (fig 3.1). After the drill was withdrawn from the heart, it was immersed in liquid nitrogen while still mounted on the bore. The time delay between taking the biopsy and the irmersion in liquid nitrogen was 2-3. $\mathrm{s}$. After cooling of the dril1, it was removed from the bore and put into a cold resistant polypropylene tube filled with liquid nitrogen and subsequently stored in a Dewar container filled with the same fluid. After termination of the experiment, the tissue containing drills were stored at $-80^{\circ} \mathrm{C}$. After freeze drying these samples were divided into subendo, meso and subepicardial tissue samples.

b. Biopsies for the determination of myocardial fatty acid content were taken from the left ventricular free wall with an electrically driven drillbare, on which drills were mounted with a length of $2 \mathrm{~cm}$ and a inner diameter of $1 \mathrm{~cm}$. . The first tissue sample was taken from the LAICA perfusion area. Subsequently, two biopsies were taken from the area perfused by the LCCA and at last another biopsy from the LAICA perfusion area was taken. The whole biopsy procedure took about $5 \mathrm{~min}$. In most cases, ventricular fibrillation occurred after taking the second biopsy. No significant differences have been abserved between biopsies taken before and within 5 min after onset of ventricular fibrillation. The wet weight of the biopsies ranged from 500 to $900 \mathrm{mg}$. Adhering blood was removed with an ice-cold physiological saline solution. Then the biopsies were divided into subepi, meso and subendocardial samples. Subsequently, the samples were frozen between the tongues of an aluminum $c 1$ amp which was cooled in 1 iquid nitrogen. The whole procedure from taking the biopsy till freeze-clamping of the tissue took less than 15 seconds. The frozen tissue samples were stored at $-80^{\circ} \mathrm{C}$.

\subsubsection{Anti-coagulation}

Administration of heparin was deliberately avoided because of its influm ence on myocardial metabolism. Heparin, after all, releases 1 ipoprotein lipase from the endothelial wall, thereby preventing the myocardium to use triacylglycerol as a substrate (Jansen, 1975). Besides, the release of 1ipoprotein Tipase increases arterial non-esterified fatty acids (NEFA) concentrations (Riemersma et al 1977b; Van der Vusse et a1, 1980) which may affect 
the relative contribution of MEFA combustion to myocardial substrate supply (Kjekhus and HJ5, 1972; Dagenals and Jalbert, 1977). Moreover, the use of heparin causes a more rapid in vitro lipolysis in seruin which gives rise to artefacts in the measurement of blood NEFA concentrations latacomini et al, 1980). The effect of elevating the arterial NEFA concentrations during ischemia by administration of heparin, intralipid or both substances is described and discussed in chapter 8 .

Avolding the administration of heparin had also the advantage that less bleeding occumred from surgical wounds like the edge of the thorax and from the sites of insertion of the catheters.

Catheters were kept patent with a continuous infusion of saline. The catheters for measurement of aortic and coronary artery pressure and for microsphere injection were connected to a Sorenson Intraflo continuous infusion system with an infusion rate of $6 \mathrm{~m} / . \mathrm{h}^{-1}$ (Sorenson Research Company, Salt Lake City, USA). The thermodilution injection catheter, the local venous catheter and the arterial reference sample catheter were connected to syringes mounted on Harvard infusion/withdrawal pumps (infusion at a rate of 10-12 $\left.m l \cdot h^{-1}\right)$. Although no saline infusion was performed through the lumen of the catheter tip micromanometer, no influence of the deletion of heparin was observed on the pressure measurement with this micromanometer: an identical signal was obtained th an external Ailtech transducer measuring through the lumen of the moromanometer.

\subsection{Hemodynamic measurements}

\subsubsection{Intraduction}

Measurement of general hemodynamic parameters like ECG and aortic and left ventricular pressure were perfomed because they provide information about the cardiovascular condition of the experimental animal. Moreover, the separately recorded end-diastolic left ventricular pressure and the maximal first derivative of the left ventricular pressure ( $\left.d p_{1} / d t m a x\right)$ are sensitive parameters to assess the condition of the left ventricle. Measurement of left ventricular pressure using a catheter-tip micromanometer provides a signal with minimal time delay ( $<1 \mathrm{~ms})$ or reflections due to the large pressure wariations, as is the case with waterfilled catheters. The coronary artery pressure distal to the stenosis was detemined to serve as a measure for the degree of ischemia (section 3.1.4). Electromagnetic measurement of aortic 
flow was used to describe the ejection phase of left ventricular contraction (essential for the interpretation of the results on the assessment of regional mechanical performance).

Electromagnetic measurement of flow in the LAICA was not performed because in the majority of the experiments one or more side branches of this artery had to be ligated to be able to implant both the occluder cuff and the flow probe. Moreover, more detailed infomation about myocardial blood flow can be obtained with the microsphere methad (section 3.4).

Signals of left ventricular pressure, aortic and coronary artery pressure as well as phasic aorta flow and the ECG were contiuously visualized on a Knott GS-8 monitor.

\subsubsection{Blood pressures and derived parameters}

The external Ailtech pressure transducer in series with the aortic sample catheter had a frequency response of $35 \mathrm{~Hz}(-3 \mathrm{~dB})$. In series with the catheter in the side branch of the LAICA, the frequency response was $15 \mathrm{~Hz}(-3 \mathrm{~dB})$.

The catheter-tip micromanometer (7F Millar, PC470) for the measurement of left ventricular pressure $\left(\mathrm{p}_{1 \mathrm{v}}\right)$ had a frequency response of $0-20 \mathrm{kHz}$. The maximal first derivative of left ventricular pressure $\left(\mathrm{dP} \mathrm{P}_{\mathrm{w}} / \mathrm{dtmax}\right)$ was determined with an analog differentiator as described by schaper et al (1965). End-diastolic left ventricular pressure ( $p_{1 \text { ved }}$ ) was separately recorded by clipping the $P_{1 v}$ at $200 \mathrm{mV}(2.7 \mathrm{kPa})$ and subsequently amplifying the signal on the recorder.

The pressure transducers were calibrated before each experiment. The output voltage for $13.3 \mathrm{kPa}(100 \mathrm{mmHg})$ was detemined using a mercury column. An electrical output signal and the signals on the recorder and the monitor were thus calibrated, barometric pressure serwing as zero reference. A pressure of $13.3 \mathrm{kPa}$ gave an output signal of 1 volt. On the recorder $13.3 \mathrm{kPa}$ was equal to $20 \mathrm{~mm}$, except for the $p_{\text {Ived, }}$, where $20 \mathrm{~mm}$ represented $2.7 \mathrm{kPa}$.

At each sample time, the zero and electrical full scale callibration of the external transducers were checked on the monitor and the recorder. By an external pressure transducer, measuring the pressure through the lumen of the Millar catheter-tip micromanometer, the zero shift of this manometer was checked and was corrected if necessary. The gain of the Millar transducer did not change noteworthy during the experiment as was checked by comparing the amplitude of the signals obtained from the Ailtech and Millar transducers on the monitor. In this procedure the variation in gain of the Ailtech transdu- 
cer. though small, could not be checked.

\subsubsection{Blood flow (electromagnetically measured)}

Phasic aortic flow was measured with an electronagnetic flow probe (Skalar). The probes were connected to a sine wave electromagnetic floweter with a carrier frequency of $600 \mathrm{~Hz}$ (Transflow 600). The upper frequency response of the floweter was $100 \mathrm{~Hz}(-3 \mathrm{~dB})$.

Zero drift of the flow probe was checked by comparing the electrical zero with the end-diastolic level of the phasic flow signal on the monitor. Because phasic aortic flow was used to assess the start and duration of the ejection phase and no quantitative flow measurement was required, full scale cal ibration was not performed.

To deternine the start of the ejection phase accurately a time delay has to be taken into account. Time delay firstly occurs due to the distance between the valve and the flow probe. With a maximal distance of $5 \mathrm{~cm}$ and assuning a pressure pulse wave velocity of $4 \mathrm{~m} \cdot \mathrm{s}^{-1}$, this delay will be no more than $12 \mathrm{~ms}$. Additional delay (electronic) is induced by filtering in the flowmeter, which was in our case about $3 \mathrm{~ms}$. Hence the total delay between the start of the ejection phase and its assessment from the electromagnetic flowmeter reading will be maximally $15 \mathrm{~ms}$, for which has been corrected.

\subsubsection{Cardiac output}

\subsubsection{Introduction}

Several methods for the detemination of cardiac output could have been used in the present study: electromagnetic aortic flow measurement, the radioactive microsphere method or the indicator dilution techniques. The first technique was not employed because in vivo full scale calibration af the flowprobes is problematic and coronary flow is systematically missed. The indicator dilution technique was preferred over the radioactive microsphere method because the former can be performed almost unl imited whereas use of the latter method, in combination with the measurement of regional myocardial blood flow, is limited by the single use of each isotope. Temperature was employed as indicator because of its easy application and low costs of the set-up. 


\subsubsection{Instrumentation}

Cardiac output was measured by thermodilution using a Swan-Ganz balloon guided themistor catheter (Edwards) and a $8 F$ NIH injection catheter (USCI). This method has been described previously in detail by snoeckx et al (1976). The large injection catheter enabled the injection of a relatively large volume of saline within a short period of time, which enlarges the obtained signal and thereby improving the accuracy of the method. Before injection of saline, blood from the animal was sucked into the catheter to prevent cold dissipation from the catheter. After a steady baseline registration (see below), $10 \mathrm{ml}$ of sal ine at room temperature were injected manually as fast as possible. Immediately after the syringe was emptied the catheter was filled again with blood, thereby reducing the non-exponential character of the last part of the thermodilution curve due to cold dissipation from the catheter after injection (V1iers et al, 1973).

The catheter was connected to a themodilution amplifier of our own design. The resilstance in the Wheatstone bridge of this apparatus was adjusted to the resistance of the catheter (about $5 \mathrm{kOhm}$ ). The temperature measured was shown on a small digital display, allowing the continuous visualization of body temperature.

Thermodilution curves were registrated on a Linselis series 2000 recarder at a speed of $50 \mathrm{~mm} . \mathrm{s}^{-1}$. The sensitivity of the recording system was calibrated after the experiments with waterbaths of different temperatures and an independent thermometer.

\subsubsection{Calculation of cardiac output}

The area under the curve was measured by integration using a Digital MINC II minicomputer. Points of the curve were stored an file using a Hewlett Packard Digitizer (9874 A), at a sampling rate of $20 \mathrm{~Hz}$. To calculate cardiac output the TERDIL program was used. In this procedure at first the data points were made equidistant. Subsequently a Fourier analysis was performed according to which high-frequency noise was filtered $(>20 \mathrm{~dB})$. After backward transformation, the surface of the resultant curve was determined as follows. The onset of the curve was the segment with the highest first derivative of the upstroke $(d p / d t)$. From the points entered before this segment the baseline was calcullated. From the onset of the curve to its maximum $\left(y_{\text {max }}\right)$ and from $y_{\max }$ to $0.7 \times y_{\max }$, the surface under the curve was directly measured. Since the last part of the curve shows aberrations due to recirculating cold 
(Snoeckx et a1, 1976, Vljers et a1, 1973), this part of the curve was assumed to be exponential (Snoeckx et al, 1976). The equation of this exponentia) curve was determined using the points between 0.7 and $0.3 \times y_{\text {max }}$, and extrapolating the curve to zero. Thereafter the surface under this part of the curve was measured and added to the two parts integrated before. cardiac output (co) was calculated according to Snoeckx et al (1976):

$$
c 0=k \cdot \frac{v_{i} \cdot\left(T_{b}-T_{i}\right)}{s \cdot k_{1} \cdot k_{2}} \cdot k_{3} \quad \text { and } k=\frac{s_{i} \cdot g_{i}}{s_{b} \cdot g_{b}}
$$

where $s_{j}=$ specific heat injectate $\left(100 \mathrm{kcal} \mathrm{kg}^{-1}{ }^{0} \mathrm{C}^{-1}\right), g_{i}=$ specific weight injectate $\left(0.99 \times 10^{3} \mathrm{~kg} \mathrm{~m}^{-3}\right), s_{b}=$ specific heat blood $\left(0.87 \mathrm{kcal} \mathrm{kg}^{-1}{ }^{0} \mathrm{C}^{-1}\right), g_{b}=$ specific weight blood $\left(1.05 \times 10^{3} \mathrm{~kg}\right.$ $\left.\mathrm{m}^{-3}\right), V_{i}=$ volume injectate $\left(\mathrm{m}^{-3}\right), T_{b}=$ temperature blood $\left({ }^{0} \mathrm{C}\right), T_{i}=$ temperature injectate $\left({ }^{0} \mathrm{C}\right), \mathrm{s}=$ surface under the curve $\left(\mathrm{m}^{2}\right), k_{1}=$ velocity recorder $\left(\mathrm{s} \mathrm{m}^{-1}\right.$, in our experiments $\left.1.2 \times 10^{-2}\right), k_{2}=$ sensitivity recorder $\left({ }^{0} \mathrm{C} \mathrm{m}^{-1}\right), \mathrm{k}_{3}=$ correction factor from $\mathrm{ml} \mathrm{s}^{-1}$ to 1 $\min ^{-1}(=0.06)$.

\subsubsection{Accuracy of the cardiac output determination}

Because each dog served as its own contral, we will anly discuss the variations between two measurements in the same animal. The intraassay coefficient of variation in the determination of cardiac output by thermodilution can orlgin from one of the following factors:

a. variations in the injected volume. Repeated measurements of this wolume revealed a mean variation of $0.6 \%$.

b. variations in the difference between injectate and blood temperature. Because both temperatures were measured with an accuracy of $0.1^{\circ} \mathrm{C}$ and the difference between these temperatures was usually $15^{\circ} \mathrm{C}$, unnoticed variations in the temperature will not account for more than $0.6 \%$ variation.

c. variation in the determination of the surface area under the curve. This variation is caused by deviations of the digitizer pen from the recorded curve. Repeated measurements of one curve showed that this variation was 1.2. $2 \%$

Measurement of two to four curves recorded within $1-2$ min from each other during a stable hemodynamic situation showed variations of 2.8 to $9.9 \%$, with 
a mean of $6.7 \%$. The difference between this varlation and the sum af the variations mentioned in (a) through (c) being $1.4 \%$, might be caused by baselime fluctuations, inaccuracies in determining the baseline determination and difference in the shape of the curve, causing variation in exponential extrapolation of the last part of the curve.

\subsection{Regional mechanical function}

\subsubsection{Introduction}

Keeping in mind the aim of this study, a technique for the assessment of regional mechanical performance in different layers of the left ventricular wall is required. In chapter, it has been emphasized that several of the techniques available to determine this performance in the varlous layers are subject to artefacts or are less appropriate for this study. In the present study, we have used local epicardial deformation to estimate reglonal mechanical function. This deformation can be reliably and relatively easily measured in the open-chest dog preparation. Moreover, this technique does not only give information about the decrease of the epicardial surface area during ejection, which is directly related to the local contribution to the decrease of left ventricular cavity volume, but it gives also information about the transmural course of fiber shortening by assessment of a shear component beside circumferential strain and base-to-apex shortenting.

The technique of measuring epicardial defomation is described in detall by Arts and Reneman (1980). Therefore, the principles and instrumentation are only briefly mentioned below.

To investigate the reliability of the assessment of the transmural course of fiber shortening from epicardial deformation, a technique was developed to measure strains in the epicardium as well as in the endocardium (section 3.3.3).

\subsubsection{Epicardial deformation}

\subsubsection{Principles and instrumentation}

Assume a rectangle $O A B C$ on the epicardial surface prior to defomation. During contraction the rectangle $O A B C$ (fig 3.2) deforms to a parallelogram $O A^{\prime} B^{\prime} C^{\prime}$. Define $D$ as the origin, $O A$ and $O A^{\prime \prime}$ along the $c$-axis (circumferential direction) and $O C$ along the $z$-axis (base-to-apex direction, which is perpendi 


\section{THEORETICAL MODEL}

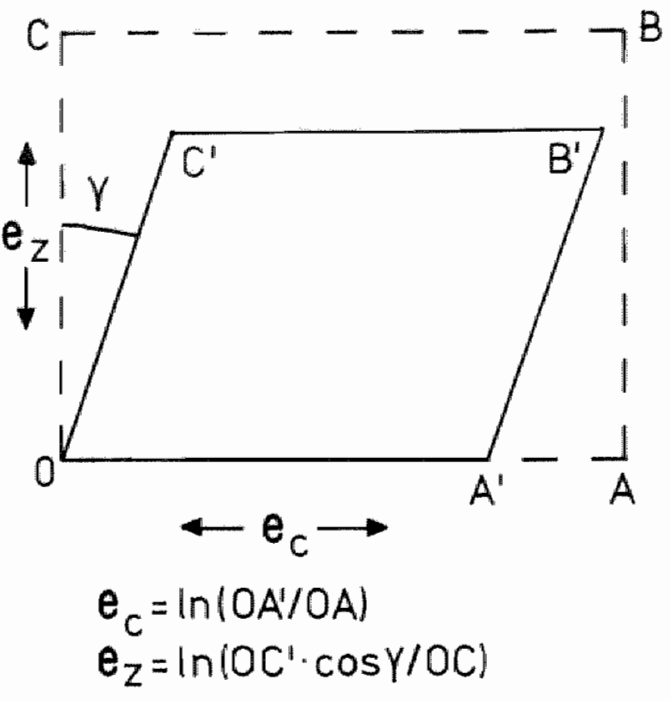

\section{PRACTICAL APPROACH}

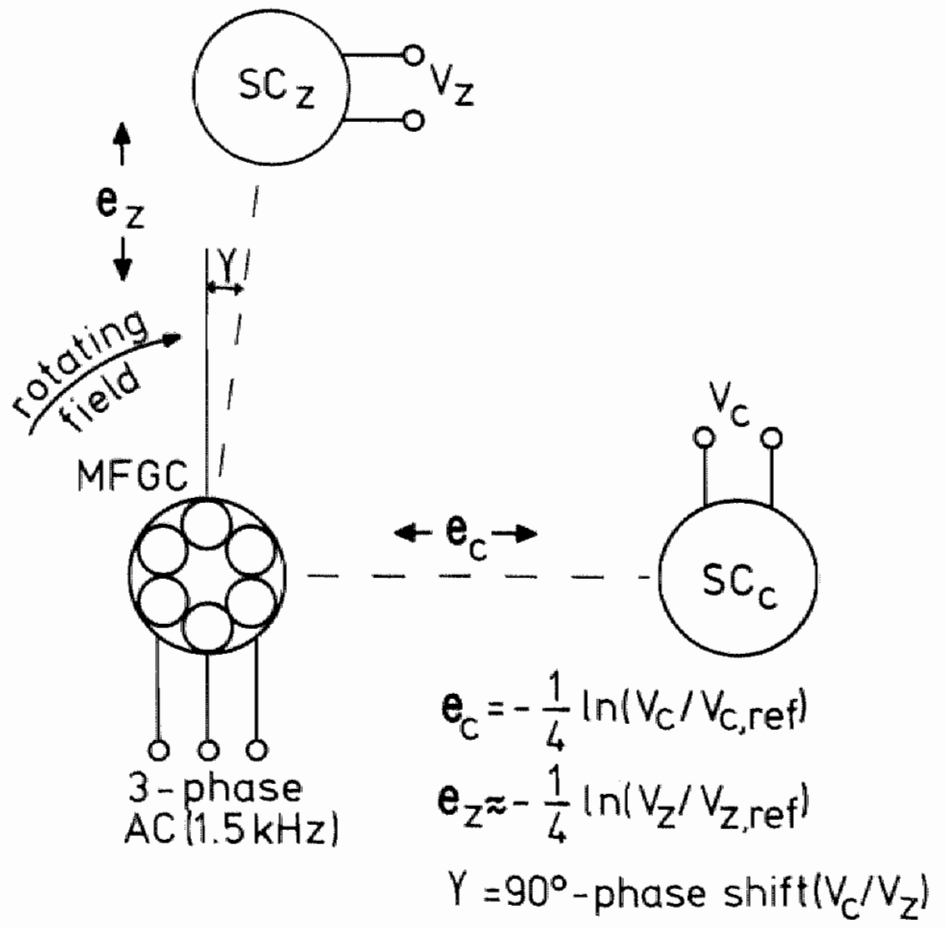

Fig 3.2

Rectangle DABC deforms to parallelogram OA'B'C'. Deformation is defined by natural strain $e_{c}$ along $D A$, natural strain $\mathrm{e}_{z}$ along $O C$ and shear angle $\gamma$.

Fig 3.3

Measurement of the deformation parameters. A magnetic field rotates around the magnetic field-generating coit (MFGC) and induces voltages $V_{c}$ and $V_{z}$ in sensor coils $S_{C}$ and $S C_{2}$, respectively. The deformation parameters are detemined from the amplitudes of and the phase difference buetween $v_{C}$ and $V_{z}$. 
cular to the $c$-axis). Natural tangential strain $\left(e_{c}\right)$, natural axial strain $\left(e_{z}\right)$, and shear angle $\gamma$ are defined as indicated in fig 3.2 .

In the experimental set-up three colls are attached to the epicardial surface, one magnetic field-generating coil (MFGC) at the origin 0 and two sensor coils at the positions $A$ and $C$. The field-generating coll is supplied by a three-phase AC system, thus generating a magnetic field that rotates. around the axis of the coll and has a strength that decreases with increasing distance from the coil (fig 3.3).

In a sensor coil, a voltage is induced proportionally to the time derivative of the magnetic field strength. Therefore the strains of the segments. between the MFGC and the sensor measured by the cails can be calculated from the changes in the induced voltages. The angle $L$ ( ' $^{\prime} O C^{\prime}$; fig 3.2 ) equals the phase difference of the voltages induced in the sensor coils (fig 3.3).

The changes in the induced voltages of the sensor coils as well as their phase difference were registrated on a physiological recorder (Schwarzer), the former at $0.2,0.4$ or $0.8 \%$ per mm and the latter at 0.005 or 0.01 rad per mm. For normal cardiac contractions, the accuracy of the method is better than $\pm 2 \%$ for strain measurements and $\pm 10 \%$ for shear angle measurements (Arts and Reneman, 1980).

\subsubsection{Assessment of epi and subendocardial fiber shortening}

As discussed in section 2, torsion of the left ventricle is related to the transmural course of fiber shortening. The shear angle, as measured on the epicardial surface is directly related to this torsion. As will be shown in chapter 5, changes in shear angle after inducement of ischemia can vary between experiments, which might be due to differences in the initiall orientation of the right angular configuration of the colls with respect to the base-apex direction. To be less dependent on this orientation, the principal strains $e_{\min }$ and $e_{\max }$ were calculated from $e_{c}, e_{z}$ and $\gamma$. The relation between these parameters is shown in fig 3.4. The ellipse determined by $e_{C}, e_{z}$ and $\%$, and represents the inscribed circle of the square after this square is defomed to the parallelogram. The short and lang axis of this ellipse denote the direction of maximal ( $\left.e_{m a x}\right)$ and minimal shortening $\left(e_{m i n}\right)$, respectively. These parameters were calculated as follows: A first order approximation of the matural strain along a line forming an angle $B$ with the circumferential direction is 


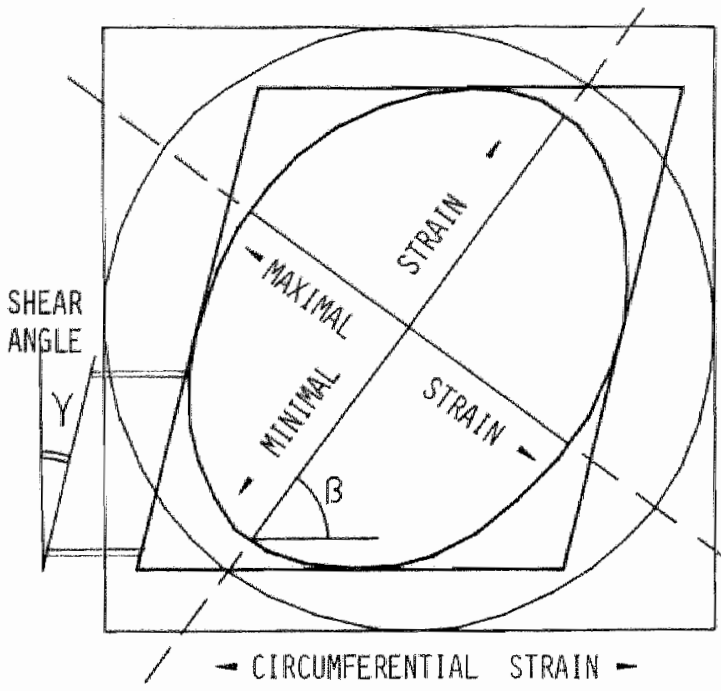

Fig 3.4

Circumferential strain, axial (or base-to-apex) strain and shear angle detemine the deformation of a square into a parallelogram. From these three para- meters, minimal straím, maximal strain and the angle of minimal Strain ( $B_{\text {min }}$ ) can be calculated, wetemining the deformation of the inscribed circle of the Equare (assumed at onset of ejection) into the ellipse (at the end of ejection). At the epicardium, orientation of maximal shortening is close to subepicardial fiber direction. The minimal shortening direction is close to the fiber direction in the inner layers.

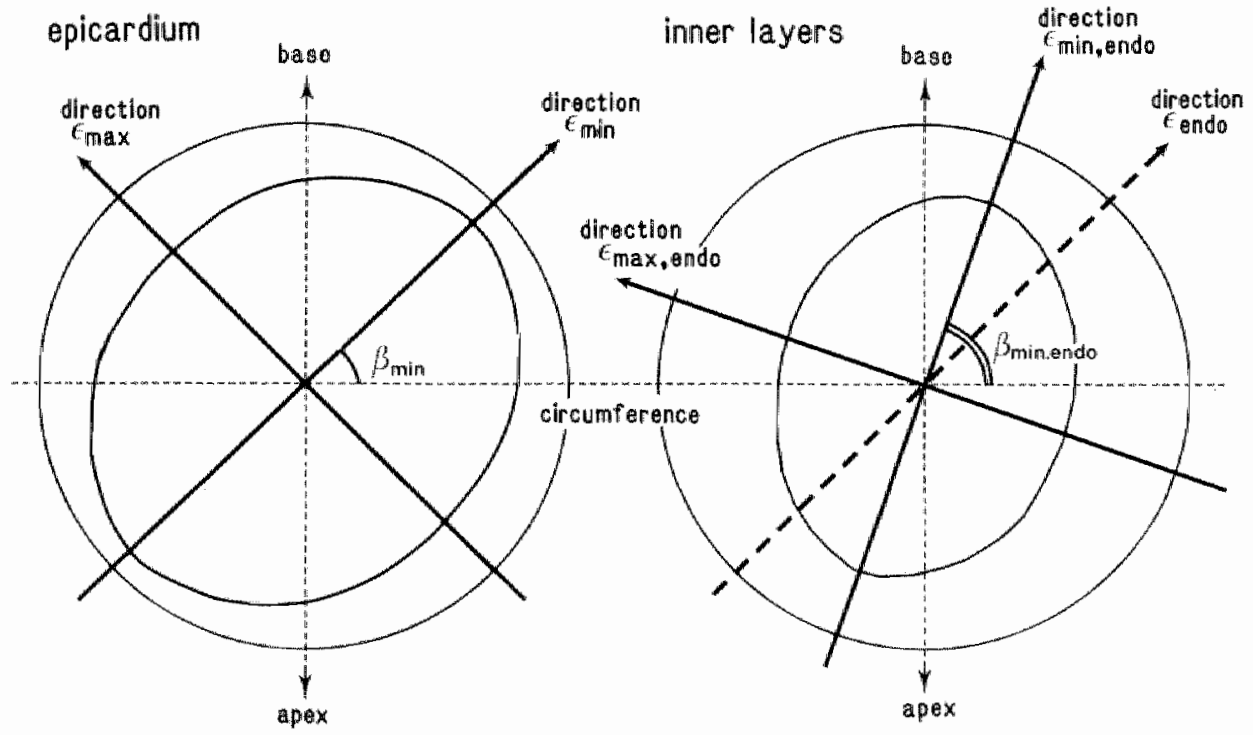

Fig 3.5 Deformation of a circle (onset of ejection) into an ellipse (end of ejection) at the epicardium (left panel) and in the inner layers (right panel). Orientation of minimal and maximal shortening at the eplicardium ( $\mathrm{e}_{\mathrm{min}}$ and $\mathrm{e}_{\max }$, respectively) and in the inner layers (emin, endo and emax, endo, respectively) is shown by drawn arrows. $B_{\text {min }}$ (outer layers) and Bmin,endo (inner layers) are the angies of minimal shortening. Shortening in the inner layers in the $B_{\text {min }}$ direction is called eendo (interrupted arrow). Orientation of the shortening directions is conform model calculations by Arts et al (1982a). Shortening as drawn in the figure is twice the calculated values. 


$$
e(B)=e_{c} \cdot \cos ^{2} B+e_{z} \cdot \sin ^{2} B+\gamma \cdot \cos \beta \cdot \sin \beta
$$

The maximal and minimal values of $e(\beta)$ are found by solving $d e / d \beta=0$, which results in

$$
\tan (2 B)=\gamma /\left(e_{c}-e_{z}\right)
$$

Substitution of the thus found values of $\beta$ into equation (1) results in the maximal $\left(e_{m a x}\right)$ and minimal values $\left(e_{m i n}\right)$ of the natural strain, which are also the principal strains:

$$
\begin{aligned}
& e_{\min }=0.5\left(e_{c}+e_{z}\right)-0.5 \sqrt{\left(e_{c}+e_{z}\right)^{2}+p^{2}} \\
& e_{\max }=0.5\left(e_{c}+e_{z}\right)+0.5 \sqrt{\left(e_{c}+e_{z}\right)^{2}+\gamma^{2}}
\end{aligned}
$$

Experimentally (chapter 5) the orientation of $e_{\text {max }}$ was found to be close to the anatomically measured fiber orientation in the inner layers (Streeter et al, 1969). The fiber orientation in the inner layers is approximately perpendicular to the fiber orientation in the outer layers (Streeter et all, 1969). So the direction corresponding to emin at the epicardium is clase to the fiber orientation in the inner layers. Thus, $e_{\max }$ is close to shortening along the epicardial fiber direction and $e_{\text {min }}$ reflects shortening of the epicardial surface along the fiber direction in the layers.

\subsubsection{Transmural differences in deformation}

\subsubsection{Principles}

To measure directly endo and eplicardial shortening perpendicular to the epicardial fiber direction, three needles were inserted through the myocardial wall so that they fomed a rectangular triangle like the positioning of the magnetic colls used for measurement of epicardial surface deformation (section 3.3 .2$)$ *

On each needle, two coils identical to those used for epicardial surface defomation (Arts and Reneman, 1980) were placed, 2 and 12 mm above the eplcardium. So the deformation parameters were measured at two levels (fig 3.5). Deformation at the epicardium and in the inner layers was calculated by linear extrapolation along the needles from the measured deformation data. 

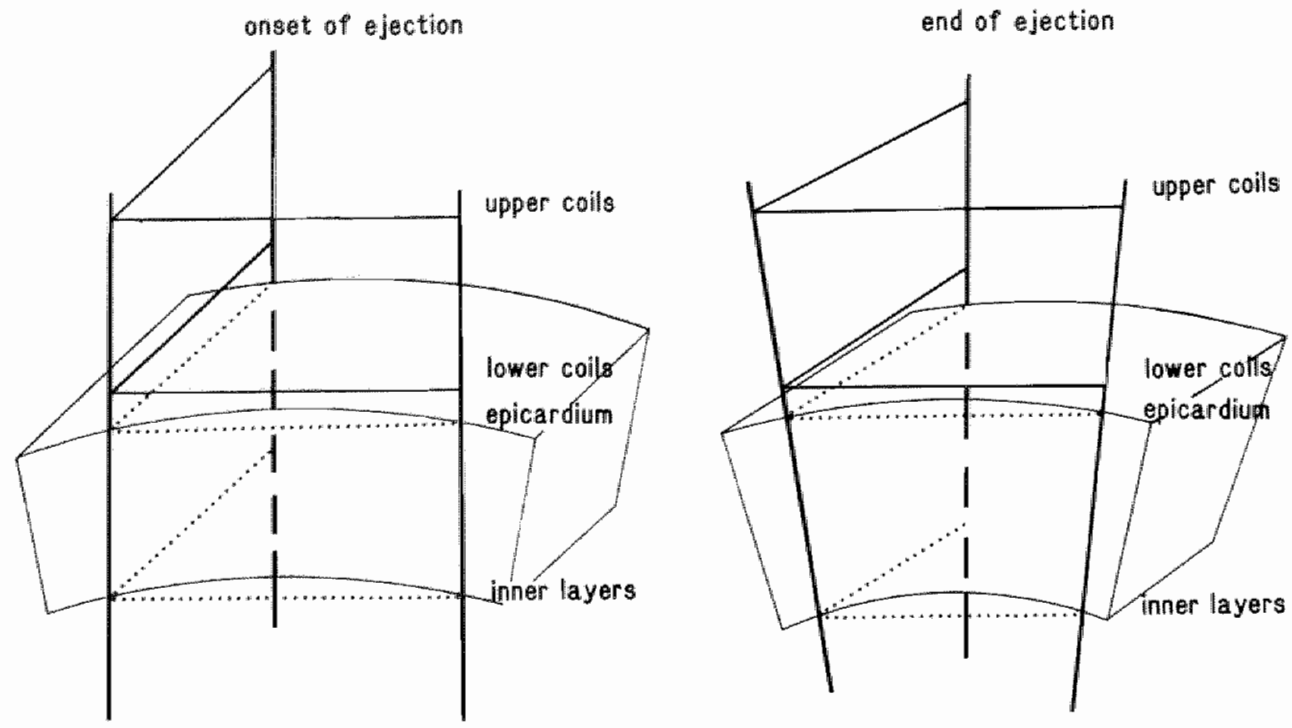

Fig 3.6

Measurement of mutual movement and angulation of needles pierced into the myocardial wall during the ejection phase is performed by determining circumferential shortening, base-to-apex shortening and shear angle at two levels above the epicardium (stralght lines). From these measurements, the three deformation parameters can be calculated on the epicardium and in the inner layers by extrapolation (dotted lines). Note that the thus detemined epicardial parameters are comparable with those measured directly on the epicardium (fig 3.2).

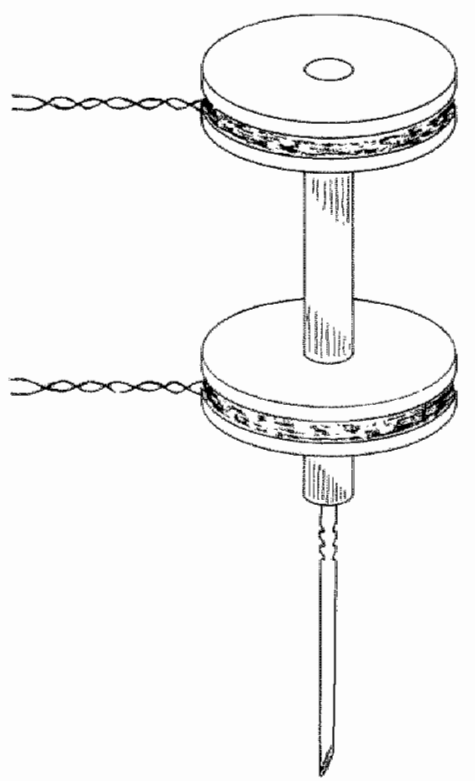

Fig 3.7 Needle used for the measurement of transmural differences in deformation. Distance between the coils is $10 \mathrm{~mm}$. 
Mall thickness was estimated from the relation between left ventricular weight and wall thickness as described by McHale and Greenfield (1973). For the calculation of defomation in the inner layers variations in wall thickness due to contraction or ischemia were neglected, because this technique was used as a first order approximation.

From the epicardial and subendocardial $e_{c}, e_{z}$ and $\psi$ thus detemined, emin and $e_{\max }$ in these layers can be calculated as described in section 3.3.2.2.

Epicardial $e_{\text {min }}$ in these experiments was close to $e_{m i n}$ as calculated from data on epicardial defomation measurements (section 3.3.2.2). This e e in foms an angle $\beta_{\text {min }}$ with the circumferential direction. Epicardial shortening along $B_{\text {min }}$ will probably be related with subendocardial shortening along $B_{\text {min }}$. Therefore, subendocardial shortening along the $e_{m i n}$ direction was calculated and defined as e endo (fig 3.6). Because the orientation of $e_{\text {min }}$ at the epicardium, and $e_{\text {endo }}$ is close to the fiber orientation in the inner layers (section 3.3 .2 .2 ), the relation between endo and epicardial e min depicts the relation between subendocardial shortening along a direction close to the fiber orientation and shortening along the same direction on the epicardium.

\subsubsection{Instrumentation}

The stem of each needle consisted of a PVC cylinder (2mim outer diameter, $15 \mathrm{~mm}$ height). Underneath this stem a Tungsten needle $(0.6 \mathrm{~mm}$ diameter, $25 \mathrm{~mm}$ length) was placed. To measure the mutual position of the needles, an each needle two coils were mounted 2 and $12 \mathrm{~mm}$ above the epicardium, respectively (fig 3.7). On the needle at the right angled corner, two magnetic field generating coils (MFGC) were mounted, and on the other two needles, two sensor colls were mounted. The same colls were used for the measurement of epicardial surface deformation (Arts and Reneman, 1980). It is known that insertion of needles of this size results in only little damage, as measured by histolagical and electrophysiological techniques (Franklin, 1974). To obtain fixation of the needle within the myocardium, small notches about $2 \mathrm{~mm}$ below the PVC cylinder, were made in each needle (fig 3.7). The electronic circuitry used in these experiments was the same as the one used in the measuring set-up in the previous section. So the amplitude of the changes of $\mathrm{e}_{c}, \mathrm{e}_{z}$ and $\mathcal{v}$ as measured during the cardiac cycle, could be registrated directly for only one level of coils at a time. Therefore, the signals from each level were alternatingly registrated with periods of 3-5 heart beats 
using a switch. For each variable, the walues of 2 or 3 beats were averaged.

\subsection{Regiona! myocardial blood flow}

\subsubsection{Introduction}

In 1967, Rudolph and Heymann introduced the microsphere method to measure regional blood flow with tracer microspheres of $50 \mu \mathrm{m}$ in diameter. These spheres were injected into the circulation and were trapped in the smaller vessels. After the experiments, the organs were removed and their radioactivity counted. Repeated measurements could be made by using different muclides and separating them by gamma-spectrometry. In several studies (Rudolph and Heymann, 1967; Domenech et a1, 1969; Hoffbrand and Forsyth, 1969; Ut ley et al. 1972; Rudolph and Heymann, 1967; Buckberg et al, 1971; Yipintsoi et al, 1973) It was shown that the fraction of injected radioactivity retrieved in various organs was similar to the fraction of cardiac output reaching those organs during the transit of the spheres. If the flow to one organ and its microsphere content is known, the flow to any other organ or part of an organ, not in series with other microvascular beds, can be callculated.

Since both Heymann et a) (1977) and Schamhardt (1980) reviewed the theoretical and practical aspects as well as the advantages and 1 imitations of this technique, in the next sections the nicrosphere method is discussed only as far as relevant to the present study.

\subsubsection{Choice of the type of microspheres}

In this section, the choice of microspheres with respect to their size and specific activity will be discussed. Spheres with a diameter of $15 \mu \mathrm{m}$ were used in the present study for the following reasons. When the transmural distribution of myocardial blood flow in the free wall af the left ventricle is investigated with microspheres, larger sized spheres systematically overestimate blood flow in the inner (endocardial) layers (Domenech et al, 1969; Ut ley et a1, 1974; Yipintsoi et al, 1973). This has been ascribed to the more axial migration of larger spheres as compared with smaller ones (Segre, 1961; Phibbs and Dong, 1970). Because of this "streaming", larger spheres are preferentially deposited in areas with higher flow velocities (Fung, 1973). since the outer layers receive blood during the whole cardiac cycle and the inner layers only during diastole, and mean blood flow to both areas is almost equal, it is evident that flow velocities are higher in branches 
supplying the inner Tayers at equal vessel diameters (Estes et al, 1966). Shaller spheres which migrate more peripherally in the transmural arteries (originating from the larger epicardial coronary arteries) might be trapped preferentially in more proximal (epicardial) branches. With diffusable tracers, endo/epicardial blood flow ratios have been found to be above unity in the isolated dog heart preparation (Yipintsoi et al, 1973) as well as in the intact dog heart (Prokop et a), 1974). Microspheres with a diameter of $9 \mu \mathrm{m}$ give endo/epi ratios which are well comparable with those obtained with diffusable tracers (Heymarn et a7, 1977: fig 3). According to this figure, 15 $\mu$ beads give a slight overestimation of this ratio. Fan et al, (1979) showed that in the outer layers blood flow values obtained with 9 and 15 um spheres are comparable, but walues in the inner layers are about $10 \%$ higher for the $15 \mu \mathrm{m}$ spheres as compared with $9 \mu \mathrm{m}$ spheres.

On the other hand, a relatively high arterio-venous shunting was found when using $9 \mu \mathrm{m}$ spheres varying between 1 and $6 \%$ under normal conditions (Ut ley et a1, 1974; Crystal et a 1, 1979; Downey et a1, 1979; Fan et a1, 1979; Tripp et al, 1977) and increasing to $8 \%$ during elevation of arterial pco2 (Fan et a1, 1979) or increased perfusion pressures, up to $26.7 \mathrm{kPa}$ (Crysta) et a1, 1977). In the myocardium, the untrapped fraction of $15 \mu$ microspheres was always less than $2 \%$ (Fortuin et a1, 1971; Ut ley et a1, 1972; Fan et al, 1979), even at elevated arterial $\mathrm{P}_{\mathrm{CO}}$ (Fan et al, 1979).

In this study, microspheres with a diameter of $15 \mu \mathrm{m}$ were used because they seem to be the best compromise between the validity of transmural bload flow measurement and the entrapment of microspheres in the small vessels. Moreover, microspheres of $15 \mu \mathrm{m}$ are less expensive than the smaller sized ones.

The specific activity of the microspheres used in this study is lower than that used in other investigations. The lower specificity was selected because of the lower radiation load for the investigators. At a specific activity of $3 \mathrm{mCi} \cdot \mathrm{g}^{-1}$ (weight of spheres), the radioactivity in the spheres is sufficiently high to acquire an accurate gamma counting. In fact, at specific activities down to $0.5 \mathrm{mci} \cdot \mathrm{g}^{-1}$, the number of microspheres per sample and not the gamma counting is the main determinant of the accuracy of the method. An additional advantage is that less radioactivity has to be injected to obtain a certain number of spheres per sample. The price per number of microspheres is more favorable at the lower specific activities as well. 


\subsubsection{Checks before experimental use}

The microspheres were purchased from either the $3 \mathrm{M}$ Company Minnesota, USA) or New England Nuclear (Boston, USA). Microspheres were delivered in injection wills, suspended in $10 \%$ Dextran with $0.05 \%$ Tween 80 as surfactant to reduce aggregation of the spheres. Before use in experiments, each batch was checked on: (a) purity of the nuclide, (b) specific activity of the microspheres, (c) integrity of the spheres, (d) leakage of the nuclides from the spheres and (e) diameter distribution of the beads, according to Heymann et al $(1977)$.

ad (a) Purity of the nuclide is required for accurate gammia spectrometry. The purlty was checked by analysis of the spectrum of a small sample of each batch on the monitor of the Multi-Channel Analyzer. In each case, the right nuclide was delivered and no contamination with other nuclides was found.

ad (b) Of each batch of microspheres the specific activity was measured to check whether the materials delivered were according to the manufacturer's specifications. Furthemore, for accurate determination of the number of microspheres in each blood or tissue sample the specific activity of the beads has to be known precisely. For this determination, a droplet of a diluted suspension of microspheres was spread on a piece of graph paper. The number of microspheres (usually 1000-2000) on this piece of paper was counted microscopically at an enlargement of $100 x$. After this procedure, the radiaactivity of this piece of paper was counted in a gamma counter. Subsequently, it serwed as an isotope reference sample during counting of each series of samples. from an experiment (section 3.4.4).

ad (c) Damaged microspheres may have other flow behavior, may fall to be entrapped and may cause leakage of the nuclide from the spheres. These factors negatively influence the accuracy of the method. Therefore, microsphere integrity was checked microscopically in a small sample at an enlargement of $100 x$. A few hundred beads were checked per sample. In each case, less than $1 \%$ damaged spheres were observed.

ad (d) Substantial leakage of nuclides from the spheres will invalidate the method because in this case not only radioactivity is injected which is trapped by the micracirculation, but also soluble radioactivity which is recirculating.

This leakage was checked as follows. A sample of microspheres was 
taken from batch, sedimentated and once washed (to mimic the treatment of microspheres to be injected in the animal, section 3.4.4). After a few $110 \%$ Dextran with $0.05 \%$ Tween 80 was added and the tube was thoroughly shaken on a Vortex mixer during 1 min and sonificated in an ultrasound bath during $5 \mathrm{~min}$, this tube was counted. Thereafter, the suspension was shaken again on the Vortex and subsequently filtered through a $0.22 \mu \mathrm{m}$ millipore filter (Cathivex). The supernatant was counted and from its activity divided by the activity of the whole microsphere sample the percentage leakage was calculated. This acute lleakage was maximally $0.15 \%$. The mean walue of acute leakage was $0.03 \%$ with a s.d. of $0.05 \%$, for $3 . M$ and NEN spheres combined. These values were lower than the specifications of the manufacturers $10.16 \% \pm$ $0.12 \%, x \pm s . d$.$) .$

The leakage at $37^{\circ} \mathrm{C}$ over longer periods of time was determined in four batches of microspheres. After vigorous shaking, samples of these batches were stored in a $37^{\circ}$ waterbath for 1 to 2 weeks. Intermittently, the suspensions were shaken about five times. After this period, leakage was determined in the same way as in the acute leakage experiments. Values of longterm leakage were found to be about twice as high as those for the acute leakage which is in agreement with the manufacturer's specifications, mentioning a leakage of less than $1 \%$. These results show that microspheres will loose only a negligible portion of their radioactivity in an animal over a period of 2 hours. This is supparted by the observation that blood, withdrawn one hour after the last microsphere injection, contained no substantial radioactivity.

ad (e) Diameter distribution of the microspheres. The importance of a narrow diameter distribution of each batch of microspheres has been emphasized by Reneman et at (1975). Because beads of different size have different rheological properties (section 3.4.2), a large variation in microspheres size will also introduce larger coefficients of variation.

For this reason and also to check whether the right size of spheres was delivered, in each batch the diameter distribution was determined in a sample of 50 microspheres. Initially, this measurement was performed with an ocular micrometer in the light microscope using a magnification of 400-600x. The ocular micrameter was calibrated with 
an objective micrometer. However, the accuracy of this method was 0.5 um due to physical limitations of the light microscope. Therefore, later in this study the diameter of the spheres was measured with an imagesplitting eyepiece (Vickers A.E.I.) mounted on a light microscope. This reduced variations in the diameter measurement to almost $0.1 \mu \mathrm{m}$. The observed diameters and their distributions were comparable with the data provided by the manufacturers.

\subsubsection{Experimental use of microspheres}

The number of spheres in each batch was calculated using data concerning total activity (mCi) and specific activity $\left(\mathrm{mCi} \cdot \mathrm{g}^{-1}\right)$ as well as the number of spheres per gram as provided by the manufacturer. From each batch a stock suspension in fresh $10 \%$ Dextran with $0.05 \%$ Tween 80 was made containing $5 \times 10^{6}$ microspheres per ml. Prior to each experiment, the wanted number of microspheres was taken from this stock solution and diluted twice in $10 \%$ Dextran in a $5 \mathrm{ml}$ syringe.

Before injection, the syringe, which was closed by a stopcock, was thoroughly shaken on a Vortex mixer to suspend all microspheres. Then the syringe was put into a beaker in an ultrasonic bath. The beads were sonificated for 5-10 min to break up clumps of spheres. (Reneman and Verheyen, 1977). Shortly before injection, the syringe was taken out of the bath and again shaken on the Vortex mixer for about $1 \mathrm{~min}$. Within $1 \mathrm{~min}$ after stopping this procedure, the microspheres were injected into the left atrium via a silastic catheter (inmer diameter $2 \mathrm{~mm}$, length $\mathrm{ca} .25 \mathrm{~cm}$ ). The syringe was washed once with about $3 \mathrm{ml}$ physiological saline and subsequently the catheter was flushed with another $7 \mathrm{ml}$ of physiological saline to remove the microspheres.

An arterial reference sample was taken from the brachial artery at a rate of about $20 \mathrm{ml} . \mathrm{min}^{-1}$, using a Harvard suction pump. Withdrawal of blood started $5 \mathrm{~s}$ before the injection of the microspheres and was continued during at least $1 \mathrm{~min}$. The artemial blood was put into test tubes and the sample syringe was flushed once with a few ml of water. After killing the animal by an overdose of barbiturate, the heart was excised, rinsed and stored in formaldehyde 5\%. The free wall of the left ventricle was cut into 5 slices (parailel to the base of the heart). Each slice was cut into 5 pieces of approximately 3 gram. Each piece was divided into a subendocardial, middle, and subepicardial layer (see fig 3.8). The tissue samples were put into PvC $10 \mathrm{ml}$ test tubes. These tubes were weighed empty and with the sample. The 


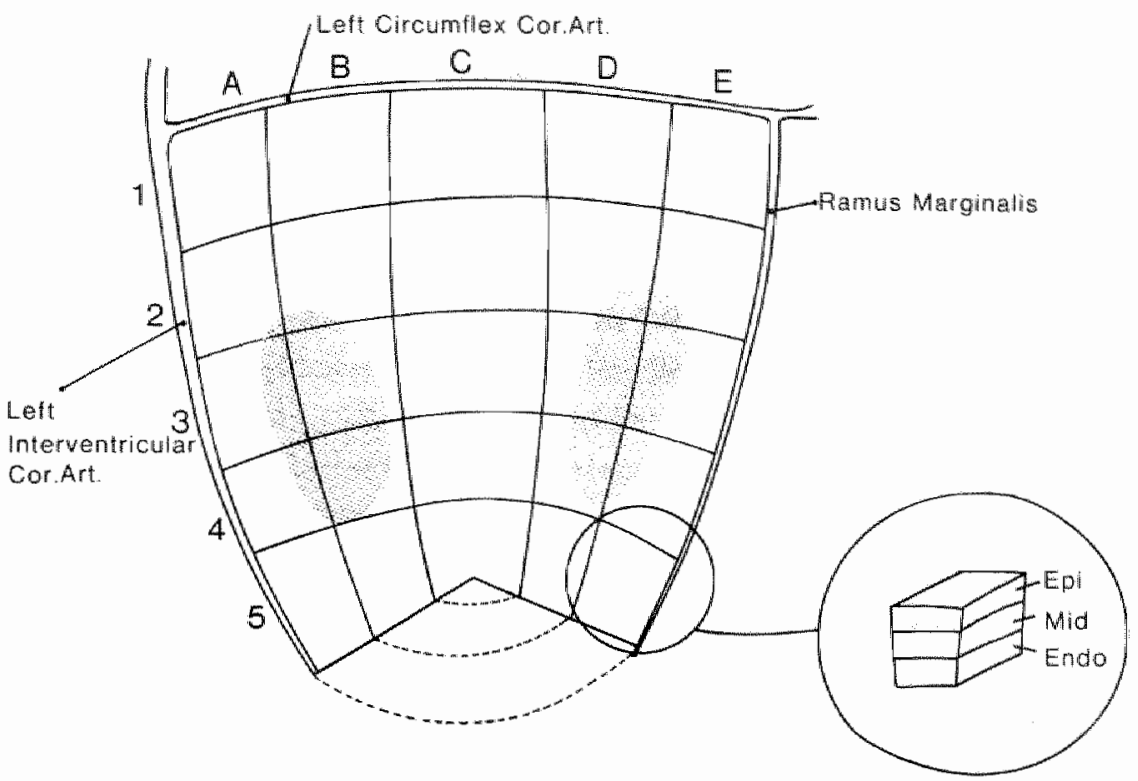

Fig 3.8. Schematic drawing of the method of dividing the left ventricular free wall. The dotted area indicates the position of the papillary muscles. 1-5 are called slices, A-E are called sections.

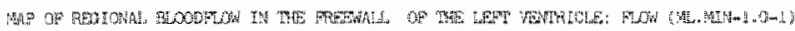

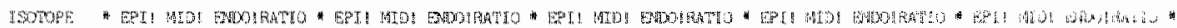

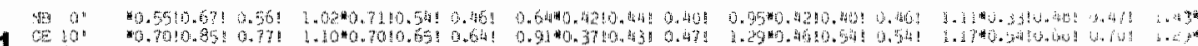

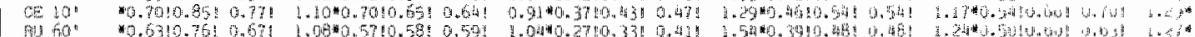

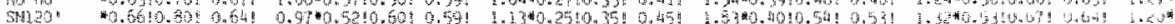

踏

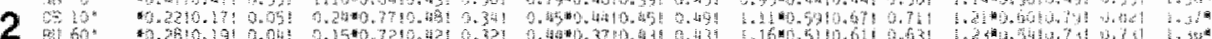

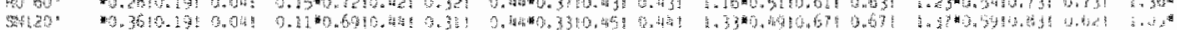

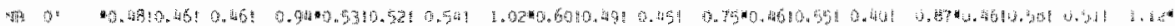

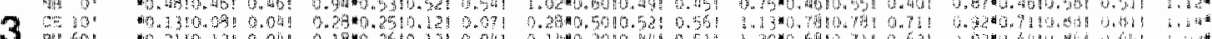

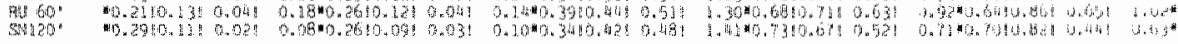

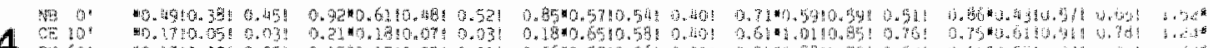

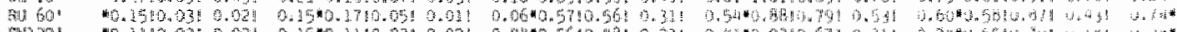

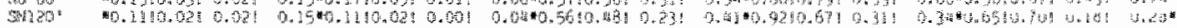

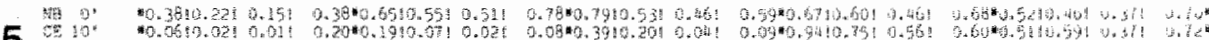

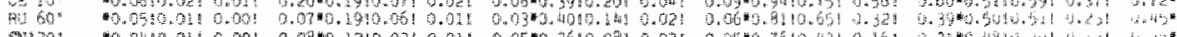
Q7120" wo [ A I B I C I D I E

Fig 3.9 Parts from the output of the MICRO-program for the calculation of regonal myocardial blood flow, showing the values of myocardial blood flow (ml.min $\cdot \mathrm{g}^{-1}$ ) and the endo/epicardial blaod flow ratio according to the location of the samples in the left ventricular free wall (see fig 3.8). 
weighing results were typed in on a data-entry system with a portable memory (3.84 kbytes).

In the Packard Multi-Channel Analyzer the following samples were counted according to the MIC II program input (Schosser et a1, 1979): background samples, isotope reference samples, substract samples (meant for empty syringes), arterial and venous reference samples and tissue samples.

To be able to distinguish between the radioactiwity of different nuclides within one sample as much counting windows were programed as isotopes were present. Each window was located around the photopeak(s) of an isotope, taking into account that the overlap of other nuclides in that window was as small as posstble. The spectrum of each isotope could be wisualized on a display, facilitating the positioning of the windows.

\subsubsection{Calculation of regional blood flow}

Data obtained from the gamma counter were sample number in the gamma counter, counting time and the gross counts in each window. These data were printed on paper and on papertape. The papertape data were fed into the MINC II computer, using a Facit papertape reader, and stored on fille on a floppy disc.

The weighing data in the portable memory were read into the computer by a data entry (manufactured at the University of Limburg) in octal code and subsequently converted into alpha numeric figures. By a screeming pragram, these data were checked on errors in the input and the data were ranked in negative numbers (for the empty tubes) and positive numbers (for tubes with samples) for direct use in the MICRO program.

The MICRO program is based on the MIC 11 program of Schosser et al (1979). Shortly, the analysis of the energy spectra is performed accarding to the matrix method. Isotope reference samples (containing each a certain amount of one pure isotope) are measured to obtain the overlap matrix. The unknown amounts of the nuclides in the samples are calculated by solving a set of linear equations. The original MIC II program has been changed for convenience on a few points:

a. Calculation of the ratio count per min (cpm)per microsphere. This ratio was originally detemined by dividing the activity of the whole injectate by the estimated number of injected microspheres. Direct gamma counting of the injectate however is nat feasible when a large experimental animal is 
used, because a high dose of radioactivity is required. Therefore, from each nuclide 1000-2000 microspheres were counted microscopically on a piece of graph paper and after counting put into a counting tube. Manual input into the MICRO program of this number of microspheres, tagether with the papertape input of the counting data results in the cpm/microsphere.

b. Determination of the injected numstract samples) to correct for microspheres remaining in the syringes is not necessary. Thus in the present study, substract samples were replaced by empty tubes. The injected number of microspheres was estimated from the volume of the stock suspension used for injection.

c. Because the left ventricular free wall is divided systematically into 75 pieces (section 3.4.4) it was possible to make a "map" of MBF in each experiment. To provide this "map", the MICRO program was extended to obtain geographic information about the distribution of MBF in the free wall of the left ventricle (see fig 3.9).

The output of the computer was stored on file and subsequently printed. Beside the data provided in the original version of the MICRO-program (Schosser et al, 1980). Also the MBF values and the endo/epicardial blood flow ratios of the 25 transmural pieces of all 75 samples are given (fig 3.9 ).

Because prior to dissection of the heart the tissue samples in which biopsies had been taken for the assessment of ATP, creatine phosphate and glycogen or fatty acid content, had been marked, the MBF values of these samples could be related to these biochemical variables. Total MBF in the ischemic and non-ischemic area was calculated as well. The ischemic area was considered to be the zone perfused by the left anterior interventricular coronary artery which was identified macroscopically. For the determination of total flow in this ischemic zone, only samples in which during stenosis flow in the subendocardial part of the transmural sectlon was reduced by at least $40 \%$ as compared with the pre-stenotic period, were taken into account. The non-ischemic area was considered to be the zone of tissue along the left circumflex coronary artery and alang the marginal branch of this artery (fig 3.8). The OVERAL computer program grouped tissue samples per layer so that beside total flow, MBF in the three layers of the non-ischemic and ischemic zones could be calculated as well as the mean endo/epicardial blood flow ratio. 


\subsubsection{Accuracy of the method}

Vartations in the assessment of regional blood flow by radioactive microspheres originate mainly from two factors: properties of the microspheres and measurement of the presence of these spheres. Variations in the latter one originate from errors in gama counting of tissue and blood samples, in the weighing of the tissue samples and in the matrix calculations.

The weight of the tissue samples is determined with an accuracy of $1 \mathrm{mg}$ fritroducing a variation of about $0.1 \%$ in the tissue samples (mean weight about $1 \mathrm{~g})$.

For a proper determination of the radioactiwity of a sample, the background activity has to be known as well. This background activity shows relatively large variations within the counting times used (10 min). For $\mathrm{Ce}^{141}, \mathrm{Sn}^{113}, \mathrm{Ru}^{103}$, and $\mathrm{Mb}^{95}$, the variation in the background activity was $12.4,5.5,5,8$ and $6.6 \%$, respectively. However, in tissue samples containing radioactivity of at least 10 times the background, the assay variation is less than $2 \%$. Because the background in each window ranged from 10-40 cpm, only in samples with a small amount of spheres (samples from severely ischemic tissue, for example) this variation has to be taken into account.

Errors due to the matrix calculations providing corrections for compton scatter were evaluated in a simulation experiment. The input data for the isotope reference samples were chosen to mimic the nuclides I ${ }^{125}, \mathrm{Sr}^{85}$, and $\mathrm{Nb}^{95}$. The relative activity of the different nuclides in the simulated tissue samples were varied to simulate flow differences up to a factor of 10 at the different injection times. This error was $1.0 \%$ for $1^{125}$ and less then $0.01 \%$ for the other three isotopes. For experiments where 8 isotopes were used, Schosser et al (1979) reported errors of less than $0.23 \%$.

In contrast to the above-mentioned factors, errors caused by properties of the microspheres mainly determine the variations in the results obtaimed with the microsphere method: inhomogeneous distribution of the spheres over the cross-sectional area of the blood vessel, incomplete mixing of spheres in the blood and statistical variation in milcrosphere distribution.

Inhomogeneous distribution of microspheres over the crass-sectional area of the vessel is responsible for differences in transmural distribution across the left wentricular wall between different sizes of microspheres (section 3.4 .2$)$.

To check adequate mixing of the microspheres in the blood, 6 experiments were performed. In 3 experiments, 4 isotopes were simultaneously injected. In 
each of the 3 experiments, activity was $4.7 \% \pm 5.0 \% ; 1.8 \pm 1.6 \%$ and $0.2 \pm$ 1. $4 \%$ higher in the femoral than in the brachial artery sample (mean and $5 . d$. of the 4 isotopes). In 3 other experiments, 4 isotopes were injected subsequently, at an interval of 5 min during a stable hemodynamic period. In these experiments activity was $2.1 \% \pm 3.3 \%$ lower; $2.6 \pm 2.5 \%$ and $1.9 \pm 0.6 \%$ higher in the femoral than in the brachial artery sample. These results indicate that microspheres are not preferentially distributed to either the brachial or the femoral artery, suggesting a homogeneous distribution of microspheres in the blood, which is in agreement with results obtained by other investigators (Hoffbrand and Forsyth, 1969; Buckberg et a1, 1971). These experiments also show that between different microsphere injections a coefficient of variation of $3.5 \%$ exists.

Because microspheres are distinct particles, variations in the concentration of spheres accur as a result of statistical variation even with homogeneous blood distribution. This variability approximates the Poisson distribution (Buckberg et al, 1971). This implies that the variation in the microsphere method is dependent on the number of spheres in each sample (Buckberg et a1, 1971; Reneman et a1, 1975; Flameng et a1, 1977). To investigate whether in our experimental set-up this variation is comparable to those found by these authors, in 2 experiments 4 isotopes were injected simultaneously into the left atrium. Before this injection, the LAICA was stenosed to create inhomogeneous flow distribution withim the left ventricle resulting in large differences in microsphere content of the tissue samples. The results of these experiments are shown in table 3.1. The differences in calculated myocardial blood flow (MBF) values between 2 isotopes in each sample are expressed as the relative error (E) or as coefficient of variation. The relative error was calculated according to the following equation (De Jonge, 1964):

$$
E=1.96 \cdot \frac{\sqrt{2 d i^{2} / 2 k}}{\bar{x}} \cdot 100 \%
$$

where $d_{j}=$ the difference in calculated MBF walues between 2 isotopes in the various samples, $k=$ the number of samples and $\bar{x}=$ the mean MBF calculated from the 2 isotopes. 
Table 3.1 Coefficient of vartation and relative error (section 3.4 .6 ) of myocardial blood flow values abtained with any two isotopes after simultaneous injection of four isotopes during coronary artery stenosis.

\begin{tabular}{lccc}
\hline $\begin{array}{l}\text { Number of micro- } \\
\text { spheres per iso- }\end{array}$ & $\begin{array}{c}\text { Coefficient } \\
\text { of variation } \\
\text { tope per sample }\end{array}$ & $\begin{array}{c}\text { Relative error } \\
\text { ( })\end{array}$ & $\begin{array}{c}\text { Number of } \\
\text { comparisons }\end{array}$ \\
72000 & 3.2 & 7.1 & \\
$1000-2000$ & 3.6 & 8.2 & 72 \\
$700-2000$ & 5.0 & 7.0 & 81 \\
$400-700$ & 5.6 & 9.9 & 30 \\
$200-400$ & 6.4 & 15.5 & 24 \\
$100-200$ & 9.0 & 16.0 & 56 \\
100 & 30.0 & 70.3 & 78 \\
\hline
\end{tabular}

Table 3.2 Coefficient of variation of myocardial blood flow values obtained with any two isotopes, separately injected during a stabile hemodynamic situation after coronary artery stenosis.

Number of microspheres

per isotope per sample
Coefficient of

variation $(\%)$
Number of

comparisons

\begin{tabular}{lrr}
\hline$>2000$ & 12.8 & \\
$1000-2000$ & 10.7 & 14 \\
$700-1000$ & 11.8 & 31 \\
$400-700$ & 13.8 & 11 \\
$200-400$ & 15.0 & 15 \\
$100-200$ & 20.7 & 16 \\
$<100$ & 40.4 & 9
\end{tabular}


The coefficient of variation was calculated according to the equation:

$$
C . V .=s \cdot d \cdot 1 \bar{x}
$$

where s.d. = standard deviation and $\bar{x}=$ mean calculated MBF.

Tissue samples were classified in groups containing $<100,100-200,200$ $400,400-700,700-1000,1000-2000$ and $>2000$ microspheres per sample. No s19nificant differences were observed between the MBF values af the 4 isotopes. Therefore, the analysis of the results from the comparison between each pair of isotopes was combined (see table 3.1).

These results show that in samples containing at least 400 microspheres. variation of the MBF determination is less than $10 \%$. This value is comparable to the values found by Buckberg et al, 1971 (in arterial reference samples), Flameng et al, 1977 (in tissue samples from an isolated heart preparation), and Reneman et a1, 1975 (in a set-up identical to the one used in this study). In comparison with the latter investigators, the relative error in our experiments tends even to be less. This might be due to a more narrow diameter distribution of the spheres used in this study.

It lhas to be emphasized that the variations found in these 2 experiments are the sum of all experimental variations mentioned above, except for the variations in arterial reference sampling. However, the other variations are not influenced or only to a limited extent to the number of microspheres im one sample. Thus, the variations shown in table 3.1 are the intra-assay variations for a certain number of microspheres.

The inter-assay variation theoretically will be equal to the intra-assay variation plus the arterial reference sample variation. This variation could be detemined by injecting the isotopes not simultaneously but separately at short time intervals. However, in this case, no discrimination can be made between the inter-assay variation and real changes in flow even in an apparent stable hemodynamic situation. Nevertheless, we investigated these variations in 2 experiments, while the LAICA was stenosed. Variation coefficients in samples with different microsphere contents are shown in table 3.3. Again, the relation between the number of spheres per sample and the vartation coefficient is clear. However, comparison with the data from table 3.1 show that for any number of microspheres the variation coefficient is $7-10 \%$ higher in case of separate injections. This difference will be caused by variations 


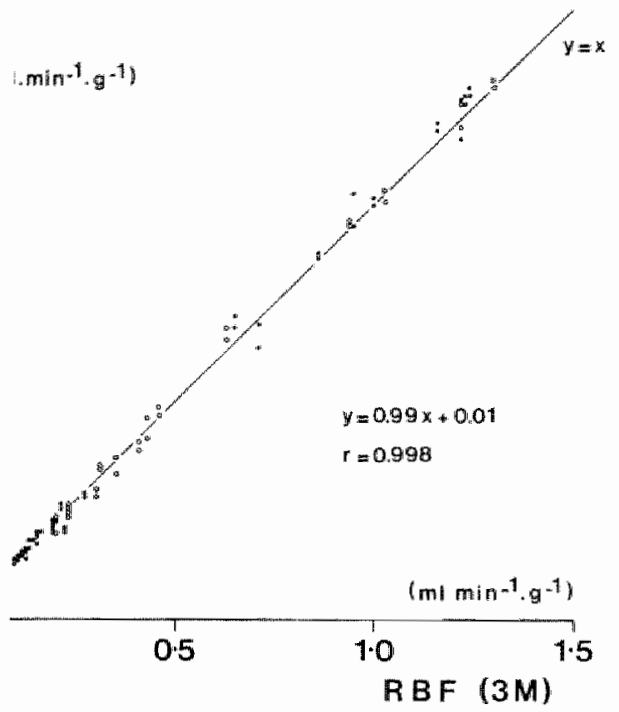

if regional blood flow values as obtained from $3 \mathrm{M}$ : N (Ru 103 and $S n^{113}$ ) microspheres. Shown are the organs in the systemic circulation (w) and from of the 4 animals. 
Table 3.3 Relative errors (section 3.4.6) in MBF values from organs in the systemic circulation, obtained after simultaneous injection of three isotopes. n depicts the number of comparisons.

\begin{tabular}{|c|c|c|c|c|c|c|}
\hline $\begin{array}{l}\text { Number of } \\
\text { microspheres } \\
\text { per sample }\end{array}$ & $\begin{array}{c}N b-S n \\
(3 M)(N E N)\end{array}$ & $n$ & $\begin{array}{l}\text { NG }- \text { Ru } \\
(3 M) \text { (NEN) }\end{array}$ & $n$ & $\begin{array}{l}\text { Sn - Ru } \\
(3 M) \text { (NEN) }\end{array}$ & $n$ \\
\hline $\begin{array}{l}>2000 \\
1000-2000 \\
400-1000 \\
100-400 \\
<100\end{array}$ & $\begin{array}{r}3.6 \\
4.6 \\
12.0 \\
21.8 \\
29.2\end{array}$ & $\begin{array}{r}16 \\
11 \\
8 \\
12 \\
11\end{array}$ & $\begin{array}{r}6.0 \\
4.6 \\
3.7 \\
7.9 \\
14.4\end{array}$ & $\begin{array}{r}2 \\
9 \\
11 \\
13 \\
14\end{array}$ & $\begin{array}{r}4.5 \\
5.8 \\
2.3 \\
2.9 \\
15.5\end{array}$ & $\begin{array}{r}2 \\
9 \\
11 \\
13 \\
14\end{array}$ \\
\hline
\end{tabular}


in arterial reference sampling as well as in the hemodynamic situation. In other experiments, the variation in arterial reference sampling have been shown to be $3.5 \%$ so even in an apparent stabile situation, variations in MBF of 3.5-6.5\% seem to be common and should be emphasized in interpreting results obtained with the microsphere method.

\subsubsection{Compartson between 3M and NEN microspheres}

Unt 11 recently, the only brand of non-biodegradable spheres avallable and extensiveily investigated on their validity for the measurement of regional blood flow were those manufactured by the $3 M$ Company. Since a few years, NEN also delivers radioactive microspheres which are claimed to be at least as reltable as the $3 M$ spheres. Knowledge about the exact composition of either brand of spheres is absent. The $3 M$ spheres are made of tan inert plastic material" which is carbonized; the NEN spheres consist af "styrene-divinyl benzen copolymer coated with a polymeric resin".

However, in using any type of microspheres to measure regional blood flow, a number of assumptions are implicit. Since $3 M$ microspheres have been extensively investigated and validated (section 3.4.1), a comparison between the results obtained with $3 M$ and NEN spheres mas made.

The comparison of both types of microspheres was performed in 4 rabbits (mean weight $4 \mathrm{~kg}$ ). The animals were anesthetized with $0.4 \mathrm{~m} 1 . \mathrm{kg}^{-1}$ Rompun and $0.2 \mathrm{ml} . \mathrm{kg}^{-1}$ Vetalar and ventilated after endotracheal intubation with a pediatric positive pressure respirator. The thorax was opened through the left 5th intercostal space and the pericardium was opened. For injection of the microspheres a small silastic catheter was inserted into the left atrium. A polyethylene catheter was inserted into a brachial artery to obtain an arterial reference sample. With a syringe, a mixture of $15 \mu \mathrm{microspheres} 1$ abeled with $\mathrm{Nb}^{95}(3 M)$, Rut 103 (NEN) and $\mathrm{Sm}^{113}$ (NEN) was injected into the left atrium. The reference sample was taken at a rate of $6.0 \mathrm{ml} . \mathrm{min}^{-1}$, using a Harvard suction pump. Withdrawal of blood started $5 \mathrm{~s}$ before injection of the spheres and was continued during at least $1 \mathrm{~min}$.

After the experiment, tissue samples of different size were taken from the heart, kidneys, liver, spleen, skeletal muscles and lungs. From these samples, regional blood flow was determined as described in section 3.4.5.

The coefficients of variation in blood flow values in the heart alone as well as these values combined with blood flow values in the liver, kidneys and skeletal muscles are shown in table 3.3. The variations in blood flow 
values in these organs were combined to obtain in each class of number of spheres per sample a reasonable number of observations. Moreover, no consistent differences were observed between the variations in the different organs. The obtained values of the relative error are comparable to those found after simultaneous injection of 3 microspheres with 3 different isotopes (table 3.1).

Linear regression analysis showed an excellent relation between the obtained MBF values of $3 M$ and NEN spheres (see fig 3.10). A1so entrapnent of either type of microspheres in the lungs was almost identical, suggesting that no differences in shunting through the systemic circulation were present.

According to these results, it was concluded that measurement of regional blood flow with NEN microspheres has the same validity as 3M microspheres. This is in agreement with the results of Hales et al (1979) in sheep.

\subsection{Detemination of chemical substances in blood}

\subsubsection{Introduction}

The determination of several substances in the blood was performed for several reasons. Firstly, assessment of myocardial substrate utilization requires the measurement of the uptake of oxygen, glucose, lactate and fatty acids by the myacardium (section 2.3). As mentioned in section 3.7, the uptake of these substances was estimated from the product of myocardial regional blood flow and the respective arteriolocal venous (AV) differences of these substances. Moreover AV differences of MEFA were determined to investigate to which extent the accumulation of NEFA during ischerria, as observed in a previous study is caused by uptake of these NEFA(Van der Vusse et a 1,1982$)$. Secondly, the release of lactate, inorganic phosphate, potassium, $\mathrm{CO}_{2}$ and $\mathrm{H}^{+}$was determined because these substances are known to be good biochemical markers of myocardial ischemia.

At last, the determination of blood gases, pH and oxygen content of arterial blood was used to check the respiratory and metabolic condition.

\subsubsection{Blood gases and blood $\mathrm{pH}$}

The blood pH was determined potentiometrically using a pH glass electrode and a calomel reference electrode. The $\mathrm{p}_{\mathrm{CO} 2}$ was measured using a $\mathrm{p}_{\mathrm{CO} 2}$ electrode, in fact a $\mathrm{pH}$ electrode the surface of which can only be activated by 
Table 3.4 Precision of the detemination of several substances in the blood. For calculation of the coefficient of wariation, see section 3.4.6.

Variable

$\mathrm{CO} 2$

$\mathrm{PO} 2$

Hb

Qquisteration

Lactate

Inorganic phophate

Potassium

$\mathrm{pH}$

\section{Intra-assay coefficient}

of variation $(\%)$

Table 3.5 Precision of the gaschromatographic method for the estimation of NEFA in dog serum (8 replicate assays).

2.3

2.3

2.8

0.5

1.1

2.2

1.4

0.6

0.007 units

\section{Sample}

number

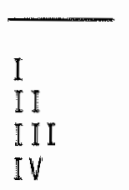

Mean
Mean amount of NEFA estjmated (unol. $\left.1^{-1}\right)$

278
179
123
103

$\begin{array}{cl}\text { SD } & \text { Intra-assay } \\ \left.\text { (umo } .1^{-1}\right) & \text { coefficient of } \\ \text { variation }(g)\end{array}$

4
4
5
3

1.4

2.2

3.9

2.6

2.5

Table 3.6 Precision of the GLC method for estimation of individual fatty acids of the NEFA class in dog serum (8 repl. assays) Intra-assay coefficient of variation $(\%)$

\begin{tabular}{|c|c|c|c|c|c|}
\hline Sample number & I & $\mathbb{I}$ & III & IV & mean \\
\hline MEFA: & & & & & \\
\hline Myristic acid & 5.3 & 10.3 & 21.9 & 10.8 & 12.0 \\
\hline Palnitic acid & 4.5 & 5.2 & 2.4 & 2.1 & 3.6 \\
\hline Palmitoleic acid & 1.9 & 3.6 & 4.4 & 7.3 & 4.3 \\
\hline Stearic acid & 2.4 & 4.6 & 4.9 & 3.5 & 3.8 \\
\hline oleic acid & 1.4 & 3.3 & 2.9 & 1.5 & 2.2 \\
\hline Linoleic acid & 3.6 & 3.3 & 2.8 & 2.7 & 3.1 \\
\hline Arachidonic acid & 28.6 & 70 & 14.7 & 9.3 & 15.1 \\
\hline
\end{tabular}


uncharged molecules due to a thin Tefion outer membrane. Deteminination of $p_{02}$ was performed with an amperometrical method. Intra-assay coefficients of wariation of these three methods are shown in tabie 3.4 . Detemination of the blood gases and blood pH was perfomed at $37 \mathrm{C}$ using a blood gas analyzer (IL 413 or Radioneter ABL3).

\subsubsection{Hemoglobin, oxygen saturation and oxygen content}

These measurements were performed using a Radiometer OSM 2 hemoximeter. The method is based on spectrophotometric analysis at 505 and 600 nm at $37^{\circ} \mathrm{C}$. The molar absorbances of $\mathrm{Hb}$ and $\mathrm{HbO}_{2}$ are identical at 505 mon but widely dif ferent at $600 \mathrm{~nm}$. Intra-assay coefficient of variation of the $0_{2}$ saturation determination was $0.5 \%$ and of the hemoglobin determination $2.8 \%$ (table 3.4 ).

The oxygen content of the blood was definedasthe product of hemglobin concentration oxygen saturation. Since the amount of 02 in the plasma is smaller compared to the henoglobin bound oxygen.

\subsubsection{Glucose, lactate, inorganic phosphate and potassium}

The concentration of these substances in the serum of the blood samples was determined by spectrofotonetry on a Technicon AAII Auto-analyzer.

Glucose was determined with hexohinase and glucose-6-phosphate dehydrogenase as described by Bergmeyer et al, (1974).

Intra-assay coefficient of variation of the blood glucose determination was $1.1 \%$. Lactate was detemined with lactate dehydrogenase as described by Gutmann and Wahlefeld, (1974), modified for assessment on the Auto-analyzer. Intra-assay coefficient of variation of this method was $2.2 \%$.

Serum inorganic phosphate concentrations were determimed with ammonium molybdate according to Fiske and Subbarow (1926). These complexes were spectrophotometrically assessed. For this method, the intra-assay coefficient of variation was $1.4 \%$ (table 3.4 ).

Concentrations of potassium in the serum of blood samples were determined with a Technicon Auto-analyzer Flame Photometer IV coupled to the abovementioned Auta-analyzer. The method is based on a procedure described by Berry et al (1946). Intra-assay coefficient of variation of this determination was $0.6 \%$ (table 3.4).

Materials for the glucose, inorganic phosphate and potassium determination were purchased from Technicon, Tarrytown. For the lactate determination LDH was purchased from Boehringer, Mannheim, and lactate from Sigma, St. Louls, 
and the other chemicals from Merck, Darmstadt.

\subsubsection{Non-esterlfied fatty acids}

The concentration of non-esterified fatty acids (NEFA) in bilood can be detemined using a colorimetric, titrimetric, radiometric, enzymatic or gaschromatographic method. Initially, this concentration was determined using a colorimetric method (data presented in chapter 8). However, in the course of this study, we preferred the gaschromatographic method (other data),giving also data concerning the individual NEFA. The colorimetric assay was performed with the standard Boehringer test kit (Boehringer, Gemany). NEFA form with copper nitrate salts which are soluble in chlaroform. With diethylthiocarbaminate, yellow complexes are formed, the color intensity of which can be measured spectrophotonetrically at $420 \mathrm{~nm}$. The detemination was started inmediately after the samples were thawed. For each determination, $0.1 \mathrm{ml}$ of serum was used. The intra-assay coefficient of variation was $4 \%$.

For gaschromatographic determination of the serum concentration of NEFA, $100 \mu 1$ serum was extracted with $2.0 \mathrm{ml}$ methanol/chloroform $(1: 2, v / v)$ at room temperature. Serum extracts were subsequently treated in a similar fashion as the extracts of myocardial biopsies (section 3.6.4). In table 3.5 and 3.6, respectively, the standard deviation and intra-assay coefficient of variation of the total NEFA determination and of the individual NEFA is shown far 4 samples, each value being calculated from 8 replicate assays. The high coefficient for myristic acid and arachidonic acid is caused by their very low concentrations in the blood. Manufacturers of the materials used for this determination are mentioned in 3.6 .4 .

\subsubsection{Triacylglycerol}

After thinlayer chromatography of the serum, the triacylglycerol spot was scratched off, the fatty acid moieties were transmethylated and gaschromatographically determined (for conditions during this determination, see section 3.6.4). Intra-assay coefficient of variation of this method varies from 1.4 to $2.8 \%$ (mean $2.2 \%$ ), as calculated from 8 replicate assays of 4 samples (table 3.7 ).

Manufacturers of the materials used for this determination are mentioned in 3.6 .4 . 
Table 3.7 Precision of the gaschromatographic method for the estimation of fatty acids of triacylglycerol in dog serum $(8$ replicate assays).

\begin{tabular}{|c|c|c|c|}
\hline $\begin{array}{l}\text { Sample } \\
\text { number }\end{array}$ & $\begin{array}{l}\text { Mean amount of } \\
\text { FA estimated } \\
\left.\text { (umol. } 1^{-1}\right)\end{array}$ & $\begin{array}{c}\mathrm{SO} \\
\left(\mu \mathrm{mol} \cdot \mathrm{T}^{-1}\right)\end{array}$ & $\begin{array}{c}\text { Intra-assay } \\
\text { coeff. of war. } \\
(\%)\end{array}$ \\
\hline $\begin{array}{l}\mathbb{I} \\
\mathbb{I I} \\
\mathbb{I I I} \\
\mathbb{I V}\end{array}$ & $\begin{array}{l}750 \\
733 \\
721 \\
670\end{array}$ & $\begin{array}{r}20 \\
12 \\
6 \\
19\end{array}$ & $\begin{array}{l}2.7 \\
1.6 \\
1.4 \\
2.8\end{array}$ \\
\hline
\end{tabular}

Table 3.8 Precision of the determination of several substances in nyocardial tissue

Variable

Intra-assay coefficient of variation $(\%)$

$\begin{array}{lc}\text { ATP } & 4.7 \\ \text { CP } & 3.3 \\ \text { GTycogen } & 3.8 \\ \text { NEFA } & 2.3 \\ \text { Triacylglycerol } & 6.5^{\star} \\ \text { Phospholipids } & <7.2^{*}\end{array}$

Difference between two samples in the same heart (see text)

Table 3.9 Precision of the gaschromatographic method for the estimation of the individual fatty acids of the NEFA class in normoxic dog myocardial tissue

\section{Intra-assay coefficient of variation (o)}

Sample number

Number of measurements

$\begin{array}{llll}\text { I } & \text { II } & \text { II } & -\end{array}$

NEFA:

Myristic acid

Palmitic acid

Palmitoleic acid

Stearic acid

oleic acid

linoleic acid

36.1

7.6

21.1

3.1

20.1

18.9

1.2

9.6

6.1

3.3

15.7

13.9

16.2

4.7

11.1

3.7

6.0

9.5

4.5

7.3

5.5

arachidonic acid

24.1

30.1

0.5

4.8

27.1 


\subsection{Determination of chemical substances in myocardial tissue}

\subsubsection{Introduction}

Tissue samples have been taken for two purposes. The first was to obtain information about energy stores present in the myocardium during ischemia. For this purpose transmural biopsies (about $100 \mathrm{mg}$ ) were taken. These samples were divided into samples from the outer, middle and inner layers, in which ATP and creatine phosphate concents were determined. To obtain information about the carbohydrate store, giycogen concent was determined in the same biopstes.

The second purpose was to investigate the time course of the ischemia Induced changes in tissue concents of fatty acids in the non-esterified fatty acid, triacylglycerol and phosphoglyceride classes. For this purpose, separate biopsies were taken, because these determinations require relatively large tissue samples (see below). These biopsies were divided into three parts as well.

\subsubsection{Handling of the tissue samples}

Before chemical analysis the tissue samples for ATP, creatine phosphate and glycogen determination were freeze dried within the drills in a Virtis freeze dry apparatus. Care was taken that during this procedure the biopsies stayed at a temperature not higher then $-30^{\circ} \mathrm{C}$ unitil they were dry. Thereafter the biopsies were pushed out of the drills and divided into samples from the outer, middle and inner layers. To reduce interference with the chemical analysis, adherent dried blood was removed as much as possible under a binocular microscope using a small pincet and a needle. Subsequently, these samples were stored again at $-80^{\circ} \mathrm{C}$ ar directly used for chemical analysis.

\subsubsection{ATP, creatine phosphate and glycogen}

The dried tissue was crushed with a glass rod in a $0.2 \mathrm{ml}$ water-acetone (1:1, w/v) mixture, containing $2 \mathrm{mM}$ EDTA and $0.4 \mathrm{M}$ perchloric acid at a temperature of $-15^{\circ} \mathrm{C}$. The whole mixture was subsequently neutralized with $0.1 \mathrm{mI}$ ice-cold TRIS-KOH and centrifuged for $10 \mathrm{~min}$ at $4^{\circ} \mathrm{C}$ with a relative centrifugal force of $1100 \mathrm{~g}$. The clear supernatant was carefully removed and aliquots were used for the determination of ATP and creatine phosphate. The residue containing fragments of tissue and insoluble salts was used for the detemination of glycogen (vide infra). 
ATP and creatine phosphate were analyzed with a fluomometric technique (Lamprecht and Trautschold, 1974; Lamprecht et a1, 1974), modified by Drake et al (1980b). The reaction mixture per liter was: TRIS buffer (55 mol, pH=8.1), NADP ${ }^{+}\left(1\right.$ mol), glucose (1 mol), $\mathrm{ggCl}_{2}(1 \mathrm{mmol})$ and glucose 6-phosphate dehydrogenase $(160 \mathrm{U})$. After addition of $10 \mu 1$ tissue extract to $1.0 \mathrm{ml}$ reaction mixture, the reaction was started with hexokinase $(690 \mathrm{mu})$. The amount of ATP was calculated by comparison of the change of fluorescence in the test cuvet with the standard cuvet $(100 \%$ fluorescence has been standardized with $5 \mathrm{nmol}$ NADPH in $1.0 \mathrm{ml}$ buffer). From a subsequent addition of ADP (final concentration $0.05 \mathrm{~mol}$ ) and creatine kinase (980 mu) the amount of creatine phosphate was determined in the same cuvet.

The afore-mentioned residue (see ATP and creatine phosphate determination) was kept at $37^{\circ} \mathrm{C}$ for 3 hours after addition of $1.0 \mathrm{ml} 1.0 \mathrm{M} \mathrm{NaOH}$. Subsequently, $1.0 \mathrm{ml} \mathrm{95 \%} \mathrm{ethanol} \mathrm{was} \mathrm{added} \mathrm{and} \mathrm{the} \mathrm{whole} \mathrm{mixture} \mathrm{was} \mathrm{heated} \mathrm{for} 10$ min at $85^{\circ} \mathrm{C}$. After cooling to $4^{\circ} \mathrm{C}$, the mixture was stored at this temperature for 24 hours. The mixture was centrifuged at $4^{\circ} \mathrm{C}$ with $1100 \mathrm{~g}$ for 20 min. The clear supernatant was carefully removed with a pipette, and the residue was washed twice with $0.5 \mathrm{~m} 160 \%$ ethanol. After centrifugation at $4^{\circ}$ $\mathrm{C}$ with $1100 \mathrm{~g}$ for $30 \mathrm{~min}$, the residue was hydrolyzed at $85^{\circ} \mathrm{C}$ for 3 hours after addition of $1.0 \mathrm{ml} 1.0 \mathrm{M} \mathrm{HCl}$ to the residue. The mixture was subsequently neutralized with $0.5 \mathrm{ml}$ TRIS-KOH and aliquots were used for the fluorometric assay of the glucose moieties.

Instead of glucose, ATP (1 mM) has been added to the afore-mentioned reaction mixture. After addition of $10 \mu 1$ tissue extract, the reaction was started with hexokinase (690 mu).

The determinations were performed with a Zeiss ZFM4 Fluorometer, at a temperature of $25^{\circ} \mathrm{C}$. The intra-assay coefficient af variation of the determination of ATP, creatine phosphate and glycogen are shown in table 3.8 .

\section{Materials}

Enzymes hexokinase $(140 \mathrm{U} / \mathrm{mg})$, creatine kinase $(25 \mathrm{U} / \mathrm{mg})$ and glucose 6 -phosphate dehydrogenase (350 U/mg) were purchased from Boehringer Mannheim, B-nicotinamide-adenine dinucleotide phosphate (disodium salt) and adenosine 5-triphosphate (disodium salt) from Sigma, St. Louis. Creatine phosphate (disodium salt) was purchased from Boehringer, Mannheim. Glucose, giycogen, TRIS, EDTA and other chemicals used in this study were produced by Merck, Damistadt. 


\subsubsection{Fatty acids}

Tissue concentrations of fatty acids were determined according to van der Vusse et al (1980). Aliquots of deeply frozen tissue (150-300 mg of wet welght) were pulwerized in an aluminium mortar with a stainless steel pestle, previously cooled in liquid nitrogen. The tissue powder was transferred to test-tubes coaled with liquid nitrogen. The test-tubes were placed at $-21^{\circ} \mathrm{C}$ and the tissue powder was wetted with $2 \mathrm{ml}$ methanol of $-21^{\circ} \mathrm{C}$. The content of the test tubes was allowed to warm up till room temperature and was subsequently weighed. Chloroform was added til1 a mixture of chloroform and methanol of $2: 1 \mathrm{v} / \mathrm{w}$ was obtained. As antioxydant butylated hydroxytoluene $(0.01 \%)$ was present in the methanol and chloroform. Subsequently, a mixture of heptadecanoic acid, cholesteryl heptadecanoate and triheptadecanoin was added to the extraction mixture in arder to correct for losses during the assay procedure. Non-esterified fatty acids (NEFA), triacylglycerol, cholesteryl esters and total phospholipids were isolated from the extracts by thin-layer chromatography using TLC plates coated with Silica gel F 254. The lipid spots were predeveloped with chloroform/methanol/ $\mathrm{H}_{2} \mathrm{O} /$ acetic acid $(10: 10: 1: 1$, w/v) unti) the liquid front had reached a level of $1 \mathrm{~cm}$ above the site of application of these spots. Hexane/diethyl ether/acetic acid $(24: 5: 0.3, v / v)$ was used as developing solvent. The lipid spots were made visible with Rhodamine $G$, scraped from the plate and transferred into test-tubes, containing $0.5 \mathrm{ml} 7 \%$ $\mathrm{BF}_{3}$ solution. The fatty acid moiety of the various lipid classes was methylated at $20^{\circ} \mathrm{C}$ for $15 \mathrm{~min}$ (NEFA) at $100^{\circ} \mathrm{C}$ for 30 min (triacylglycerol) and at $100^{\circ} \mathrm{C}$ for $45 \mathrm{~min}$ (cholesteryl esters and phospholipids). The methylesters were extracted from the methylating mixture with pentane. After evaporation of the pentane under a stream of $\mathrm{N}_{2}$ at $37^{\circ} \mathrm{C}$, the methylesters originating from the NEFA, triacylglycerol and phospholipids were dissolved in trimethyl pentane, containing appropriate amounts of methyl pentadecanoate (about 3 nmol per assay) as internal standard. The lipid spots were extracted from the silica gel powder with diethyl ether/methanol $(50: 1, v / v)$. The methylester mixtures were analyzed by gas-liquid chromatography using glass columns packed with $5 \%$ OEGS on chromosorb W-AWDMCS (1)ength 6 feet; inner diameter 2 $\mathrm{mm})$. Starting temperature of the column was routinely $150^{\circ} \mathrm{C}$, the temperature gradually increased up to $190^{\circ} \mathrm{C}$, with an increase rate of $4^{\circ} \mathrm{C} \cdot \mathrm{min}^{-1}$. Carrier

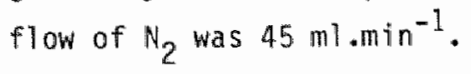

Tissue samples in this study weighed between 150 and 300 ng. Given a blank value of $3 \mathrm{nmol}$ and NEFA tissue contents of $30 \mathrm{nmol} . \mathrm{g}^{-1}$, this implies that 
measurements were about three times the blank value. The correction for the blank walue was rather accurate in our hands, as is shown by the NEFA intraassay coefficient of variation of $2.3 \%$ (table 3.8 ).

A1 so the intra-assay caefficient of other fatty acids in tissue is shown in table 3.8. The exact intra-assay wariation of the phosphoglyceride determination can only be validly calculated if the recovery of each individual phosphoglyceride is known. Because this is not the case in this study, the coefficient of variation of the values of two samples in the perfusion area of the left circumflex coronary artery is shown. The real coefficient of variation witl be lower ar equal to this figure. In table 3.9, the intra-assay coefficient of variation of the individual NEFA in normoxic tissue is shown. Mean coefficient of variation for the different NEFA ranges from 4.8 to $6.1 \%$ for the NEFA, present in the relatively higher amount, and from 16.2 to $27.1 \%$ for myristic acid, palmitoleic and arachidonic acid, NEFA which are present in very low amounts during normoxia.

\section{Materials}

Silicagel F 254, chloraform and methanol were purchased from Merck, Damistadt, borontrifluorid from Sigma, St. Louls and diethylether, pentane, petroleum-ether $\left(35^{\circ}-60^{\circ} \mathrm{C}\right)$, tri-methyl-pentane and toluene from Baker, Phi1 ipsburg.

\subsection{Assessment of myocardial metabolism}

In the present study, myocardial metabolism was assessed by measuring concentrations of substances in tissue as well as by measuring the artertolocal venous (AV) difference of substances across the normoxic or ischemic myocardium. Division of tissue samples from the outer, middle and inner layers (each about $1 / 3$ of the wall), enabled the study of differences in these processes across the myocardial wall.

Tissue contents of ATP and creatine phosphate were determined to investigate the depletion of high-energy phosphate stores in the ischemic myocardium. AV differences of inorganic phosphate most likely prowide information about the release of phosphate liberated from ATP and creatine phosphate into the ischemic venous blood. Determination of the tissue concentrations of breakdown products of high-energy phosphates was not performed because our primary interest was the presence of ATP and creatine phosphate and not the 
metabolism of adentne nucleotides.

Substrate metabollsm during nomoxia as well as ischemia was assessed by measuring tissue glycogen and fatty acid content as well as AV differences for glucose, lactate, MEFA and triacylglycerol. Aerobic metabolism was assessed by measuring the oxygen Av differences.

The influence of ischemia on cellular regulation of ion concentrations was assessed by measuring the AV differences for potassium.

Possible damage of cellular membranes as well as accumulation of possibiy noxious substances was estimated by measurement of the tissue content of phosphoglycerides, NEFA and triacylglycerol together with the AV differences of the latter two substances. Gaschromatographic detemination of these substances enabled the measurement of the concentrations of the individual fatty acids within these three classes. Because each of these classes has a different relative fatty acid composition in blood and in tissue, accumulatlon or breakdown from one class into another can be estimated.

uptake or release of substances by the myocardium can be approximated by the product of total myocardial blood flow and the whole blood (oxygen) or serum (all other substances in the present study) AV difference.

\section{Critique on the experimental design}

The major problems inherent to the experimental design chosen, 1 ie in the validity of the assessment of metabolic changes in the ischemic tissue by the uptake or release of substances. Objections include the following: (a) the uptake as detemined in this study does not fully cover the utilization since the use of substances released from endogenous stores is not taken into account. Therefore, the term "net uptake" or "net release" is used in the present study; (b) multiplying myocardial blood flow with serum AV differences is anly justified if it is assumed that transport of the substances from the plasma into the erythrocyte and vice versa, was not influenced by the inducement of ischemia (chapters $6,7,8$ ) or the substances administered to elevate the arterial NEFA concentrations (chapter 8); (c) another assumption in this calculation is that $10 c a l$ venous blood is sampled from the ischemic area in which myocardial blood flow is determined with the radiaactive microspheres, without contribution of blood from other, normally perfused areas. However, comparison of the net uptake or release of the various substrates assayed on simultaneousily taken blood samples overcomes this critique; (d) during ischemia, net uptake has also to be used with caution, since it is not 
clear whether the venous blood samples reflect the average of transmural venous blood or mainly blood from one particular layer.

Critical comments should also be made with regard to the assessment of fatty acid metabolism. AV differences of triacylglycerol can be detemined with an accuracy of $3 \%$. However, uptake of triacylgiycerol within the error of the detemination already has extensive consequences for substrate supply. For the same reason, highly significant increases in the tissue content of NEFA might not necessarily be reflected by reduced contents of triacylglycerol or phosphoglycerides because of the extremely low tissue concentration of the NEFA.

3.8 Relation between blood flow, metabolism and mechanics

A major purpose of this study was to relate the changes in myocardial blood flow after inducement of ischemia to the changes in metabolism and mechanics in various layers of the ischemic area. These relations were assessed as follows. Tissue samples for determination of ATP, creatine phosphate, glycogen and fatty acids were taken from the area where the colls for determination of epicardial deformation had been attached. These colls were removed just before taking the biopsies. Because the biopsies were too small for reliable blood flow determination, we have used the blood flow data of the area closely surrounding the tissue used for chemical analysis. The tissue samples for high-energy phosphate and glycogen determination had a diameter of $4 \mathrm{~mm}$, the biopsy for fatty acid analysis had a diameter of $10 \mathrm{~mm}$ (in each experiment two of these biopsies were taken from the ischemic areal, the samples for determination of myocardial blood flow had a surface of $2-4 \mathrm{~cm}^{2}$ and the surface of the surrounding rectangle of the three colls was $4-6 \mathrm{~cm}^{2}$. This means that the site of sampling of the data concerning blood fllow, metabolism and mechanics were not identical. Because of possible inhomogeneities of one or more of these parameters within the same layer of the myocardium, the variation in the mutuli relations might be larger than in case of determining all parameters in the same sample. This is also the case for the relation between tissue contents of ATP and NEFA (chapter 7). Information about the size of this variation is given in chapter 4 . 
4. IMVESTIGATION ON THE HONOGEMEITY IN TIME AND SPACE OF MYOCARDIAL MECHANICAL PERFORMANCE, BLOOD FLOW AND METABOLISM IN THE NORMALLY PERFUSED LEFT VENTRICLE: EVALUATION OF THE EXPERIMENTAL MODEL*

\subsection{Introduction}

In the following chapters, the data related to the influence of ischemia on left ventricular blood flow, metabolism and mechanical performance are described. The influence of partial occlusion (stenosis) of the left anterior interventricular coronary artery (LAICA) is evaluated by comparing the differences between either the values of the parameters during ischenia with those before inducement of the stenosis or the values of the parameters in ischemic and non-ischemic areas of the left ventricle. These comparisons are only allowed if during the experimental period ( 2 hours), without inducement of stenosis, (a) the values of the measured parameters do not change significantly and (b) no signiftcant differences exist between the parameters determined in different perfusion areas of the left ventricle.

ad (a). To check the stability of the preparation, two series of experiments were performed. In the first series we measured hemodynamic variables, myocardial blood flow (MBF), epicardial defomation, and arterial and local venous concentrations of the substances mentioned in section 3.6. In the second series, beside these variables also the tissue contents of ATP, creatine phosphate and glycogen were determined in biopsies from the myocardium. Results from these investigations are presented in section 4.2.

ad (b). During normoxia, the tissue contents of ATP, creatine phosphate and glycogen in the perfusion areas of the LAICA and the left circumflex coronary artery (LCCA) were assessed by taking biopsies from these areas at various time intervals. Inhomogeneities in MBF, if any, were

* Parts of the results presented in this chapter have been published in: Basic Res. Cardiol. 76: 431-437. 


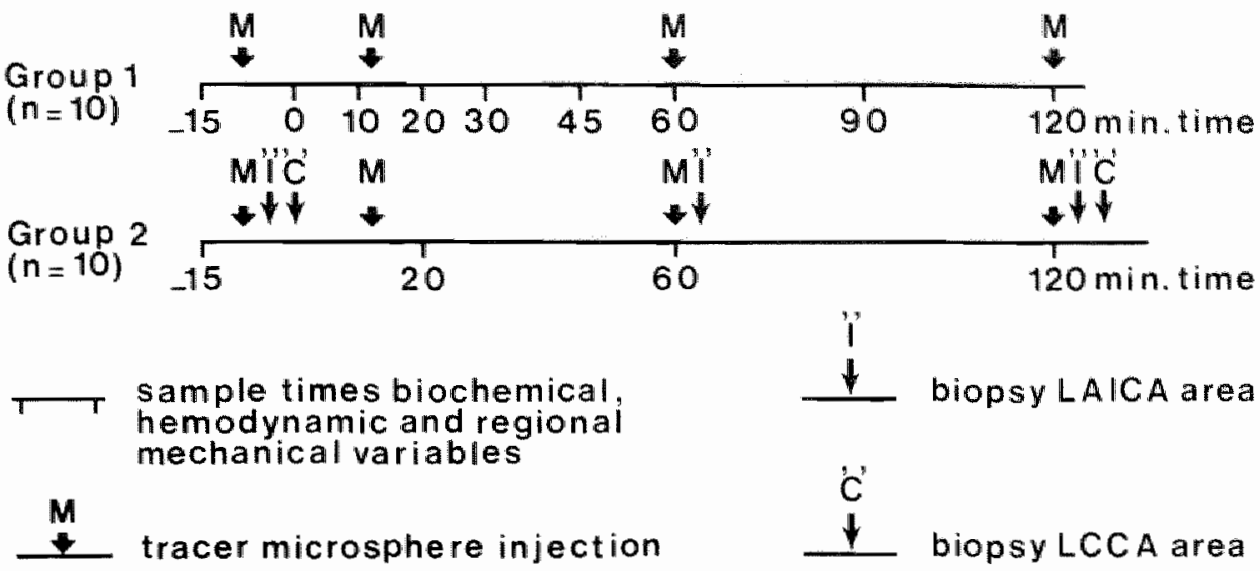

Fig 4.1 Protocol of the experiments.

Table 4.1 Time course of hemodynamic variables during 135 min nomoxia in experiments without (group $I, n=10$ ) and with tissue sampling (biopsies; group II; $n=10$ ). Median values and $95 \%$ limits are shown.

\begin{tabular}{|c|c|c|c|c|}
\hline & \multicolumn{2}{|c|}{ group I } & \multicolumn{2}{|c|}{ group II } \\
\hline & $-15 \mathrm{~min}$ & 120 min & -15 min & $120 \mathrm{~min}$ \\
\hline $\begin{array}{l}\text { Heart, rate } \\
(\min -1)\end{array}$ & $\begin{array}{l}90 \\
75-155\end{array}$ & $\begin{array}{l}123 \\
65-195\end{array}$ & $\begin{array}{l}105 \\
65-150\end{array}$ & $\begin{array}{l}123 \\
80-140\end{array}$ \\
\hline $\begin{array}{l}\text { Systolic aortic } \\
\text { pressure (kPa) }\end{array}$ & $\begin{array}{l}11.9 \\
10.4-14.7\end{array}$ & $\begin{array}{l}11.1 \\
10.0-13.3\end{array}$ & $\begin{array}{l}12.5 \\
11.1-14.7\end{array}$ & $\begin{array}{l}11.7 \\
10.9-13.3\end{array}$ \\
\hline $\begin{array}{l}\text { Diastolic aortic } \\
\text { pressure (kPa) }\end{array}$ & $\begin{array}{l}8.8 \\
7.3-9.3\end{array}$ & $\begin{array}{l}8.6 \\
7.7-11.3\end{array}$ & $\begin{array}{l}9.3 \\
8.3-10.7\end{array}$ & $\begin{array}{l}9.3 \\
8.0-10.3\end{array}$ \\
\hline $\begin{array}{l}\text { Systolic coronary } \\
\text { artery pressure } \\
\text { (kPa) }\end{array}$ & $\begin{array}{l}12.0 \\
10.0-14.7\end{array}$ & $\begin{array}{l}10.7 \\
9.3-13.3\end{array}$ & $\begin{array}{l}12.7 \\
10.9-14.7\end{array}$ & $\begin{array}{l}11.3 \\
10.5-12.8\end{array}$ \\
\hline $\begin{array}{l}\text { Diastolic coronary } \\
\text { artery pressure } \\
\text { (kPa) }\end{array}$ & $\begin{array}{l}7.6 \\
6.7-10.0\end{array}$ & $\begin{array}{l}8.0 \\
6.4-9.3\end{array}$ & $\begin{array}{l}8.9 \\
6.0-10.0\end{array}$ & $\begin{array}{l}8.7 \\
6.7-9.6\end{array}$ \\
\hline $\begin{array}{l}\mathrm{dp}_{1 \mathrm{w}} / \mathrm{dtmax} \\
\left(\mathrm{kPa} \cdot \mathrm{s}^{-1}\right)\end{array}$ & $\begin{array}{l}213 \\
187-227\end{array}$ & $\begin{array}{l}193 \\
160-227\end{array}$ & $\begin{array}{l}213 \\
133-240\end{array}$ & $\begin{array}{l}187^{*} \\
133-200\end{array}$ \\
\hline $\begin{array}{l}\mathrm{p}_{1 \text { ved }} \\
(\mathrm{kPa})\end{array}$ & $\begin{array}{l}0.8 \\
0.5-1.1\end{array}$ & $\begin{array}{l}0.8 \\
0.7-1.2\end{array}$ & $\begin{array}{l}1.1 \\
0.5-1.3\end{array}$ & $\begin{array}{l}0.8 \\
0.4-1.7\end{array}$ \\
\hline
\end{tabular}

* Significantly different from time -15 min. 
studied by analyzing the data obtained from various areas of the left ventricle during the pre-ischemic period. The results of these studies are presented in section 4.3 .

\subsection{Stability of the preparation during two hours of normal perfusion}

\subsubsection{Protocol}

The experiments were perfomed on mongrel dogs, two groups of 10 animals each. The protocols are shown in fig 4.1. In group $\mathbb{I}$ (without tissue sampling), arterlal and local venous samples for blood chemistry were taken at times $-15,0,10,20,30,45,60,90$ and $120 \mathrm{~min}$. The continuous $1 \mathrm{y}$ recorded hemodynanic and local mechanical variables were also detemined at these moments. Regional myocardial blood flow was determined by microsphere injections at approximately $-15,10,60$ and $120 \mathrm{~min}$. In group II (including tissue sampling), arterial and local venous blood samples were drawn at times -15 , 10, 60 and $120 \mathrm{~min}$. At the same time intervals, cardiac output and the hemodynamic and local mechanical variables were determined. Microspheres were injected just after $-15,10,60$ and $120 \mathrm{~min}$. Transmural biopsies were taken from the area perfused by the LAICA a few minutes after the microsphere injections at times $-15,60$ and $120 \mathrm{~min}$ and from the area perfused by the LCCA at times -15 and $120 \mathrm{~min}$.

To study possible changes during the period of $135 \mathrm{~min}$, the values of all variables determined after sample time -15 min were compared with sample time 120 min. Differences between the values of the various variables were evaluated for statistical significiance by applying wilcoxon's matched-pairs signedranks test.

\subsubsection{Results}

\subsubsection{Hemodynamic variables}

In table 4.1 , only the hemodynamic variables in the two groups at times -15 and 120 mim are shown because these variables showed a regular time course. In both groups heart rate tended to increase in the course of the experiment, from about 100 ta 120 beats.min ${ }^{-1}$, while aortic pressure decreased by about $0.8 \mathrm{kPa}$. This decrease was significant at time $120 \mathrm{~min}$ in the experiments where biopsies were taken (group II). Because no stenosis had been induced, the changes in coronary artery pressure were similar to those 
Table 4.2 Arterial concentrations of several chemical variables in the blood at the onset and the end of nomoxic experiments without (group I, $n=10$ ) and with tissue sampling (group II; $n=10$ ). Median values and $95 \%$ limits are shown.

pH

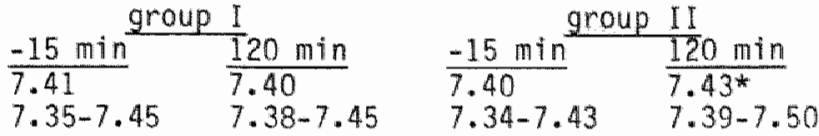

\section{PCO2 (kPa)}

$H\left(m a l .1^{-1}\right)$

oxygen saturation

$($ o)

$\begin{array}{ll}4.1 & 3.9 \\ 3.7-4.5 & 3.6-4.4\end{array}$

8.2

$6.2-8.8$

8.1

$6.3-9.8$

0.86

$0.82-0.91$

0.90

$0.88-0.91$

4.3

$3.6-4.9$

4. $1^{*}$

$3.3-4.6$

8. 2

$6.0-9.4$

8.1

$6.3-9.1$

1.00

$0.89-1.01$

0.99

$0.92-1.01$

$\underset{\text { G1 ucose }}{\left(\text { mol } .1^{-1}\right)}$

6.6

$5.6-7.8$

6.7

$5.5-8.2$

5.4

4. $9-8.1$

5.8

NEFA

(mmol. $1^{-1}$ )

0.21

$0.16-0.27$

0.20

$0.18-0.32$

0.28

$0.10-0.43$

0.30

$0.11-0.73$

Lactate
$\left(\right.$ mmol $\left..1^{-1}\right)$
1.23

$0.84-1.57$
2.01

$1.08-3.53$
1.80

$1.51-3.67$

Table 4.3 Arterial-local venous (AV) differences of several chentical variables in the blood at the onset and the end of normoxic experiments (see table 4.2).

\begin{tabular}{cllll}
\multicolumn{2}{c}{ group I } & \multicolumn{2}{c}{ group II } & \\
$\mathrm{pH}$ & $\frac{-15 \mathrm{~min}}{0.04}$ & $\frac{120 \mathrm{~min}}{0.04}$ & $\frac{-15 \mathrm{~min}}{0.04}$ & $\frac{120 \mathrm{~min}}{0.03}$ \\
$0.02-0.04$ & $0.02-0.10$ & $0.03-0.07$ & $0.02-0.08$
\end{tabular}

\begin{tabular}{|c|c|c|c|c|}
\hline $\begin{array}{l}\text { Oxygen } \\
\left(\text { mmol } .1^{-1}\right)\end{array}$ & $\begin{array}{l}4.4 \\
3.5-7.0\end{array}$ & $\begin{array}{l}4.3 \\
3.7-6.8\end{array}$ & $\begin{array}{c}4.7 \\
4.2-4.9\end{array}$ & $\begin{array}{l}4.9 \\
3.0-6.0\end{array}$ \\
\hline $\begin{array}{l}\text { Glucose } \\
\left(\text { mol } 11^{-1}\right)\end{array}$ & $\begin{array}{l}0.4 \\
(-0.3)-0.8\end{array}$ & $\begin{array}{l}0.5 \\
(-0.1)-1.4\end{array}$ & $\begin{array}{l}0.3 \\
0.0-0.6\end{array}$ & $\begin{array}{l}0.3 \\
(-0.1)-2.2\end{array}$ \\
\hline $\begin{array}{l}\text { NEFA } \\
\left(\text { mono } 1.1^{-1}\right)\end{array}$ & $\begin{array}{l}0.06 \\
0.0-0.13\end{array}$ & $\begin{array}{l}0.05 \\
0.01-0.13\end{array}$ & $\begin{array}{l}0.04 \\
0.00-0.23\end{array}$ & $\begin{array}{l}0.06 \\
0.03-0.10\end{array}$ \\
\hline $\begin{array}{l}\text { Lactate } \\
\left(\text { mol } 1.1^{-1}\right)\end{array}$ & $\begin{array}{l}0.46 \\
(-0.03)-0.55\end{array}$ & $\begin{array}{l}0.39 \\
0.13-0.53\end{array}$ & $\begin{array}{l}0.69 \\
0.31-0.99\end{array}$ & $\begin{array}{l}0.48 \\
0.13-0.71\end{array}$ \\
\hline $\begin{array}{l}k^{+} \\
\left(\text {meno } 1.1^{-1}\right)\end{array}$ & $\begin{array}{l}-0.08 \\
(-0.25)-0.05\end{array}$ & $\begin{array}{l}-0.05 \\
(-0.25)-0.10\end{array}$ & $\begin{array}{l}-0.03 \\
(-0.20)-0.05\end{array}$ & $\begin{array}{l}-0.03 \\
(-0.20)-0.10\end{array}$ \\
\hline $\begin{array}{l}\text { Inorganic } \\
\text { phosphate } \\
(\text { mono1. } 1.1)\end{array}$ & $\begin{array}{l}-0.10 \\
(-0.14)-(-0.03)\end{array}$ & $\frac{-0.07}{(-0.10)-0.03}$ & $\begin{array}{l}-0.04 \\
(-0.09)-0.04\end{array}$ & $\begin{array}{l}-0.02 \\
(-0.04)-0.04\end{array}$ \\
\hline
\end{tabular}


in aortic pressure. The first positive derivative of left ventricular pressure $\left(d p_{1} / d\right.$ tmax) did not significantly change in the experiments of group $I$. However, when biopsies were taken (group II), this variable decreased from $213 \mathrm{kPa} . \mathrm{s}^{-1}$ at time -15 min to $187 \mathrm{kPa} . \mathrm{s}^{-1}$ at time $120 \mathrm{~min}$. In both groups, end-diastolic left ventricular pressure remained almost constant at $0.5-1.7$ kPa $(95 \% \mathrm{THmits})$.

\subsubsection{Biochenical variables in blood}

The arterial values of $\mathrm{pH}, \mathrm{P}_{\mathrm{CO}}$ and $\mathrm{O}_{2}$ saturation and the arterial concentrations of $\mathrm{Hb}$, glucose, lactate and non-esterified fatty acids (NEFA) at times -15 and $120 \mathrm{~min}$ are shown in table 4.2. Except for a silight but significant increase in $\mathrm{pH}$ (from 7.40 to 7.43) and a decrease in $\mathrm{p}_{\mathrm{CO}}$ (from 4.3 to $4.1 \mathrm{kPa}$ ) in group II (including tissue sampling) no significant differences were abserved in both groups. In table 4.3, the AV differences of $\mathrm{pH}$, PCo?, $\mathrm{O}_{2}$, glucose, NEFA, lactate, $\mathrm{K}^{*}$ and inorganic phosphate at times -15 and 120 min are shown. No significant changes in these variables could be detected during the experiments in both groups.

\subsubsection{Biochemical variables in myocardial tissue}

Changes in tissue contents of ATP, creatine phosphate and glycogen during the experimental period were investigated in the LAICA and LCCA perfusion areas both, in the immer and outer layers separately. Tissue contents of the two energy-rich phosphates, did not significantly change in any perfusion area or layer. Glycogen contents in the LAICA area tended to increase within that perfod (from 120 to $175 \mu$ mol.g $\mathrm{g}^{-1}$ dry weight) while these contents tended to decrease in the LCCA area (from 185 to $165 \mu$ mol. $g^{-1}$ dry weight) ( $P$-values between 0.05 and 0.20$)$. Contents of these substances in the inner and outer layers did not change significantly during the experimental period. To sumarize the results, the data of all biopsies were grouped per sample time (table 4.4). Also in this case, no significant changes were abserved during the two hour-period.

\subsubsection{Mechanical variables}

The values of the epicardial deformation variables are shown in table 4.5. In group I (without tissue sampling), no significant differences were found in each of the variables throughout the experimental period. However, in group II (including tissue sampling), significant decreases were found in 
Table 4.4 Values of tissue ATP, CP and glycogen contents (umol. $9^{-1} \mathrm{dry}$ weight) at the onset and the end of $135 \mathrm{~min}$ of nomoxia. All transmural samples, and samples from the imner and outer layers were grouped per sample time.

time (min) median value $95 \%$ limits $\underline{\text { n }}$

$\begin{array}{lcccc}\text { ATP } & -15 & 17 & 13-21 & 25 \\ & 120 & 17 & 12-19 & 28 \\ \text { Creatine } & -15 & 42 & 35-50 & 22 \\ \text { phosphate } & 120 & 42 & 30-51 & 23 \\ \text { Glycogen } & -15 & 175 & 130-190 & 29 \\ & 120 & 165 & 145-190 & 29\end{array}$

Table 4.5 Time course of mechanical wariables measured by epicardial defomation during 135 min of nomoxia without (group I; $n=10$ ) and with tissue sampling (group II; $n=10$ ).

\begin{tabular}{|c|c|c|c|c|}
\hline Group I & $-1.5 \mathrm{~min}$ & $20 \mathrm{~min}$ & $60 \mathrm{~min}$ & $120 \mathrm{~min}$ \\
\hline $\begin{array}{l}\text { Circumferent } 1 \text { a } 1 \\
\text { shartening }(\%)\end{array}$ & $\begin{array}{l}6.5 \\
3.0-7.0\end{array}$ & $\begin{array}{l}6.0 \\
4.0-8.0\end{array}$ & $\begin{array}{l}6.5 \\
1.5-10.0\end{array}$ & $\begin{array}{l}5.0 \\
1.5-9.0\end{array}$ \\
\hline $\begin{array}{l}\text { Base-to-apex } \\
\text { shortening ( }(\%)\end{array}$ & $\begin{array}{l}2.0 \\
0.0-4.0\end{array}$ & $\begin{array}{l}1.5 \\
(-2.0)-4.0\end{array}$ & $\begin{array}{l}2.0 \\
(-1.0)-3.0\end{array}$ & $\begin{array}{l}1.5 \\
0.0-4.0\end{array}$ \\
\hline $\begin{array}{l}\text { Shear angle } \\
\text { (rad) }\end{array}$ & $\begin{array}{l}0.05 \\
0.02-0.05\end{array}$ & $\begin{array}{l}0.04 \\
0.02-0.07\end{array}$ & $\begin{array}{l}0.04 \\
0.01-0.05\end{array}$ & $\begin{array}{l}0.04 \\
0-0.04\end{array}$ \\
\hline Group II & $-15 \mathrm{~min}$ & $20 \mathrm{~min}$ & $60 \mathrm{~min}$ & $120 \mathrm{~min}$ \\
\hline $\begin{array}{l}\text { Circumferential } \\
\text { shortening }(\%)\end{array}$ & $\begin{array}{l}4.1 \\
1.7-7.7\end{array}$ & $\begin{array}{l}4.3 \\
0.1-8.1\end{array}$ & $\begin{array}{l}3.4 \\
0.4-8.1\end{array}$ & $\begin{array}{l}3.4 \\
0.9-7.2\end{array}$ \\
\hline $\begin{array}{l}\text { Base-to-apex } \\
\text { shortening }(\%)\end{array}$ & $\begin{array}{l}5.1 \\
0.0-6.8\end{array}$ & $\begin{array}{l}1.7^{*} \\
0.0-3.0\end{array}$ & $\begin{array}{l}1.7^{\star} \\
(-0.8)-3.7\end{array}$ & $\begin{array}{l}0.9^{*} \\
(-0.9)-1.7\end{array}$ \\
\hline $\begin{array}{l}\text { Shear angle } \\
\text { (rad) }\end{array}$ & $\begin{array}{l}0.04 \\
0.02-0.12\end{array}$ & $\begin{array}{l}0.05 \\
0.01-0.145\end{array}$ & $\begin{array}{l}0.05 \\
0.03-0.07\end{array}$ & $\begin{array}{l}0^{*} \\
0.0-0.14\end{array}$ \\
\hline
\end{tabular}

significantly different from time $-15 \mathrm{~min}$ 
base-to-apex shortening (from $5.1 \%$ at $-15 \mathrm{~min}$ to $0.9 \%$ at $120 \mathrm{~min}$ ) and shear angle (from 0.04 rad at -15 min to 0 rad at $120 \mathrm{~min}$ ). Circumferential shortening was not significantly depressed (table 4.5 ).

\subsubsection{Myocardial blood flow}

In experiments without tissue sampling (group I), MBF hardly changed during the obserwation period of 120 min (table 4.6). At that time, anly a significant decrease was observed in epicardial MBF in the area perfused by the LCCA and hence an increase in endo/epi ratio. In contrast, in tissue located in the direct yicintity of the site of sampling (group II), MBF in the varlous layers decreased at time $60 \mathrm{~min}$ (data not shown) as well as time 120 min by $5-27 \%$. The most pronounced decrease was seen in the LAICA perfusion area. In the area perfused by the LCCA, MBF was not significantly affected. In the LAICA perfusion area, the decrease in the various layers amounted to $11-26 \%(p<0.05$; table 4.6).

\subsubsection{Discussion}

The tendency of increasing heart rate during the two hour experimental period can be explained by the diminished activity of fentany1, given in the premedication, which is known to be a vagotropic compound. The decrease in blood pressure likely results from the barbiturate infusion.

Except for the above-mentioned changes, no significant deviations occurred in the hemodynamic variables and myocardial mechanics, metabolism and blood flow if no biopsies are taken during the experiment. In contrast, significant decreases in $d p_{1} / d$ tmax, base-to-apex shortening and phase angle are seen when tissue samples are taken within the experimental period. Yet MBF decreases in the direct vicinity of the site of sampling and even in the whole LAICA perfusion area. This is in agreement with the results of Allard et al (1981) who found, taking biopsies of similar diameter as compared with the present study $(4 \mathrm{~mm})$, a decrease in MBF around biopsy sites from $30 \%$ within $0.5 \mathrm{~cm}$ from that site to $15 \%$ at $2-3 \mathrm{~cm}$. This shows that by taking biopsies a rather extensive part of the left ventricular free wall is affected.

Beside these disadvantages of taking biopsies during the experiment, another drawback should be mentioned. In 3 out of 11 experiments ventricular fibrillation occurred already after taking the first biopsy. In 2 of these cases, no recovery occurred.

Because of these findings, the protocol of the experiments in which ische- 


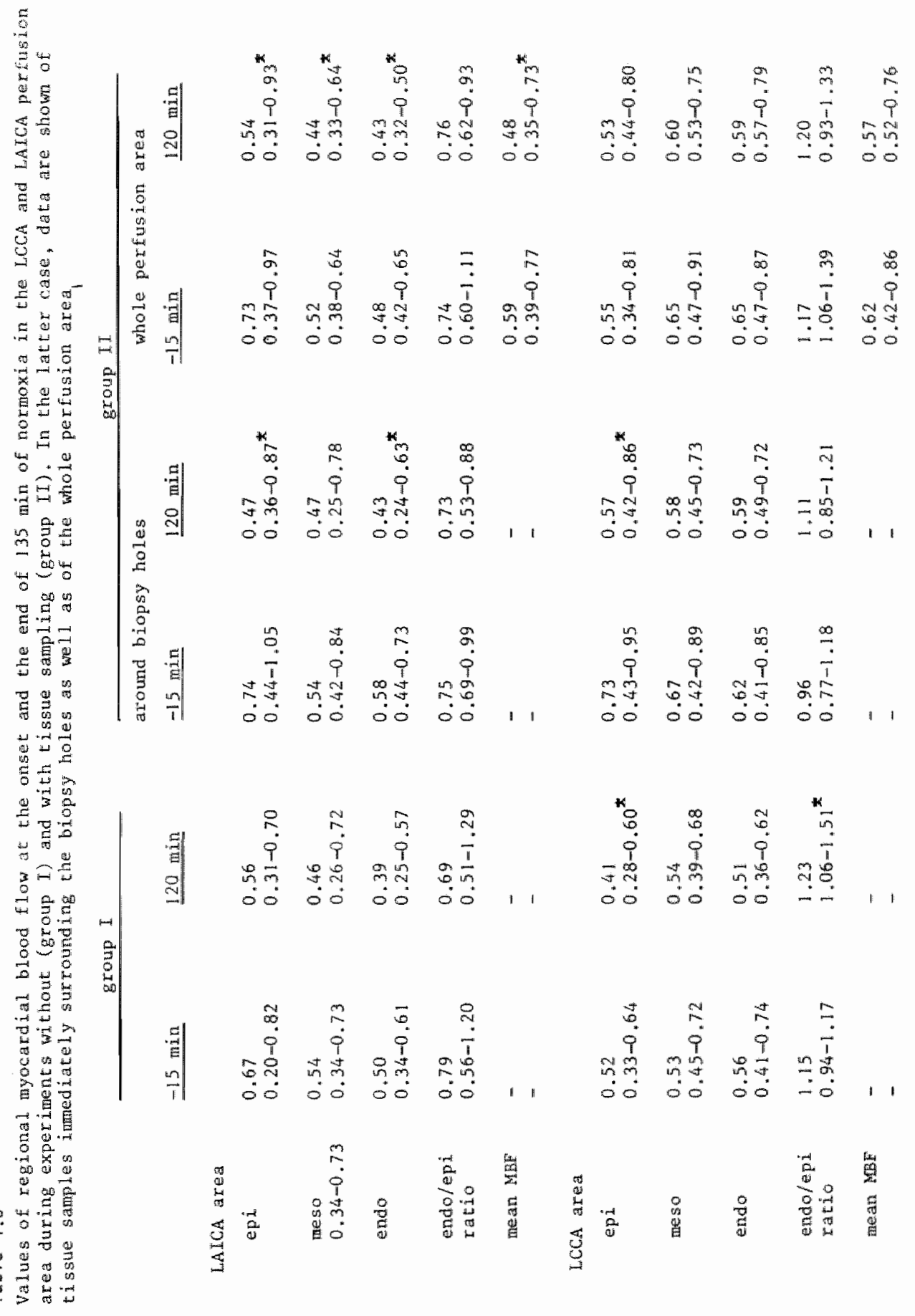


mia was induced was changed and it was decided to stop each experiment after two tissue samples were taken; one from the area perfused by the LAICA and one from the area perfused by the LCCA. In this way, tissue contents of ATP, creatine phosphate and gllycogen at various time intervals after inducement of the stenosis were abtained from different groups of animals (see chapter 6 and 7 ).

4.3 Regional differences in left ventricular blood flow and metabolism during nomal perfusion

\subsubsection{Protocol}

\subsubsection{Biochemical variables in myocardial tissue}

To investigate whether differences in tissue contents of ATP, creatine phosphate and glycogen exist between different layers of the myocardilum, the contents of samples in the inner layers were compared with those from the outer layers wilthin each experiment. Similarly, the contents of the three substances in the areas perfused by the LAICA and the LCCA were evaluated on differences, if any. For this purpose we used the data presented in section 4.2. Differences between the value of the various vatriables were evaluated for statistical significance by applying Wilcoxon's matched pairs signedranks test (two tailed probability).

\subsubsection{Myocardial blood flow}

To study possible inhonogeneities in axial and circumferential direction, MBF and the endo/epicardial flow ratios (endo/epi ratio) were grouped per slice $(1-5)$ and per section $(A-E)$, (fig 3.8). Adding the MBF values and the endo/epi matios of all pieces prowided respectively total MBF and the overall endo/epi ratio.

Differences in MBF between varfous sites of the free wall of the left ventricle were evaluated for statistical significance by applying a two-way variance analysis for the MBF per layer and a one-way analys is for the endo/epi ratios. A p value $<0.05$ was considered to be significant. 


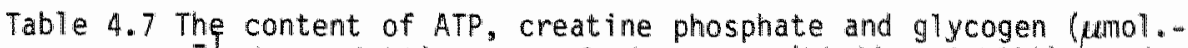
$g^{-1}$ dry weight) per perfusion area (LAICA and LCCA) as derived from all normoxic tissue samples (see text).

\begin{tabular}{|c|c|c|c|c|}
\hline & perfusion area & median value & $95 \%$ limits & $\underline{n}$ \\
\hline ATP & $\begin{array}{l}\text { LAICA } \\
\text { LCCA }\end{array}$ & $\begin{array}{l}19^{*} \\
18\end{array}$ & $\begin{array}{l}16-26 \\
13-19\end{array}$ & $\begin{array}{l}23 \\
23\end{array}$ \\
\hline $\begin{array}{l}\text { Creatine } \\
\text { phosphate }\end{array}$ & $\begin{array}{l}\text { LAICA } \\
\text { LCCA }\end{array}$ & $\begin{array}{l}45 \\
41\end{array}$ & $\begin{array}{l}38-54 \\
35-51\end{array}$ & $\begin{array}{l}21 \\
21\end{array}$ \\
\hline Gilycogen & $\begin{array}{l}\text { LAICA } \\
\text { LCCA }\end{array}$ & $\begin{array}{l}165 \\
165\end{array}$ & $\begin{array}{l}135-190 \\
150-185\end{array}$ & $\begin{array}{l}24 \\
24\end{array}$ \\
\hline
\end{tabular}

* $p<0.05$ as compared with the LCCA area

Table 4.8 Transmural contents of ATP, creatine phosphate and glycogen (umo1.g ${ }^{-1}$ dry weight) during normoxia. All tissue samples have beem grouped per lacation: outer layers=epi and inner layers $=$ endo.

\begin{tabular}{|c|c|c|c|c|}
\hline & Location & Median value & $95 \% 11 \mathrm{mits}$ & $\underline{n}$ \\
\hline ATP & $\begin{array}{l}\text { epi } \\
\text { endo }\end{array}$ & $\begin{array}{l}21 \\
17\end{array}$ & $\begin{array}{l}17-26 \\
13-20\end{array}$ & $\begin{array}{l}31 \\
31\end{array}$ \\
\hline $\begin{array}{l}\text { Creatine } \\
\text { phosphate }\end{array}$ & $\begin{array}{l}\text { epi } \\
\text { endo }\end{array}$ & $\begin{array}{l}45 \\
41\end{array}$ & $\begin{array}{l}40-57 \\
34-54\end{array}$ & $\begin{array}{l}29 \\
29\end{array}$ \\
\hline GTycogen & $\begin{array}{l}\text { epi } \\
\text { endo }\end{array}$ & $\begin{array}{l}165 \\
165\end{array}$ & $\begin{array}{l}145-205 \\
150-180\end{array}$ & $\begin{array}{l}33 \\
33\end{array}$ \\
\hline
\end{tabular}

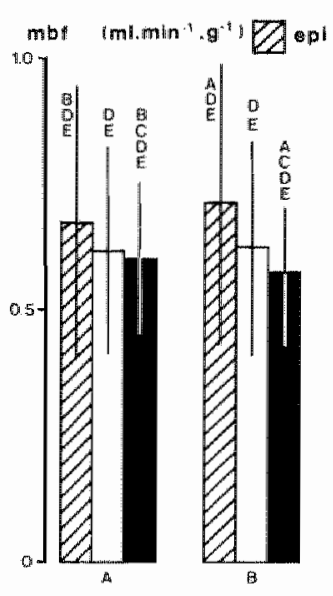

- H. intervoriats

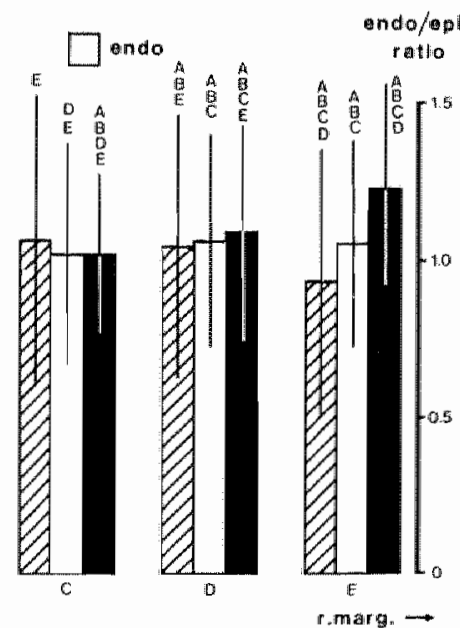

Fig 4.2

Myocardial blood fllow in the outer (ept, $\square)$ and inner layers (endo, $\square$ ) and the ratio of blood flow in the inner and outer layers (endo/epi ratio, - in the sectians $A-E$ of the left ventricular free wall. Characters above each bar indicate significant differences between the particular section and the indlcated one (s). The means and standard deviation of 17 experiments are presented. 


\subsubsection{Results}

\subsubsection{Biochemical variables in myocardial tissue}

As can be seen from table 4.7, no significant differences in ATP, creatine phosphate or gTycogen content were observed between biopsies from the LAICA and LCCA area, in the inner layers, the outer layers or the transmural biopsies, except for the ATP content in samples from the outer layers af the LAICA area which was significantly higher than that in similar biopsies from the LCCA area. The transmural differences in the three substances were not significant, although the median values of ATP and creatine phosphate were higher in the eplcardium (table 4.8 .

\subsubsection{Mrocardial bload flow}

Overall MBF in the left ventricular free wall was $0.64 \pm 0.23 \mathrm{mi} . \mathrm{min}^{-1}{ }^{-}$$g^{-1}$ (mean $\left.\pm s . d.\right)$. The overall endo/epi ratio in this part of the myocardium was $1.05 \pm 0.31$ (mean \pm s.d.). The mean values of blood flow in the inner and outer myocardial layers and of the endo/ept ratios per sample site are shown in table 4.9. The mean values of these variables per slice and per section are shown in the figs. 4.2 and 4.3 , respectively. The values of blood flow in the outer layers were the lowest at the base of the left ventricle, near the marginal branch (E.1) and increased gradually in the direction of the apex and of the LAICA. Blood flow in the outer layers was lower near the base than near the apex of the heart and higher along the LAICA than along the marginal branch. In the middle layer. MBF was almost equally distributed over the left ventricular free wall. The blood flow values in the inner layers although less pronounced, tended to be opposite to the values in the outer layers. The endo/epi ratios were higher near the base than near the apex, and higher along the marginal branch than along the LAICA. The highest mean vaiue (1.44) was found at the base of the heart near the marginal branch.

\subsubsection{Discussion}

\subsubsection{Biochemical variables in mocardial tissue}

It is known that the ATP and especially the creatine phosphate contents rapidly decrease in biopsies between sampling and freezing. Kleinert and Weiss (1981) showed that the blopsies should be frozen within $5 \mathrm{~s}$ while results of Hearse and Chappe11 (1976) suggest the necessity of an even shor- 
Table 4.9 Distribution of blood flow in the epi (upper) and endocardial layers (middle) and of the endo/epicardial blood flow ratio (Tower panell) in the left ventricular free wall. The mean values of 17 experiments are presented.

Fig 4.3

Myocardial blaod flow in the outer (epi, $\square$ ) and inner layers (endo, $\square$ ) and the endo/epi ratio ( $\square$ ) in the slices 1-5 of the left ventricular free wall. Figures above each bar indicate significant differences between the particular slice and the indicated one(s). The means and standard deviation of 17 experiments are presented.

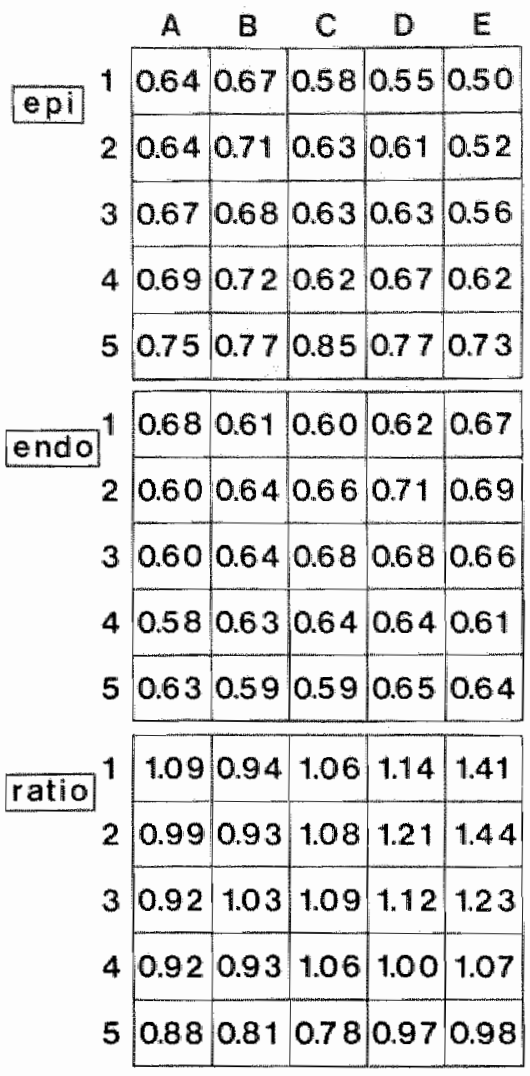

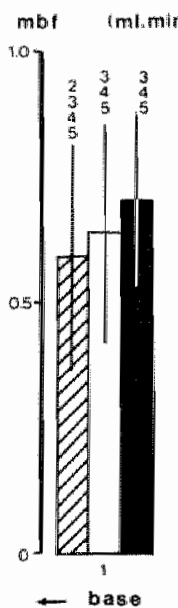
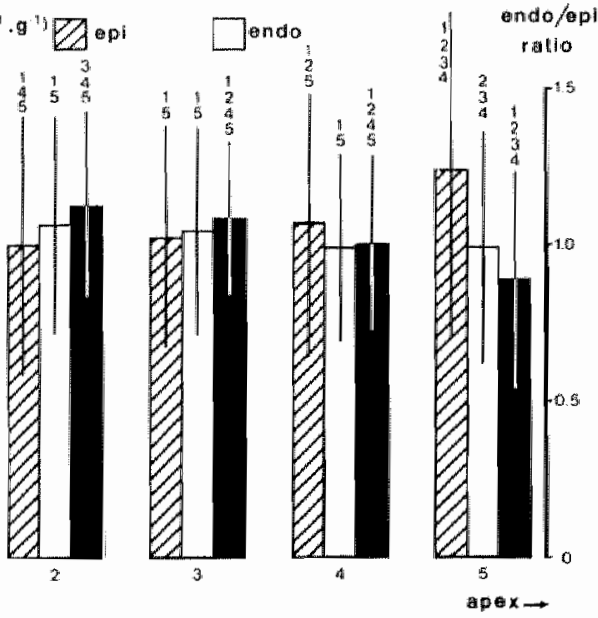
ter delay time. In our hands, creatine phosphate contents as determined in biopsles from nomoxic tilssue more than 5 s after sampling showed a decrease of twice the standard deviation below the mean value of these contents in biopsies taken within 3 s. Therefore, only biopsies were used with a delay time shorter than $3 \mathrm{~s}$. The usual transit time in our preparation was $2-3 \mathrm{~s}$. The normoxtc contents of ATP and creatine phosphate as found in the present investigation were $18(15-20)$ and $42(36-45) \mu m o 1 . g^{-1}$ dry weight, respectively (median values and $95 \%$ linits). These values are comparable with values. from other investigators (ATP $15-22$ and creatine phosphate: $30-50 \mu \mu_{01} \cdot g^{-1}$ dry welght (Takenaka and Higuchi, 1974; Hearse and Chappel1, 1976; Opie and Owen, 1976; Weishaar et a1, 1977; Allison et a1, 1978; Dunn et a1, 1978). Our data are in close agreement with those obtained by Allard and co-workers (1981). These authors used a rapid freezing biopsy drill drawing the biopsy into the liquid nitrogen within $1.75 \mathrm{~s}$ by vacuum and found creatine phosphate values of 40 and ATP values of $18 \mu \mathrm{mol} . \mathrm{g}^{-1}$ dry weight.

The absence of significant differences between ATP contents of the inner and outer myocardial layers is equivocal with data from the literature (Takenaka and Higuchi, 1974; Dunn et al, 1978; Deboer et al, 1980).

Significantly lower creatine phosphate contents in the subendocardium were found by Dunn et al (1978) and Takenaka and Higuchi (1974). A1though the difference between layers was not significant in the present study, the $10 \%$ lower median value in the inner than in the outer layer is equal to the difference found by Dunn et al (1978) who performed a substantial larger number of experiments.

In the present study, glycogen contents of $165(130-190) \mu m o 1 . g^{-1}$ dry weight have been measured (median value and $95 \%$ limits). Glycogen contents found in the normoxic dog myocardium in situ range from $100^{*}$ to $250 \mu \mathrm{mol}^{-\mathrm{g}^{-1}}$ dry welght (Jedeikin, 1964 and Crass I and Sterrett, 1975, respectively). The values found in our study are comparable with the more recent findings which show values of $150-250 \mu \mathrm{mol} . \mathrm{g}^{-1}$ dry weight (Hewitt et al, 1973 ; Crass and Sterrett, 1975, Allison et al, 1978, Ichïhara et a1, 1979).

Concerning the transmural distribution of glycogen conflicting results have been presented. Opie et al (1976) did not find transmural differences in the baboon, while Ichihara and Abiko (1975), Allison et al (1977), Jedeikin (1964) and Crass and Sterrett (1975) found higher endocardial than epicardial contents of glycogen in the dog heart. However, the latter two authors showed that this high glycogen content is only present in the cells of the His 
bundle and Purkinje system. A different way of dividing the biopsies into different layers might have caused the absence of a significantiy higher glycogen content in the inner layers than in the outer ones.

In our preparation, little differences are present between the tissue contents of the various substances in the LAICA and LCCA perfusion area, even when various layers of the mocardium were compared. This was the case for creatine phosphate and glycogen (table 4.7). The small but significant difference in ATP contents between the two perfusion areas seems of little physiological significance. From these findings, it was concluded that the tissue contents in the area perfused by the LCCA are representative of the normoxic content of the free wal1. This enabies us to make intra-individual comparisons between ATP, creatine phosphate and glycogen contents in normoxic myocardium (LCCA sample) and their content in ischemic myocardium (LAICA sample) in the experiments where the LAICA was partially occluded. Moreover, jt will be shown that the tissue concentrations of these three substances do not significantly change in the LCCA area within 2 hours after inducement of a stenosis of the LAICA (chapter 7).

\subsubsection{Myocardial blood flow}

The present study indicates that the endo/epi ratios are higher near the base than near the apex of the heart (axial gradient) and lower allong the LAICA than along the marginal branch of the LCCA (circumferential gradient). The axial gradient in endo/epi ratios confirms the finding of Reneman et al (1977) and Marcus et al (1975), while the circumferential gradient in this variable is in agreement with the findings in other studies in open-and closed-chest animals (Cobb et a1, 1974; Prokop et a1, 1974; Ball et al, 1975). These gradients mainly result from variations in blood flow in the outer layers which is lower near the base than near the apex and higher along the LAICA than along the marginal branch.

An abvious question is whether the variations in blood flow in the outer layers over the left ventricular free wall are real or due to artefacts. Assuming a direct relation between blood flow and mechanical performance, real inhomogeneities imply differences in workload at various sites of the left ventricular free wall or in case of an equally distríbuted workload, differences in oxygen extraction from site to site. On the one hand, Weiss and co-investigators did not find significant differences in oxygen uptake over the free wall of the left ventricle (1978) suggesting an equally distri- 
buted workload. On the other hand, regional differences in epicardial as well as intramural shortening have been found in open-chest dogs (Ingels et al, 1971; Elshuraydeh, 1981).

Varfations in endo/epi ratios might result from the open-chest preparation, used in the present study. Indeed, Cobb et al (1974) showed that MBF was rather homogeneously distributed in the non-anesthetized dog, but that a similar circumferential gradient in endo/epi ratio was found, as in our investigation, when the experiments were performed in open-chest animals. In their study, however, this gradient was mainly caused by variations in MBF in the inner layers, which is in contrast with our study. The findings of cobb et al (1974) suggest that drying out or shrinking of epicardial tissue in the outer layers in the open-chest preparation cannot be considered as the major cause of the inhomogenelties in bllood flow in these layers found in the present study. Besides, shrinking or drying out do neither explain the higher blood flow in the outer layers values along the LAICA than along the marginal branch - the opposite would be expected - nor the differences in this variable from base to apex, because the latter areas are about equally exposed to the open air. An effect of the open-chest preparation which cannot be excluded in advance, is the low temperature in the outer layers of the wall although Ten Velden et al (1982) did not find significant differences in blood flow distribution when epicardial temperatures were decreased by about $3^{\circ} \mathrm{C}$.

A source for artefacts may be the microsphere assay method. Microspheres, after all, tend to migrate axially within a blood vessel because of their substantial mass (Segre, 1961; Phibbs and Dong, 1970). Dverestimation of blood flow in the inmer layers has been ascribed to this streaning (Domenech et a1, 1969; Yipintsoi et al, 1973; Utley et a1, 1974). Streaming of microspheres and relatively low flow velocities in the side branches of the LAICA and of the marginal branch could explain the higher concentration of beads near the apex than near the base. The lower blood flow values in the outer layers along the relatively small marginal branch, than along the LAICA support this idea. On the other hand, streaming does not explain the higher blood flow values along the LAICA in the outer layers than in the inner ones. Part of the described inhomogeneities in blood flow were also found when the $k^{43}$ method was used (Prokop et al, 1974).

It is not likely that ligation of a small side branch of the LAICA, to insert the pressure catheter, is responsible for the lower endo/epicamdial ratios near the apex. First of all, the lower ratio is mainly caused by 
changes in blood flow in the outer layers. Secondly, in case of ischemia a more pronounced lacal fall in blood flow in the innem layers would have been expected (Bishop et al, 1976). Moreover, the endocardial blood flow values near the apex as obtained in the present study did not differ significantly from those found in experiments without implanted catheters for coronary artery pressure measurements (unpublished results).

In conclusion, at the present state of knowledge it remains uncertain whether the inhomogeneities in blood flow distribution in the various layers of the left ventricular free wall are real or partially or completely due to artefacts.

\subsection{Conclusions}

- When no biopsies were taken during the experiments, the preparation is stable during 135 min of normal perfusion.

- Experiments where ischemila will be induced, should be terminated after biopsies have been taken. To evaluate the changes due to ischemia, the contents in the biopsies from the ischemic LAICA area cam be compared with the contents in the biopsies from the non-ischemic LCCA area in the same experiment.

- Regional blood flow in the outer layers of the left ventricular free wall was higher near the base than near the apex and lower in the posterior than in the anterior regions. The cause of this inhomogeneity is not known. 
5. PREDICTION OF FIBER SHORTENING IN THE INNER LAYERS OF THE LEFT VENTRICULAR WALL FROM EPICARDIAL DEFORMATION MEASUREMENTS DURING MORMOXIA AND ISCHEMIA

\subsection{Introduction}

During ischemia steep gradients in myocardial blood flow and metabolic varlables indicate that the inner layers of the left ventricular wall are more susceptible to ischemia than the outer layers (chapter 1). Determination of mechantcal performance during acute occlusion of a coronary artery showed very rapid loss of contractile function and even indicated lengthening of ischemic segments during systole ("systolic bulging") (Tennant and Wiggers, 1935; Banka and Helfant, 1974; Tyberg et a1, 1974; Theroux et a1, 1976; Crozatier et a1, 1977).

Little is known about transmural differences in mechanical performance during regional ischemia because of the difficulties encountered in assessing these differences. The most recent approach has been the measurement of transmural shortening by positioning pairs of ultrasonic crystals within the outer and inner layers (Weintraub et al, 1981). This method, however, has disadvantages. Firstly, improper location or movement of the crystals due to the mechanical activity of the ventricle may change the orientation of the crystals with respect to each other, causing inaccurate measurements. Secondly, the positioning of crystals within the myacardium induces injuries because positioning of the crystals in the inner layers requires incisions or stab wounds of about $1 \mathrm{~cm}$ deep.

A different approach is to estimate transmural differences in fiber shortening from epicardial deformation. The principle of this method is the assumption, that shortening aiong the fiber direction in a certain layer in the myocardial wall is closely related to shortening along the same direction at the epicardial surface. Thus shortening of the fibers in the inner and outer layers is estimated from shortening of the epicardial surface along the fiber direction in the inner and outer layers. Epicardial deformation was assessed by an inductive technique (Arts and Reneman, 1980). From thus measured values of circumferential natural strain, base-to-apex natural strain, and shear, shortening along all directions on the epicardial surface could 
be calcullated.

The atm of this part of the study was to investigate the influence of local ischemia on (a) regional mechanical function as measured by epicardial deformation, and (b) on transmural gradients in contractile behavior in the wall of the left ventricle.

In order to assess the validity of the technique of obtaining information about the transmural contractile behavior from measurement of epicardial deformation, 6 additional experiments were performed. In these experiments defomation of the eplcardium and the inner layers was assessed simultaneously by measurement of mutual movement and angulation of 3 needles pierced into the myocardial wall, using the inductiv ve technique.

\subsection{Experimental design}

\subsubsection{Protocol}

The experiments were performed on 19 mongrel dogs. The animals were allotted to 2 groups. In group 1, consisting of 13 animals, a1 so used in the studies described in the chapters 6 and 7 , epicardial deformation was measured (section 3.1 .3 and 3.3.2). From these measurements epicardial maximal shortening $\left(e_{\max }\right)$ and minimal shortening $\left(e_{m i n}\right)$ and the angle of $e_{\text {min }}$ with the circumference $\left(B_{\text {min }}\right)$ were calculated as described in section 3.3.2.2. In the 6 amimals of group II, transmural deformation was assessed using the method described in section 3.3.3. In these experiments, from the assessed $e_{c}, e_{z}$ and $\gamma$ at the eplicardium and in the inner layers, $e_{\text {max }}, e_{m i n}$ and $\beta_{m i n}$ at the epicardium and their counterparts in the inner layers ( $e_{m a x, e n d o} e_{m i n, e n d o}$ and

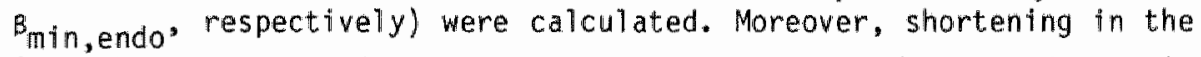
inner layers in the direction of $e_{m i n}$, called endo (section 3.3.3.1). In both groups, ECG, left ventricular pressure, aortic pressure, coronary artery pressure and phasic aortic flow were determined as described in section 3.2 .

Following a base-lime registration, in all antmals the left anterior interventricular coronary artery (LAICA) was occluded by inflation of the occluder cuff around this artery (section 3.1.4). After 
epicardial

deformation

$(n=13)$

transmural

deformation

$(n=6)$

\section{occlusion}

$0102030405060 \mathrm{~s}$

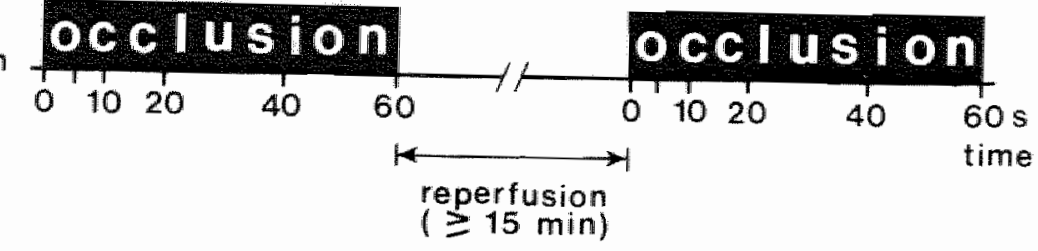

Fig 5.1 Protocols af the experiments. Beside the regional mechanical variables, left ventricular, aortic and coronary artery pressure as well as phasic aortic flow were determined at the depicted sample times.

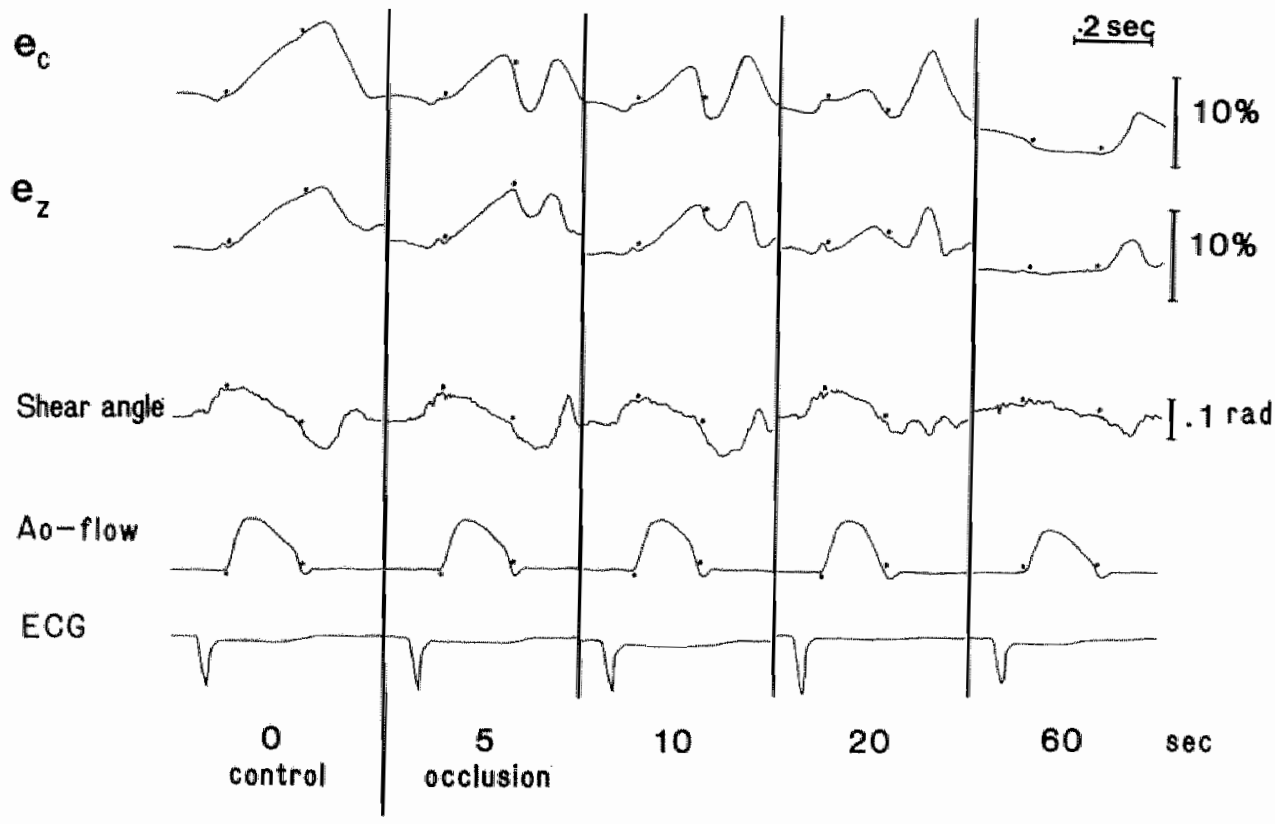

Fig 5.2 Samples of the registration of circumferential shortening $\left(e_{c}\right)$, base-to-apex shortening $\left(e_{Z}\right)$, shear angle $(\mathcal{V})$, phasic aortic flow and ECG of a typical experiment. Onset and end of the ejection phase are marked by dats. 
one minute, the occlusion was released. In group II a second coronary artery occlusion of one min was perfomed. The time interval between these occlusions was at least 15 min, which was considered to be sufficient for recovery of the myocardium from the previous occlusion (fig 5.1 ).

The values of all continuously registrated variables were calculated just before and $2,4,6,8,10,20,30,40,50$ and $60 \mathrm{~s}$ after coronary artery occlusion in the epicardial deformation study (group 1) and just before and 5, 10, 20, 40, and $60 \mathrm{~s}$ after occlusion in the transmural deformation study (group II; fig 5.1).

\subsubsection{Data analysis}

Information about the effect of acute coronary artery occlusion on regional myocardial mechanical performance was obtained by using the animal as its own control. The effects on the various variables were evaluated by comparing the values during occlusion with those just before occlusion (time $0 \mathrm{~s}$ ). Mareover, changes in these variables after $20 \mathrm{~s}$ of occlusion were evaluated by comparing the data at time $30,40,50$ and $60 \mathrm{~s}$ with those at time $20 \mathrm{~s}$. Differences between the values of the various variables were evaluated for statistical significance by applying Wilcoxon's matched pairs signed-ranks test (twotailed probability).

The relationship beween $e_{\text {endo }}$ and $e_{\text {min }}$ was investigated by linear correlation and tested for significance by Spearman's signed-rank correlation test.

The data are presented as median values and $95 \%$ limits. A value of $p<0.05$ was considered to be a significant difference.

\subsection{Results}

\subsubsection{Epicardial deformation (group I)}

During normal perfusion heart rate and mean aortic pressure were $118(92-127)$ beats.min ${ }^{-1}$, and $11.9(9.6-13.3)$ kPa, respectively, (median values and $95 \%$ limits). After one minute occlusion, heart rate increased to $140(84-160)$ beats.min ${ }^{-1}$ ( $\left.p<0.05\right)$, while mean aortic pressure did not change significantly (11.9;9.3-12.4 kPa). Mean 

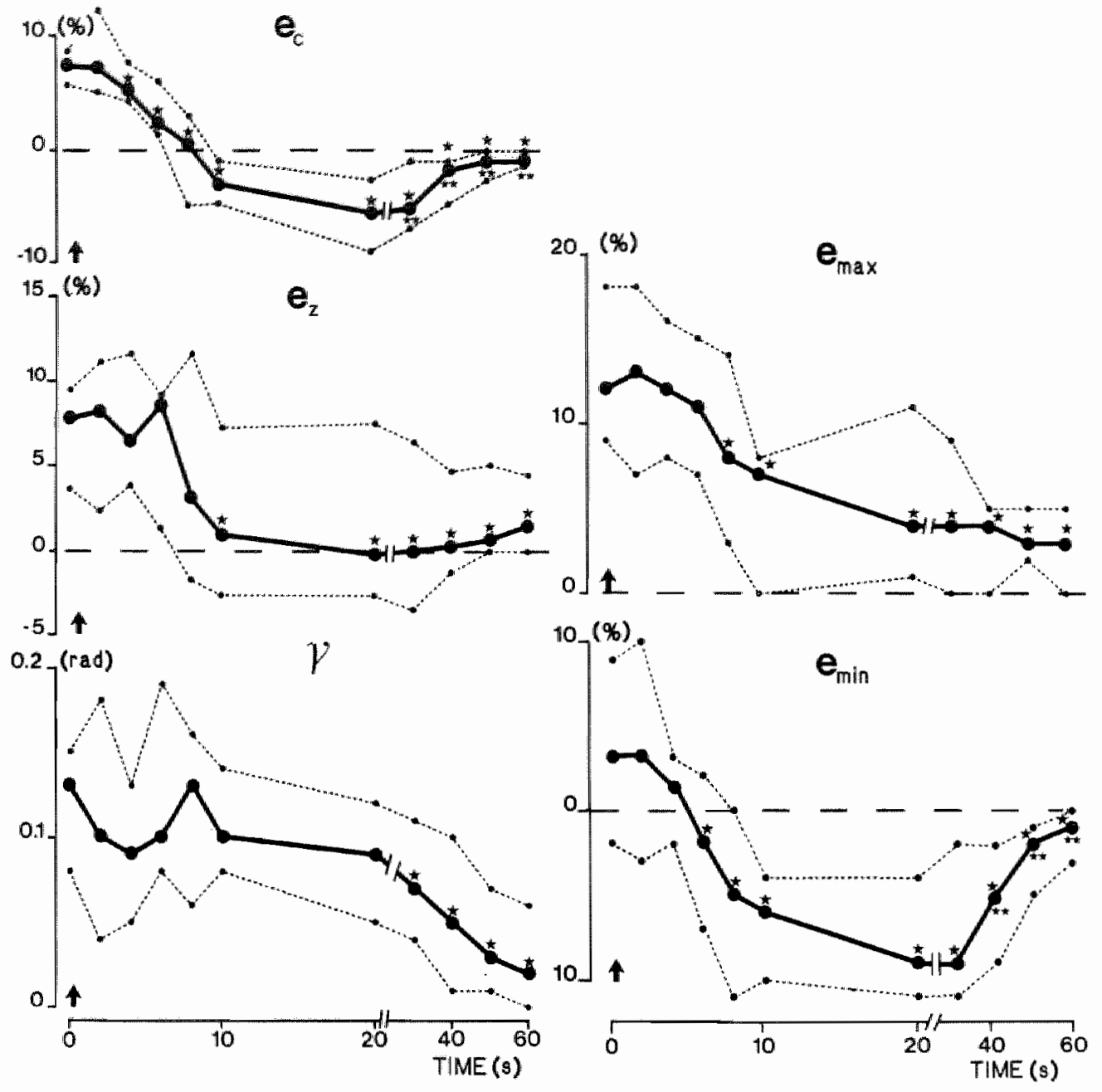

Fig 5.3

Time course of $e_{c}, e_{z}$ and $\gamma$ during one min of acute coronary artery occlusion as determined from epicardial deformation measurements $(n=13)$. The arrow ind $i$ cates the onset of occlusion.

Fig 5.4

Time course of $e_{m i n}$ and $e_{\text {max }}$ during one min of acute coronary artery occlusion as determined from epicardial deformation measurements $(n=13)$. For explanation of the symbols, see fig 5.3 .

Median values and $95 \%$ limits are shown. $* p<0.05$ as compared with $t=0 \mathrm{~s}$.
$p<0.05$ as compared with $t=20 \mathrm{~s}$. 
coronary artery pressure $\left(p_{\text {cor }}\right)$ was $10.5(9.2-14.0) \mathrm{kPa}$ before coronary artery acclusion. After occlusion, mean $p_{\text {cor }}$ decreased signifi cantly to $3.7(2.5-4.7) \mathrm{kPa}$ after $2 \mathrm{~s}, 2.9(2.0-4.3) \mathrm{kPa}$ after $4 \mathrm{~s}$, $2.5(1.7-3.5) \mathrm{kPa}$ after $6 \mathrm{~s}, 2.5(1.5-2.8) \mathrm{kPa}$ after $10 \mathrm{~s}$ and 2.7 $(2.0-3.3) \mathrm{kPa}$ after $60 \mathrm{~s}$.

An example of the registration of $e_{c}, e_{z}, \gamma$, aortic flow and ECG just before and $5,10,20$ and $60 \mathrm{~s}$ after occlusion is given in fig 5.2. Already after 55 circumferential lengthening occurred before the end of ventricular ejection, followed by a delayed shortening during the end of the relaxation phase. With prolongation of occlusion, maximum shortening during the ejection phase decreased. After $60 \mathrm{~s}$ occlusion, circumferential lengthening occurred already in the isovolumic phase and hardly any changes in length were found during the ejection phase. In this experiment, changes in shear angle were not seen before $20 \mathrm{~s}$ of occlusion. Thereafter, a gradual decrease takes place to one third of the pre-acclusion value after $60 \mathrm{~s}$ *

Under normal conditions, the median values and $95 \% 1 \mathrm{imits}$ of circumferential shortening $\left(e_{c}\right)$, base-to-apex shortening $\left(e_{Z}\right)$ and shear angle $(\mathcal{V})$ during the ejection phase were $7.4 \%(5.7-8.7 \%), 7.7 \%(3.6-$ $9.4 \%$ ) and $0.13(0.08-0.15)$ rad, respectively (fig 5.3 ). After $4 \mathrm{~s}$ of occlusion, $e_{c}$ decreased and became regative (=lengthening) after $10 \mathrm{~s}$ occlusion. $e_{c}$ reached its minimum after about $20 \mathrm{~s}$, increasing thereafter to less negative values. A significant decrease in $e_{z}$ was not observed before $10 \mathrm{sec}$ after onset of occlusion. Moreover, base-toapex lengthening was only seen in a few experiments. The median value of $e_{z}$ was close to zero after $20 \mathrm{~s}$ and sightly increased thereafter.

In the first $20 \mathrm{~s}$ of acclusion, changes in $\gamma$ showed large interindividual variations: an increase was found in 7 experinents, and a decrease in 6 experiments. However within each experiment these early changes in $\gamma$ always preceeded the changes in $\mathrm{e}_{c}$ and $\mathrm{e}_{z^{*}}$. From 20 to 60 $s$ after onset of occlusion, $\mathcal{\gamma}$ gradually decreased in all experinents to a value about one fifth of the pre-occlusion value (filg 5.3).

The length of the circumferential and base-to-apex segments (distance between the coils) at the onset of the ejection phase increased, starting $20 \mathrm{~s}$ after occlusion (table 5.1). This pre-ejection length gradually increased to 107.7 and $107.9 \%$ of the pre-ilschemic values in 
Table 5.1 Time course of circumferential and base-to-apex segment length (-istance of the colls) at the onset of the ejection phase before and after acute coronary artery acclusion, normalized on the segmentlength at time $05 . \quad(n=13)$

\begin{tabular}{|c|c|c|c|c|c|}
\hline Time (s) & 0 & 10 & 20 & 40 & 60 \\
\hline $\begin{array}{l}\text { Circumfe- } \\
\text { rential }(\%)\end{array}$ & 100.0 & $\begin{array}{l}101.2^{*} \\
100 \cdot 0-102.1\end{array}$ & $\begin{array}{l}102.1^{*} \\
100.6-103.4\end{array}$ & $\begin{array}{l}106.4^{*} \\
103.4-107.7\end{array}$ & $\begin{array}{l}107.7^{*} \\
106.0-110.2\end{array}$ \\
\hline $\begin{array}{l}\text { Base-to- } \\
\text { apex }(\%)\end{array}$ & $\begin{array}{c}100.0 \\
-\end{array}$ & $\begin{array}{l}102.0 \\
98.3-106.8\end{array}$ & $\begin{array}{l}104.8^{*} \\
100.9-108.5\end{array}$ & $\begin{array}{l}107.2 \\
101.3-116.2\end{array}$ & $\begin{array}{l}107.9 * \\
104.3-114.9\end{array}$ \\
\hline
\end{tabular}

Table 5.2 Epicardial and subendocardial $e_{\text {min }} e_{\text {max }}$, and the directian of emin referred to the circumference $\left(\beta_{\mathrm{min}}\right)$ as obtained from a mathematical model (Arts et al, 1982a) and from measurement of transmural deformation (median walues and $95 \% 1$ imits, 6 animals, $n=12$ ).

\section{Model Measurement}

$\begin{array}{llll}\text { Epicardfum } & \mathrm{e}_{\max }(\%) & 15 & 15 \\ & \mathrm{e}_{\min }(\%) & 2 & 9-19 \\ & & 3 & 2-6 \\ & B_{\min }(\text { rad }) & 0.75 & 0.86 \\ & & & 0.20-1.37\end{array}$

$\begin{array}{llll}\text { Subendocardium } & e_{\max } \text {, endo }(\%) & 28 & 23^{*} \\ & & & 10-27 \\ & e_{\text {min, endo }}(\%) & 8 & 2^{*} \\ & & 5-8 \\ & & 0.83^{*} \\ & & 0.09-1.45\end{array}$

* $\mathrm{p} \times 0.05$ as compared with the model

Table $5.3 \beta_{\text {minn }}$ on the epicardium and in the inner layers ( $B_{\text {min,endo }}$ ) before and after acute coronary artery occlusion in 6 animals $(n=12)$. Median values and $95 \% 1 \mathrm{imits}$ are shown.

\begin{tabular}{|c|c|c|c|c|c|c|}
\hline Time & 0 & 5 & 10 & 20 & 40 & 50 \\
\hline $\begin{array}{l}B_{\min } \\
(\mathrm{rad})\end{array}$ & $\begin{array}{l}0.86 \\
0.20-1.37\end{array}$ & $\begin{array}{l}1.11 \\
0.75-1.45\end{array}$ & $\begin{array}{l}1.07^{*} \\
0.86-1.44\end{array}$ & $\begin{array}{l}1.06^{\star} \\
0.90-1.18\end{array}$ & $\begin{array}{l}1.03 \\
0.65-1.34\end{array}$ & $\begin{array}{l}0.67 \\
0.44-1.36\end{array}$ \\
\hline $\begin{array}{l}B_{\text {mad }} \text {, enda } \\
(\mathrm{rad}\end{array}$ & $\begin{array}{l}0.83 \\
0.09-1.45\end{array}$ & $\begin{array}{l}1.08 \\
0.83-1.31\end{array}$ & $\begin{array}{l}1.30^{*} \\
0.94-1.41\end{array}$ & $\begin{array}{l}0.98^{*} \\
0.90-1.54\end{array}$ & $\begin{array}{l}1.01 \\
0.75-1,42\end{array}$ & $\begin{array}{l}0.88 \\
0.60-1.48\end{array}$ \\
\hline
\end{tabular}

* p0.05 compared with time 0 s. 
circumferential and base-to-apex direction, respectively which means a 15.6\% enlargement of the epicardial surface.

The time course of $e_{\max }$ and $e_{m i n}$, as calculated from $e_{c}$, $e_{z}$ and (see above) is shown in fig 5.4. A significant decrease occurred approximately $2 s$ earlier in $e_{\text {min }}$ than in $e_{\text {max }}$. Moreover, values of $e_{\text {max }}$ remained positive whereas values of $e_{\text {min }}$ became negative within 8 $s$ of occlusion. A further difference between these two variables is that the values of $e_{\text {max }}$ did not change between 20 and $60 \mathrm{~s}$ of occlusim on whereas the values of emin increased after 20 s to just below zero.

\subsubsection{Transmural deformation (group II)}

Table 5.2 shows the experimental data on maximum and minimum shortening and the direction $B_{\text {min }}$ of minimum shortening at the epicardial surface and in the inner layers, as well as values of these variables obtained from model calculations (Arts et al, 1982b). The median of the measured values of epicardial $e_{\max }, e_{\min }$ and $\beta_{\text {min }}$ as measured, appear to be close to the values of these variables as calculated with the model of left ventricular wall mechanics. The difference between the measured and predicted value of maximal shortening in the inner layers ( $e_{\max }$ endo) was less than $25 \%$ but significant. The measured values of both $e_{m i n}$ and $B_{\text {min }}$ in the inner layers ( $e_{\text {min, endo and }}$

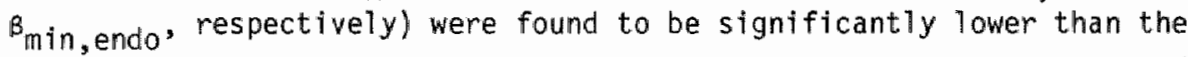
model calculations of these variables. Both predicted and measured values of emin,endo were higher as compared with their epicardial counterparts $\left(\mathrm{e}_{\mathrm{min}}\right)$.

The values of $e_{\text {min }}$ and $e_{\text {endo }}$ obtained during normoxia and one min of coronary artery occlusion were plotted against each other for each individual experiment (fig 5.5). In 5 out of 6 experiments, the relation between the latter parameters was significant $(p<0.05)$. Based on the combination of all data the relation between the two parameters was found to be highly significant $(p<0.001)$.

Fig 5.6 shows the time course of $e_{m i n}$ and endo as assessed from transmural deformation. During the normoxic and ischemic period, e min and eendo were not significantly different. The values of both variables became negative within $10 \mathrm{~s}$ after coronary artery occlusion, indicating lengthening along the corresponding direction during the 


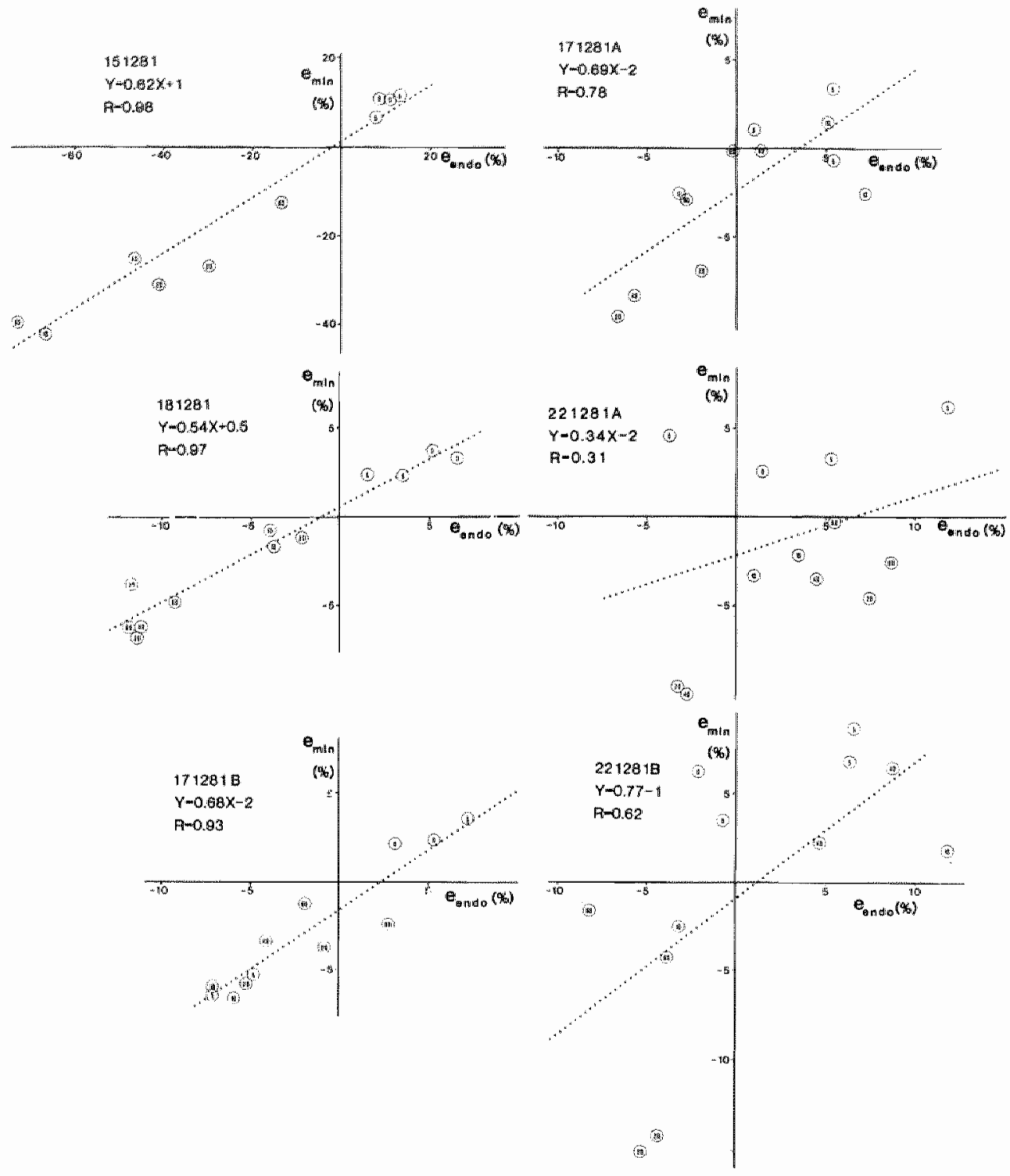

Fig 5.5 Relationship between $e_{\text {min }}$ and $e_{\text {endo during normoxia and }}$ ischemia in 6 experiments. The encircled figures depict the sample time (s) after onset of acute coronary artery acclusion. Regression equation and correlation coefficient were determined according to linear regression. 
ejection phase. Lengthening occurred during the rest of the experimental period.

Before as well as after acute coronary artery occlusion, the orientation of $e_{\text {min }}$, endo and $e_{\text {max, endo }}$ was not significantly different from the orientation of their epicardial counterparts (table 5.3). At each sample time, the angle between $e_{\text {min }}$ and $e_{\text {endo }}$ was less than $0.5 \mathrm{rad}$. Both angles $\beta_{m i n}$ showed a transient increase 10 and $20 \mathrm{~s}$ after the onset of occlusion.

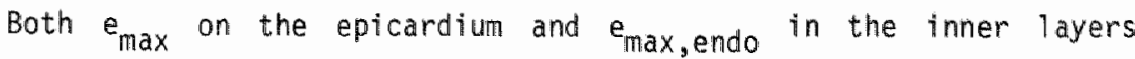
decreased after acclustion, the fall in the latter variable being more pronounced in the first $10 \mathrm{~s}$ (fig 5.7). However, $60 \mathrm{~s}$ after acclusion the relative decrease in shortening is approximately the same in both layers (fig 5.7 ).

\subsection{Discussion}

\subsubsection{Reliability of the assessment of the tramsmural course of fiber shortening from epicardial deformation.}

The amount of shortening in the deeper layers of the myocardium can be estimated from epicardial deformation if shear between the various layers in the left ventricular wall is small compared to changes in strain along the fibers during contraction. During nomal perfusion, Feigl and Fry (1964) showed the latter shear to be 0.02 rad without preferential direction. These authors concluded that in the normoxic heart the transmural course of deformation during ejection might be determined with reasonable accuracy from the deformation of the epicardial surface.

In the present study, the effect of acute coronary artery occlustion on epicardial and subendocardial deformation was assessed in openchest dogs, using the inductive technique, mentioned in section 3.3. To assess the effect of shear between the myocardial layers during normoxia and ischemia, in 6 experiments transmural deformation was measured directly, using 3 needles each with a pair of colls attached to it and pierced through the myocardial wall (group II).

Inaccuracy of the latter measuring technique might be introduced by impaired mobility of the measuring needles because of their inertia. 

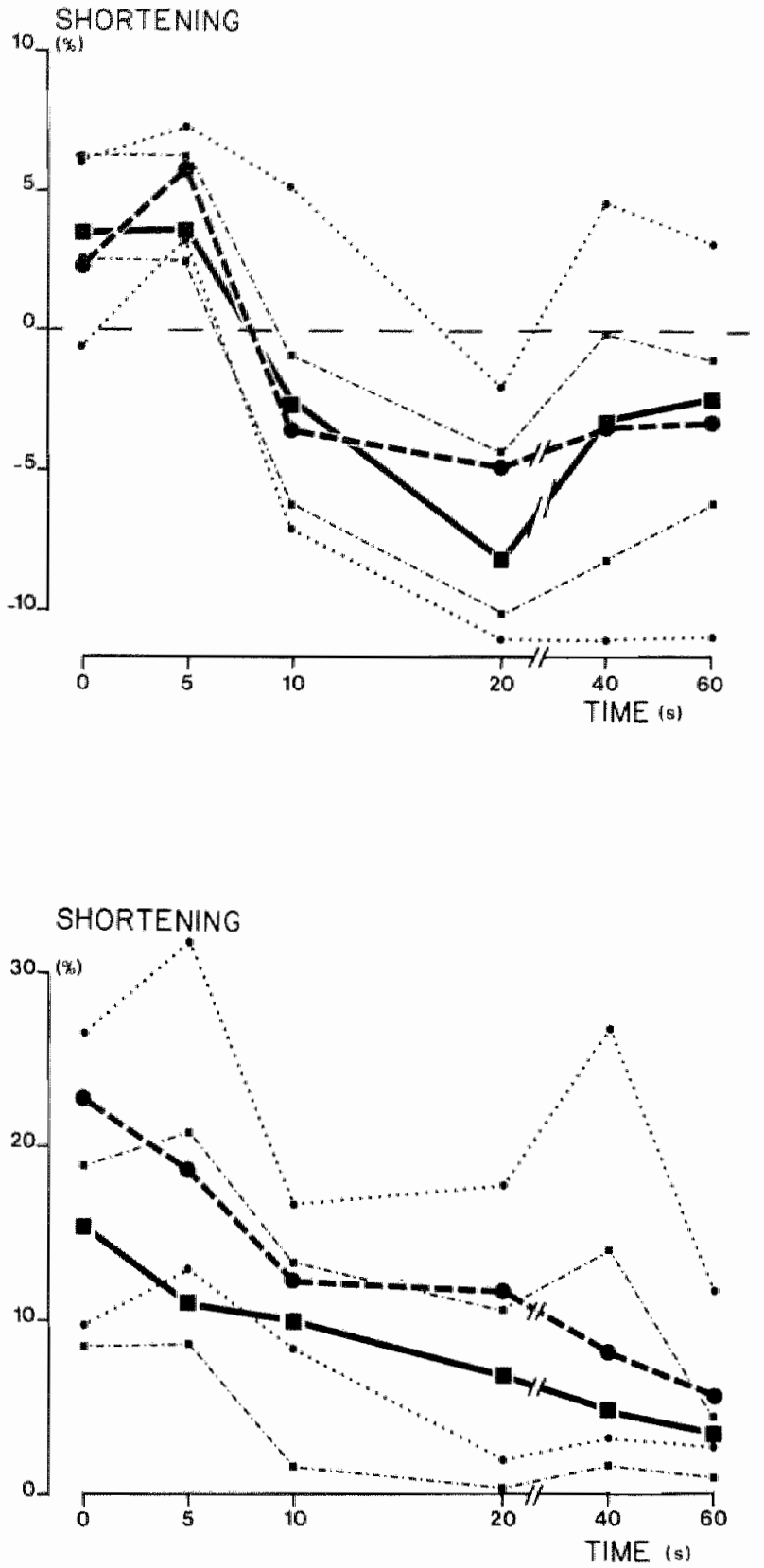

Filg 5.6 Time course of $e_{\min }(--t-)$ and endo (....) during 1 min of acute coronary artery occlusion as determined from transmural deformation measurements (data from 2 occlusions in 6 animals). For explanation of the symbols, see fig 5.3 .
Fitg 5.7

Time course of $e_{m a x}$ $(-1-)$ and $e_{\max }$,endo $(\ldots .$.$) during one min$ of acute coromary artery occlusion, determined from transmural deformation measurements (data from 2 acclusions in 6 animals). Median values and $95 \%$ limits are shown. 
The influence of inertia on the measurenent is probably small because our data were obtained during systole, when the stiffness of the myocardium is increased, and the mechanical contact of the meedles with the surrounding tissue is improved. The minor importance of the inertia of the needles with colls is also indicated by the fast responses, found in the defomation signals during the cardiac cycle, up to $21 \mathrm{~Hz}$.

Using the above-mentioned technique, no significant differences coutd be observed between the values of epicardial minimal shortening $\left(e_{\min }\right)$ and shortening in the $e_{\text {min }}$ direction in the inner layers ( $e_{\text {endo }}$ ) during normoxia as well as ischemia, although possible differences could be masked by the large variation in the values of endo. The variation in emin as deternined by epicardial and transmural deformation measurements is similar as shown by comparing the figs 5.4 and 5.6. Except for the influence of shear between the various layers, the greater variation in endo might result from the fact that endo is calculated from strains, the values of which are extrapolations from strains measured over the epicardium. Also non-parallel orientation of the meedles through the ventricular wall could induce variations in the measurements. In both cases, initially small errors at the levels of the coils will cause larger errors at the level of the subendocardium. Despite this large variation in eendo" the relation between $e_{\min }$ and $e_{\text {endo }}$ was significant (fig 5.5).

After onset of ischemia, bath epicardial $\left(e_{\max }\right)$ and subendocardial maximal shartening $\left(e_{\text {max, endo }}\right)$ decrease, the latter more pronounced in the first $10 \mathrm{~s}$ after occlusion. After one min of occlusion, however, the relative decrease in both variables is similar, which may be caused by a similar relation between $e_{\max }$ and $e_{\mathrm{max}}$, endo as has been shown above to exist for $\mathrm{e}_{\mathrm{min}}$ and $e_{\text {endlo }}$

The relation between epicardial and subendacardial shortening in a particular direction suggests that shear between layers is indeed small enough to assess reliably the transmural course of deformation during ejection from epicardial defomation, as was al ready suggested to be possible during nomoxia by Feigl and Fry (1964). A schematical representation of the relation between shortening in two myocardial layers, which fibers are directed perpendicular to each other, is 


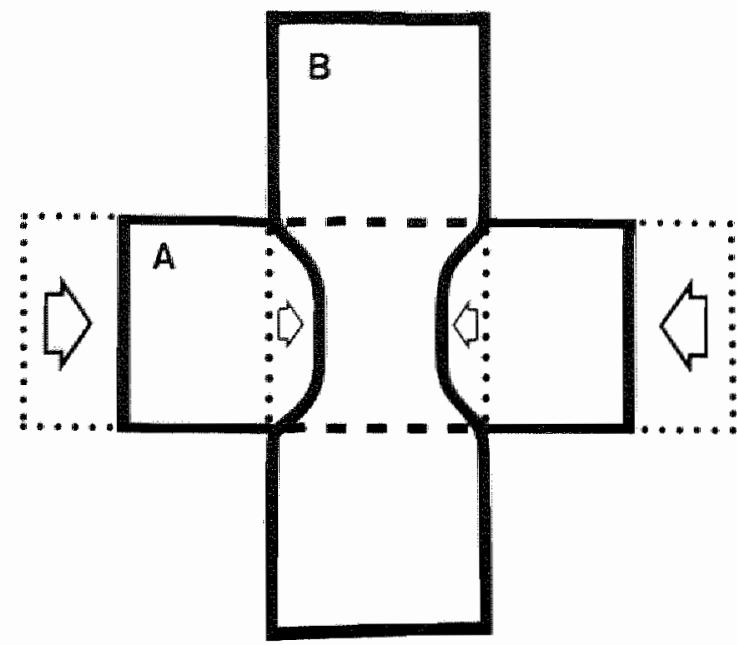

Fig 5.8

Propased relationship between shortening in a direction in two different layers of the myocardial wall. Shortening along fuber A also causes shortening in the same direction of fiber $B$, located in a different layer and oriented perpendicular to fiber A. epicardium inner layers

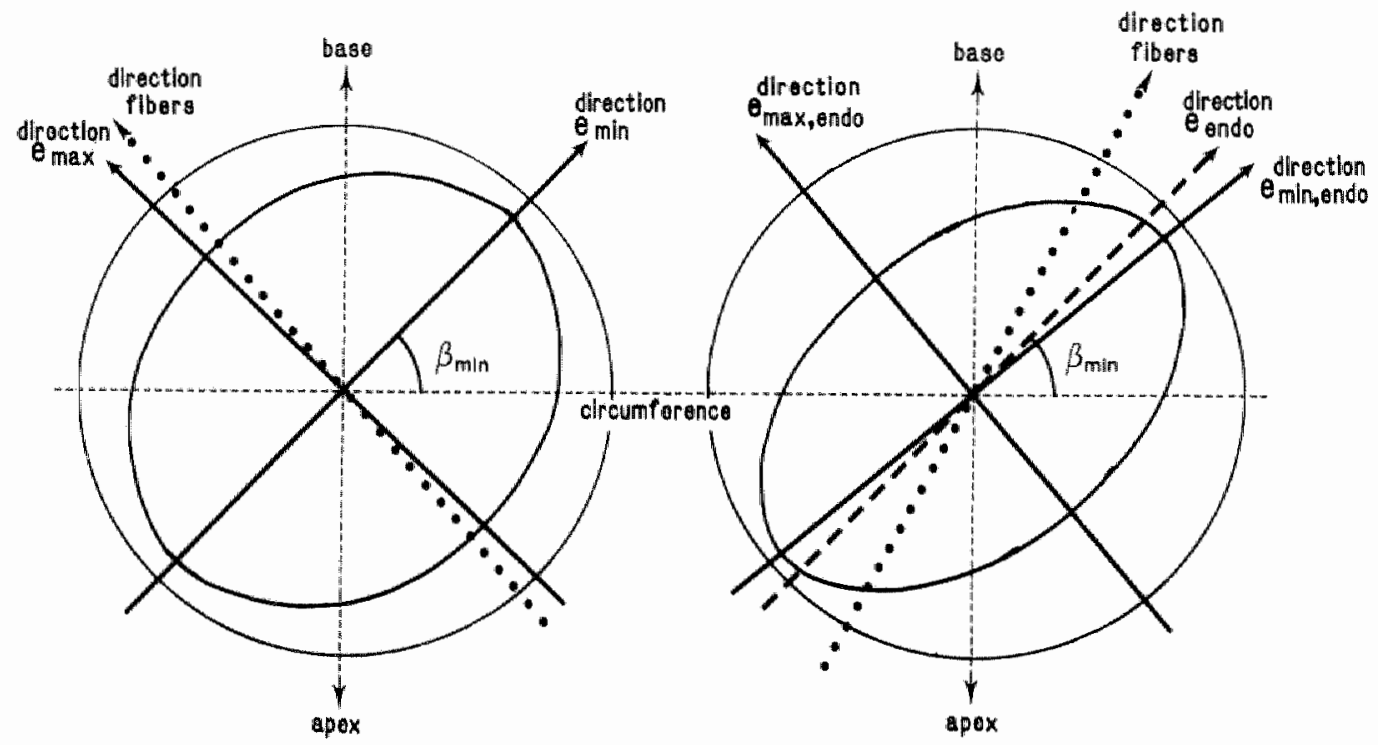

Fig 5.9 Relation between the fiber direction at the epicardium and in the inner layers, and the direction of shortening in the various directions as derived from transmural deformation measurements. At the onset of ejection, two circles are assumed in both layers. Due to shortening during the ejection phase, the circles are deformed to ellipses. The form and orientation of the ellipses are conform the transmural deformation measurements. Shartening in all directions has been amplified by a factor 2. 
shown in fig 5.8. Shortening in the fiber direction of one layer also results in shortening in the same direction in other 1 ayers.

During nomoxia, the model predicts fiber shortening in the inmer and outer layers to be the same (Arts, 1978). Measurements with ultrasonic crystals revealed larger shortening in the inner layers (Weintraub et al, 1981). In our experiments endo was measured to be less than half the value of $e_{\max }$ at the epicardium. This might be due to non-alignement of the orientation of endo with respect to the fiber direction in the inner layers. After all, the orientation of eendo is defined to be perpendicular to the orientation of $e_{\max }$. According to the model prediction, $e_{\max }$ is within 0.05 rad of the fiber direction in the outer layers but the orientation of endo is at an angle of 0.3 rad with the fiber direction in the immer layers (Arts et a1, 1982). This difference in arientation will cause endo to be less than fiber shortening in the inner layers. Nevertheless eendo provides information on fiber shortening in these layers, as is shown in fig 5.9.

The present results show that during normoxia as well acute ischemia epicardial shortening along the direction of minimal shortening is closely reliated to shortening in the inner layers along the same direction, which is close to the fiber direction in these layers. This is especially true if measurements can be referred to a control situation in the same animal (paired analysis) as is the case in the present study.

\subsubsection{Transmural differences in the changes of shortening along the approximate fiber direction}

The early decline in shortening after acute coronary artery occlusion is in agreement with findings of other investlgators studying regional ischemia (Banka and Helfant, 1974; Tyberg et a1, 1974; Theroux et al, 1976; Crozatier et al, 1977) or anoxia (Hearse, 1979).

The earlier decline in $e_{\text {min }}$ as compared with $e_{\text {max }}$ suggests that after onset of coronary artery occlusion fiber shortening in the inner layers is affected earlier than fiber shortening in the outer layers. In chapter 6, it will be shown, that after onset of coronary artery stenosis the time lag between the decrease of $e_{\min }$ and $e_{\max }$ is even more pronounced.

The results from both deformation studies show that between 10 and 
30 s after coronary artery occlusion lengthening occurs along a direction clase to the fiber direction in the inner layers. After this time interval hardly any length changes occur during ejection. This disappearance of lengthening is only an apparent improvenent, since it is caused by the earlier start of lengthening in the isovolumic phase. The decrease in lengthening may also be caused by increased myocardial stiffness (Edwards et a1, 1981).

After one min of coronary artery occlusion, differences in the changes of shortening between the inner and outer layers were measured to be less than those faund after 20 5. By studying shortening with ultrasonic crystals, Weintraub et al (1981) did not abserve significant differences between the relative decreases in shortening in these two layers. Except for the measuring interval after flow reduction and the assessment of shortening during the whole systolic phase rather than the ejection phase, differences between their results and ours may arise from the orientation of the crystals. These authors positioned the subendocardial and subepicardial crystals parallel to the circumferential and base-to-apex axis, respectively. As can be seen from the data in fig 5.3, after one min of occliusion differences between circumferential and base-to-apex shortening were less than the differences between $e_{m i n}$ and $e_{\text {max }}$, suggesting that the relative decrease in fiber shortening might be slightly more pronounced in the inner than in the outer layers.

\subsubsection{Comparison of measured and predicted transmural deformation}

Previous experiments have been performed to verify the model (Arts et a1, 1982). Values of epicardial defomation obtained in these experiments compared well with model calculations. Dffferences between the aforementioned experiments and those in the present study may originate from the differences in localization of the measuring device on the left ventricle between these two studies. The former has been performed near the base of the left ventricle whereas in this study deformation has been measured in the middle or apical region of this vertricle, because data had to be obtained from the center of the ischemic area. The basal region distinguishes itself from the middle and apical regions at various points, which may contribute to the observed difference between both studies. 
Firstly, the presence of the anterior papiliary muscle in the more apical region may influence the distribution and direction of shortening. Secondly, the apical geometry cannot be represented by a cylinder, which is the case in the basal region and is assumed in the model. At last, the fiber direction in the inner and outer layers is steeper in the apical than in basal region of the left ventricle (Streeter et a1, 1959; Ross and Streeter, 1975). These differences in fiber orientation might influence regional transmural deformation. For the inner layers the model predicts the direction of minimal shortening to be at an angle of 1.4 rad with the circumference assuming a fuber direction of $0.75 \mathrm{rad}$ in the inner subcylinder. In the apicall region, fiber direction has been shown to be about 1.3 rad (Streeter et a1, 1969). Because the minimal shortening direction at the epicardium will probably not be the same as the fiber direction in the inner layers and because relatively little fibers are circumferentially oriented in the apical region, the minimal shortening direction in the inner layers might be more circumferentially ariented in apical than in basal regions.

\subsection{Conclusions}

- Measurement of epicardial minimal shortening is closely related to shortening along the fibers in the inner layers.

- After onset of acute coronary artery occlusion shortening approximately parallel to the fiber direction in the inner layers ceases earlier (about 2 s) and more pronounced than shortening along the fiber direction in the outer layers.

- Within the first 30 s after onset of coronary artery occlusion large differences in fiber shortening between the inner and outer layers are found. After one min occlusion these differences are relatively sma 11. 
6. RELATIONSHIP BETWEEN FIBER SHORTENING, MYOCARDIAL BLOOD FLOW AND METABOLISM IM THE VARIOUS LAYERS OF THE LEFT VENTRICULAR WALL WITHIN 5 MINUTES AFTER CORONARY ARTERY STENOSIS

\subsection{Introduction}

During ischenia myocardial blood flow (MBF) and metabolic processes are known to be more severely affected in the inner than in the outer layers of the left ventricle. Within a few seconds after anset of ischemia, myocardial contraction is impaired (chapter 1). However, knowledge of the relation between this performance, MBF and metabolic variables in the various layers, is limited because information about the behavior of fiber shortening in the various layers of the myocardial wall is difficult to obtain (section 2.1.3).

In the previous chapter, measurement of maximal and minimal shortening of the epicardial surface resulted in useful measures of shortening along the epicardial fiber direction as well as shortening clase to the fiber direction in the inner layers.

The purpose of the study described in this chapter was to investigate the relation between the in this way measured shortening and MBF and metabolism in the various layers of the myocardial wall as a function of time within the first 5 min after coronary artery stenosis.

\subsection{Experimental design}

\subsubsection{Protocol}

The experiments were performed on 30 mangrel dogs which were allotted to 3 groups according to the time of myacardial tissue sampling (e.g. 1, 3 and 5 min after onset of stenosis). To assure equal conditions before onset of ischemia, care was taken, that between these 3 groups no significant differences existed in heart rate, mean aortic pressure $\left(p_{a 0}\right)$ and $d p_{1 v} / d t_{\text {max }}$. Evaluation of the differences between the three aforementioned variables in the three groups did not reveal any significant difference by applying the kruskal-Wallis test.

The experimental protocol is shown in fig 6.1. For baseline measurements, arterial and local venous samples were drawn 15, 5, and $0.5 \mathrm{~min}$ prior to 
stenosis. The continuously recorded hemodynamic and regional mechanical variables were also determined at these moments. Cardiac output was determined 15 and 5 min prior to stemosis. Microsphere injection for the determination of regional myocardial blood flow was performed between 15 and 5 min prior to stenosis.

After these measurements had been performed, the occluder cuff was manual$1 y$ inflated until after $15-30$ seconds post-stenotic coronary artery pressure had reached the desired value (1.e. $3.3 \mathrm{kPa}$; see section 3.1.4). Time 0 min was defined as the moment at which this pressure was reached. During stenosis, samples for detemination of hemodynamic, blood biochemical and regional mechanical variables were taken $0.5,1,2,3,4$ and 5 min after onset of stenosis. At each sample time the registration for the determination of the hemodynamic variables was made just before arterial blood sampling (fig 6.1). Local venous blood was continuously sampled from time 0 min till the end of the experiment. Blood withdrawn between times 0 and $0.5 \mathrm{~min}$ was called sample $0.5 \mathrm{~min}$, between times 0.5 and $1 \mathrm{~min}$ was called sample 1 min and so on. Cardiac output was determined at about $0.75 \mathrm{~min}, 1.75 \mathrm{~min}, 2.75 \mathrm{~min}, 3.75 \mathrm{~min}$ and $4.75 \mathrm{~min}$. Microspheres for the determination of regional myocardial blood flow were injected immediately after temination of arterial blood sampling at times 1,3 and 5 min. Transmural biopsies for the determination of ATP, creatine phosphate and glycogen (section 3.1.6) from the ischemic (LAICA-) and nomoxic (LCCA-) area were taken $15-30 \mathrm{~s}$ and $30-60 \mathrm{~s}$ after the last microsphere injection had been performed, respectivelly. After this procedure, the dogs were killed by an overdose of pentobarbital.

\section{2 .2 Data analysis}

Information about the effect of ischemia was obtained by comparison of the data within each animal. The choice of each dog serwing as its own control was made because of the large differences between animals. Influences on hemodynamical, regional mechanical and blood biochemical variables as well as MBF were evaluated by comparing the walues at vartous time intervals after onset of ischemia with those at time $-5 \mathrm{~min}$. At each sample time changes in the content of the various substances within the ischemic myocardium (LAICA area) were evaluated by comparing the values of these contents with those in the non-ischemic tissue (LCCA area) in the same experiment. Indications for the correctness of this approach have been presented in chapter 4 . The differences were evaluated for statistical significance by applying Wilcoxon's 


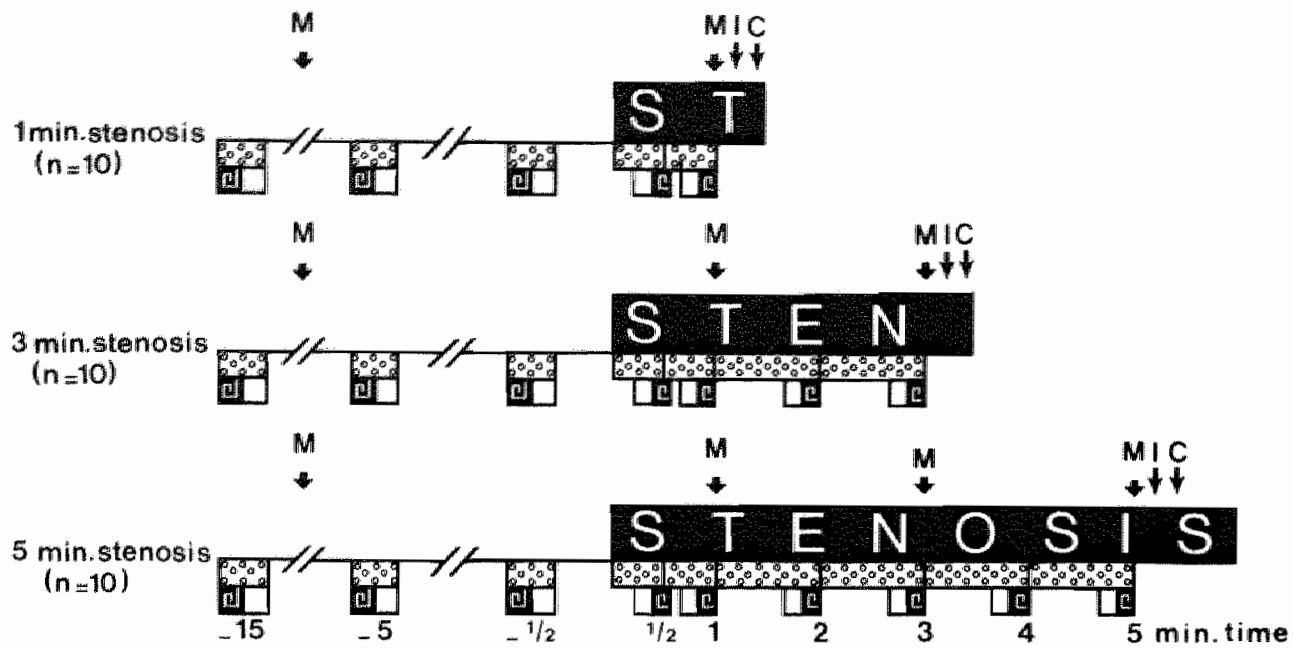

sample times

hemodynamic and regional mechanical varialbles

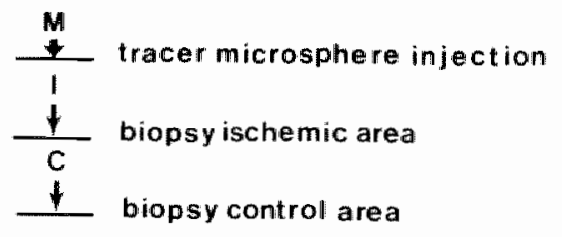

Fo: sample times local venous

$$
\text { blood }
$$

Fig 6.1 Protocol of the experiments.
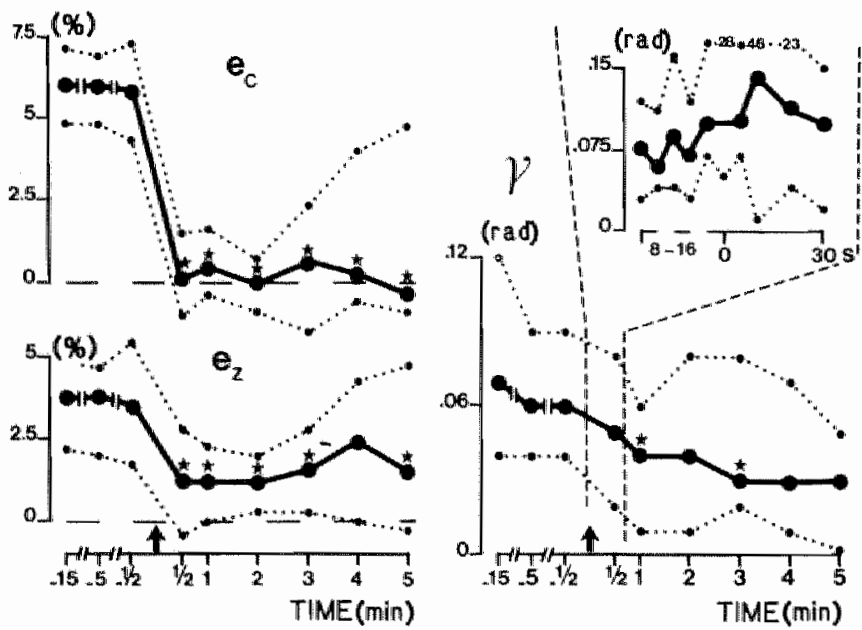

Fig 6.2 Time course of $\mathrm{e}_{\mathrm{C}}, \mathrm{e}_{\mathrm{z}}$, and $\gamma$ during 5 min of coronary artery stenosis. Median values and $95 \%$ limits are show * $p<0.05$ as compared with time $=-5 \mathrm{mim}$. 
matched-pairs signed-ranks test (two-tailed probability). The data are summarized as median values and $95 \%$ limits. A value of $p<0.05$ was considered to be a significant difference.

\subsection{Results}

\subsubsection{Inducement of stenosis}

By manual inflation of the cuff, mean post-stenotic coronary artery pressure was reduced from 9.7 to $3.3 \mathrm{kPa}$ (median values) within 10-30 $\mathrm{s}$. Because of the use of the servosystem (section 3.1.4) this pressure hardly changed during the ischemic period and was approximately equal for all animals. (fig $6.3)$.

\subsubsection{Time course of regional mechanical variables}

The data obtained from the measurement of epicardial surface deformation are given in fig 6.2. Ouring normal perfusion, values of circumferential shortening $\left(e_{c}\right)$ were about twice the values of base-to-apex shortening $\left(e_{z}\right)$. The median values $6.0 \%$ and $3.7 \%$ respectively. Analysis of the registration of these parameters in the first half min of stenosis in 11 animals revealed that shortening in both directions decreased already during the 10-30 s period of manual inflation of the cuff around the LAICA (not shown) and that $e_{c}$ transiently reached negative values, indicating the existence of circumferential lengthening during the ejection phase. After half a minute, shortening had decreased to median values of $0.1 \%\left(e_{c}\right)$ and $1.2 \%\left(e_{z}\right)$, indicating that the former variable is more sensitive to ischemia. From $30 \mathrm{~s}$ to $5 \mathrm{~min}$ after onset of stenosis, these values did not change significantly (fig 6.2).

In contrast to the shortening variables, the decrease in shear angle $\gamma$ was nore gradual and less pronounced. In the first min after onset of stenosis $v$ tended to increase transientiy, but these changes did not reach the level of significance (inset in fig 6.2). After $5 \mathrm{~min}$ of stenosis the value of $y$ was close to half the normoxic value (fig 5.2).

In chapter 5 , it has been shown that minimal and maximal shortening ( $e_{\text {min }}$ and $e_{\text {max }}$ as calculated from $e_{c}, e_{z}$ and $y$ were useful markers of shortening in directions approximately parallel to the fiber direction in the inner and outer layers of the myocardial wall, respectively. The results of calculations based on the present data are shown in the figs 6.3 and 6.4 . During inflation of the cuff, $e_{m i n}$ decreased al ready. The value of $e_{\text {min }}$ was negative 

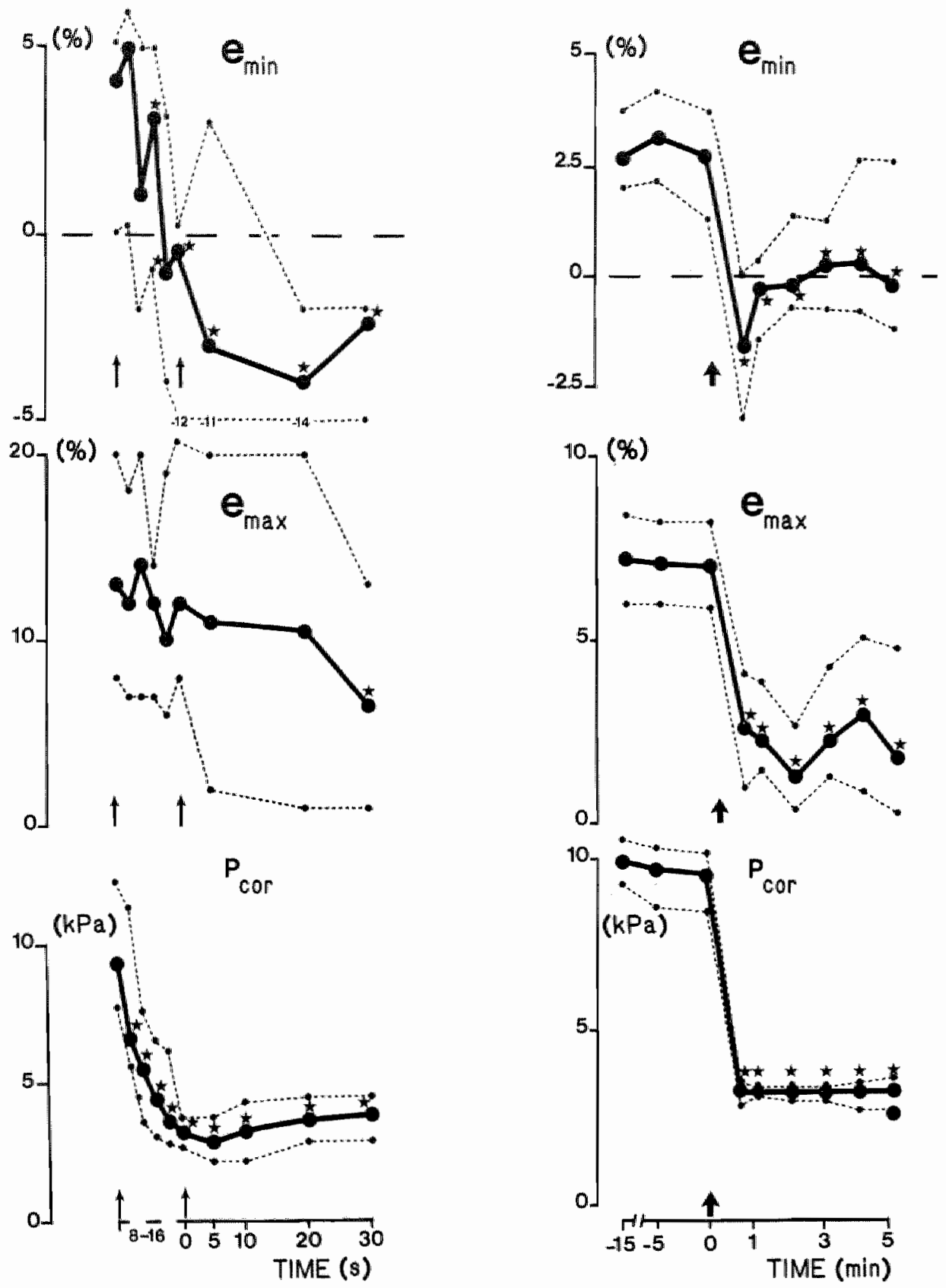

Fig 6.3 and 6.4 Time course of mean $p_{c o r}$, $e_{\text {min }}$ and $e_{\text {max }}$ during the first $30 \mathrm{~s}$ ( fig $6.3 ; n=11$ ) and $5 \mathrm{~min}$ of acute coronary artery stenosis ( $\mathrm{fig}$ $6.4 ; n=30)$. The first small arrow in fig 6.3 indicates the onset of decrease in mean $\mathrm{p}_{\mathrm{con}}$, the second one indicates time $0 \mathrm{~s}$, defined as the moment on which meah $p_{\text {cor }}$ reaches the appropriate level (= about 3.3 $\mathrm{kPa}$. In fig 6.4 the arrow indicates the onset of stenosis. For explanation of symbols see fig 6.2 . 
when the cuff was appropriately inflated and decreased further until 20 s after onset of stenosis (fig 6.3). However, after one min, emin returned to about zero and was stabile during the next 4 min (fig 6.4). In contrast to the imediate decline in $e_{\min }$, $e_{m a x}$ did not change significantly until $30 \mathrm{~s}$ after onset of stenosis (fig 6.3). Emax reached the lowest values (33\%) of the pre-ischemic values after one min of ischemia and remained constant thereafter (fig 6.4).

\subsubsection{Time course of regional myocardial blood flow}

The MBF values as measured with the radioactive microsphere method are shown in table 6.1. During normoxia MBF was almost homogeneously distributed across the ventricular wall in the LAICA perfusion area. In the area perfused by the LCCA, the perfusion of the outer layers was 10-25\% lower than that of the inner layers (discussed in detail in chapter 4). By inducement of stenosis of the LAICA, MBF in its perfusion area became inhomogeneous, and decreased much more in the inner layers than in the outer ones. From 1 to 5 min after onset of stenosis, median MBF in the inner and outer layers further decreased from $32 \%$ to $19 \%$ and from $64 \%$ to $46 \%$ of their pre-1schemic values, respectively. The differences between the values at 1 and 5 min were not statistically significant (table 6.1).

In the non-ischemic LCCA perfusion area, MBF significantiy increased in the outer but not in the inner layers. Therefore, the 10-15\% increase in MBF in the outer layers was associated with a smal1 but significant decrease in endo/epicardial flow ratio (table 6.1).

\subsubsection{Time course of regional metabolic variables}

The ATP, creatine phosphate and glycogen contents in the inmer and outer layers of the ischemic and non-ischemic area are shown in table 6.2. After 1 , 3, and 5 min of ischemia, no significant decrease in ATP and glycogen content was observed except for a decrease in the glycogen content of the outer layers after $3 \mathrm{~min}$ of ischemia (table 6.2). In contrast, creatine phosphate content rapidly decreased. Within 1 min of ischemia, creatine phosphate content was halved in the inner layers of the nyocardiall wall, without significant decrease in the middle (not shown) and outer layers (table 6.2). After 3 and 5 min of ischemia, creatine phosphate content was significantly decreased in all three layers; contents in the inner layers remaining significantly lower than in the outer layers (table 6.2). 
Table 6.1 Regional myocardial blood flow $\left(\mathrm{ml}^{1} \cdot \mathrm{min}^{-1} \cdot \mathrm{g}^{-1}\right)$ in the outer (EPI) and inner (ENDO) layers as well as the endo/epicardial blood flow (ENDO-EPI) ratio of the ischernic and non-ischemic tissue as well as the mean (transmurai) blood flow of the ischemic tissue. Median values and $95 \%$ 1imits are shown.

\begin{tabular}{|c|c|c|c|c|}
\hline Time (min) & -5 & 1 & 3 & 5 \\
\hline $\begin{array}{l}\text { Ischemic region } \\
\text { EPI }\end{array}$ & $\begin{array}{l}0.83 \\
0.73-0.95\end{array}$ & $\begin{array}{l}0.53^{\star} \\
0.44-0.62\end{array}$ & $\begin{array}{l}0.44^{*} \\
0.41-0.56\end{array}$ & $\begin{array}{l}0.38^{*} \\
0.22-0.54\end{array}$ \\
\hline ENDO & $\begin{array}{l}0.76 \\
0.64-0.88\end{array}$ & $\begin{array}{l}0.24 * \\
0.20-0.32\end{array}$ & $\begin{array}{l}0.23^{*} \\
0.19-0.29\end{array}$ & $\begin{array}{l}0.15^{*} \\
0.04-0.26\end{array}$ \\
\hline ENDO-EPI RATIO & $\begin{array}{l}0.96 \\
0.86-1.06\end{array}$ & $\begin{array}{l}0.50^{\star} \\
0.45-0.61\end{array}$ & $\begin{array}{l}0.51^{\star} \\
0.40-0.60\end{array}$ & $\begin{array}{l}0.45^{*} \\
0.25-0.65\end{array}$ \\
\hline Mean MBF & $\begin{array}{l}0.78 \\
0.66-0.95\end{array}$ & $\begin{array}{l}0.40^{*} \\
0.26-0.48\end{array}$ & $\begin{array}{l}0.34^{\star} \\
0.24-0.39\end{array}$ & $\begin{array}{l}0.28^{*} \\
0.10-0.55\end{array}$ \\
\hline $\begin{array}{l}\text { Non-I schemilc regi } \\
\text { EPI }\end{array}$ & $\begin{array}{l}0.7 \\
0.64-0.86\end{array}$ & $\begin{array}{l}0.86^{*} \\
0.76-0.96\end{array}$ & $\begin{array}{l}0.83^{*} \\
0.71-0.90\end{array}$ & $\begin{array}{l}0.86^{\star} \\
0.63-0.98\end{array}$ \\
\hline ENDO & $\begin{array}{l}0.85 \\
0.75-0.96\end{array}$ & $\begin{array}{l}0.90 \\
0.78-1.02\end{array}$ & $\begin{array}{l}0.90 \\
0.80-1.10\end{array}$ & $\begin{array}{l}0.78 \\
0.70-1.10\end{array}$ \\
\hline ENDO-EPI RATIO & $\begin{array}{l}1.17 \\
1.11-1.25\end{array}$ & $\begin{array}{l}1.11 * \\
1.02-1.19\end{array}$ & $\begin{array}{l}1.14 \\
1.00-1.21\end{array}$ & $\begin{array}{l}1.07^{\star} \\
0.95-1.20\end{array}$ \\
\hline
\end{tabular}


Breakdown of energy-rich phosphates shortly after onset of stenosis was. also indicated by the release of inorganic phosphate into the local venous blood which was significant within one min after this onset (table 6.3). Simultaneously with inorganic phosphate, potassium (table 6.3) and lactate (fig 6.5) were released into the blood. It can be seen that the release (calculated from the product of mean MBF in the ischemic area and the respective AV differences, section 3.7) of these substances rapidly increased during the first 3 min of ischemia, and hardly changed during the mext 2 min.

The data depicted in fig 6.5 show a delay of 3-4 min between the changes in the AV differences of lactate and glucose. The median values of net glucose uptake revealed an initial decrease, that did not reach the level of significance. Therefore, glucose uptake returned to the pre-ischemic values due to the pronounced increase in AV differences (6-fold of median increase, value table 6.3).

AV differences of NEFA tended to increase in the first min after anset of stenosis $(p=0.06)$ but returned to pre-ischemic walues at the next two sample times. This resulted in a decrease of net NEFA uptake similar to the decrease in mean MBF in the ischemic area after 3 and 5 min (table 6.3). Oxygen uptake decreased from 3.8 at -5 min to $1.8 \mu \mathrm{mol} . \mathrm{g}^{-1} \cdot \mathrm{min}^{-1}$ at -5 and 5 min (table $6.3)$.

\subsubsection{Estimation of ATP utilization in the inner and outer layers during nor- moxia and ischemia}

Myocardial energy metabolism was estimated from results in the present study and data published by other investigators. Oxygen uptake in the various layers was estimated from the measured oxygen uptake and the reported transmural gradient on oxygen uptake during normoxia and ischemia (Helss et al, 1978; Weiss, 1980). From these values, aerobic ATP production in the inner and outer layers was calculated (table 6.4). Anaerobic ATP production was calcullated to be 0.5 and $2.0 \mu m a 1 . g^{-1} . \mathrm{min}^{-1}$ in the outer and inner layers, respectively, based on the reported lactate accumulation during ischemia (Griggs et al, 1972). The energy needed for basal metabolism and electrical processes has been reparted to be 10-20\% of total normoxic energy production (Mckeever et a1, 1958; Klocke, 1966). For the present calculation d value of 15\% was assumed. According to these estimations, it follows that under normoxic conditions 16.7 and $19.4 \mu \mathrm{mol} . \mathrm{min}^{-1} \cdot \mathrm{g}^{-1}$ ATP is used for mechanical processes in the auter and inner layers, respectively (table 6.4). After 


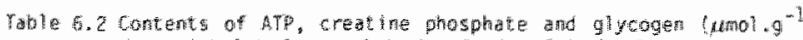

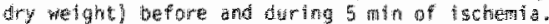

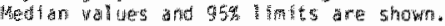

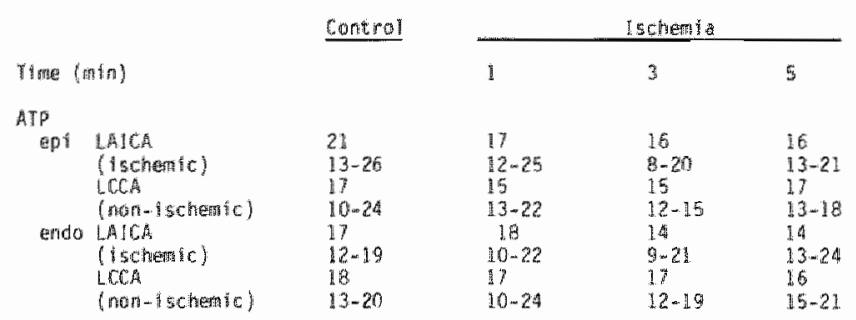

\begin{tabular}{|c|c|c|c|c|c|}
\hline \multicolumn{6}{|c|}{ Greatifue phosphate } \\
\hline $\mathrm{ep}$ 自 & $\operatorname{tarCA}$ & $h^{2} \frac{3}{x}$ & 36 & $31 *$ & $22 \%$ \\
\hline & (Ischentc) & $26-54$ & $21-30$ & $23-38$ & $15-30$ \\
\hline & ECchen & 48 & 38 & 44 & 35 \\
\hline & $($ non-1 1 chent 0$)$ & $26-61$ & $31-59$ & $34-51$ & $27 \times 51$ \\
\hline errobo & LACA & 37 & $20 \%$ & $23^{*} 0$ & $15 \div 0$ \\
\hline & (Hschem ic) & $29-53$ & $14-26$ & $12-46$ & $11-20$ \\
\hline & LCCA & & & 39 & 40 \\
\hline & (mon-ischentic ) & $25 \cdot 51$ & $35-190$ & $30-56$ & $26-76$ \\
\hline
\end{tabular}

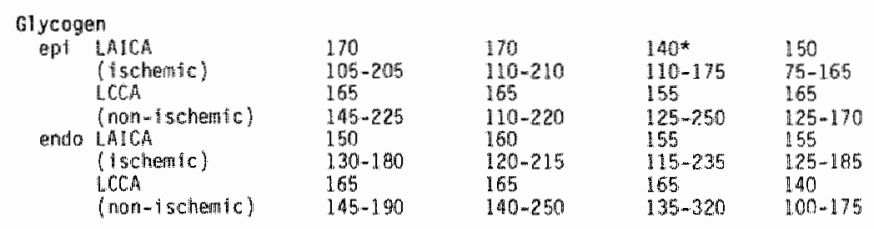

* $p<0.05$ as compared wh the nomoxic situatian.

0 p 0.05 as compared with the outer layers.

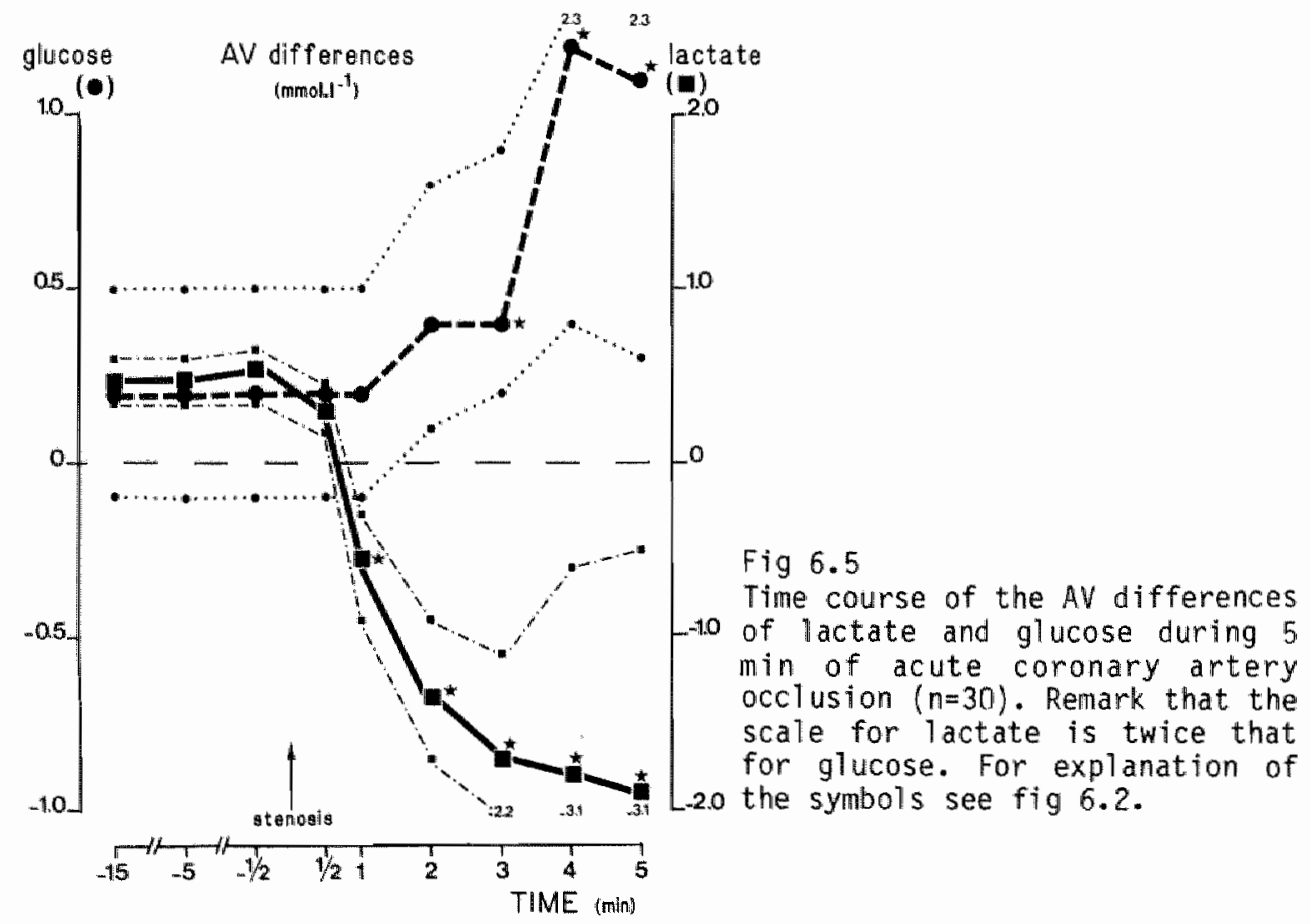


Table 6.3 Arterial concentrations (mM). AV differences (mM) and uptake (Amo1. $\mathrm{g}^{-1}$. $\mathrm{min}^{-1}$ ) of substances in the blood before and during 5 min of ischemia. Medians and $95 \% 1$ imits are shown.

\begin{tabular}{|c|c|c|c|c|}
\hline Time (min) & -5 & 1 & 3 & 5 \\
\hline \multicolumn{5}{|l|}{ oxygen } \\
\hline $\begin{array}{l}\text { Arterial } \\
\text { Av diff. } \\
\text { Uptake }\end{array}$ & $\begin{array}{l}7.3 \\
6.7-8.3 \\
4.5 \\
3.9-5.2 \\
3.8 \\
2.9-4.2\end{array}$ & $\begin{array}{l}7.3 \\
6.8-7.8 \\
5.4^{*} \\
4.9-5.9 \\
2.0 * \\
1.3-2.4\end{array}$ & $\begin{array}{l}7.4 \\
6.6-8.4 \\
6.2^{\star} \\
5.0-7.1 \\
1.8^{\star} \\
1.3-3.1\end{array}$ & $\begin{array}{l}7.0 \\
6.6-9.3 \\
5.6^{*} \\
4.5=7.9 \\
1.8^{*} \\
0.3-2.9\end{array}$ \\
\hline
\end{tabular}

Giucose

Arterial

6.4

6.2

6.2

6.7

AV diff.

$6.2-7.5$

$5.4-7.3$

$5.3-6.8$

$0.4 *$

$5.7-7.4$

0.2

$0.2-0.9$

1. $1^{*}$

$(-0.1)-0.5$

$(-0.1)-0.5$

Uptake

$\begin{array}{ll}0.1 & 0.1 \\ (-0.1)-0.5 & (-0.1)-0.2\end{array}$

0.1

$0.3-2.3$

$0.0-0.3$

0.2

$(-0.1)-0.8$

\section{Lactate}

Arterial

$$
1.86
$$

$1.23-2.34$

AV diff.

0.49

1.93

1. $31-2.61$

$-0.55 *$

1.67

1.73

$(-0.90)-(-0.30)$

Upitake

$0.30-0.61$

0.39

$-0.22 *$

$1-2 * 24$

$0.81-2.77$

$-1.70^{*}$

$-1.92^{*}$

$(-2.39)-(-1.10)(-3.11)-(-0.50)$

-0.51 *

$-0.44^{*}$

$(-0.40)-(-0.06)$

$(-0.87)-(-0.27)(-0.86)-(-0.40)$

NEFA

$\begin{array}{lllll}\text { Arterial } & 0.31 & 0.28 & 0.28 & 0.24 \\ & 0.20-0.45 & 0.14-0.50 & 0.12-0.48 & 0.10-0.48 \\ \text { AV diff. } & 0.13 & 0.17 & 0.13 & 0.14 \\ & 0.09-0.17 & 0.06-0.27 & 0.05-0.28 & 0.01-0.31 \\ \text { Uptake } & 0.10 & 0.07^{*} & 0.04 * & 0.04 * \\ & 0.06-0.14 & 0.03-0.08 & 0.02-0.07 & 0.00-0.09\end{array}$

Inorganic phosphate

$\begin{array}{lllll}\text { Arterial } & 1.70 & 1.72 & 1.71 & 2.08 \\ & 1.35-1.84 & 1.53-1.94 & 1.46-2.02 & 1.62-2.21 \\ \text { AV diff. } & -0.02 & -0.30^{*} & -0.70^{*} & -0.90^{*} \\ & (-0.08)-0.00 & (-0.43)-(-0.22) & (-0.88)-(-0.52)(-2.35)-(-0.56) \\ \text { Uptake } & -0.02 & -0.08^{*} & -0.23^{*} & -0.26^{*} \\ & (-0.08)-(-0.02)(-0.11)-(-0.05) & (-0.33)-(-0.10)(-0.68)-(-0.05)\end{array}$

Potassium

$\begin{array}{lllll}\text { Arterial } & 3.55 & 3.75 & 3.73 & 3.65 \\ & 3.35-3.90 & 3.35-4.00 & 3.40-4.05 & 3.55-4.45 \\ \text { AV diff. } & -0.04 & -0.75^{*} & -1.15^{\star} & -1.10^{*} \\ \text { Uptake } & (-0.14)-0.02 & (-1.00)-(-0.60) & (-2.05)-(-0.95)(-2.45)-(-0.75) \\ & -0.04 & -0.23^{\star} & -0.34^{*} & -0.33^{*} \\ & (-0.15)-0.07 & (-0.35)-(-0.17)(-0.72)-(-0.18) & (-1.02)-(-0.09)\end{array}$


one min of ischemial, assuming energy for basal metabolism and electrical activity to be constant, only 14.4 and $9.3 \mu \mathrm{mol} . \mathrm{g}^{-1}$.min ${ }^{-1}$ ATP is avallable for mechanical activity in the outer and inner layers, respectively (table $6.4)$.

\subsubsection{Time course of hemodynamic wariables}

In table 6.4, the values of seweral hemodynamic variables are shown before and during 5 min of coronary artery stenosis. Heart rate gradually increased by $11 \%$ and mean aortic pressure gradually decreased by $12 \%$ during 5 min of ischemta. Within 1 min of ischemia, $d p_{1 v} / d t m a x$ decreased by $23 \%$ and $p_{1 v e d}$ increased by $25 \%(p<0.05)$. These changes became more pronounced during the next $4 \mathrm{~min}$ of ischemia. Median values of cardiac output decreased, but this decrease was not significant.

These results show that the inducement of ischemia resulted in a decreased global left ventricular function, but without a significant decrease in cardiac output and the occurrence of serious arrhythmias.

\subsection{Discussion}

\subsubsection{Effects of ischemia on general hemodynamics}

By stenosis of the LAICA, 10 to $20 \%$ of the left ventricle is rendered ischemic (section 3.4). Impaired mechanical function in this area exerts significant influences on the hemodynamic variables. The loss of contractility of the ventricle as a whole is reflected by the decreased $d p y / d t m a x$, while cardiac output tended to decrease. This loss in contractility hampers the ejection of blood as is also shown by the increase in $p_{1 v e d}$. The increase in heart rate is probably reflexogenic and secondary to the decrease in aortic pressure.

Despite these significant effects on global hemodynamics, cardiac output was hardly affected. This might be partiy due to compensatory mechanical function of the non-ischemic area as suggested by the increased MBF in this area. In the early phase of ischenia, slight but non significant increases in non-ischemic MBF were also observed by Driscoll and Eckstein (1964), Domenech (1974) and Rivas et al (1976).

\subsubsection{Effects of ischemia on myocardial blood flow}

Stenosis of the coronary artery leads to a fall in post-stenotic coronary 
artery pressure and coronary flow. The degree of stenosis used in the present study caused a significant $50 \%$ fall in mean MBF in the ischemic area after one min of stenosis, slightly but not significantiy decreasing in the next 4 $\min$.

The inhomogeneous distribution of MBF across the ischemic left ventricular wall, resulting in a relative underperfusion of the inmer layers, has been extensively described (chapter 1). This is caused by the higher intranyocardial pressure in the inner than in the outer layers (Hoffman, 1979; Arts et a), 1979).

\subsubsection{Effects of ischemia on myocardial metabolism}

The reduction of myocardial blood flow results in an impaired oxygen delivery to the affected perfusion area. The oxygen shortage causes rapid and pronounced changes in metabolism of the ischemic area, as indicated by the release of lactate, inorganic phosphate and potassium within 1 min after onset of stenosis. These observations are in agreement with the findings of Obeid et al (1972) and Opie et al (1973) as well as with the results of Gudbjarmason et al (1970) who showed tissue lactate accumulation within $30 \mathrm{~s}$ after coronary artery occlusion. The net lactate release during the first 5 min of ischemia exceeded the net glucase uptake in that period. This observation suggests anaerabic breakdown of other carbohydrate sources (e.g. glycogen) during this early phase of ischemia. Median values of glycogen content were lawer in the ischemic than in the non-ischemic tissue but the difference was only significant in the outer layers after 3 min of ischemia. However, a decrease of 1 Mmal. $g^{-1}$ glycogen(glucose), which is within the interindividual variation, easily covers this additional lactate release. such a rapid enhancement of glycogenolysis cannot be excluded, since at the beginning of ischemia the inactive phosphorylase b is rapidly converted into the active phosphorylase a (Kuebler and spieckemann, 1970; Ichihara and Abiko, 1977) and phosphorylase b itself is activated within one mim of ischemia (Wollenberger and Krause, 1968). Moreover, after inducement of anoxla in an isolated heart preparation, lactate release was not severely depressed if a glucose-free perfusion was employed (Opie, 1971/72).

The delayed change in glucose AV differences, as compared to those for lactate, is incompletely understood. A relatively slow activation of the carrier mediated glucose uptake into the cells is one possiblifity. A rapid increase of glucose uptake simultaneously with a release of glucose units 
Table 6.4 Calculation of the amount of ATP (umol. $9^{-1} \cdot \mathrm{min}^{-1}$ ) availiable for mechanical activity, from the median values of MBF $\left(m l \cdot g^{-1} \cdot m_{i n}^{-1}\right)$, oxygen $A V_{1}$ dfference $(m M)$, and creatine phosphate content (umol. $\mathrm{g}^{-1}$ wet weight). Data on transmural differences in oxygen extraction during nomoxia and ischemia were obtained from Weiss et al (1978) and Weiss (1980), respectively. Anaerobic ATP production in the warious layers has been estinated from the lactate accumulation, as reported by Griggs et al (1972).

\begin{tabular}{|c|c|c|c|c|}
\hline & \multicolumn{2}{|c|}{ Normoxia } & \multicolumn{2}{|c|}{ I min ischemia } \\
\hline & outer & Inner & outer & inner \\
\hline $\begin{array}{l}\text { MBF } \\
\text { Oxygen extraction } \\
\text { Oxygen uptake }\end{array}$ & $\begin{array}{l}0.83 \\
4.0 \\
3.3\end{array}$ & $\begin{array}{l}0.76 \\
5.0 \\
3.8\end{array}$ & $\begin{array}{l}0.53 \\
5.3 \\
2.8\end{array}$ & $\begin{array}{l}0.24 \\
5.3 \\
1.3\end{array}$ \\
\hline $\begin{array}{l}\text { Aerobic ATP production } \\
\text { Anaerobic ATP production } \\
\text { Creatine phosphate } \\
\text { break down }\end{array}$ & $\begin{array}{c}19.7 \\
0 \\
0\end{array}$ & $\begin{array}{c}22.8 \\
0 \\
0\end{array}$ & $\begin{array}{c}16.9 \\
0.5 \\
0\end{array}$ & $\begin{array}{l}7.7 \\
2.0 \\
3.0\end{array}$ \\
\hline $\begin{array}{l}\text { Total ATP suppiy } \\
\text { ATP used for basal metabolism } \\
\text { and electrical activity }\end{array}$ & $\begin{array}{r}19.7 \\
3.0\end{array}$ & $\begin{array}{r}22.8 \\
3.4\end{array}$ & $\begin{array}{r}17.4 \\
3.0\end{array}$ & $\begin{array}{r}12.7 \\
3.4\end{array}$ \\
\hline $\begin{array}{l}\text { ATP avallable for mechanical } \\
\text { activity }\end{array}$ & 16.7 & 19.4 & 14.4 & 9.3 \\
\hline
\end{tabular}

Table 6.5 Values of several hemodynamic variables before and during 5 min of ischemia. Median values and $95 \%$ Iimits are shown.

\begin{tabular}{|c|c|c|c|c|}
\hline Tfrne (min) & -5 & 1 & 3 & 5 \\
\hline $\begin{array}{l}\text { Heart rate } \\
(\text { b.min }\end{array}$ & $\begin{array}{l}135 \\
115-150\end{array}$ & $\begin{array}{l}138^{*} \\
115-145\end{array}$ & $\begin{array}{l}138^{\star} \\
110-158\end{array}$ & $\begin{array}{l}150^{*} \\
135-180\end{array}$ \\
\hline $\begin{array}{l}\text { Mean aortic } \\
\text { pressure (kPa) }\end{array}$ & $\begin{array}{l}10.4 \\
10.0-11.5\end{array}$ & $\begin{array}{l}10.3 \\
9.5-11.2\end{array}$ & $\begin{array}{l}9.5^{\star} \\
8.3-10.7\end{array}$ & $\begin{array}{l}9.3^{*} \\
8.0-11.2\end{array}$ \\
\hline${ }_{(\mathrm{kPa})}^{\text {Mean }} \mathrm{P}_{\mathrm{cor}}$ & $\begin{array}{l}9.7 \\
8.7-10.4\end{array}$ & $\begin{array}{l}3.3^{\star} \\
3.2-3.5\end{array}$ & $\begin{array}{l}3.3^{*} \\
3.1-3.5\end{array}$ & $\begin{array}{l}3.3^{*} \\
2.8-3.7\end{array}$ \\
\hline$\left(\mathrm{dp}_{\mathrm{a}} \mathrm{x}^{\left.\mathrm{d} \mathrm{s}^{-1}\right)^{\mathrm{tg}}}\right.$ & $\begin{array}{l}229 \\
188-263\end{array}$ & $\begin{array}{l}186^{\star} \\
167-220\end{array}$ & $\begin{array}{l}173^{*} \\
160-220\end{array}$ & $\begin{array}{l}160 * \\
147-220\end{array}$ \\
\hline $\begin{array}{l}\mathrm{p}_{1 \text { ved }} \\
(\mathrm{kPa})\end{array}$ & $\begin{array}{l}0.4 \\
0.3-0.4\end{array}$ & $\begin{array}{l}0.5^{\star} \\
0.4-0.7\end{array}$ & $\begin{array}{l}0.5^{\star} \\
0.4-0.7\end{array}$ & $\begin{array}{l}0.7^{*} \\
0.5-0.8\end{array}$ \\
\hline $\begin{array}{l}\text { Cardiac output } \\
\left(1 . \mathrm{min}^{-1}\right)\end{array}$ & $\begin{array}{l}3.0 \\
2.7-3.6\end{array}$ & $\begin{array}{l}2.9 \\
2.4-3.5\end{array}$ & $\begin{array}{l}2.5 \\
2.2-3.4\end{array}$ & $\begin{array}{l}3.0 \\
1.9-3.8\end{array}$ \\
\hline
\end{tabular}


through early glycogenolysis (see above) is nat likely to occur, because heart muscle does not comtain glucose-6-phosphatase (Stetten, 1964).

The observed potassium release could indicate changes in the function of the sodium-potassium pump or the potassium conductance of the sarcolemma. Rau and Langer (1978) observed that potassium loss during anoxia continues, despite, uncoupling of excitation and contraction or increasing glycolytic energy production. However, no potassium loss occurred when the preparation was electrically quiescent. Because the sodium-potassium pump continued to function until $60 \mathrm{~min}$ of anoxia (Rau et al, 1977), it was concluded that the potassium loss is mainly caused by a higher potassiun conductance. Involvement of a membrane oxygen sensing system (Meduski et al, 1977) has been proposed.

Increased potassium conductance has been related to the origin of arrhythmias (Coraboeuff et a 1, 1976). However, severe arrhythmias did not occur when ischemia was induced in our preparation as well as in that of owen et al (1970) and of Opie et al (1973).

\subsubsection{Relation between cessation of shortening and myocardial bllood flow and metabol ism}

Due to axygen shortage, energy supply for contractile activity will be impaired. After inducement of ischemia as well as anoxia, decreasing contractile activity did not coincide with depletion of energy-rich phosphate stores in the whole myacardial wall or in samples from the outer layers (Braasch et a1, 1968; Gudbjarnason et a1, 1970; Hearse, 1979; Imai et a1, 1979). The present study shows that in the ischemic area cessation of fiber shortening im the inner layers occurs without depletion of energy-rich phosphate stores in these layers.

The absence of a tight relation between ATP content and contractile function is even better 111 ustrated by the finding that during catecholamine-induced stimulation. ATP values decrease to values lower than those during acute ischemia, but wilthout impaiment of contractile function (Kamermeier et al, 1974). Moreover, it is well known that during reperfusion after complete ischemia, mechanical recovery occurs while ATP contents remain depressed (Hearse, 1974).

To explain cessation of contractlle activity despite the presence of energy-rich phosphates, several alternative hypotheses have been proposed, which are summarized in section 2.1 .2 , and will be discussed here in relation to 
the results obtallned in the present study.

Accumulation of NEFA as a possible cause of early mechanical failure as proposed by Katz and Messineo (1981), is not likely. Uptake of MEFA from the blood $\left(0.07 \mu m o l . g^{-1}\right.$.min $\left.{ }^{-1}\right)$ may cause an increase in cellular NEFA concentration of $70 \mathrm{mmol} \cdot \mathrm{g}^{-1}$. Since st.111 $2 \mu \mathrm{mol} \cdot \mathrm{g}^{-1}$ oxygen is taken up and the uptake of glucose has decreased, most of these NEFA will be axidized. The remaining NEFA might well be coupled to free CoA or carnitine. Therefore, it seems likely that cellular NEFA concentrations are hardly affected within I min of ischemia. Moreover, in the next chapter it will be shown that the content of these substances does not increase before $10 \mathrm{~min}$ af ischemila.

Glycogen deplletion has been reported to occur within 4 min of anoxia in isolated hearts. Simultaneously, ATP synthesis and mechanical activity were impalired (Rovetto, 1979). The findings in the present study, however, show that no depletion of glycogen occurs within $5 \mathrm{~min}$ after onset of ischemia and hence glycogen depletion is not likely to be the cause of the early cessation of fiber shortening. These contradictory results may be explained by a higher glycolytic fiux during anoxia (Liedtke, 1981).

The rapid decrease of $\mathrm{pH}$ in local venous blood after anset of stenosis indicates an even more pronounced decrease in cellular pH. A proton induced change in calcium homeostasis has been suggested as a possible trigger for contractile failure. This would be induced by decreased affinity of troponin for calcium at high hydrogen ion concentrations (Katz and Hecht, 1969) or by interference of protons with calcium movements during the action potential (revlewed by Nayler et a 1, 1979). As mentioned in section 2.1.2, an important role of pH in the deterioration of mechanical function is rather unlikely. This is supported by the observation that the decline in pressure development in the anoxic lsolated working rat heart preparation (Hearse, 1979) occurs at a similar time interval as the cessation of shortening after acute coronary artery occlusion (chapter 5), despite the maintained flow and washout of carbon dioxide and protons during anoxia.

Whereas the above mentioned theories bypass the invalvement of energy-rich phosphate breakdown in early contractile failure, several recent theories stress the major role of this process in the inhibition of contraction.

Breakdown of energy-rich phosphates after oxygen deprivation will result in increased cellular concentrations of inorganic phosphate. High cellular inorganic phosphate concentrations were considered to be responsible for the binding of considerable amounts of calcium (Kuebler and Katz, 1977). These 
authors calculated an 8 fold increase in this substance during ischemia. Indeed, the early inorganic phosphate release after onset of stenosis, 11 kely reflects elevated cellular concentrations of this substance. However, as can be calculated from results of the present study the amount of inorganic phosphate liberated from energy-rich phosphates within one min of ischemia is no more than $4 \mu m o l . g^{-1}$ wet weight in the inner layers of the myocardium, which increase would be less than two-fold the normoxic tissue content. Because of the release of this substance into the blood, the actual concentration will even be lower. These findings are comparable to the values found by Imai et al (1979) in the isolated guinea pig heart after 0.5 and 1 min of ischemia and are far below the increase in inorganic phosphate concentration as estimated by Kuebler and Katz (1977; section 2.1.2).

The observed negative AV differences of imorganic phosphate (already after $0.5 \mathrm{~min}$ of stenosis significantiy different from the pre-ischemic value) indicate rapid breakdown of energy-rich phosphates, most likely creatine phosphate. This is consonant with an early decrease in the phosphorylation potential, experimentally shown to occur in the ischemic guinea pig heart within $0.5 \mathrm{~min}$. This decrease was synchronous with the decrease in mechanlcal perfomance (Imai et al, 1979). Similar findings were reported by Kammermejer et al (1981) in the hypoxic isolated rat heart. Moreover, these authors calculated a decreased phosphorylation potential from estimated cytoplasmatic concentrations instead of gross tissue contents. An interesting consequence of this theory is that breakdown of creatine phosphate could directiy impair mechanical function, even in the presence of sufficient ATP.

Approval nor disapproval is obtained in the present study on the pressence of different cellular compartments for ATP as proposed by Gudbjarnason et al $(1970$; section $2 \cdot 1 \cdot 2)$.

\subsubsection{Changes of mechanical activity in various layers of the left ventricu-}

\section{lar wall during ischemia}

Fiber shortening decreases more rapidly in the inner than in the outer layers, as indicated by the earlier decline in $e_{\min }$ as compared to $e_{\max }$. This phenomenon is likely to be melated to the more pronounced decrease of blood flow in the inner layers (68\%), than in the outer layers within one min of coranary artery stenosis. Consistent with this finding is, that after acute coronary artery occlusion $\mathrm{P}_{02}$ in the inner layers decreased at a higher rate and to lower values as compared to the outer layers (Winbury et at, 1979). 
The higher energy demand in the inner layers than in the outer ones, as indicated by the higher axygen uptake in the former layers (Holtz et al,1977; Weiss et al, 1978), might also play a role in the earlier diminishing of fiber shortening in the former layers. The disappearance of lengthening along the fiber direction of the inner layers during ejection after one min of ischemia is probably no improvement of mechanical performance since it is associated with an early increase in segment length at the onset of ejection. This lengthening before ejection, occurring during ischemia, was also found by Edwards et al (1981). Al so the almost immediately increasing stiffness of the ischemic tissue (Theroux et al, 1974, 1977; Edwards et al, 1981) may reduce lengthenting during ejection along the fiber direction in the inner layers.

During the interval between the decrease of $e_{m i n}$ and $e_{\text {max }}$ considerable differences in shortening along the fuber direction are present between inner and outer layers of the left ventricle. One min after onset of ischemia, however, transmural differences in shortening have become relatively smail. Downey (1976) studied the contractile force in the inner and outer layers, using eplcardially mounted strain gauges oriented paraliel to the fiber direction of the inner and outer layers, a set-up which is comparable to the ane used in this study. He also observed relatively small differences between "superficial and deep force". The results from their study and ours provide qualftative indications and thus do not allow conclusions about absolute differences in fiber shortening in the various layers. Using ultrasomic crystals, Weintraub et al (1981) recently showed that during variaus degrees of ischemia the relative decrease in shortening in the inner and outer layers was not significantly different.

The relatively small differences in the changes of shortening are in contrast with the steep gradients in myocardial blood flow and creatine phosphate contents between the warious myocardial layers. After one min of ischemia in the outer layers blood flow had decreased by only $36 \%$ and creatine phosphate content was not significantily affected in contrast to a $64 \%$ decrease in blood flow and halved creatine phosphate stores in the inner layers. A possible explanation for this paradoxal situation might be a redistribution of fiber stress across the wal1. The outer layers may have to bear more stress due to failure of the inner layers. Several arguments may support this hypothesis.

The slower decrease of $e_{\text {max }}$ compared to $e_{m i n}$, shown in this chapter and in 
chapter 5, suggests that after diminishment of shortening in the inner layers, the fibers in the outer layers still try to shorten. After acute coronary artery occlusion (chapter 5), fibers in the outer layers continue to shorten for only several seconds, whereas after stenosis (fig 6.3) this shortening continues for half a minute. This difference may be explained by the higher blood supply to the ischemic area than in the latter situation, enabling the outer layers to persist mechanical function for a longer time.

Recent studies showed that in the inner layers the decrease in shortening is related to the decrease in blood flow, but that such a relationship does not exist in the outer layers. However, the decrease in fiber shortening in the outer layers proved to be related to the decrease in fiber shortening in the inner layers, suggesting that subendocardial ischemia results in a transmural redistribution of mechanical loading and contractile function (Gallagher et a1, 1978; Genain et al, 1979; Weintraub et a1, 1981).

The bearing of compensatory stress by the outer layers is ailso suggested by estimated ATP utilization in the inner and outer layers (table 6.4). Because mechanical activity in the ventricle depends mostiy on stress development of the fibers, and little differences seems to be present between shortening in the inner and outer layers, the difference in estimated energy utilization between these layers suggests, that the contractile mechanism in the inner layers develops less stress due to the pronounced energy shortage. The increased workload thus caused in the outer layers may result in a decrease in fiber shortening in these layers to such an extent that the transmural differences in fiber shortening are not as large as the transmural differences in blood flow or creatine phosphate contents.

\subsection{Conclusions}

- The first measurable effect after inducement of ischemia is a decrease in regional fiber shortening, which occurs within half a minute. Within this short time interval large differences in fiber shortening are present between the various layers, since fiber shortening cessates earlier and more pronounced in the inner layers than in the outer ones.

- Cessation of regional shortening occurs without a decrease in ATP content and with a decrease in creatine phosphate content only in the inner layers. these results indicate, that depletion of energy-rich phophates is not the cause of diminishing local pump function after onset of ischemia. 
- Of the causes of this early contractile fallure mentioned in the literature (section 2.1.2), decrease of the energy provided by hydrolysis of ane mol ATP most adequately explains the results from the present study.

- During ischenta of longer duration than one min, transmural differences in fiber shortening are relatively small despite the higher oxygen delivery in the outer layers than in the inner ones. This observation suggests that during ischemia, the outer layers are impeded to shorten by the inner 1ayers.

- Early lactate release cannot completely be explained by the net uptake of glucose, which might be explained by early glycogen breakdown.

- The rapidly declined mechanical activity in the ischemic area exerts significant effects on general hemodynamic variables. Increased MBF in the non-ischemic area suggests increased mechanical activity in this area to compensate for function loss by the ischemic tissue. 
7. TIME COURSE OF CHANGES IN BLDOD FLOW, LOCAL MECHANICS AND METABOLISM IN MYOCARDIAL TISSUE DURING 120 MIN OF ISCHEMIA WITH SPECIAL REFERENCE TO ACCUMULATION OF NEFA

\subsection{Intraduction}

The content of non-esterified fatty acids (NEFA) in ischemic myocardium was reported to be increased (Weishaar et a1, 1977, 1979; Van der Vusse et al, 1982). Several studies showed that high intracellular or extracellular NEFA concentrations exerted deleterious effects on the activity of several enzymes and on membrane function (reviewed by Katz and Messineo, 1981; Van der Vusse, 1982). If NEFA, accumulated during ischemia, have noxious effects on the oxygen-restricted area, one would expect that this accumulation preceeds the deteriaration of the processes proposed to be affected in this region.

Therefore, it is interesting to compare the time course of this accumulation with that of the content of other lipid classes, glycogen and high energy phosphates as well as the time course of blood flow and fiber shortening in the ischemic myocardium.

Changes in the afore-mentioned variables were determined in the outer, middle and inner layers of the free wall of the left ventricle since reduction of coronary artery blood flow results in marked underperfusion of the inner layers, which might cause transmural differences in myocardial metabolism of the afore-mentioned substances as well as in mechanical perfomance of these layers.

An indication about the contribution of extracellular and intracellular sources to NEFA accumulation was made possible by gaschromatographic determination of the content of the individual fatty acids in the NEFA, triacylglycerol and phosphoglyceride classes in the myocardium as well as the arteriolocal venous (AV) differences of the individual fatty acids of the two first mentioned classes (section 3.7).

\subsection{Experimental design}

\subsubsection{Protocol}

The experiments were performed on 30 mongrel dags which were allotted to 3 
groups, according to the time of myocardial tissue sampling (e.g. 10, 60 and 120 min after onset of ischemia). To assure similar conditions before onset of ischenia, care was taken that between these 3 groups, no differences existed in heart rate, mean aortic pressure $\left(p_{a 0}\right)$ and $d p_{1 v} / d t$ max. Moreover, to obtain a comparable degree of stenosis in the animals of the three relatively small groups, allotting an animal to a certain group occurred so, that after $10 \mathrm{~min}$ of ischemia mean $p_{c o r}$ and the change in $\mathrm{pH}$ and $0_{2}$ saturation in the lacal venous blood were comparable between the groups. These variables were chosen to assess the degree of ischemia because (a) they can be determilied during the experiment, (b) a decrease in local venous pH reflects lactate production by the ischemic myocardium, (c) similar values of mean $p_{\text {a }}$ and $p_{\text {cor }}$ assure a comparable degree of stenosis in the groups. Evaluation of the differences between the 6 afore-mentioned variables in the 3 groups did not reveal any significant difference by applying the Kruskal-Wallis test indicating that the procedure of allocation had been successful.

The protocol of these expertments is shown in fig 7.1. Stenosis was induced at time 0 min by inflation of the occluder cuff until the desired pcor was reached $(3.3 \mathrm{kPa})$. In these experiments, arterial and local vemous blood samples were taken at times $-15,-5,10,20,30,45,60,90$, and $120 \mathrm{~min}$. The continuousiy recorded hemadynamic and regional myocardial mechanical variables as well as cardiac output were also determined at these moments. Radioactive microspheres for determination of regional myocardial blood flow were injected just after times $-15,10,60$, and $120 \mathrm{~min}$. Transmural biopsies were taken from the ischemic (LAICA) and non-ischenic (LCCA) area just after the microsphere injections, 10,60 , or $120 \mathrm{~min}$ after onset of stemosis, depending on the group in which they were perfomed. In all experiments, biopsies were taken for the determination of ATP, creatine phosphate and glycogen. In 5 experiments of each group, al so biopsies were taken for the detemination of fatty acids (section 3.1.6). In these 15 experiments the biopsies for the determination of ATP, creatine phosphate and glycogen were taken just prior to those for fatty acid detemination. Four additional experiments were performed, including microsphere injections and biopsies for fatty acid detemination after $60 \mathrm{~min}$ of ischemia. At the end of the experiments, the dogs were killed by an overdose of pentabarbital.

For the analysis of the NEFA contents in myocardial tissue and the relation between these contents and myocardial blood flow, we also used the data from biopsies, taken in separate experinents after 120 min of normal perfu- 
10 min.stenosis

$(n=10)$

$60 \mathrm{~min}$. stenosis

$(n=10)$
$\substack{120 \min . \text { stenosis } \\(n=10)}$

$(n=10)$
$\substack{120 \min . \text { stenosis } \\(n=10)}$

$(n=10)$
$\substack{120 \min . \text { stenosis } \\(n=10)}$$$
(\ln =10)
$$

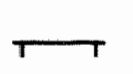

Sample times biochemical mechanical variables

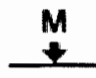

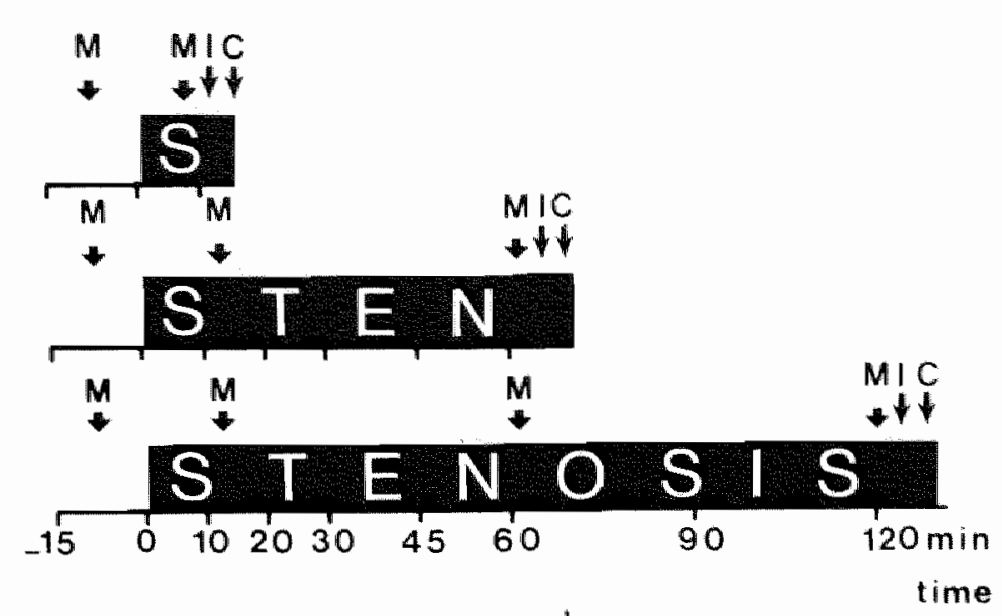

time

$\downarrow$ biopsy ischemic area

$\stackrel{c}{\downarrow}$ biopsy control area

Fig 7.1 Protocol of the experiments.

Table 7.1 Time course of several hemodynamic variables before and during $120 \mathrm{~min}$ of ischemia. Median values and $95 \%$ imits are shown.

\begin{tabular}{|c|c|c|c|c|}
\hline Time (min) & -5 & 10 & 60 & 120 \\
\hline $\begin{array}{l}\text { Heart rate } \\
\text { (b.min }\end{array}$ & $\begin{array}{l}116 \\
85-160\end{array}$ & $\begin{array}{l}130 * \\
95-175\end{array}$ & $\begin{array}{l}124 \\
85-155\end{array}$ & $\begin{array}{l}113 \\
65-150\end{array}$ \\
\hline $\begin{array}{l}\text { Mean aortic } \\
\text { pressure }(\mathrm{kPa})\end{array}$ & $\begin{array}{l}10.8 \\
10.3-11.3\end{array}$ & $\begin{array}{l}10.5 * \\
9.9-11.1\end{array}$ & $\begin{array}{l}10.8 \\
9.7-11.5\end{array}$ & $\begin{array}{l}9.5^{*} * * \\
8.7-10.1\end{array}$ \\
\hline $\begin{array}{l}\text { Mean coronary ar- } \\
\text { ery pressure ( } \mathrm{kPa})\end{array}$ & $\begin{array}{l}10.5 \\
9.9-11.1\end{array}$ & $\begin{array}{l}3.3^{\star} \\
3.2-3.5\end{array}$ & $\begin{array}{l}3.2^{*} \\
2.9-3.5\end{array}$ & $\begin{array}{l}3.2^{\star} \\
2.8-3.6\end{array}$ \\
\hline$p_{1 \text { ved }}(\mathrm{kPa})$ & $\begin{array}{l}0.6 \\
0.4-0.8\end{array}$ & $\begin{array}{l}0.8 * \\
0.7-1.1\end{array}$ & $\begin{array}{l}1.2^{*} \\
0.7-1.5\end{array}$ & $\begin{array}{l}0.7^{*} \\
0.4-1.3\end{array}$ \\
\hline $\begin{array}{l}\mathrm{dp}_{1 \mathrm{v}} / \mathrm{dtmax} \\
\left(\mathrm{kPa} \cdot \mathrm{s}^{-1}\right)\end{array}$ & $\begin{array}{l}206 \\
173-240\end{array}$ & $\begin{array}{l}181 * \\
147-220\end{array}$ & $\begin{array}{l}160^{*} \\
120-190\end{array}$ & $\begin{array}{l}133^{*} \\
93-173\end{array}$ \\
\hline $\begin{array}{l}\text { Cardiac output } \\
\left(1 . \min ^{-1}\right)\end{array}$ & $\begin{array}{l}2.9 \\
2.4-3.4\end{array}$ & $\begin{array}{l}2.6^{\star} \\
2.2-3.2\end{array}$ & $\begin{array}{l}2.5^{*} \\
2.2-2.7\end{array}$ & $\begin{array}{l}2.4^{\star} \\
1.9-2.9\end{array}$ \\
\hline $\begin{array}{l}\text { Stroke vol ume } \\
\text { (mi) }\end{array}$ & $\begin{array}{l}28 \\
22-33\end{array}$ & $\begin{array}{l}23^{*} \\
17-27\end{array}$ & $\begin{array}{l}21^{*} \\
16-24\end{array}$ & $\begin{array}{l}20^{*} \\
17-30\end{array}$ \\
\hline
\end{tabular}


sion (control experiments, $n=5,10$ biopsies from the LAICA area and 10 biopsies from the LCCA) and after $120 \mathrm{~min}$ of stenosis $(n=8,16$ biopsies from the ischentc LAICA area and 16 biopsies from the nomoxic LCCA area). These data have been published recently (Van der Vusse et a1, 1982).

\subsubsection{Data analys is}

Information about the effect of ischemia was obtained by comparison of the data within each animal as well as between groups of animals.

The choice of each dog serving as its own control was made because of the great differences between animals. Influences on hemodynamical, regional mechanical and blood blochemical variables as well as MBF were evaluated by comparing the values at various intervals after onset of ischemia with those at time $-5 \mathrm{~min}$. At each sample time, changes in the content of the various substances within the ischemic myocardium were evaluated by comparing the values of these contents with those of the non-ischemic tissue in the same experiment (validated in chapter 4). These differences were evaluated for statistical significance by applying Wilcoxon's matched-pairs signed-rank test (two-tailed probability).

Differences in tissue contents of the various substances in the LAICA and LCCA area between groups of experiments without stenosis (for fatty acids: data in Van der Vusse et a1, 1982; for ATP, creatine phophate and glycogen: data presented in chapter 4) and including the inducement of stenosis, were evalluated for statistical significance by applying the two-tailed wilcoxon's rank-sum test (aligned ranks).

The data are summarized as median values and $95 \%$ limits. A value of $0<0.05$ was considered to be a significant difference.

\subsection{Results}

7.3.1 Time course of hemodynamic variables during 2 hours of regional ischemila

The effect of acute coronary artery stenosis on these variables is shown in table 7.1. Using the serwa system, post-stenotic coronary artery pressure was kept constant at about $3.3 \mathrm{kPa}$ with less than $0.3 \mathrm{kPa}$ intra-individual variation throughout the experimental period and the same variation between animals.

After onset of stenosis, heart rate increased within 1 min (section 6.3 .6 ) 


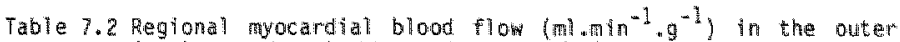
(EPI), middle (UID), and inner (EHDO) layers of the left

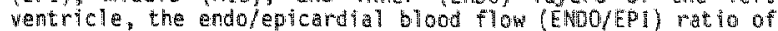
the ischemic and nom-ischemic tissue as well at the mean transmural blood flow of the ischamito tissue before and

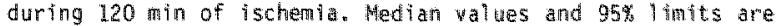
shown.

Time (nim)

Ischentc region EPI

MID

EMDO

ENDO/EPI RATIO

Meam MBF

Non-ischemic regton

EPI

MID

ENDO

ENOO/EPI RATIO

1.17

$1.11-1.25$

0.75

$0.64-0.96$

$0.8 .2 *$

$0.68-1.00$

0.80

$0.48 *$

$0.68-0.92$

$0.75-1.03$

0.85

$0.75-0.96$

0.87

$0.76-0.98$

1.15

$1.05-1.26$

* p<0.05 as compared with time -5 min

** $8 \times 0.05$ as compared with time 10 min
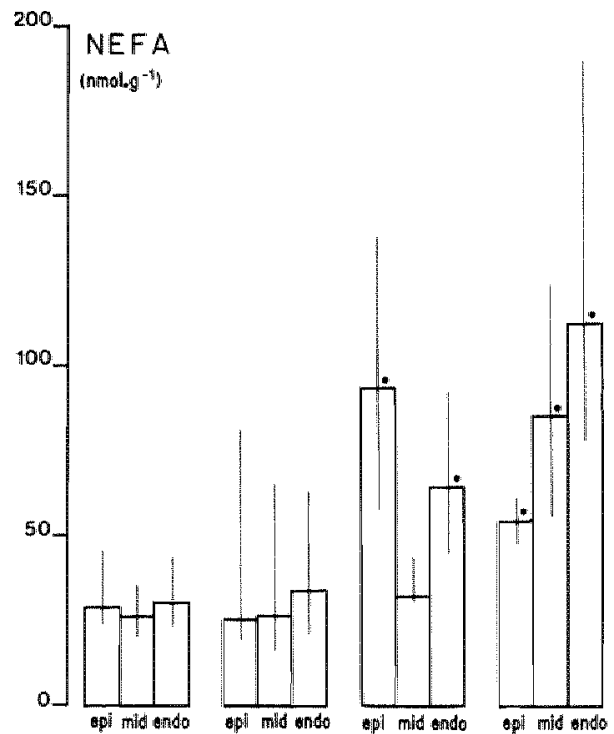

comtrol
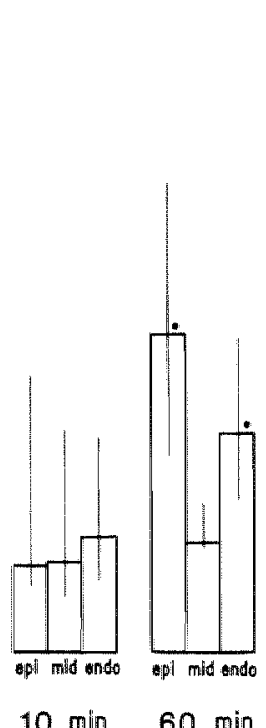

$60 \mathrm{~min} 120 \mathrm{~min}$

\section{0}

$0.34 *$

$0.22 \times 0.41$

0.. $3.5 *$

$0.18-0.59$

$0.19^{*}$

10. $13-0.24$

0.19 .

$0.09-9.30$

$0.13^{\pi}$

$0.10 * * *$

$0.07-0.19$

$0.104-10.18$

$0.34^{\text {th }} * x$

$0.28-0.42$

$0.28 * *$

$0.15 \cdot 0.40$

D. $24^{*}$

$0.17 \times$

$0.12-0.35$

$0.11-0.34$

0.71

0.63

$0.60-0.82$

$0.55-0.98$

1..75

0.68

$0.65-0.84$

$0.48-0.91$

0.75

$0.62-0.89$

0.68

1.15

$1.04-1.23$

1.13

$0.93-1.36$
Fig 7.2

NEFA content in tissue samples from the LAICA perfusion area of animals without inducement of stenosis ("control") and from animals after 10,60 , or $120 \mathrm{~min}$ of ischemia. Shown are the median values and $95 \%$ limits of the outer (epi), middle (mid), and inner layers (endo). * p<0.05 as compared with the control group. 
and remalned constant for 10 min. Thereafter heart rate gradually decreased, reaching preischemic values after $120 \mathrm{~min}$. Mean aortic pressure slightly but significantly decreased simultaneously with the increase in heart rate, and returned to pre-ischemic values after $60 \mathrm{~min}$. During the second hour of ischemia, the median values of mean aortic pressure decreased by $12 \%$ which was statistically signiflcant. The maximal positive first derivative of left ventricular pressure ( $d p_{1 \mathrm{v}} / \mathrm{dtmax}$ ) continued to decrease after the initial fall during the first 5 min of ischemia (section 6.3.6). After 120 min of ischemia, the values of this variable had decreased to $65 \%$ of the preischemic values. End-diastolic left ventricular pressure steadily and significantly increased to 133 and $200 \%$ of the pre-ischemic values at 10 and 60 min of ischemia, respectively, but thereafter tended to return to the preischemic values although no significant difference could be detected between the values at time 60 and $120 \mathrm{~min}(p=0.11)$. The median values of cardiac output during ischemia were approximately $15 \%$ below the pre-ischemic values. Due to the slightly higher heart rates during ischemia, the fall in stroke volume was more pronounced ( $30 \%$ after $120 \mathrm{~min}$ ).

\subsubsection{Time course of regional myocardial blood flow}

The inducement of ischemia caused an inhomogeneous distribution of MBF. In the outer layers MBF decreased by about $60 \%$ after 10 to $120 \mathrm{~min}$. After $10 \mathrm{~min}$ of ischemia, MBF in the inner layers was already reduced by about $80 \%$ and continued to decrease to a reduction of about $87 \%$ after $120 \mathrm{~min}$. The transmural gradient in MBF between the inner and outer layers is expressed in the endo/epicardial blood flow ratio. This ratio decreased from 0.96 at time -15 min to 0.50 after 10 min and 0.28 after 120 min of ischemia (table 7.2).

After 10 min of stenosis, in the non-ischemic area blood flow significant$1 \mathrm{y}$ increased in the outer $(9 \%)$ and middle layers (10\%), but the increase of $2 \%$ in the inner layers did not reach the level of significance (table 7.2). After ischemia of longer duration, blood flow in this area decreased so that the values at time 120 min tended to be lower than those at time $-15 \mathrm{~min}$. In the normoxic area, the transmural distribution of myocardial bload flow did not change during the whole experimental periad (table 7.2).

\subsubsection{Time course of myocardial fatty acid contents during ischemia}

After 10 min of ischemia, NEFA contents in the three studied layers of the ischemic area were not significantly different from those in the three layers 
Fig 7.3 Content of the individual NEFA in myocardial tissue samples from the outer (7.3a) and inner (7.3b) layers of the myocardium in the groups mentioned in fig 7.2. Median values and 95\% Timits are shown.

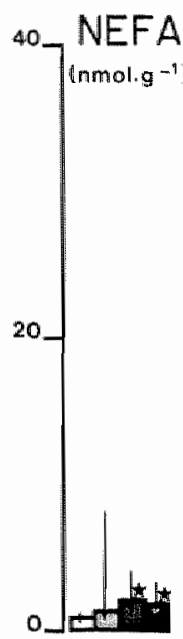

$14: 0$

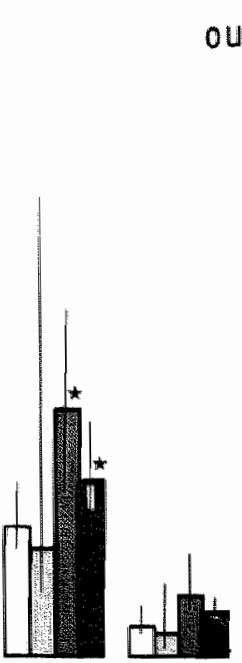

$16: 0$

$16: 1$

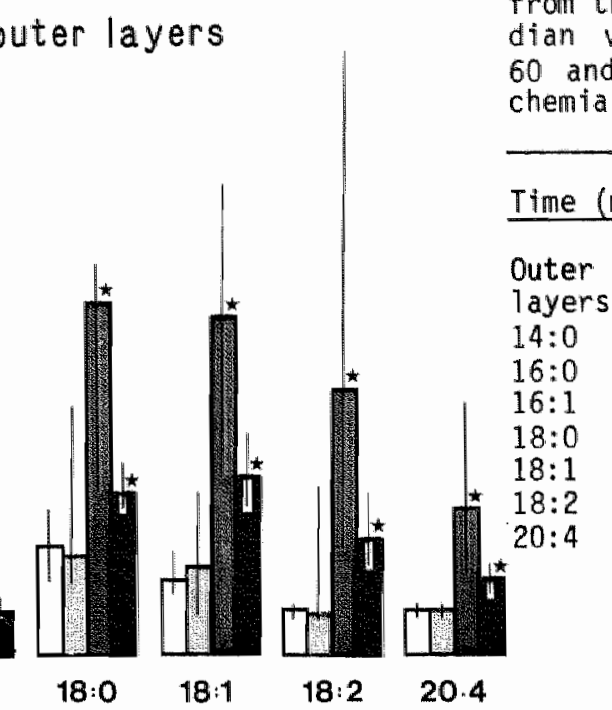

inner layers

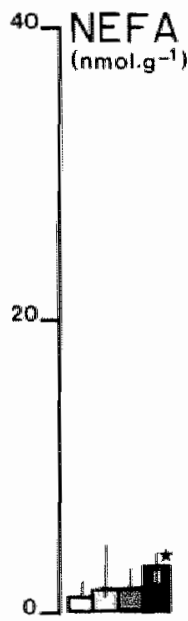

$14: 0$

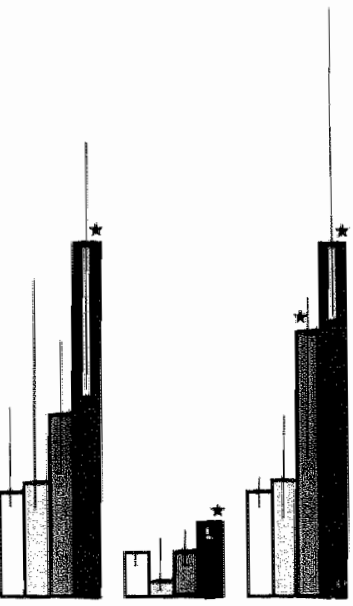

$16: 0$

$16: 1$

18:0

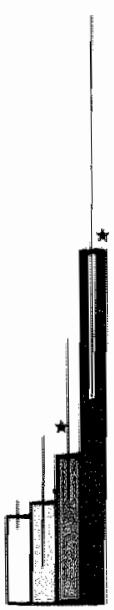

$18: 1$
Inner

layers

$14: 0$

$16: 0$

$16: 1$

$18: 0$

$18: 1$

$18: 2$

$20: 4$

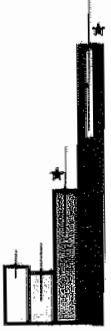

$18: 2$

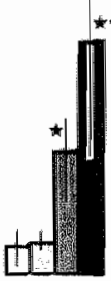

$20: 4$
Table 7.3

Ratio of ischemic content and non-ischemic content of the individual fatty acids in the inner and outer layers of the ischemic myocardium, as calculated from the respective median values after 10 , 60 and $120 \mathrm{~min}$ of is chemia.

Time (min) $10 \quad 60 \quad 120$

Outer

layers

14:0 $\quad 1.5 \quad 1.9 \quad 1.8$

$\begin{array}{llll}16: 0 & 1.0 & 2.3 & 1.6\end{array}$

$0.7 \quad 2.3 \quad 1.6$

$0.9 \quad 3.2 \quad 1.5$

$\begin{array}{lll}1.1 & 4.3 & 2.3\end{array}$

$\begin{array}{lll}0.9 & 5.6 & 2.5\end{array}$

$\begin{array}{lll}1.0 & 3.4 & 1.7\end{array}$ $\begin{array}{lll}1.3 & 1.3 & 2.5\end{array}$

$1.1 \quad 1.8 \quad 3.4$

$0.7 \quad 2.0 \quad 3.6$

$1.2 \quad 2.9 \quad 3.8$

$\begin{array}{lll}1.8 & 2.5 & 5.8\end{array}$

$1.4 \quad 3.5 \quad 7.3$

$\begin{array}{lll}1.1 & 4.2 & 8.1\end{array}$ 
of the non-1schemic LAICA area in the control experiments. However, after 60 and $120 \mathrm{~min}$, these substances accumulated in the ischemic area (fig 7.2). In the outer layers, NEFA contents increased more than 3-fold after 60 min but only 1.6-fold after $120 \mathrm{~min}$ as compared with the aforementioned control values. In contrast to this biphasic time course in the outer layers, the NEFA content in the inner layers increased approximately 2 -fold after 60 min and 4-fold after $120 \mathrm{~min}$ of ischemia. The middle layers of the ischemic myocardium did not show an increased NEFA content after $60 \mathrm{~min}$, but one hour later the NEFA content in these layers was intermediary between the content in the inner and outer layers (fig 7.2).

The individual NEFA content in tissue samples from the normoxic LAICA area in the control experiments and in tissue samples after 10, 60 and 120 min of ischemia, both in the outer and inner layers are shown in fig 7.3. In general, an increase in total NEFA content was caused by higher contents of each individual fatty acid. However, differences existed in the relative increase of these fatty acids (table 7.3, fig 7.3). At the maximum NEFA accumulation in the outer layers (after $60 \mathrm{~min}$ ) relative increases in linoleic and oleic acid were most predominant. The content of all individual NEFA in the inner layers was significantly increased after 60 min of ischemia and gradually increased thereafter. The fatty acids with the highest relative increase after 120 of ischemia were arachidonic and linoleic acid (8.1 and 7.3-fold increase, respectively; fig 7.3, table 7.3). Despite the unchanged total amount of NEFA in the middle layers after 60 min of ischemia, small but significant increases were observed in the arachidonic and linoleic acid content, (1.7 and 1.6-fold increase, respectively). These fatty acids a so showed the highest relative accumulation (4-fold, both) in this layer after $120 \mathrm{~min}$ of Ischemia (data not showm).

Intra-individual comparison of the content of triacylglycerol in the ischemic and non-ischemic area showed lower values in the non-ischemic area (significant after $120 \mathrm{~min}$ in the middle and after 60 and $120 \mathrm{~min}$ in the inner layers; table 7.41. This difference was due to a decreased content of triacylglycerol in the non-ischemic (LCCA) area as was shown by comparing these contents with those from the LCCA area in experiments without inducement of stenosis (data in Van der Vusse et al, 1982). The triacylglycerol content in the ischemic and normoxic LAICA (control group) area were not significantly different (table 7.4).

The values of the phosphoglyceride contents in the ischemic and non-ische- 
Table 7.4 Contents of thacyolycerol and phosphoglyceride (unol: $9^{-1}$ ) in animals without (control, n=10) and with stenosts of the latch durirg $10 \quad(n=10), 60 \quad(n=18)$, and 120 mini $(n=30)$. Median wallues and $95 \%$ limits are shown.

\section{Control}

T排e $(\ln i n)$

Triacylglycerol

ep" LALA

(ischemic)

LCCA

endo LAICA

non-ischertic)

(ischemic)

LCCA

(non-i schemic)

\section{Phosphoglycerldes}

epi LAICA

(1sctienic)

LCC.A

endo LAICA

(non-ischemic)

(ischemlo)

LoCA

(non-isichemic)
14. 1

$5.7-21.1$

11. 11

$6.4-35.0$

5.7

$2.5-9.1$

4.0

$1.8-13.0$
Ischemi a

\begin{tabular}{lll}
\hline \multicolumn{3}{c}{ Ischenia } \\
\hline & 60 & 120 \\
& & \\
6.7 & 10.2 & 7.5 \\
$4.6-12.2$ & $8.4-12.6$ & $5.4-13.7$ \\
8.2 & 11.2 & 10.0 \\
$3.3-31.7$ & $7.7-15.3$ & $3.0-16.3$ \\
9.0 & 8.6 & 5.7 \\
$3.5-15.9$ & $7.4-12.0$ & $4.0-7.2$ \\
3.9 & 3.9 & 2.7 \\
$1.7-9.6$ & $3.1-5.6$ & $2.4-3.9$
\end{tabular}

Table 7.5 Comtents of ATP, creatine phosphate and glycogen ( 1 mol. $g^{-1}$ dry weight) in the LAICA and LCCA perfiusion area in animis without (control, $n=10$ ) and with stenosis of the LAICA during $10 \quad(m=10), 60 \quad(n=10)$, and 120 min $(n=10)$. Median walues and $95 \% 1$ imits are shown.

\section{Control}

Tíne (min)

ATP

epi LAICA.

(ischentic)

LCCA

endo LAICA

(ischemic)

LCCA

(non-ischemic)
30.5

32.3

$33.1-38.0$

35.9

$33.6-38.0$

\begin{tabular}{|c|c|}
\hline$-31,5$ & $\begin{array}{l}29.7 \\
29.3-31.1 \\
28.7 \\
27.5-30.1 \\
28.7 \\
25.8-30.7 \\
29.7 \\
27.1-31.1\end{array}$ \\
\hline \multicolumn{2}{|c|}{$\begin{array}{l}\text { osphate and glycogen (Mmol. } g^{-1} \\
\text { LCcA perfusion area in animals } \\
\text { with stemosis of the LATCA } \\
\text { and } 120 \text { min }(n=10) \text {. Median } \\
\text { wn. }\end{array}$} \\
\hline
\end{tabular}

Ischemia

60

120

10

13

$11-16$

16

$13-22$

$13^{*}$

$10-15$

18

$16-20$

10
$6-16$
18
$11-20$
6
$4-12$
16
$15-20$

$11 *$

$5-15$

20

$0-23$

$5 *$

$3-13$

17

$12-23$

\section{Creatine phosphate}

epi LMICA

(1) schem 10 )

LCCA

(non-1schemlc)

endo LAICA

(1'scherpitic)

LCCA

(non-ischemic

41
$26-54$
48
$26-61$
37
$29-53$
39
$25-51$

$20 *$
$10-30$
32
$23-67$
$16 * 0$
$10-35$
38
$20-59$

$15 *$

$10-22$

45

$27-53$

11 *ै

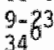

$22-43$

29*

$12-36$

41

$26-53$

$18 \% 0$

$12-22$

4.1

$31-48$

\section{Glycogen}

$\begin{array}{lllll}\text { epi LICA } & 170 & 180 & 90 * & 100 * \\ \text { (ischemic) } & 105-205 & 45-160 & 70-145 & 60-165 \\ \text { LCCA } & 165 & 140 & 150 & 160 \\ \text { (non-ischemic } & 145-225 & 110-190 & 130-220 & 125-215 \\ \text { endo LACA } & 150 & 100 * 0 & 80^{*} 0 & 60^{*} 0 \\ \text { (1SChemic) } & 130-180 & 45-165 & 40-170 & 35-120 \\ \text { LCCA } & 165 & 150 & 145 & 160 \\ \text { (non-1schemic) } & 145-190 & 75-180 & 125-230 & 130-205\end{array}$

* pe0.05 as compared with the content in the LCCA (nom-1schemic) area.

a $p<0.05$ as compared with the outer llayers of the sane area. 
mic area of the same heart after 10,60 and $120 \mathrm{~min}$ after onset of stenosis were lower than the values obtained during experiments without inducement of stenosis (table 7.4). The phosphoglyceride content in the nomoxic myocardium (both areas in the control experiments and the LCCA area in the experiments where ischemia was induced) was higher in the inner than in the outer layers. In the ischemic myocardium, however, phosphoglyceride content was lower in the inner than in the outer layers (significant after $120 \mathrm{~min}$ of ischemia; table 7.4 ).

\subsubsection{Time course of myocardial content of ATP, creatine phosphate and} glycogen during ischemila

In the ischeric area ATP content was significantly decreased in the middle and inner layers of the ischemic area as compared to the non-ischemic area after $10 \mathrm{~min}$ of 1 schemia, and subsequently decreased further in all layers onto $120 \mathrm{~min}$ of ischemta. After 10,60 , and $120 \mathrm{~min}$ of ischemia, ATP content tended to be lower in the inner than in the outer layers, but this difference was not statistically significant (table 7.5).

After the rapid decline in creatine phosphate contents during the first 5 min of ischemia (chapter 6), these contents further decreased to approximate$1 y 30 \%$ of the values in the non-ischemic area (table 7.5). However, in the second hour after the onset of stenosis the creatine phosphate content significantly increased in all three layers. At all sample times, the contents in the inner layers of the ischemic area were significantly lower than those in the outer layers $(\mathrm{tab} 7 \mathrm{e} 7.5)$.

In the inner and middle layers no significant decrease in glycogen content was found before $10 \mathrm{~min}$ of ischemia and in the outer layers not before 60 min of ischemia (chapter 6, table 7.5). The values in the inner layers were significantly lower than those in the outer layers at 10 and 120 min, but not at $60 \mathrm{~min}$. After $120 \mathrm{~min}$ of ischemia, glycogen content had decreased to $63 \%$ (outer layers) and $38 \%$ (inner layers) of the values in the non-ischemic area (table 7.5 ).

\subsubsection{Time course of biochemical variables in the blood}

The arterial concentrations of glucose, lactate, inorganic phosphate and oxygen content did not significantly change during the experimental period. The arterial MEFA concentration was temporarily increased after 10 min and the arterial potassium concentration showed an increase of $14 \%$ after 60 and 
Table 7.6 Arterial concentrations (mM), AV differences (mM) and net uptake ( $\mu$ mol. $\mathrm{g}^{-1} \cdot \mathrm{min}^{-1}$ ) of oxygen, substrates, inorganic phosphate and potassium before and during $120 \mathrm{~min}$ of ischemia. Median values and $95 \%$ limits are shown.

$\frac{\text { Time (min) }}{\text { Oxygen }}$

$\frac{-5}{7.4}$

AV diff.

$6.8-7.9$

Uptake

$$
4.7
$$

$4.1-5.5$

3.4

$2.8-4.5$ 10

7.5

$7.1-7.9$

$5.9 *$

4.9-6.5

$1.3^{*}$

$0.9-1.7$
60

7.4

6.4-7.9

$5.5 *$

$4.7-6.6$

1. 3*

$0.9-1.6$
120

7.7

$5.9-8.8$

$5.8^{*}$

$3.9-6.8$

1. 1 *

$0.5-2.0$

\section{Glucose}

Arterial

5.9

5. 5-6.1

AV diff.

0.1

6.0

5. 5-6.5

5.8

0.7 *

5.3-6.5

6.1

$(-0.2)-0.3$

$0.0-1.2$

1.1 *

4. 4-8.4

1. 1 *

Uptake

$$
(-0.1)-0.2
$$

$0.2^{*}$

$0.6-1.7$

$0.0-0.4$

$0.3^{*}$

$0.5-3.2$

0.2

$0.1-0.7$

\section{Lactate}

Arterial

1.7

$1.3-1.8$

AV diff.

0.49

$0.1-0.3$

1.7

$-1.67^{*}$

$(-2.81)-(-0.67)$

$-0.37 *$

$(-0.58)-(-0.16)$
1.7

$1.3-2.0$

$-1.07^{*}$

$(-1.74)-(-0.49)$

$-0.25 *$

$(-0.39)-(-0.15)$
1.5

$0.9-2.3$ $-0.63^{*}$

$(-0.96)-0.23$ $-0.09 *$

$(-0.23)-0.11$

NEFA

\begin{tabular}{lllll} 
Arterial & 0.24 & $0.30^{\star}$ & 0.28 & 0.25 \\
& $0.16-0.30$ & $0.21-0.47$ & $0.21-0.40$ & $0.09-0.53$ \\
AV diff. & 0.11 & $0.17^{\star}$ & 0.16 & 0.08 \\
\multirow{3}{*}{ Uptake } & $0.04-0.19$ & $0.04-0.28$ & $0.05-0.29$ & $0.05-0.24$ \\
& 0.09 & $0.04^{\star}$ & $0.04^{*}$ & $0.03^{\star}$ \\
& $0.02-0.12$ & $0.00-0.07$ & $0.02-0.06$ & $0.01-0.06$
\end{tabular}

Inorganic phosphate

Arterial 1.73

$1.62-2.01$

1.79

1.85

$1.75-2.10$

$1.67-1.98$

1.91 $-0.69 *$ $-0.13^{*}$

$1.74-2.22$

AV diff. $\quad-0.03$

$(-0.47)-(-1.08)$

$(-0.09)-0.00$

Uptake

$-0.03$

$-0.16^{*}$

$(-0.24)-(-0.04)$

$-0.10$

$(-0.24)-0.00$ $-0.03$ $-0.03$

$(-0.23)-(-0.08)$

$(-0.04)-(-0.01)$

$(-0.06)-0.00$

$\begin{array}{cl}\text { Potassium } & \\ \text { Arterial } & 3.70 \\ & 3.55-3.90 \\ \text { AV diff. } & -0.01 \\ & (-0.18)-0.17 \\ \text { Uptake } & -0.01 \\ & (-0.16)-0.10\end{array}$

$3.95^{*}$

$3.70-4.15$

$-1.06^{*}$

$(-1.65)-(-0.45)$

$-0.22 *$

$(-0.31)-(-0.13)$
$4.25 *$

$3.90-4.50$

$-0.14$

$(-0.40)-0.15$

$-0.03$

$(-0.04)-(-0.02)$
4. 20 *

$3.75-5.00$

$-0.15$

$(-0.45)-0.55$

$-0.03$

$(-0.07)-0.06$ 
120 min as compared to time -15 min (table 7.6 ).

Inducement of ischemia reduced oxygen uptake (calculated by multiplying the arterio-jocal venous (AV) differences and mean blood flow in the ischemic area; section 3.7$)$ by approximately $65 \%$ as compared to the pre-ischemic situation (table 7.6). The AV differences of glucose increased 15-fold, causing a 4.5-5 fold increase in net glucose uptake after 10 to 120 min of ischemia. Lactate was released during ischenia in a biphasic pattern (table 7.6). Net release of lactate was maximal at $10 \mathrm{~min}$ after onset of ischemia. Thereafter, this release gradually diminished but remained present in the majority of the experiments after $120 \mathrm{~min}$ of stenosis (table 7.6). Although the AV differences of NEFA increased, net uptake of these substances decreased by $45 \%$ (after 10 and $60 \mathrm{~min}$ ) and $65 \%$ (after $120 \mathrm{~min}$ ) as compared with the pre-fschemic values (table 7.6). During ischemia, the AV differences for triacylglycerol were not significantly different from those during normoxia (data not shown). In the first $10 \mathrm{~min}$ of the ischemic period, the release of inorganic phosphate and potassium paralleled that of lactate (chapter 6) but at 60 and $120 \mathrm{~min}$ the release of the former two substances was not significantly different from the pre-ischemic walues (table 7.6).

\subsubsection{Time course of regitonal mechanical variables}

As shown in chapter 6 , regional shortening in the ischemic area ceased within the first minute after coronary artery stenosis. Before time 10 min, circumferential $\left(e_{c}\right)$ and base-to-apex $\left(e_{z}\right)$ were already close to zero and the values of these variables did not change significantiy during the remaining experimental period (tabie 7.7). Ischenic values of $\gamma$ were about half the normoxic values and were approximately constant between 10 and 120 min after the onset of stenosis.

In chapter 5, it has been shown that information about differences in shortening between the inner and outer layers of the myocardial wall can be obtained from epicardial minimal ( $e_{m i n}$ ) and maximal shortening ( $e_{\max }$ ) as calculated from $\mathrm{e}_{\mathrm{c}}, \mathrm{e}_{\mathrm{z}}$, and $\gamma$ (section 3.3.2), because the orientation of $e_{\text {min }}$ and $e_{\text {max }}$ approximates the fiber directions in the inner and outer layers, respectively. Both calculated variables decreased substantially within 1 min of ischemia (chapter 6) but only slightly thereafter. The negative values of $e_{m i n}$ indicate lengthening during the ejection phase in the direction of the fibers in the inner layers. This lengthening tended to increase during the experimental period but this increase was not significant. The small 
Table 7.7 Regional shortening, shear and segment length before and during 120 min of stenosis. Median values and $95 \%$ limits are shown.

\begin{tabular}{|c|c|c|c|c|}
\hline Time $(\min )$ & -5 & 10 & 60 & 120 \\
\hline $\begin{array}{l}\text { Circumferential } \\
\text { shortening }(\%)\end{array}$ & $\begin{array}{l}5.2 \\
3.9-7.3\end{array}$ & $\begin{array}{l}0.2^{\star} \\
(-0.3)-0.6\end{array}$ & $\begin{array}{l}0.2^{*} \\
(-0.6)-0.3\end{array}$ & $\begin{array}{l}0.0 \\
(-1.1)-0.0\end{array}$ \\
\hline $\begin{array}{l}\text { Base-to-apex } \\
\text { shortening }(\%)\end{array}$ & $\begin{array}{l}4.8 \\
2.4-6.0\end{array}$ & $\begin{array}{l}0.4^{*} \\
(-0.6)-1.0\end{array}$ & $\begin{array}{l}-0.4^{\star} \\
(-0.5)-0.0\end{array}$ & $\begin{array}{l}-0.8 \\
(-1.7)-0.0\end{array}$ \\
\hline $\begin{array}{l}\text { Shear angle } \\
\text { (rad) }\end{array}$ & $\begin{array}{l}0.06 \\
0.04-0.08\end{array}$ & $\begin{array}{l}0.03^{*} \\
0.01-0.05\end{array}$ & $\begin{array}{l}0.02^{*} * * \\
0.01-0.02\end{array}$ & $\begin{array}{l}0.03^{*} \\
(-0.01)-0.07\end{array}$ \\
\hline $\begin{array}{l}\text { Minimal shor- } \\
\text { tening }(\%)\end{array}$ & $\begin{array}{l}3.7 \\
1.7-4.9\end{array}$ & $\begin{array}{l}-0.6^{*} \\
(-1.1)-0\end{array}$ & $\begin{array}{l}-0.6^{\star} \\
(-0.9)-(-0.3)\end{array}$ & $\begin{array}{l}-1.2^{*} \\
(-0.2)-(-0.7)\end{array}$ \\
\hline $\begin{array}{l}\text { Maximal shor- } \\
\text { tening }(\%)\end{array}$ & $\begin{array}{l}6.5 \\
5.3-8.0\end{array}$ & $\begin{array}{l}0.9 * \\
0-2.5\end{array}$ & $\begin{array}{l}0.1 * \star * \\
(-0.2)-0.3\end{array}$ & $\begin{array}{l}0.0 * * * \\
(-1.1)-1.5\end{array}$ \\
\hline $\begin{array}{l}\text { Begin ejection } \\
\text { base-to-apex } \\
\text { segment length }(\%)\end{array}$ & $\begin{array}{c}100.0 \\
-\end{array}$ & $\begin{array}{l}108.3^{*} \\
105.0-112.0\end{array}$ & $\begin{array}{l}110.1^{*} \\
106.1-111.9\end{array}$ & $\begin{array}{l}110.6^{*} \\
101.0-115.2\end{array}$ \\
\hline $\begin{array}{l}\text { Begin ejection } \\
\text { circumferential } \\
\text { segment length }(\%)\end{array}$ & 100.0 & $\begin{array}{l}109.5^{\star} \\
106.0-114.8\end{array}$ & $\begin{array}{l}109.8^{\star} \\
106.0-113.8\end{array}$ & $\begin{array}{l}111.8 \\
85.5-115.1\end{array}$ \\
\hline
\end{tabular}

* $p<0.05$ as compared with $t=-5 \mathrm{~min}$

* $p<0.05$ as compared with $t=10$ min 
positive median value of $e_{\text {max }}$ indicating the presence of residual shortening approximately along the epicardial fiber direction, after 10 min of ischemia disappeared in the course of the experimental period (p<0.05) (tab7e 7.7).

At the onset of the ejection phase the distance between the coils had increased by about $10 \%$ between 10 and 120 min of ischemia as compared with the control stituation, in both circumferential and base-to-apex direction.

7.3.7 The relation between MEFA content and the blood flow and ATP content in myocardial tissue

In fig 7.4 NEFA content and MBF after 120 min of ischemla are plotted against each other. In the ischemic area no increase in NEFA content was abserved in samples, which blood flow in their vicinity was more than 0.3 ml $\cdot \mathrm{min}^{-1} \cdot \mathrm{g}^{-1}$ (which are mainly samples from the outer layers). Samples with a blood flow below this value almost invariably show an increase in NEFA content. Extreme increases in NEFA content (up to 20 times the normoxic values) are predominantly obserwed in samples where blood flow is below $0.1 \mathrm{~m}^{-\mathrm{min}^{-1}}$ $\cdot g^{-1}$.

After 60 min of ischemia, high NEFA contents did not coincide with low ATP contents in the outer and middle layers, but high NEFA contents were associated with low ATP contents in the inner layers (data not shown). The relation between ATP and NEFA content after $120 \mathrm{~min}$ of ischemia in all three myocardial layers is shown in fig 7.5. Increased MEFA contents were present at ATP contents below $10 \mu$ mol. $\mathrm{g}^{-1}$ dry weight.

\subsection{Discussion}

\subsubsection{Effect of 1 schemia on global and regional myocardial function}

Stenosis of the LAICA caused ischemia in its perfusion area. This is indicated by the decrease in myocardial blood flow (MBF) and oxygen cansumption in this area as well as by the release of lactate, inorganic phosphate and potassium from the affected myocardium. Release of lactate indicates anaerobic glycolysis (w117iamson, 1966). Inorganic phosphate release is associated with breakdown of energy-rich phosphates (Opie et a1, 1972). Potassium release is ascribed to disturbances of ion exchange across the cell membrane due to energy shortage (Owen et al, 1970).

The early loss of mechanical function of the ischemic area (chapter 6) leads to significant changes in general hemodynamic variables such as heart 

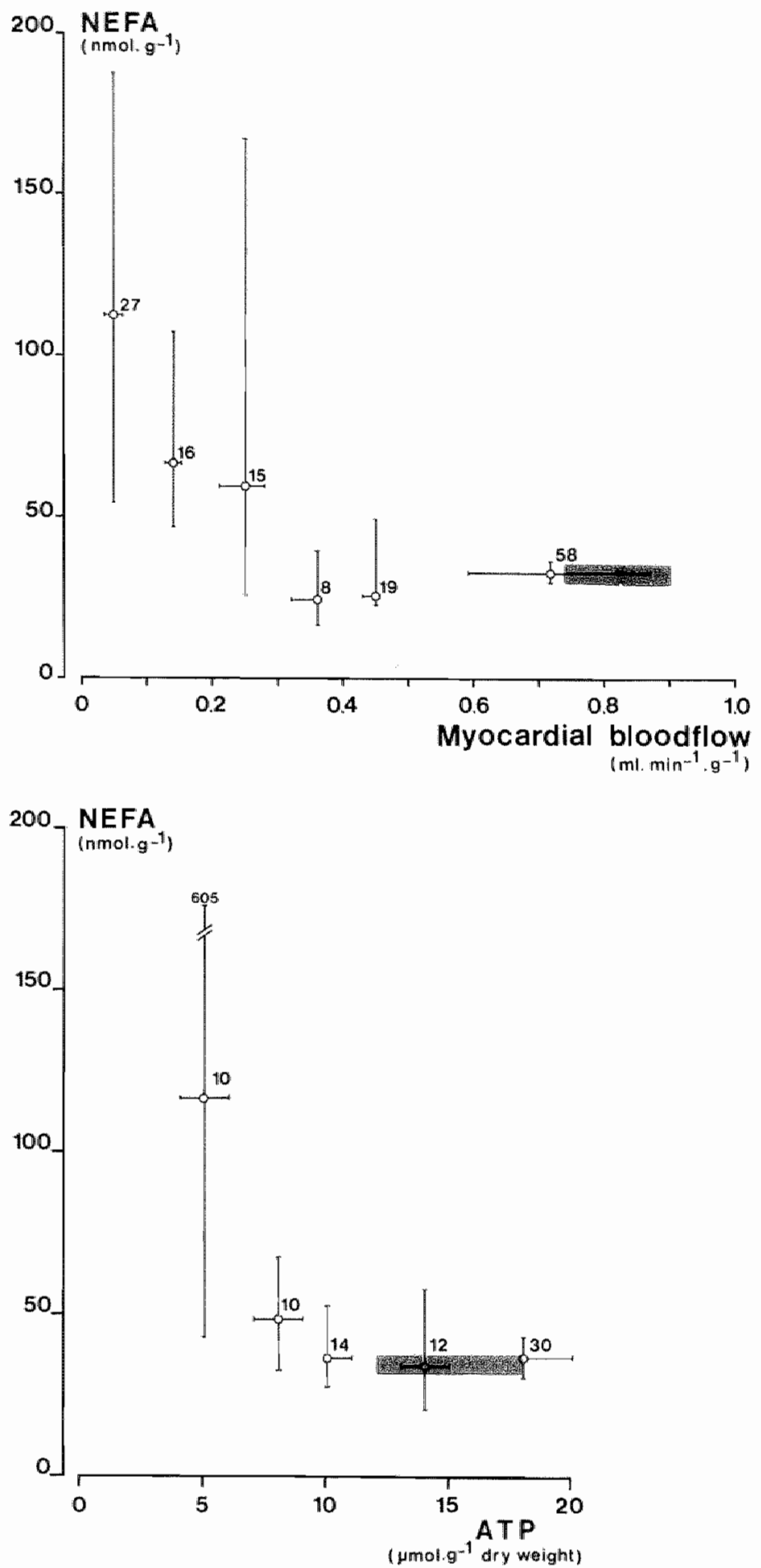

Fig 7.4

Relation beween the content of NEFA and myocardial blood flow (MBF) in samples from ischemic and non-ischemic nyocardium af ter 120 min of stenosis of the LAICA. MBF was determined in tissue from the direct vicinity of the site where samples for the determination of NEFA content were taken. Median values and $95 \%$ limits of all three myocardial layers are shown, while the figures deptct the number of observations. The shaded area shows the $95 \%$ limits of the data from all non-ischemic samples.
Fig 7.5

Relation between the contents of NEFA and ATP in separate biopsies taken from is chemic and non-ischemic myocardium after 120 min of stenosis of the LAICA. For explanation of the symbols, see fig. 7.4 . 
rate, mean aortic pressure, $d p_{1} / d t$ max, $p$ lved, and cardiac output. A more pronounced deterforation of glabal hemodymamics may have been prevented by the compensatory increase in heart rate and thus in mechanical function of the non-ischemic myocardium. This is indicated by a transient increase in MBF found between 1 and 10 min after onset of ischemia (see allso section 6). The increased non-ischemic MBF is in agreement with findings of Driscoll and Eckstein (1967) and Redding and Rees (1968), but not with the data presented by Marcus et al (1976). Alsa, the decreased triacylglycerol content in the non-ischemic area points towards an increased need for more combustible substrates for energy production (Crass et al, 1971; Van der Vusse et a1, 1982).

During the last hour of the experimental period, mean aortic pressure decreased. It is unlikely that these hemodynamic changes are caused by ischemia since the same phenomenon is observed in the experiments with two hours of normal perfusion. This decrease in aortic pressure is ascribed to the anesthesia used in the present study.

This decrease in aortic pressure is associated with a decrease in $\mathrm{dp}_{1} \mathrm{w}^{1-}$ dtmax and stroke volume indicating decreases in preload, afterload and stroke work. A lower energy demand of the left ventricle due to these changes is al so suggested by the tendency of myocardial blood flow to decrease in the non-ischemic area at $120 \mathrm{~min}$ as compared with the previous sample times (table 7.2), which was also observed in the control experiments (chapter 4). Since blood flow in the ischemic myocardium hardly changed between 10 and 120 min this could imply that oxygen shortage in the ischemic area after $120 \mathrm{~min}$ is less than after 60 min of stenosis, possibly exerting effects on metabo1 ism in the ischemic nyocardium (section 7.4.3).

The relatively small changes in regional shortening between 10 and $120 \mathrm{~min}$ of ischemia is in agreement with data obtained in the baboon (Crozatier et a1, 1978). Assessment of shortening in directions, close to the fibers in the Inner and outer layers, shows that between 10 and $120 \mathrm{~min}$ shortening decreases slightly more pronounced in the outer than in the inner layers. This suggests that during this phase of ischemia, transmural differences in shortening gradually decrease while the transmural gradients im energy rich phosphate and glycogen contents remain unchanged (section 7.4.3) and the transmural blood flow gradient becomes even steeper (section 7.4.2).

\subsubsection{Effect of ischemia on myocardial blood flow}

Stenosis of the LAICA induced a fall in perfusion pressure and blood flow 
in its perfusion area. The virtually unchanged mean transmural blood flow in the ischemic area during the first 2 hours is in contrast to the findings of ather investigators studying the effect of coronary artery occlusion in the dog (Redding and Rees, 1968; Marcus et al, 1976). These investigators found a significant increase in MBF in the ischemic area, caused by early collateral development. These different observations might be caused by differences in collateral development after occlusion or stenosis. An alternative possibili$t y$ is that the developed collateral flow is not noticed in our set-up since we do keep the perfusion pressure constant.

The relative underperfusion of the inner layers of the ischemic nyocardium is caused by the higher intramyocardial pressure in these layers as compared to the outer layers (Arts et a1, 1979; Hoffman, 1979). Despite the unchanged mean transmural blood flow, a steady decrease in endo/epicardial flow ratio during the experimental period was found. This is consonant with findings of other investigators that the early increase in ischemic blood flow (see above) is mainiy in the outer layers (Hirzel et a1, 1976; Marcus et a 1, 1976; Rivas et a1, 1976; Capurro et a1, 1979). The distribution of myocardial blood flow away from the inner layers is in agreement with the theory that during ischemia blood flow is redistributed from the necrotic inner to the surviving outer layers (Hirzel et a1, 1976).

\subsubsection{Effect of ischemia on muocardial metabolism}

The Targe AV differences of glucose and the hardly affected AV differences of NEFA during ischemia are in agreement with findings of other investigators (Opie et al, 1973). The greater role of glucose catabolism during ischemia as compared to nomoxia is shown by the increase in net uptake of glucose (present study) and by the increase in glucose oxidation rellative to that of NEFA (Opie et al, 1973).

From the present results it is not clear, whether transmural differences in glucose uptake exist, since the contribution of each myacardial layer to the measured AV differences is not known. Glycogenolysis is mostiy enhanced in the inner layers. This may be explained by a higher phosphorylase activity in the inner than in the outer layers because concentrations of AMP, inorganic phosphate and glucose-6-phosphate are higher in the former layers (Ople et al, 1976; Higuchi et al, 1981). A higher phosphorylase a and b activity in the inner than in the outer layers has been measured by Ichihara and Abiko (1975). 
Metabolic improvements occurring between 10 and 120 min of ischemia are suggested by the increased creatine phosphate contents and the decreased net release of lactate, potassium and inorganic phosphate. This might be caused by the anesthesia-fnduced decrease in left ventricular inotropy (section 7.4.1). However, 30 min after coronary artery occlusion increasing creatine phosphate contents have been reported by Ichihara and Abiko (1975), and opie et al (1973) showed that the release of the three above-mentioned substances decreased betweem 10 and $120 \mathrm{~min}$ after occlusion. A decreased energy demand due to diminisched mechanical function is not likely since shortening in the ischenic area hardly changed between 10 and $120 \mathrm{~min}$ of ischemia. A cause of this apparent metabolic improvement might be redistribution of blood flow within the ischemic area. Tissue damage has been shown to be widelly heterogeneous within the ischemic tissue: damaged and reasonably preserved cells are present in close proximity of one another (Schaper et all, 1979; Vasdew et a1. 1980; Van der Vusse and Frederik, unpublished results). Redistribution of blood flow to the surviving cells might improve the metabolic situation of these cells, because initially all cells competed for the same reduced oxygen supply.

Between 10 and $120 \mathrm{~min}$ of ischemia, metabolism in the inner layers is more affected than in the auter layers, as shown by the lower contents of creatine phosphate and glycogen in the inner layers. This is in agreenent with the findings of Griggs et al (1972), Opie et all (1975), opie and Owen (1976), and Higuchi et al (1981). The absence of a significant transmural gradient in ATP content is in agreement with the findings of Griggs et al (1972) after a relatively short period of ischemia and with those of Higuchi et al (1981) who observed relatively moderate transmural differences in ATP content only after $15 \mathrm{~min}$ of severe, but not after $15 \mathrm{~min}$ of mild ischemia.

\subsubsection{Effect of Ischemia on myocardial content of fatty acids}

As previously mentioned (Van der Vusse et al, 1981b, 1982) the myocardial NEFA content during normoxia and ischemia as found in our laboratories are much lower than those reported by others (Weglicki et al, 1973; Haider et al, 1977; Welshaar et al, 1977 and 1979; Andrieu et a1, 1979, 1980). These differences are likely due to differences in the assay method of NEFA (Christie, 1973; Kramer and Hulan, 1978; Van der Vusse et al, 1980). Evidence is present that values of tissue NEFA concentrations as found in the present study are the closest approximation to the actual myocardial content (Van der Vusse et 
al, 1981b, 1982) which is supported by data of Hunneman et al (1981). who recently reported similar low walues of NEFA in the normoxic dog heart.

In the present study it is shown that tissue contents of NEFA are not increased after $10 \mathrm{~min}$ of ischemia. However, significant accumulation of NEFA is abserved after 60 and $120 \mathrm{~min}$ of ischemia. NEFA accumulation shows remarkable differences between the various layers with respect to time course, composition and amount of accumulated NEFA, and the relation with ATP content. This suggests that the accumulated NEFA in the various layers are derived from different sources.

While NEFA content in the inner layers increase with prolongation af ischemia, NEFA accumulation in the outer layers exhibit a maximum increase after 60 min of ischemia (fig 7.2). The accumulation of the varlous individual fatty acids are different in these two layers (fig 7.3).

In all layers initially no evident relation existed between ATP and NEFA. contents, whereas this was clear in the inner layers after 60 min and in all layers after $120 \mathrm{~min}$ of ischemia. At the latter time intervall. NEFA contents proved to be increased at ATP contents below $10 \mu \mathrm{mol} . \mathrm{g}^{-1}$ dry weight. These findings are interesting, since Hearse and Stewart (1974) showed that mechanical recovery after global ischemia was impaired at similar ATP contents. ATP contents below $5 \mu$ mol. $g^{-1}$ dry weight appeared to be related to impaired wolume regulation and resynthesis of ATP after reoxygenation (Reimer et al, 1981).

In the present study, the median values of triacylglycerol content in the outer ischemic layers were lower as compared with the content in the normoxic LAICA perfusion area but this difference did not reach the level of significance (table 7.4). Possible changes may be masked by the large variation in triacylglycerol contents in the outer layers (even within one animal).

\subsubsection{Possible sources of NEFA accumulation in the outer layers after $60 \mathrm{~min}$ of ischemia}

In the outer layers, individual fatty acids with the highest relative increase after 60 min of ischemia are oleic and linoleic acid. Potential sources of these fatty acids are NEFA and triacylglycerol in the blood and triacylglycerol and phosphoglycerides in tissue, which are rich in these substances. The following mechanisms may be involved in the accumulation of NEFA in the outer layers. 
- During ischemia, the arterio-10cal wenous differences of NEFA across the affected area remain positive, indicating that uptake of NEFA continues to occur. Since fatty acid oxidation is impaired under ischemic conditions (Ople et al, 1973; Liedtke et al, 1978; Shug et al, 1978), part of the MEFA extracted from the blood, with oleic acid as predominant fatty acid (Roth1 in and Bing, 1961; Van der Vusse et a1, 1982), might be responsible for the accumulated NEFA. Because of the measured inhomogeneities in ischemic myocardial blood flow, the uptake of substrates across the ischemic tissue might vary from layer to layer. Although the higher blood flow in the outer than in the finner layers might indicate that the AV differences predominantly reflect metabolism in the outer layers, we cannot definitely conclude whether the observed extraction and tissue accumulation of NEFA occurs in the same layer or cells of the tissue where NEFA content is increased.

- Uptake of triacylglycerol from the blood has been found to be not statistically significant and thus would not contribute to the accumulation of NEFA. However, even am uptake of this substance within the measuring error $(2 \%)$ of the arterio-1ocal venous differences throughout the ischemic period could be responsible for the measured increased NEFA contents in the subepicardium.

- Lipolyis of phosphoglycerides may not be excluded, since significant accumulation of arachidonic acid is abserved and phosphoglycerides are rich in this substance (Van der Vusse et al, 1982).

- The accumulation might also be due to lipolysis of myocardial triacylglyceral. The effect of triacylglycerol lipolysis should be reflected in decreased contents of triacylglycerol. The measured MEFA accumulation, however, results from less than $1 \% 1$ ipolysis of the total amount of triacylglycerol so that this mechanism can be easily missed. Under ischemic conditions, lipolys is is indicated by the dilution of ${ }^{14} \mathrm{C}$-labeled palmitate in local venous blood with cold NEFA (Opie et al, 1973) and the glycerol release from the ischemic myocardium (Vik-Mo et a1, 1979). Moreover, Jesmok et al (1978) showed that $30 \mathrm{~min}$ after coronary artery occlusion triacylglycerol content had decreased in the outer layers. It should be mentioned that it is not known whether this lipolysis occurs in myocytes or in the eplcardial fat.

Dne should realize that the relative increase of the individual fatty acids. does not correspond completely with one of the above-mentioned sources. 
Therefore, several processes may be involwed contenporarily.

Lipolysis during ischemia is thought to be caused by release of endogenous catecholamines under ischemic conditions (Wollenberger and Shahab, 1967; Hough and Gevers, 1975). Indeed, Jesmok and coworkers (1978) showed that the early Iipolysis could be blocked with a heart-specific beta-receptor blocking agent.

After $60 \mathrm{~min}$ of ischemia, lipolys is of triaglycerol dominates synthes is of this substance to a larger extent in the outer layers, than in the imner ones, as suggested by the lower NEFA contents in the latter layers. This is in agreement with the rather increased than decreased triacylglycerol content. in the inner layers in the study of Jesmok et al (1978). The more severe degree of ischemia in the inner layers causes, among others, high glycerol-3phosphate concentrations. High concentrations of this substance may promote incorporation of NEFA into triacylglycerol (Neely and Morgan, 1974; Opie, $1976)$.

\subsubsection{Possible sources of NEFA accumulation in the inner layers}

In the inner layers, the individual fatty acids with the highest relative increase are arachidonic and linoleic acid. The source of linoleic acid may be exogenous or endogenous (see above). Since arachidonic acid is not taken up from the blood in measurable amounts (Van der vusse et a7, 1982) during ischerna, an endogenous source for at least a part of the accumulated NEFA seems feasible. The most likely candidates are myocardiall phosphoglycerides, rich in arachidonic and linoleic acid (Van der Vusse et al, 1982). This is supported by the observation of Vasdev and coworkers (1980) that the indivim dual phosphoglyceride classes in sarcolemmal and nitochondrial fractions isolated from ischemic myocardium are significantly decreased. This phosphoglyceride lipolysis may be induced by phospholipase $A_{2}$ which is stimulated by high $\mathrm{Ca}^{2+}$ concentrations (Franson et a1, 1978). During ischemila high Ca2 ${ }^{+}$ concentrations are suggested to be present within the cells because the ca ${ }^{2+}$ homeostasis is impaired by ATP depletion (Nayler, 1981).

Weglicki et al (1973) indeed suggested phospholipase $A_{2}$ to be active during ischemia. Increased levels of the products of the phospholipase $\mathrm{A}_{2}-$ phosphoglyceride interaction (i.e. Iysophosphoglycerides) have been shown to be present by Sobel et al (1978). These findings support the hypothesis that at least a part of the NEFA, accumulated in the inner layers, is the resullt of phosphoglyceride lipolysis. The not significant difference in phosphogly- 
ceride content between the ischemic and non-ischemic tissue in the same animal is not contradictory to this hypothesis, since lipolysis of only $1 \%$ of the phosphoglycerides may result in a 30 -fold increase in MEFA content.

It should be noticed that on the base of the present data it cannot be concluded whether the above-mentioned NEFA accumulation occurs in the myocytes or in other cells of the myocardium. Using an isolated heart preparation, which allowed the separate collection of coronary effluent and interstitial effluent, Stam and Huelsmann (1981) showed that hormone sensitive release of $7 y$ sophosphatidylcholine was mainjy recovered in the coronary effluent whereas products from triacyl-glycerol lipolysis were present in the interstitial effluent. These data suggest that myocardial lysophosphatidylcholine formation under these (non-ischemic) conditions took place at the level of the coronary vasculature rather than in the myocytes.

\subsubsection{Discussion on the harmful effects of NEFA accumulation}

Several harmful effects during ischemia have been ascribed to high intracellular NEFA concentration as well as high acylCOA and acylcarnitine concentrations (section 2.3.3).

During ischemia in vivo glycolytic inhibition by high NEFA concentrations as reported to occur in vitro (Lea and Weber, 1968; Ramadoss et al, 1976), does not seem to be influenced by extra or intracellular NEFA: net uptake of glucose remains constant from 10 to $120 \mathrm{~min}$ at a level 5 times the pre-ischemic value. No convincing evidence is present, that the decreased lactate release after 10 min of ischenia might be caused by glycolytic inhibition, since redistribution of blood flow to surviving cells and a decreased oxygen shortage in the 1 schemic area might cause this phenomenon (see above). Yet no support has been found for the theory that high cellular NEFA concentrations cause premature glycogen depletion (Cowan and Vaughan Williams, 1980). G7ycogen breakdown started before the onset of NEFA accumulation and the majority of the giycogen was metabollzed during the first hour of ischemia.

A proposed ATPase stimulation by increased NEFA concentrations (Pressman and Lardy, 1956; Borst et a1, 1962), is in contradiction with the findings in the present study, after $60 \mathrm{~min}$, ATP concentrations did not decrease after the first hour of ischemia, even not in the outer layers where the highest NEFA concentrations were present after $60 \mathrm{~min}$. A restriction should be made in the case that low ATP and high MEFA contents do not occur in the same cell. 
The harmful effect of high NEFA concentrations on mechanical function of the ischemic heart (Katz and Messineo, 1981; Feuvray and Plouet, 1981) is not probable since early mechanical failure occurs within one min after onset of ischemia (chapter 6), whereas after 10 min of ischemia no change in NEFA contents could be observed. Moreover, nyocardial wall shortening hardly diminishes when NEFA contents increases.

\subsection{Conclusions}

- Stenosis of the LAICA resulted in significantly inpaired global hemodynamics after 10 min of ischemia. Only slight changes in the hemodynamic variables occurred in the following 110 min of ischemia except for a decrease in aortic pressure and $d p_{y v} / d t m a x$ which was probably caused by the anesthesia used.

- Increased MBF (after 10 min of ischemia) and decreased triacyliglycerol content of the non-ischemic area suggest increased workload in this area to compensate for function loss of the jeopardized myocardium.

- Maintenance of a constant low perfusion pressure to the ischemic area resulted in a virtually unchanged mean tramsmural flow to the ischemic area between 10 and 120 min.

- At a longer duration of ischemia, the relative underperfusion of the inner layers became mare severe.

- Contents of NEFA in ischemic myocardium do not increase before 10 min of i schemia.

- In the outer layers, NEFA content transiently increased after 60 min of ischemia, whereas in the inner and middle layers NEFA content gradually increased from 60 to 120 min.

- The highest relative increase of arachidonic and linolefic acid in the inner and middle layers suggest (substantial) lipolysis of phosphoglycerides.

- The accumulation of NEFA occurred when myocardial blood flow was below 0.3 ml. min ${ }^{-1} \cdot g^{-1}$, and ATP contents were below $10 \mu m 01 . g^{-1}$ dry weight.

- The changes in mechanical function and metabolism in the ischemic myocardium are not necessarily due to NEFA accumulation. 
8. THE EFFECT OF ELEVATED ARTERIAL NON-ESTERIFIED FATTY ACID CONCENTRATIONS ON HEMOOYMAMICS AMO MYOCAROIAL METABOLISM AND BLOOD FLOW DURING ISCHEMIA*

\section{Q. Introduction}

High arterial non-esterified fatty acid (NEFA) concentrations are considered to be harmful for the ischemic myocardium (Kurien and 0liver, 1966; 01 iver et a1, 1968; Takano, 1976). In these investigations positive relations were found between arterial NEFA levels on the one hand and infarct size, ventricular arrhythmias and ventricular fibrillation on the other. In other studiles, however, these relations could not be confirmed (Rutenberg et al, 1969; Most et al, 1974; Dagena is and Jalbert, 1977).

Although the occurrence of arrhythmias and of left wentricular failure in relation to elevated plasma NEFA levels has been studied extensively, only limited information is available about myocardial metabolism and regional myocardial blood flow under these circumstances, especially during ischemia.

In this chapter, carbohydrate, NEFA and oxygen utilization of the ischemic myocardium as well as the release of potassium and inorganic phosphate from this tissue at nomal and elevated arterial NEFA levels were studied in anesthetized dogs. Left ventricular hemodynamics and regional myocardial blood flow were measured as well. Myocardial ischemia was induced by partial occlusion (stenosis) of the LAICA as described in section 3.1.4. NEFA concentrations were elevated by intravenous injection of heparin, intralipid or a combination of these substances (intralipid-heparin).

\subsection{Experimental design}

\subsubsection{Protacol}

The dogs were allotted to 3 groups of 8 animals each. In each group the same protocol was followed during the control perlod and the first $60 \mathrm{~min}$ of stenosis. Thereafter, heparin (5000 I.U.) was injected intrave-

*Has been publisched in Basic Res. Cardial. 76, 197-210 (1981) 


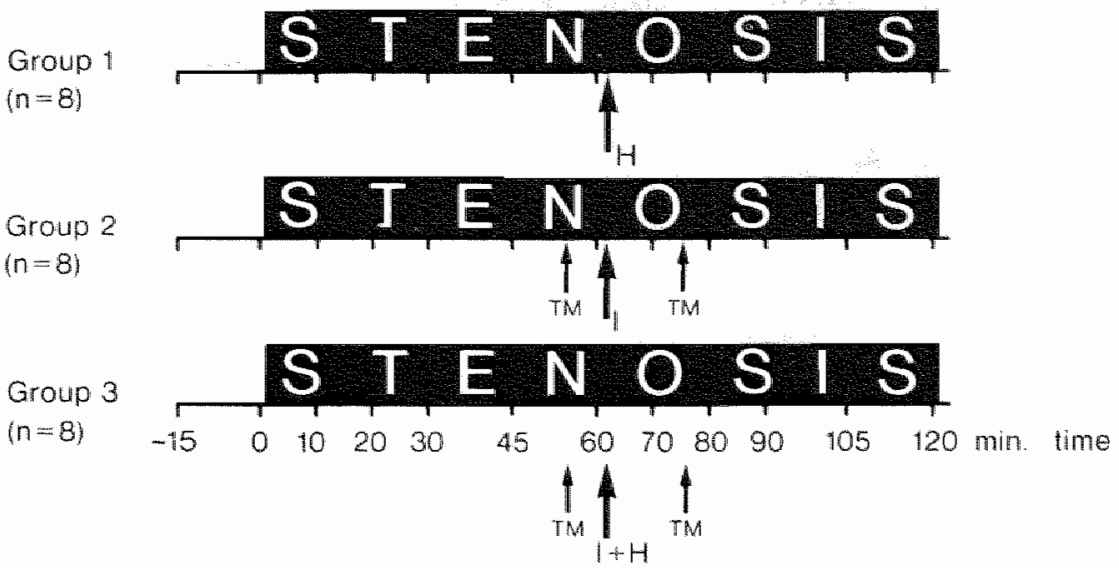

Fig 8.1 Protocol of the experiments. Heheparin 5000 I.U. i.V., I=Intralipid $50 \mathrm{ml} 20 \%$ i.v., TM= injection of radioactive microspheres. The dashes on the time axis represent the sample time for bliochemical and hemodynamical variables.

Table 8.1 Relative changes in total myocardial blood flow (MBF) and endo/epicardial blood flow ratio in ischemic and non-ischemic tissue after elevation of arterial FFA concentrations expressed as percentage of the value before injection of the substances.

\begin{tabular}{|c|c|c|c|c|}
\hline \multirow[b]{2}{*}{ Variable } & \multicolumn{2}{|c|}{ Non-ischemic } & \multicolumn{2}{|c|}{ Ischemic } \\
\hline & Intralipid & $\begin{array}{l}\text { Intralipld }+ \\
\text { Heparim }\end{array}$ & Intralipid & $\begin{array}{l}\text { Intral fold }+ \\
\text { Heparin }\end{array}$ \\
\hline Total MBF & $\begin{array}{l}13^{*} \\
5-22\end{array}$ & $\begin{array}{l}11 \\
(-9)-27\end{array}$ & $\begin{array}{l}-10 \\
(-8)-33\end{array}$ & $\begin{array}{l}-16^{\star} \\
(-45)=0\end{array}$ \\
\hline $\begin{array}{l}\text { Endo/epi- } \\
\text { cardial } \\
\text { blood flow } \\
\text { ratio }\end{array}$ & $\frac{-1}{(-1)-2.3}$ & $\begin{array}{l}-3 \\
(-7)-6\end{array}$ & $\begin{array}{l}-3 \\
(-11)-13\end{array}$ & $\begin{array}{l}-13^{*} \\
(-52)-0\end{array}$ \\
\hline
\end{tabular}

* $p<0.05$ 
nously in group I, whereas in group II and III respectively Intralipid (50 ml 20\% I.V. Vitrum, Stockholm) and intralipid-heparin were administered. The last procedure is comparable with the method of elevating arterial NEFA concentrations used by opie and co-investigators (1973). Both in group II and III, the compounds were injected slowly (within 1-2 min). Arterial and local venous blood samples were taken 15 min, just before, and $10,20,30,45,60,70,80,90,105$, and $120 \mathrm{~min}$ after inducement of the stenosis. The continuously recorded hemodynamic variables and cardiac output were also determined at these moments (fig 8.1). In group II and III, regional myocardial blood flow (MBF) was determined just before and 20 min after administration of intralipid and intralipid-heparin, respectively, using tracer microspheres as described in section 3.4 .

\subsubsection{Data analysis}

To compare the hemodynamics of the three groups just before onset of ischemia, differences between the values of heart rate and mean aortic pressure at time $0 \mathrm{~min}$ were evaluated for statistical significance by applying Wilcoxon's two-sample test.

Information about the effect of heparin, intralipid or the intralipidheparin during myocardial ischemia was obtained by comparison of the data within each animal. Influences on the hemodynamic and biochemical variables were evaluated by comparing the values at time $70,80,90,105$ and 120 min with those just before injection of the substances at time 60 min. Information about the effect on MBF was obtained by comparing the values just before (time $60 \mathrm{~min}$ ) and 20 min after injection of the substances. Differences between the values of the various variablles were evaluated for statistical significance by applying wilcoxon's matched-pairs signed-ranks test (twotafled probability). The data are presented as median values and $95 \%$ confidence limits. A value of $p<0.05$ was considered to be a significant difference.

\subsection{Results}

\subsubsection{Hemodynamic vartables}

At time $0 \mathrm{~min}$ (before onset of stenosis) the heart rate and mean aortic pressure were for group I, II and III: 110 (60-160), 135 (79177), and 85 
Tabie 8.2 Arterial values of various biachemical variables before and 20 min after administration of heparin, intralipid or both substances.

$\begin{array}{lll}\text { HEPARIN } & \text { INTRALIPID } & \text { HEPARIN + INTRALIPID } \\ \text { After } & \text { Before After } & \text { Before After }\end{array}$

Variable

$\begin{array}{lllllll}\text { NEFA } & 0.20 & 0.30^{*} & 0.33 & 0.53^{*} & 0.17 & 0.81^{*} \\ \text { (mmol/1) } & 0.16-0.32 & 0.24-0.42 & 0.27-0.37 & 0.38-0.85 & 0.14-0.20 & 0.66-1.23 \\ \text { Lactate } & 1.09 & 0.92 & 1.35 & 2.31^{*} & 1.70 & 3.43^{*} \\ \text { (mmol/1) } & 0.72-1.84 & 0.72-1.75 & 0.90-1.69 & 1.77-3.30 & 1.40-3.18 & 2.33-4.72 \\ \text { pH } & 7.43 & 7.43 & 78.39 & 7.37^{*} & 7.44 & 7.41^{*} \\ & 7.41-7.45 & 7.41-7.45 & 7.36-7.41 & 7.34-7.40 & 7.42-7.48 & 7.39-7.46 \\ \mathrm{pCO}_{2} & 3.9 & 3.9 & 4.4 & 4.3 & 3.7 & 3.6 \\ & 3.3-3.4 & 3.5-4.0 & 4.0-4.5 & 4.1-4.4 & 3.2-3.9 & 3.3-5.7\end{array}$

ॠ $p<0.05$

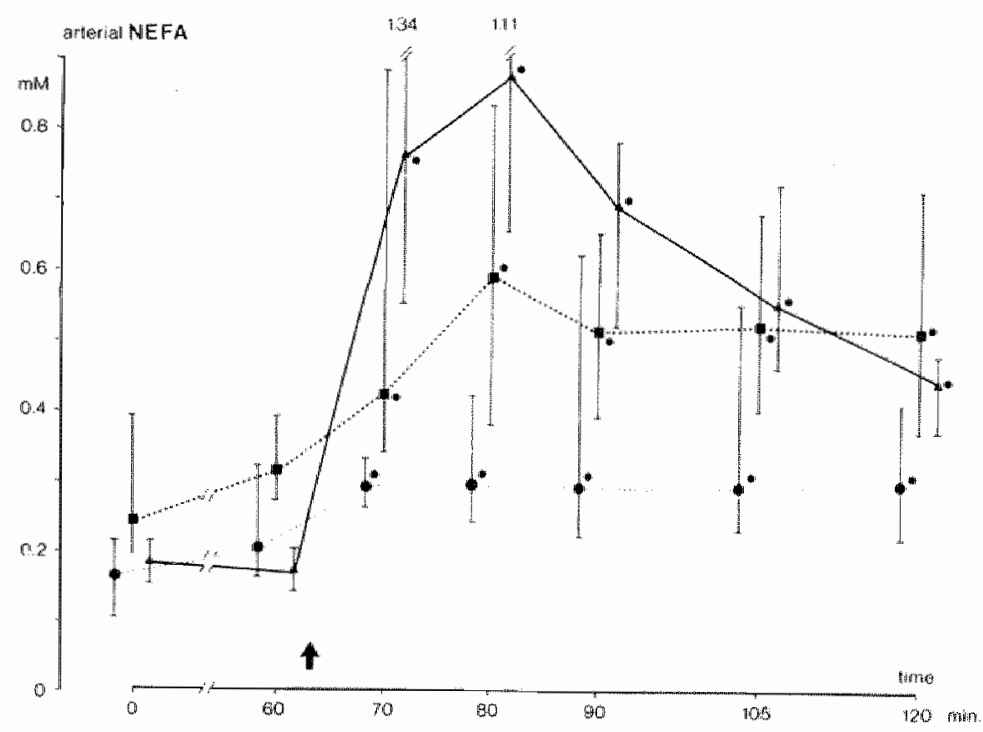

Fig 8.2 Time course of arterial NEFA concentrations in the three experimental groups. The median values and $95 \%$ limits are presented. The arrow indicates the injection of the substances. =heparin (group I)* =intralipid (grouplI). $\mathbf{\Delta}=i$ intralipid-heparin (groupIII).

* p<0.05 as compared with time $60 \mathrm{~min}$. 
Table 8.3 Myocardial blood flow (mi.min ${ }^{-1} \cdot \mathrm{g}^{-1}$ ), endo/ epicardial blood flow ratio and the AV differences (mM) and net uptake (umol. min ${ }^{-1} \cdot \mathrm{g}^{-1}$ ) of various biochenical variables in the ischemic

\section{HEPARIN}

Before After

MBF

Endo/epicardial ratio

NEFA

$\begin{array}{lcc}\text { AV difference } & 0.08 & 0.11 \\ \text { net uptake } & 0.04-0.19 & 0.07-0.15 \\ \text { Glucose } & - & - \\ \text { AV difference } & 1.5 & 1.5 \\ \text { net uptake } & 1.3-2.5 & 0.7-1.7 \\ \text { Lactate } & - & - \\ \text { AV difference } & -1.85 & -1.11 \\ \text { net uptake } & (-3.2)-(-0.37) & (-1.39)-(-0.17) \\ & - & - \\ \text { Oxygen } & & 5.6 \\ \text { AV difference } & 5.6 & 4.2-5.9 \\ \text { net uptake } & 2.3-6.6 & -\end{array}$

Table 8.4 AV differences of potassium, inorganic phosphate, pH, and $\mathrm{pCO}_{2}$ across the ischemic myocardium before and $20 \mathrm{~min}$ after

\begin{tabular}{|c|c|c|}
\hline & \multicolumn{2}{|c|}{ HEPARIN } \\
\hline & Before & After \\
\hline$k^{+}$ & $\begin{array}{l}-0.10 \\
(-0.60)-0.10\end{array}$ & $\begin{array}{l}-0.37 \\
(-1.25)-0.05\end{array}$ \\
\hline $\mathrm{Pi}$ & $\begin{array}{l}-0.13 \\
(-0.33)-(-0.03)\end{array}$ & $\begin{array}{l}-0.02 \\
(-0.22)-0.03\end{array}$ \\
\hline $\mathrm{pH}$ & $\begin{array}{l}0.10 \\
0.07-0.15\end{array}$ & $\begin{array}{l}0.09 \\
0.05-0.13\end{array}$ \\
\hline $\mathrm{pCO}_{2}$ & $\begin{array}{l}-2.3 \\
(-3.9)-(-1.7)\end{array}$ & $\begin{array}{l}-3.3 \\
(-3.9)-(-1.6)\end{array}$ \\
\hline
\end{tabular}


myocardium just before and $20 \mathrm{~min}$ after elevating NEFA concentrations by injecting heparin, intralipid or both substances. For explanation of the signs, see table 8.1 .

\section{INTRALIPID}

\section{Before}

0.21

$0.11-0.36$

0.40

$0.16-0.56$

0.05

$(-0.14)-(-0.02)$

0.01

$0.00-0.01$

1.0

$0.8-1.4$

0.2

$0.1-0.3$

$-1.03$

$(-1.73)-(-0.48)$

$-0.18$

$(-0.36)-(-0.12)$

6.1

$5.7-7.0$

1.4

$0.7-2.3$
After

0.22

$0.12-0.42$

0.35

$0.18-0.57$

$-0.01$

$(-0.11)-0.14$

0.00

$(-0.03)-0.03$

$0.7 *$

$0.5-1.1$

0.2

$0.1-0.3$
$-1.29$
$(-3.75)-(-0.07)$
$-0.19$
$(-1.56)-0.02$

6.0

$5.8-7.3$

$1.4^{*}$

$0.8-3.0$

\section{INTRALIPID + HEPARIN}

Before

0.48

$0.25-0.56$

0.52

$0.29-0.59$

0.02

$(-0.02)-0.06$

0.01

$(-0.01)-0.02$

0.4

$0.0-0.8$

0.1

$0.0-0.2$

$-0.03$

$(-0.23)-0.34$

0.02

$(-0.06)-0.18$

5.8

$3.7-6.7$

2.6

$1.3-3.3$
After

$0.29 *$

$0.21-0.45$

0.35 *

$0.22-0.58$

0.10

$0.04-0.20$

$\mathrm{O} .02$

$0.01-0.05$

0.7

$0.1-1.2$

0.2

$0.0-0.3$

$-0.50 *$

$(-0.95)-(-0.25)$

$-0.13^{*}$

$(-0.31)-0.06$

5.8

$4.8-6.4$

$1.7 *$

$1.1-2.4$

elevating arterial NEFA concentrations by injection of heparin, intralipld or both substances. For explanation of the signs, see table 8.1

\section{INTRAL IPID}

Before

$-0.53$

$(-0.65)-(-0.10)$

$-0.50$

$-0.34$

$(-0.40)-(-0.09)$

$-0.24$

$(-0.41)-(-0.13)$

0.09

$0.05-0.18$

\subsection{7}

$0.06-0.11$

$-2.5$

$(-3.1)-(-1.7)$

\section{INTRALIPID + HEPARIN}

Before

After

$-0.33$

$-0.35$

$(-0.50)-(-0.15)$

$(-0.60)-0.00$

$-0.11$

$-0.15$

$(-0.21)-(-0.03)$

$(-0.33)-(-0.05)$

0.07

0.07

$0.05-0.08$

$0.06-0.09$

$-2.1$

$(-2.4)-(-1.3)$

$-1.9$

$(-2.9)-(-0.09)$ 
$(75-115)$ beats. fin ${ }^{-1}$, and $10.8(8.8-12.4), 10.3(8.5-13.2)$ and $10.0(8.0-$ 10.3) kPa, respectively. These values were not significantly different. Intravenous injection of heparin resulted in a slight and gradual decrease in systollc (median fall maximally: $1.4 \mathrm{kPa}(=8 \%)$ ) and diastolic aortic pressure (median fall maximally: $0.7 \mathrm{kPa}(=10 \%)$ ). This decrease was significant 45 and 50 min after administration of heparin. Injection of intralipid (group II) or intralipidheparin (group III) induced a transient increase in blood pressure (of $0.5-2.0 \mathrm{kPa}$ ) within the first min after injection. Ten min after injection these changes were not significant anymore. Heart rate gradually increased significantly after administration of heparin as well as intralipid-heparin (maximum rise: $45 ; 39 \%$ and 23 beats. min $^{-1} ; 23 \%$ ). After administration of intralipid, the maximal rise in heart rate was only 4 beats.min ${ }^{-1}(2.5 \%)$. In all three groups, this increase became significant $45 \mathrm{~min}$ after injection.

Heparin, intralipid or the intralipid-heparin neither induced cardiac arrhythmias nor influenced occasionally existing arrhythmias such as noda? rhythms or atrial fibrillation.

Administration of the substances had no significant effect on $\mathrm{dp}_{1 \mathrm{v}} / \mathrm{dtmax}$, and cardiac output.

\subsubsection{Regional myocardial blood flow}

After administration of intralipid (group II), total MBF significantly increased in the non-ischemic myocardium (median increase: $13 \%$ ). In the ischemic tissue, MBF did not change significantly (table 8.1). After simultaneous injection of heparin and intralipid, total MBF did not change significantly in the non-ischemic myocardium but decreased significantiy in the ischemic part (table 8.1).

In the non-ischemic nyocardium, the transmural distribution of MBF was not significantly affected by the administration of intralipid or heparin and intralipid (table 8.1). In the ischemic myocardium, the transmural distribution (endo/epicardial ratio) of MBF was not significantly changed after the injection of intralipid. After the administration of heparin together with intralipid, however, the subendocardial layers in the ischemic myocardium became more underperfused as compared with the subepicardial layers in this area (table 8.1$)$. 


\subsubsection{Biochemilcall variables}

Intravenous injection of heparin (group I), intralipid (group II), or intralipid-heparin (group III) elevated the arterial NEFA concentrations from 0.20 to $0.30 \mathrm{mM}$, from 0.33 to $0.53 \mathrm{mM}$, and from 0.17 to $0.87 \mathrm{~m}$, respectively (table 8.2). The arterial NEFA concentrations remained constantly elevated in group I and II, but gradually decreased in group III at the end of the experimental period (fig 8.2 ). In each group, the concentrations 60 min after injection of the substances were still increased as compared to those before injection of the substances.

Immediately after injection of intralipid as well as intralipidheparin, the arterial lactate concentrations increased to values $2-3$ times higher than the control values. Arterial $\mathrm{p}_{\mathrm{CO}}$ was not affected by the elevated arterial NEFA concentrations (table 8.2).

The elevated arterial NEFA concentrations did not result in a significant: change in AV differences of NEFA and glucose across the ischemic area (table 8.3). Yet the AV differences of lactate did not change in group I and II. In group III, however, the AV difference of lactate became negative and a significant net release of lactate occurred after injection of the substances. These changes were associated with a significant decrease in oxygen uptake (table 8.3). In contrast with the elevated AV difference of lactate in graup III (table 8.3), the AV differences of $\mathrm{K}^{+}$, inorganic phosphate, $\mathrm{pH}$ and $\mathrm{p}_{\mathrm{CO}}$ (table 8.4) were not significantly affected by the elevated arterial MEFA concentration.

\subsubsection{In vitro effect of intralipid on hemoglobin ( $\mathrm{Hb}$ ) measurements}

After administration of intralipid or intralipid-heparin. Hb concentrations increased consistently. If this is an artefact due to the intralipid administration errors are made in the calculations of oxygen uptake. To investigate whether this phenomenon was an artefact, various amounts of intralipid were added to freshly drawn arterial and venous blood and the Hb concentration was determined as described in section 3.5.3. The range of concentrations used in vitro was comparable with the blood concentrations of intralipid reached in the dog after injection of $50 \mathrm{ml} 20 \%$ of this substance.

Both in witro and in vivo, Hb values measured by the hemoxymeter increased with increasing concentrations of intralipid. $0_{2}$ saturation decreased proportionally so that $\mathrm{O}_{2}$ content of the blood remained unchanged. This effect of intralipid is caused by absorption of light at the wavelengths used (Cane et 
a], 1980).

\subsection{Discusston}

\subsubsection{Artificial elevation of arterial NEFA}

In the present study, the effect of increased arterial NEFA concentrations on MBF, myocardial metabolism and hemodynamics during ischemila was studied in anesthetized dogs. NEFA concentrations were elevated by intravenous injection of heparin, intralipid or intralipidheparin. The higher plasma NEFA concentrations reached after the adninistration of intralipid-heparin than after the injection of intralipid or heparin cam be explained as follows. Intralipid causes primarily an increase of plasma triacylglycerol (Riemersma et al, 1977b) and only secondarily of plasma NEFA. The conversion into NEFA is stimulated by lipoprotein lipase which is released from the endothelium into the blood by heparin (Jansen, 1975; Riemersma et a1, 1977a). It should be kept in mind that in group II and III no distinction can be made between the effect of high arterial NEFA concentrations alone or together with heparin and high arterial triacylglycerol concentrations.

\subsubsection{Effect of elevated arterial NEFA concentrations on myocardial blood flow}

The findings in our study indicate that highly elevated NEFA levels (0.66$1.23 \mathrm{mM}$ ) result in a decrease of total $\mathrm{MBF}$, endo/epicardial blood flow ratio and oxygen uptake in the ischemic area. The decreased oxygen uptake is associated with a more pronounced net release of lactate from the ischemic myocardium, suggesting the augmentation of anaerobic glycolysis. These findings are consonant with the finding that there is a relation between these levels and infarct size reported by ople et al (1977). The higher enzyme release from regional ischemic isolated rat hearts when perfused with a palmitic acid containing solution (De Leiris et al, 1975, 1978) could also be explained by a decreased ischemic blood flow. However, following coronary artery acclusion, Most et al (1974) did not observe an influence of intralipid-heparin adninistration on myocardial injury.

Although NEFA are known to have vasodilating properties in the coronary circulation (Huelsmann, 1976; Blass et a1, 1978), it is unlikely that the decrease in MBF in the ischemic area results from a redistribution of blood flow in favor of non-ischemic areas. In our experimental set-up, after all, 
poststenotic coronary artery pressure is kept constant. Imcreased serum viscosity, resulting in elevated resistance to blood flow, might be an explanation for the decrease in MBF in the ischemic myocardium. The administration of intralipid-heparin indeed resulted in increased serum viscosity as determined by capillary viscometry (umpublished results). Whether the change in serum viscosity is less pronounced after the administration of intralipid alone, which could explain the non-significant alteration in ischemic MBF under these circumstances, is not known. Neither do we have information about the influence of NEFA alone on serum or cellular viscosity.

It is unlikely that the differences in median values of ischemic MBF between group II and II before administration of the substances (table 8.2) influence the obtained results because no relation was found between these MBF values and changes in the determined variables after the administration of the substances within these groups.

The decrease in endo/epicardial blood flow ratio can possibly be explained by the finding that during stenosis arterioles are fully dilated in the subendocardium but only partially in the subepicardium (Gould et al, 1975). In this light increased viscosity of the blood will affect subepicardial blood flow only to a limited extent because the arterioles in this layer can still dilate to compensate for the increase in resistance caused by the elevated viscosity. This dilation may even be stimulated by the increased concentration of NEFA which are known to be coronary vasodilators (Huelsmann, 1976; Blass et al, 1978). The increased MBF in the non-ischemic area may also result from this property.

Whatever the reason of the decreased ischemic bllood flow may be, this seems to be another deleterious effect of high circulating NEFA concentrations on the ischemic myocardium beside the presumed noxious effects of high intracellular MEFA, acyl-COA and acylcarnitine concentrations in the myocytes (recentiy reviewed by Katz and Messineo, 1981; Van der Vusse, 1982) and the presence of proposed NEFA-driven "oxygen-wasting" processes in ischemic tissue (Vik-Mo and Mjos, 1981). 
8.4.3 Effect of elevated arterial NEFA concentration on myocardial metabolism

The increased met lactate release from the ischemic area is in agreement with previous findings (Kjekhus and Mjos, 1972) and indicates that acutely elevated arterial NEFA concentrations do not inhibit anaerobic glycolysis in the ischemic myocardium.

Lactate, potassium and inorganic phosphate are commonly used as markers for ischemia. These markers are generally released simultaneously from the myocardium within 20 min after onset of ischemia (Owen et a1, 1970; Van der Vusse et a 1 , 1980). In the present study, a more severe degree of ischemila, as indicated by the fall in MBF associated with increased net release of lactate, does not result in an increased net release of potassium and inorganic phosphate. One explanation for this discrepancy might be that the cells are retaining potassium and inorganic phosphate. This theory is in agreement with the finding that the AV differences of these substances after one hour of ischemia do not significantly differ from those before ischemia, even when a significant lactate release extsts (Van der Vusse et al, 1980). Moreover, the data referring to the net release of potassium and inorganic phosphate during the first 60 min of ischernia (chapter 6 and 7) show that only approximately $10 \%$ of all potassium and approximately half of all liberated inorganic phosphate is released into the venous blood draining the ischemic area. Another possibility is that we missed the release of potassium and inorganic phosphate because the majority of these markers is released within 10 min after inducement of ischemia (Van der Vusse et al, 1980).

After administration of intralipid-heparin, net NEFA uptake tended to increase while after intralipid administration net MEFA uptake became negative in 5 out of 8 dogs. The latter cam be explained by an increased intravascular lipolysis of serum triacylglycerol caused by an elevated concentration of this substance. In this way, more NEFA are formed than can be taken up by the myocardium and these NEFA are released into the venous effluence. This does not occur after administration of intralipid-heparin because heparin releases the ilpoprotein lipase from the endothelium (see above).

The increased arterial lactate concentrations after the administration of intralipid as well as intralipid-heparin, reflect a systemic effect and might result from release from skeletal muscles. The elevated arterial lactate concentrations might be responsible for the not significantly changed net NEFA uptake of the ischemic myocardium, in the presence of elevated arterial 
NEFA levels since experiments in non-ischerlic hearts have shown that the uptake of NEFA is diminished at elevated arterial lactate concentrations (Spitzer, 1974).

\subsubsection{Effect of elevated NEFA concentration on hemodynamics}

The increase in heart rate found after the administration of heparin as well as heparin and intralipid is probably caused by the former because heart rate did not change after the injection of intralipid alone. This is supported by the finding that intralipid administered to heparinized dogs had no significant effect on heart rate both in the non-ischemic (Mjos, 1971a and b; Kjekhus and Mjos, 1972; Mast et al, 1973) and in the flow-restricted (Kjekhus and Mjos, 1972) heart. It is unikely that our experimental design is responsible for the increase in heart rate because in studies without intervention no significant changes in heart rate were found during 2 hours of stenosis (Van der Vusse et al, 1980, section 7).

The present findings indicate that elevated NEFA concentrations do not induce arrhythmias which is in accordance with data presented previously (Nelson, 1970a, b; Russo et al, 1970; Opie et al, 1971; De Leiris et al, 1975; Riemersma et a1, 1977a; Riemersma and Dliver, 1979) but in disagreement with the findings of 0liver and Yates (1971) and Yamazaki (1978). This discrepancy is incompletely understood. A possible explanation might be that the plasma NEFA levels in our study were too low to induce arrhythmias (maximum $1.35 \mathrm{~m} / \mathrm{M}$ ) because 01 iver and Yates (1971) described their effects at plasma NEFA levels of $2.5 \mathrm{mM}$. On the other hand, Opie and co-investigators did not find an effect on arrhythmias at plasma NEFA 1evels of $6 \mathrm{mM}$ (1971). Opte and Lubbe (1975) have stated in a good survey on the possible arrhythmogenlic properties of free fatty acids that correct interpretation of the experimental findings can be influenced by species differences, experimental set-up (e.g. problems in the preparation of the NEFA:albumin complex, microelectrodes which could act as irritable focus) and concomitant raised catecholamine levels. 


\subsection{Conclustons}

- A 4-fold elevation of arterial NEFA concentrations after 60 min of Ischemia caused a decrease in total myocardial blood flow (MBF), endo/epicardial blood flow ratio and oxygen uptake in the ischemic myocardium. Such changes were not observed when arterial NEFA concentrations were only 1.5-2-fold elevated.

- The decrease in MBF mentioned above, was concomitted by a significant release of lactate but not of inorganic phosphate, potassium or $\mathrm{CO}_{2}$

- After elevation af arterial NEFA concentrations, no significant changes in glucose or NEFA uptake were observed. 


\section{SUMMARY AND CONCLUSIONS}

The aim of the present study was to investigate the relation between fiber shortening, blood flow and metabolism in the various layers of the left ventricular wall during two hours of ischemia. Special attention is paid to the cessation of fiber shortening and the accunulation of non-esterified fatty acids (NEFA) in ischemic myocardium. Also the effect of artificially elevated of arterial NEFA concentrations on the ischemic myocardium has been studied. The experiments were performed on anesthetized open-chest dogs. Myocardial blood flow (MBF) and metabolism were determined in the inner (subendocardial), middle and outer (subepicardial) layers of the left ventricular wall, whereas fiber shortening was assessed in the inner and outer layers. Fiber shortening was estimated from the epicardial surface deformation (Arts and Reneman, 1980). MBF was detemined with the radioactive microsphere method (reviewed by Heymann et al, 1977). Myocardiall metabolism was assessed by detemination of the contents of ATP, creatine phosphate, glycogen, NEFA, triacylglycerol and phosphoglycerides in tissue samples from the myocardial wall, and of myocardial uptake from the blood of oxygen, glucose, lactate, NEFA, triacylglycerol, inorganic phosphate and potassium. Systemic hemodynamic variables were measured as usual. Cardiac output was measured by thermodilution according to Snoeckx et al (1976).

Ischemia was induced by partial or complete occlusion of the left anterior interventricular coronary artery (LAICA) by inflating a cuff around this artery. The degree of partial occlusion (=stenosis) was estimated from the mean coronary artery pressure $\left(p_{c a r}\right)$ distal to the stenosis. An appropriate degree of stenosis was obtained by careful manual inflation of the cuff until a mean $p_{\text {cor }}$ of $3.3 \mathrm{kPa}(25 \mathrm{mmHg})$ was reached. Mean $p_{\text {cor }}$ was kept constant during the experimental period with a servosystem controlled by this pressure.

Before studying the effects of ischemia, the experimental model was evalum ated during 2 hours without intervention (chapter 4 ). During this period, MBF as well as the hemodynamical, regional mechanical and metabolic variables were stable (i.e. did not change significantiy). However, serial tissue sampling during the experiments caused significant decreases in epicardial deformation and MBF. Therefore, it was decided to terminate each experiment after two biopsies had been taken, one from the ischemic (LAICA) and one fram the non-ischemic (LCCA) area. Changes due to ischenia can be evaluated by comparing the content of a substance in the LAICA bilopsy with that in the 
LCCA blopsy of the same experiment since during nomal perfusion, the contents of the warlous substances were similar in both regions.

In chapter 4, it has also been shown that MBF in the outer layer of the left ventricular free wall is inhomogeneously distributed. MBF in these layers was higher near the apex than near the base and lower in the posterior than in the anterior region of the free wall. The cause of these differences is incompletely understood.

In chapter 5, the prediction of fiber shortening in the inner layers from epicardial deformation was validated. Epicardial minimal (emin) and maximal shortening ( $\left.e_{\text {max }}\right)$ were calculated from the measured epicardial shortening in clrcumferential and base-to-apex direction and the shear angle during the ejection phase (section 3.3). According to a mathematical model of the left ventricle (Arts, 1978, 1980, 1982a,b), the direction of e max was approximately equal to the fiber direction in the outer layers and the direction of $e_{\text {min }}$ was close (within 0.3 rad) to the fiber direction in the inner layers. The relation between $e_{m i n}$ and shortening in the inner layers in the direction of emin (called endo) was subject of a study where deformation was assessed simultaneously at the eplcardium and in the inner layers by measurement of mutual movement and angulation of three needles pierced into the myacandial wa11. During normoxia and ischemia, emin was found to be clearly related to fiber shortening in the inner layers, so that information about this shortening could be obtained from measurements at the epicardium.

After onset of ischenia $e_{\text {min }}$ started to decrease $2 \mathrm{~s}$ (occlusion, chapter 5) and $30 \mathrm{~s}$ (stenosis, chapter 6) before a significant change in e max could be detected. emin transiently reached negative values (i.e. lengthening of the fibers), which was more pronounced after occlusion than after stenosis. However. $e_{\text {max }}$ gradually decreased to about $20 \%$ of the pre-ischemic values within the first min and the median did not reach negative values. These results show that after onset of acute ischemia fiber shortening is earlier and more severely affected in the inner than in the outer layers. Transmural differences in shortening are pronounced during the first half min but relatively small after one min of ischemia.

In chapter 6, the relation between this early cessation of shortening after stenosis of a coronary artery and the changes in MBF and metabolism was studied. Stenosis caused a decrease in MBF of $68 \%$ and $81 \%$ in the inner layers and of $36 \%$ and $54 \%$ in the outer layers after 1 and 5 min of ischemia, respectively. Within 5 min of ischemia, no significant changes could be detec- 
ted in myocardial ATP content but creatine phosphate content in the inner layers had halved within one min of ischemia and further decreased gradually in all layers during the next 4 min. Signtficant release of inorganic phosphate into the venous blood draining the ischemic area, within half a nimute of ischemia also indicated the early breakdown of energy-rich phosphates. Giycogen contents in the various layers were hardly affected within 5 min of ischemia. These results were compared with the current hypotheses on the cause of the early cessation of contractile activity as discussed in section 2.1.2. Based on the results of the present study the early cessation of shortening might be explained by the decrease in free energy provided by ATP hydralysis. A major inhibition of shortening by local depletion of glycogen or accumulation of inorganic phosphate per se seems unlikely.

Because of the higher axygen delivery (higher blood flow and probably small differences in $\mathrm{O}_{2}$ extraction) to the outer than to the inner layers and because of the relatively small differences in the changes in fiber shortening during ischemia, it is suggested that the outer layers are impeded to shorten by the inner layers and are forced to bear stress which cannot be built up by the inner llayers.

During the first $5 \mathrm{~min}$ of ischemia, the lactate release from the affected myocardium could only partially be explained by the uptake of gllucose. An early, but hardly measurable glycogenolysis might be invalved.

In chapter 7, the time course of blood flow, fiber shortening and metabo$1 \mathrm{ism}$ during two hours of ischemia was studied. At the constant law perfusion pressure (see above), MBF to the whole ischemic area did not change significantly between 10 and $120 \mathrm{~min}$ of ischemia. In contrast, the relative underperfusion of the inner layers became worse at langer duration of ischemla. The tissue contents of ATP, creatine phosphate and glycogen after 10, 60, and 120 min of ischemia were diminished, the lowest values being reached in the inner layers. ATP content in the inner layers gradually declined to $28 \%$ of the normoxic value after 120 min of ischemia. In the inner layers, the creatine phosphate content after $60 \mathrm{~min}$ was about $25 \%$ of the normoxic value, but increased to about $50 \%$ of the mormoxic value after $120 \mathrm{~min}$. Glycogen content in the inner layers gradually decreased to $38 \%$ of the normoxic content after 120 of ischemia. The already severelly affected regional myocardial fiber shortening after $10 \mathrm{~min}$ of ischemia, subsequently deteriorated during the next 110 min; $e_{\max }$ declining to a slightly more pronounced degree than e ein" These results show that transmural differences in metabolism invariably exist 
between 10 and $120 \mathrm{~min}$, the transmural gradient in blood flow even increases within this period, and the differences in shortening in the myocardial wall tend to decrease.

No significant increase in NEFA content was observed 10 min after onset of Ischemia. In the outer layers NEFA content showed a biphasic pattern with a maximum increase (about 3-fold) after $60 \mathrm{~min}$ of ischemia, whereas in the inner layers NEFA content gradually increased to approximately 4 times the nomoxic values after $120 \mathrm{~min}$. In the outer layers an important part of this accumulation may be caused by lipolysis of endogenous triacylglycerol or fatty acids extracted from the blood. The relatively highest increase in Iinoleic and arachidonic acid in the inner layers suggests that lipolysis of phosphoglycerides is an important source of these NEFA. NEFA accumulation in the inner layers after $60 \mathrm{~min}$ and in all layers after $120 \mathrm{~min}$, proved to be related to MBF and ATP content of the ischemic area. After 120 min of ischemia NEFA contents were found to be increased when MBF was lower than 0.3 $\mathrm{ml} . \mathrm{min}^{-1} \cdot \mathrm{g}^{-1}$ and ATP content was lower than $10 \mu \mathrm{mol} \cdot \mathrm{g}^{-1}$ dry weight.

From these data it has been hypothetized that the NEFA accumulation in ischemic myocardium is likely not the cause of impaired mechanical performance and metabolism as well as cell death.

In chapter 8 the effect of elevated arterial NEFA concentrations on MBF, myocardial metabolism and hemodynamics during ischemia was studied. NEFA concentrations were elevated by intravenous injection of heparin, intralipid or both substances (intralipid-heparin).

After elevation of NEFA concentrations by heparin or intralipid-heparin, heart rate gradually increased, while aortic pressure tended to decrease.

Slight elevation of arterial NEFA levels (up to $0.53 \mathrm{mM}$ ), had no significant effect on total MBF and uptake of glucose, NEFA, and oxygen or release of lactate in the ischemic myocardium. However, elevating arterial NEFA levels up to $0.81 \mathrm{mM}$ (by intralipid-heparin), significantly decreased total MBF (16\%), rat to of blood flow in the inner and outer layers (13\%) and oxygen uptake $(34 \%)$ in the ischemic myocardium, and resulted in release of lactate from this area. The release of potassium, inorganic phosphate and $\mathrm{H}^{+}$as well as plasma $\mathrm{CO}_{2}$ concentration were not influenced. Neither was the uptake of glucose and NEFA.

Although the role of the simultaneously elevated arterial triacylglycerol levels can not be excluded, these findings suggest that elevated arterial NEFA concentrations can decrease MBF and augment lactate production. Glycoly- 
sis in the ischenic myacardiun is not inhibited.

In short the findings of the present study indicate that:

- fiber shortening in the various layers of the left ventricular wall can be estimated from myocardial defomation during the ejection phase as measured at the epicardial surface

- after onset of ischemia, cessation of fiber shortening starts in the inner layers and subsequently is seen in the outer layers

- the cessation of fiber shortening after inducement of ischemia can not be ascribed to depletion of ATP or creatine phosphate stores

- during ischemia of one min and longer, transmural differences in fiber shortening are small compared to differences in blood flow and metabolic variables, suggesting that fiber shortening in the outer layers seems to be impeded by the severely affected function of the inner layers

- accumulation of NEFA in ischemic myocardium could be detected at 60 and 120 min, but not after 10 min of ischemia

- the changes in mechanical function and metabolism in the ischemic myocardium are not necessarily due to NEFA accurnulation

- an important part of the accumulated NEFA, especially in the inner layers after $120 \mathrm{~min}$ of ischemia, is probably derived from endogenous phosphoglycerides.

- after 120 min of ischemia, accumulation of NEFA is highest in the inner layers and lowest in the outer layers. The extent of accumulation daes not depend on the myocardial layer itself but on the amount of MBF and the content of ATP in the ischemic myocardium: increased NEFA contents are observed when myocardial blood flow is lower than $0.3 \mathrm{ml} \cdot \mathrm{min}^{-1} \cdot \mathrm{g}^{-1}$ and when the ATP content is lower than $10 \mu \mathrm{mol} \cdot \mathrm{g}^{-1}$ dry weight.

- artificial 4-fold elevation of arterial NEFA concentrations by administration of intralipid-heparin causes "a $16 \%$ decrease in ischemic myocardlat blood flow. 


\section{SAMENVATTIHG}

Het hart is een holle spier, die dienst doet als pomp om het bloed door de bloedvaten voort te stuwen. De rechter en de linker harthelft bestaan ieder utt een dunwandige boezen, warin de aders uitmonden, die het bloed naar het hart terugvoeren en een sterk gesplerde kamer die het bloed de slagaders impompt. De rechter harthelft ontvangt het zuurstafarme bloed uit de aders van het lichaam en pompt het naar de longen (de kleline bloedsomloop). De linker harthelft ontvangt het zuurstafrijke bloed uit de Tongen en ponpt het naar alle organen van het 1 ichaam (de grote bloedsomloop).

Het hart werkrijgt energle woor het rondpompen van het bloed door glucose, melkzuur en vetten tie verbranden met behulp van zuurstof. Deze zuurstof wordt aangevoerd door het bloed in de kransslagaders. Vernauwing of afsluiting van een kransslagader leidt tot zuurstofgebrek (=ischemie) wan de hartspier. Het optreden van ischemie van de hartspier leidt binnen een minuut tot verminderde samentrekking van de spiervezels (dus verminderde pompfunctie) en binnen een tot twee uur tot celdood. Indien dit latste optreedt bij patienten, spreekt men wan een hartinfarct.

Tijdens de hartcyclus is de doorstroming van de kransslagaders aan sterke veranderingen onderhevig, vooral in de linker kamer. Om het bloed de slagaders van het 1 ichaam in te pompen wordt door samentrekking van de kamers een hoge druk opgebouwd in de kamerholte, die zich ook voortplant in de wand van de kamers. Deze weefseldruk belemmert echter de doorbloeding van de spierwand. Deze belemmering is het sterkst in de binnenste lagen van de linker kamerwand, war de weefseldruk het hoogst is. Onder normale omstandigheden wordt het tekort aan doorbloeding tijdens samentrekking gecompenseerd door een versterkte doorstroming wanneer de hartspler ontspannen is. Echter wanneer de nomale doorstroming door de kransslagaders gehinderd wordt door een vernauwing van het vat, schiet deze compensatie te kort. Hierdoor treedt ischemie het snelst op in de binnenste lagen van de linker kamer. Bij patienten wordt een hartinfarct overwegend in de binnenste lagen gevonden en experimenteel is aangetoond dat bij belemerde doorstroming van de kransslagaders niet alleen de doorbloeding mar ook de stofwisseling van de binnenste lagen het sterkst verstoord wordt door ischemie.

Weinig is nog bekend over de werschillen in spiervezelverkorting binnen de kamerwand ondat het technisch moellijk is de spiervezelverkorting te meten in de binnenste lagen wan de wand. 
Verhoogde concentraties van onveresterde (=vrije) vetzuren, zowel in de cel als in het bloed, worden door verschillende onderzoekers als schadelijk beschouwd voor het ischemische hartspierweefsel.

In het onderzoek, beschreven in dit proefschmift, is de relatie bestudeerd tussen doorbloeding, splervezelverkorting en stofwisseling in verschillende lagen van de ischemische linker kamerwand. Het onderzoek vond plaats in honden met open borstkas, onder volledige verdoving. Ischemie van een gedeelte $(10-20 \%)$ van de linker kamerwand is veroorzaakt door vernauwing of afsluiting van de voorste afdalende tak van de linker kransslagader.

De belangrijkste conclusies uit dit onderzoek zijn:

- spiervezelverkorting in de verschillende lagen van de linker kamerwand kan bepaald worden uit de vormverandering van deze wand, zoals deze gemeten wordt aan het buitenoppervlak van de ventrikel (het epicard).

- na het begin van ischemie neemt de splervezelverkorting in de binnenste lagen van de kamerwand het eerst en het sterkst af, gevolgd door een meer geleidelijke afname in spiervezelverkorting in de buitenste lagen.

- de afname van de spiervezelverkorting na het aanleggen van ischemie, kan niet toegeschreven worden aan depletie van ATP of creatine fosfaat voorraden.

- gedurende ischemie wan een minuut en langer zijn de verschilien tussen de bimnenste en buitenste lagen van de kamerwand wat betreft spiervezelverkorting relatief klein ten opzichte van de verschillen in doorbloeding en stofwisseling. Een mogelijke verklaring hiervoor is dat spiervezelverkarting in de buitenste lagen van de kamerwand belemmerd wordt door de ernstilg aangedane functie van de binnenste lagen van deze wand.

- ophoping van onveresterde vetzuren in ischemisch hartspierweefsel kon niet aangetoond worden na 10 , maar wel na 60 en $120 \mathrm{~min}$ ischemfe.

- een belangrijke oorzaak van de ophoping vam onveresterde vetzuren, vooral in de binnenste lagen na $120 \mathrm{~min}$ ischemie, is warschijnlijk de afbraak van fosfoglyceriden (fosfolipiden), stoffen die voorkomen in membranen van de cel.

- na 120 min, ischemie is de ophoping van onveresterde vetzuren het grootst in de binnenste lagen en het kleinst in de buitenste lagen van de linker kamerwand. De grootte van deze vetzuurophoping is echter niet afhankelijk van de laag in de wand, maar van de mate van afname van de doorbloeding en het ATP-gehalte in het ischemische hartspierweefsel: een verhoogd gehalte 
onveresterde vetzuren is aangetroffen als de doorbloeding lager is dan 0.3 mll min ${ }^{-1} . g^{-1}$ en als het ATP gehalte lager is dan $10 \mu$ mol. $\mathrm{g}^{-1}$ drooggewicht.

- de veranderingen in mechanische functie en stafwisseling in de ischemische linker kamerwand zijn warschijnlijk niet te wijten aan de ophoping van onveresterde vetzuren, zoals well is voorgesteld door andere onderzoekers op grond van proeven met geisoleerde harten of enzymsystemen.

- een viervoudige kunstmatige verhoging wan de concentratie onveresterde vetzuren in het bloed veroorzaakte een afname van $16 \%$ wan de doorbloeding in het ischemische deel van de linker kamerwand. 


\section{HTERATURE}

Albert, 䊉R., M.A. Cordon: Myofibrylliter adenosine triphosphatase actiwity in conges tive heart: fallure.

Ma 3. Phystol. 202: 940m:046, 1962.

Mllard, J.R., R.L. Combarti, G.J. Mathakes, M.J. O'Nell1, and J.1.E. Hof fmen: Ravid-freezing transmural cardiac biopsy drill.

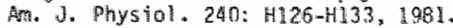

Allella, A., F.L. Whllians, C. Bolenem liams, and L.M. Katz: Intermelation betineen cardiac oxygen consumption and coronary blaod flowe.

Aya. J. Plysiol. 183: 570-582, 1955.

Allison, T.B., C.A. Ramey, and U.W. Holsinger: Tramsmurali gradients of left ventriculam tissue metabolites after circumflex coronary artiery ligation in dogs.

3. Mol. Cell. Cardial. 9: 837-852, 1977.

Alison, T.B., C.A. Ramey, and A.H. Holsinger Jr.: Effects on lablie metabolites of temporal deliay in freezing biopsy samples of dog myacardium in liquid nitragen.

Cardfovasc. Res. 12: 162-166, 1978.

Andrieu, JaL., C. Vial, B. Font, O. Goldschmidt, M. Lievre, and G. Faucan: Myocardial biochermical modifications induced by theophylline th reference to its value as antianginal drug.

Arch. Int. Pharmacodyn, 237: 330-342, 1979.

Andrieu, J.L., M. Lyevre, Q. Timour chath, and G. Faucon: Effects of propranolol on the biachemical modifications induced by a betamadrenergic drug in ischemic hearts.

Biochen. Phamacol. 29: 2687-2690, 1980.

Apstein, C.S., F. Gravino, H.B. Hood Jr. J. Frazer" "L. Hagopian, and P. Bissell: Limitations of lactate production as an index of myocardial ischemia.

Circulation $60: 877-888,1979$.

Ampur, J.A. and K.C. Randall: Canime left ventricular intramyaciardial pressures. Am. 3. Physiol. 220: 1833-1839, 1971.

Arts, M.G.J.: A mathematical model of the dynamics of the left ventricle and the corto nary chroulation.

Ph. D. -thesis, Untwersity of L4mburg. Mastricht. The Netherlands, 1978 .

Arts, M. G.u. and R.S. Reneman: Analysis of intirampocandia pressure (MP).

81b1. Anat. 15: 103-107, 1977.

Arts, M.G.J. and R.S. Reneman: Measurement of deforiatian of camine epicardium in viwo during cardiac cycle.

An. J. Physial. 239: H432-4437, 1980.

Arts, T., M. S. Reneman, and P.C. Veenistra: A unodel of the imechantcs of the left ventricle. Ann. Blomed. Eng. 7: 299-318, 1979.

Arts, T., S. Meerbaum, R.S. Reneman, and E. Corday: Cardlac wll mechanics and torstan of the left ventricle during ejection.

proce of the $3^{\text {rd }}$ Meeting of the Eurapean society of Bionechantes, $1982^{\text {a }}$ (in press).

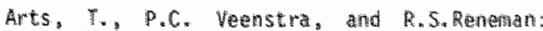
Epicardial defomatom and left ventricular wall mechanics durlng ejectlon in the tog. Hit. J. Phystal. $19 x^{\circ}$ (in press).

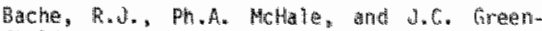
field Ju.: Transenural myocardial perfusion during restricted coronary inflow in the awake a

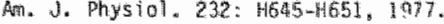

Ball, R.M., R. J. Bache, F, R. Cobb, and J.C.

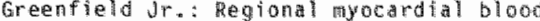
flow during oraded treathill exercise in the dog.

J. Clin. Invest. $55: 43-49,1975$.

Banka, W.S., M.M. Bodenhemer, and R.H. Hellfant: Relation between progressive decreases in regianal coronary perfusion and contractine abnomm lit.ies.

An. J. Cardiol, 40: 200-205, 1977 .

Barany, M. .E. Gatjens, K. Garany, and $E$ Karp: Comparat lve studies of rabbit cardiac and skeletal musins.

Arch. Blochen. Biaphys. 106: 280m293, 1964.

Berger, H.d., B.L. Zaret, L, Speroff, L.S. Cohen, and 5 . Wolfsom: Regineal cardiac prostaglandin release during mocardial ischemia in anesthet lized doas.

Circ. Res. 38: 566-571, 1976.

Bergmeyer, H.U. E. Bernt, F Schnidt, and $H$ Stork: D-glucose detemination with hexuk inase and glucose-6iaphosphate dehydrogenase.

In: Methods of enzymatic analysis. Ed. H.U. Bergmeyer, Acadentic Press, New York, N.Y., 1974, pp 1106-1201.

Berne, R.: Cardiac mucleotides in hypoxia: possible role in regulation of coronary blood flow:

Ant. J. Phys ioll. 204: 317-322, 1963.

Berry, 3.W. D.G. Chappell, and R.B. Barmes: Inproved method of flame photometry. Ind. Eng. Chem. Amal. Ed. 18: 19-24, 1946.

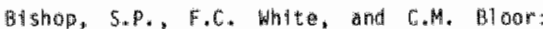
Reglonal myocardal blood flow durlng acute noyocardial infarction in the conselous dog. Circ. Res. 38: 429.438, 1976.

Blass, K.-E., P. Mernt. Effects of unsaturated fatty actes on canime coronary flow.

Acta Bial. Med, Ger, 37: 765-767, 1978.

Boerth, R. C. J.H. Cowell, 5.C. Seagren, and P.E. Pooll: High arergy phosphate concentro tions in dow mocardith durtng stress. Art. 3. Phys 10l. 216: 1103 1106, 1969 .

Borst, P., J.A. Loos, E.J. Christ, and E.C. Slater: Uncoulitiog actirity of long-chain fatuty acids.

Blochim. Blophys. Acta 62: 509:519, 1962 .

Bouskela, E., and C.A.t. Wilderhelm: Microwas cular myogentc reactlon in the wing of the intact unanestheztzed bat.

Am d. Phys 101, 237: $459-465,1979$.

Bratesch, H., 5. Gudbugarmasora, P.S. Purt K. G.

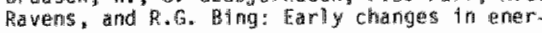


gy metabolism in the mocarding following arume coronary artery declustan in anesthethied doges.

chectes. 23: $59-430,1968$

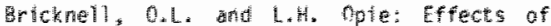

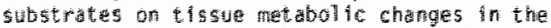

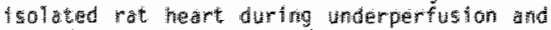
on release of liatate dehydrogerase and ar

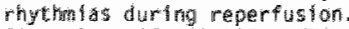

Circ, Res, $3: 102-115,1978$.

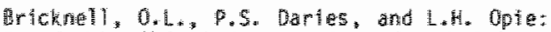

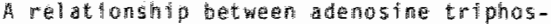
phate. glycolysis and ischemic contracture in the isoliated rat heart.

J. Mol, Cel 1. Gathol, 13: 941-945, 1951.

Buckberg, 63., D., J.C. Luck, 0, B. Payne, J.1.

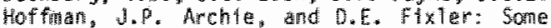
sources of error ur mexsuring regiona blood

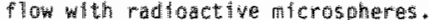

J.Appl. Phystol, 31: 598-604, 1971

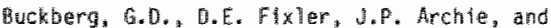

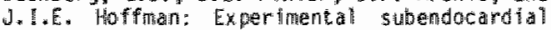

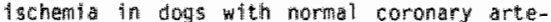
rites.

C1rc. Ris. 30: $67-81,1972$.

BuY-Mong-Kung, G. Jarry, and D Laurant: Determination of left' wertictalar heat production in worktng dag heart.

J. Physiol., Paris 77: 711-710.

Burns, a.k. J.W.Covel1, R. Mers, and J. Ross: Comparison of directly measured left ventmicular wall stress and istress calculated from geometric reference figures.

Circ, Res. 28: 611-621, 1971 .

Burrows, M. E, and P.C. Johnsom: Diameter. wall tension, and flow in mesenteric arterioles during autaregulition.

An. J. Physto1, 241: H929-H837, 1981.

Came, R., R.A. Harroson, R.A. Shaptro, and 3. Kavanatigh: The spectrophotometric absorbance of intral ipid.

biesthes lology $53: 53-55,1980$

Capurro, H.L., K.C. Marr, A. Anoudt, R.E.

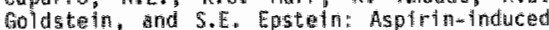

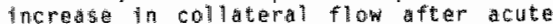
coromary acclustan ton dogs.

Circulation 59: $744-74$, 1979 .

Carlsson, E.: Expeminental studies of ventri-

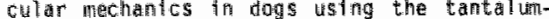
Wabel ed heart.

Fed. Prow, 28, 1224-1329, 1969 .

Christie, W. Wh: The isolation of $11 \mathrm{ptids}$ from tissues.

In: Lipld analys's. Pergamon Press, Dxard (1073), pq. $30-41$ (chapter 2$).$

Cobb, F, R. R. Bacher, and $y, c$. Greenfteld

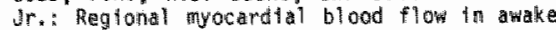
dogs.

J.C11n. Irmesit 53: $1613-1625,1974$.

Cobbe, 5.H. and P.A. Poolentlson: Tissue acidosis th myocardin hypoxia.

J. Mol. Cel1. Cadlat, 12:761-770, $198 \mathrm{n}$.

Coraboeuf, E. E. Deroubatx, ard J. Hoerter:

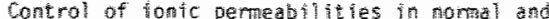
ischerist beart.

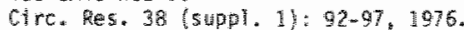

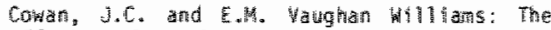
effects of varions fatty actis on action potential sibortening durithg sequential periods of ischemationd reperfustion.

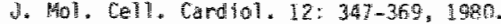

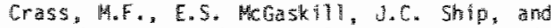
V. K. Murith: Wetzbolis of entogenous lipids in cardiac muscle: Effect or pressure development.

ha. d. Prysiol. 220: 428-435, 197 1.

Crass, M.F, and G.M. pieper: lo sid and alyoogen ofetalisolism the hypoxit heart: Effects of epinephrine.

Am. W. Phys101. 229: 505-889, 1975.

Crass, M.F. and P.R. Stemettit Distribution of glyoogen and lipids in the ischemlc canine left wentricle: blochemical and light and electron microscoptc correlates.

Recent Adv. Stud. Cardiac Struct. Hetab. 10 : $25:-261,1975$

Crozatier, E. M. Ashreat, M. Franklin, J. Ross Jr, L. Nimo, and a. Wckown: Sarcomere lengith in experimental zyocardial infarction: evidence for samcomere overstretch it dysklmetic ventricular regions.

J. Mol. Cel1. Biol, 9: 785-797, 1977.

Crozatier, B., D. Franklin, H. Tomolke, and d. Poss Jr.: Nitroglycerine $1 \mathrm{f}$ experimental nyocardal infarction in the babow. The effect of reducing the precharge and postcharge on regional myocandial function.

Arch. mal Caeur 71: 701-710, 1978.

Crystal, G.J., R.B. Boatwright, H.F. Downey, and F.A. Bashour" Shunting of wicrospheres acrosis the canime coronary carculation... An. J. Physiol. 236: H7-Hil2, 1979

Dagemats, G.R. and B. Jalbert: Effect of lincreased free fatty acids on myocardial oxygen extraction and anglinat threshold during atiol macing.

C1rcilation 56: $315-319,1977$.

Danforth, W.H.: Activator of glycolytic pathisidy in muscle.

In: Control of energy gentalism. (eds.: B. Wharace, R.H. Eastbroolk, J!n. Willtamsom), Acadientic press, 1965 , p $287-297$.

Deboer, L.W.V., 3.5. Ingwall, R.A. Kioner, *ind E. Braunwald: prolonged derangements of camine myocardial purine metabolism after brief coronary artery acclusion not associ. ated with anatomic evldemce or necrosts.

Proc, Nat, Acad. Sct. US Blot. Sct: 77: $5471-5476.1980$.

Dhinlla, M.S., a.C. Vates, D.A. walz, V.A. Mctonald, and R. E. O son: Correlat ton between changes in the endogenows enemgy stores and myocardia function due to hypoxia in the Isolated perfused rat heart.

Can. J. Physiol. Pharacol, 50: 333-345, 1972

Domenech, R.J., J. L.E. Hoffian, M. I, M. Noble, 
K. S. Saunders, J.R. Henson, and S. Subijianto: Total and regional coromary blood flow mea sured by radioactive microspheres in conscious and anesthet ized dogs.

Circ. Res. 25:501-596, 1969.

Domerech, Pas. : Total and regional coronary blood fllow during acute coronary occlusion in anesthetized and conscious dogs.

Carditavic. Res, 8:415-422, 1974 .

Dowell, R.T.: Transmural citrate symthase and lactate dehydrogenase levels in hypertrophiced rat left ventricle.

Prioc. Soc. Exp. Biol. Mec. 158: 599-603, 1978.

Dowmey, U.M.: Myocardial contractile force as a function of coronary blood flow.

An. J. Physiol. 230: 1-6, 1976.

Downey, J.M., and E.S. Kirk: Inhibition of coronary blood flow by a vascular waterfill mechamism.

Circ. Res. 36: $753-760,1975$.

Downey, H.F., F.A. Bashour, 8. Jishi, ard P. E. Parker: Amternovenous shunts in dilated or reperfused canine comonary yascullature.

Microwasc. Res. 17: 22-27, 1979.

Orake, A.J., J.R. Haines, and M.I.M. Moble: Preferentiai wptake of lactate by the nomal myocardium in dogs.

Cardiovasc. Res. 14:65-72, 1980a.

Drake, A.d., D.E. Papadoyannis, R.G. Butcher, d. Stubos, and M.ll.M. Moble: Inhibition of glycolysis in the denervated dog heart.

Circ. Res. 47: $338-345,1980 \mathrm{~b}$.

Driscoll. T.E. and R.W. Eckstein: Coronary inflow and out flow response to coromary artery occlusion.

Circ. Res. 20: 485, 1967.

Dunn, R.B. and D.M. Griggs Jr.: Transmural gradients in ventricular tissue metabolites produced by stopping coronary blood flow in the rog.

Circ. Res. 37: 430-445, 1975 .

Dumn " A.B. K.M. MCDonough, and D.M. Griggs Ar.: Cardioacceleration by atrial pacting and transmural metabollte levels in the cantane left ventricle.

Proc. Soc. Exp. Siol. Med. 158: 230-242, 1978.

Edwards, C.H., J. Scott Rankin, P.A Mchale, D Ling, and $R . W$. Anderson: Effects of Ischertit a on Peft ventricular regional function in the consclous dag.

An. J. Physiol, 240: H413-H420, 1981.

El shuraydeh, $k$ : Cardac dimensions and intraFlural deformations.

Ph. a. thests, University of lutrecht, The petherlands, 1991.

Estes, E.H. "M., L. Entman, H.B. Dixon, and D.B. Hackel: The vascular supply of the left venticultar wall.

Am Heart d. 71: 58-67, 1966.

Evans, L.: Starling's principles of human physlology. J.A. Church111, London (1936). pp. 706.

Evans, M.R.; Inpowitance of fatty acti in myocardial metabol ism.

Circ. Res. 14 (suppi. 2): $96 \times 108,1964$.

Fan, F. -C., G.B. Schuesslear, R.Y.2. Chen, and S. Chien: Determathations of blood flow and shenting of 9-un exte 15um spineres in regional beds.

An. J. Physiol, 237: H25m-H34, 1979.

Feigl, E.0.: Contral af macardial oxpen tension by syapathetic coronary vasoconstic. triction in the dog.

Circ. Res. 37: $88.95,1975^{a}$.

Feigl, E.0.: Reflex parasympathet te coronary vasadilatetion elicited from cardilac receptors in the dag.

Circ. Res. 37: $175 m, 182,1975^{\mathrm{b}}$

Feigl, E.0. and O.L. Fry: Intramural myocar. dial shear during the cardiac cycle.

Circ, Res. 14: 536-540, 1964.

Feigl, E.0., G.A. Stmom, and D.L. Fry: Auxotonic and isometicic cardac force transtilcers.

J. Appl. Phystol. 23:597-600, 1967.

Fenton, T.R., Jak. Cherry, and G.A. Klassen: Transmural myocardial deformation in the canine left ventricular wall.

Arri. 1. Phys 101, 235, $1523-4530,197 \%$.

Feurray, D., J.A. Idell-benger, and J.R. Neely: Effects of ischemila on rat myocardial function ard metabolisin in diabetes.

Circ. Res. $44: 322-329,1979$.

Feuwray, D. and d. Plouet: Relationship between structure and fatty acid metabol ism in mitachondria isolated fram ischemlc rat hearts.

Circ. Res. 48: $740-747,1991$.

Fiske, C.H. and Y. Subbaraw: The calarimetric determination of phosiphorus.

J.B 101. Chent. 66: $375-400$ : 1926 .

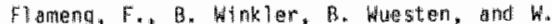
Schaper: Miniutival requlitremients for the mea surement of regtonal myacardial flow usting tracer microspheres.

Bib1. Arat. 15: 24-29, 1977.

Franklin, 0.: The detenmination of myocardila? wall thickness by witrasonic means: general discussion.

In: Cardtovascular applications of ultraw soumd. Ed. R.\$. Rerieman, Morth-Holland Puiditishing Company, Amsterdam, 1974, p 454 n

Franson, R.C.: D.C. Pang, D.W. Towle, and W. B. Weglickli: Phospholfipse A actlytty of hlighly enriched preparations of cardiac sarcollema from hamster and $\mathrm{dog}$.

J. Hol, Cell. Cardal. 10: 921-930, 1978.

Fung, Y. wh.: Stochastic flow in capllary bload vesseils.

Microwasc, Res. 5: 34-48, 1973.

Gallagher, K.P., T. Kumada, A.B. Reese, D. Mckown, and J." Rass ur.: Correlation of 


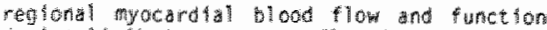

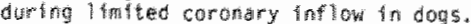

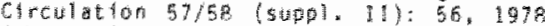
(abetract).

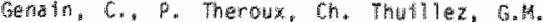
Gourdss, and D.f. Waters: The frtarrala-

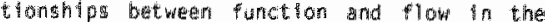
suberdocaralat arbo subuevicardial reglons of the left vertiriche.

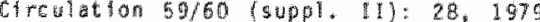
(abestract)

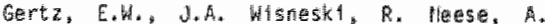
Houser. R. Rorte, and doD. Erlstan: Mocar-

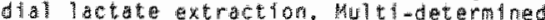
metabolic inction.

circulation 61: 256-262, 1990.

Gevers, H.: Germeration of protons by metabolic processes ini heart cells.

J.Mol1. Cell. Cardol. 9: 867-874, 1377.

Glacomint, hu, s.E. Swezey, d.C. Glacomint, Bra T.F. Buschke: Adrinistration of heparin causes in whro release of non-esterifted fatty actos th humain plasma.

Life $501.27: 771-781,1980$

Gibos, C.L." Candiac energettics.

shystol. Rev. 58: 174-255, 1978 .

Giesen, $d$. and 4 , Kanmermeler: Relationship of phosphorylution potential and axygen consumption in isolated perfused rat hearts.

J. Mol. Cell. Cardiol. 12: 891-909, 1980.

Glaster, d. and P. Harris: Fatty acid binding to cytoplasmic protelns of myocamdium and red and white skeletal muscle in the rat. has sible new role for moglobin.

Biachern. Btophys. Res. Commun. 74: 506-513. 1977.

Goldfarb, R.o. and Th.M. Glem: Beneftcial effects of prostaglandin $F$ alpha in experimental myocardian finfarctiofm.

At. J. Cardiol, 33: 139, 1974 (abstract).

Gould, K.L., K. Lipscomb, and C. Calvert: Comperisatory thanges of the distal coronary wasular bed during progresstue coromary constriction.

efrevilation 52: 1085-1094, 1975.

faregg, D.E.: The natural history of coronary collliteral feveloment.

Clrc. Res. 35: 335-344, 1974 .

Griggs, D.M., W. W. Tchokgev, and C.C. Chen: Trumsmural differences in ventricular tistate substrate heveis due to comonary constriction.

Am. J. Phystol, 222: 705-700, 1972 .

Ginton, A.F., H.L. Lin, and B.R. Gritum: Left ventricular free wall and intraventricular pressture-sarconere length distributions.

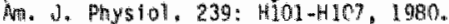

Gudbuarmason, S.,P. Mathes, and $x$. Ma. Ravens: Functional compartmentation of ATP and creathe phosphate in heart muscle.

J. Mol. Cell. Cardol. 1: 325-339, 1970.

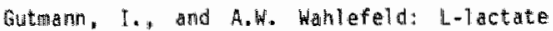
determination wh lactate dehydrogenase and NAD.
In: Methods of enzmidts andysis. Ed. H. l.

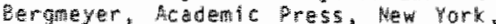
M. $\gamma, 1974$, pp $1464-1468$.

Guntheroth, H.6.: In vivo measurents of $d$. menstons of veins with fanplications regardting control of verous returin.

IEEE Trams. Bioned. Eng. 16: 247-25\%, 1969.

Ha der, B., 5.5. Ahined, C.B. Hoschos, H. H. Qldewertel, and T.R. Regan: Hyocardial function and coronary blood flow response ta acute ischemia in chrontc canine diabetes. clrc. Res. 40: $577.584,1977$.

Hales, A.R.S., R.B. King, and A, A. Fawcett: Observations on the valfdity of usting MEllo Trac microspheres. For measurting organ blood 11)

pellwegers Arch. 379: 295-296, 1979 .

Hearse, 0.d.: Dxyger deprivation and early mycardial contractile fallure. Reassessmert of the posistble role of adenosine trilohosphate.

Am. J. Cardiol. 44:1115-1122, 1979.

Hearse, D.J. and D.A. Stewart: Functonal

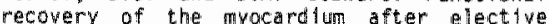
cardfac arrest in the 1501 it ted rat heart. The Lancet $\|$ : 192-194, 1974 .

Hearse, D.J. and D.H. Chappell: A multiple head issue sampler drill for regional mocandial studies.

J. Mol. Cell. Cardiol, B: 803-809, 1976.

Hess, 0.5. and R.d. Bache: Transmural right ventricular myocardial blood flow during sy'stole in the awake dog.

Circ. Res. 45: 88-94, 1979.

Hewitt, R.L., D.M. Lolley, G.A. Adroumy, and T. Drapanas: Pratectiwe effect of glycogen and glucose on the amoxic arrested heart. Surgery 75: 1-10, 1974.

Heymann, M.A., B.D. Payre, U.I.E. Hoffman, and A.M. Rudollph: Bload flow measurements with radtonuclide-labeled particles.

Prog. Cardiovasic. Dis. 20:55-79, 1977.

Heyndrickn, G.F." R. H. Mt11 ard, R.J. MacRitGhie, P.R. Maroko, and S.F. vatner: Regianal myocardial functional afol electrophystological allerations afeer brief coronary artery occluston in consclous dogs.

J. Clin. Invest. 56: 978-985, 1975 .

Higginsi, T.J.C., P.J. Balley, and D, All sopp: The influence of ATP depletion or the action of phospholipase $c$ on cardiac myocyte membrame phosshol ipids.

J. Mol. Cel1. Cardiol. 13: 1027-1030, 1981.

Higuchi, H. E. Tomonatsu, and K. Mish Tramsmural distribution of mocardial high energy phosphates and lactate in relation to the ploardial ECO in the underperfused canthe heart.

Pf lwegers Arch. 391: 101-104, 1981.

Hunds ,J.E. E.W. Hawthorne, C.B. Mullins, and $1 . H$. Mitchel: Instantaneous changes in the ventricular leingths occurring in dogs during the candiac cycle.

Federation Proc. 28: $1351-1357,1969$. 
Hirzel, H.0., G.R. Helson, E.H. Sonnenblick, and $\mathrm{E}_{\text {. }}$. Kirk: Redistribution of collatieral blood flow from necrotic to surwiving mocar dith following coronary occlusion in the dog. Circ. Res. 39: 214-222, 1976.

Matforand, Q.1. and R.P. Forsyth: Valdity studies of the radioactive microsphere nuthod for the study of the distribution of cardiac output, argan blood flow, and resistance in the conscious rhesus morkey.

cardiowasc. Res. 3: $326-342,1969$.

Hoffonan, u.1.E*: Deteminants and prediction of trensfoural mocardial perfusion.

Circulation 58: $381-391,1978$.

Hoffman, J.I.E.: The effect of intraniyocardial forces on the distribution of intram mylocardial blood flow.

J. Biomed. Eng. 1: 33-40., 1979.

Holtz, J., W.A. Grunewald, R. Manz, H. wan Restorff, and $E$. Bassenge: Sntracapillary hemoglobine oxyger saturation and oxyger consumption in different layers of the left ventricular mocardium.

Pfluegers Arch. 370: 253-258, 1977.

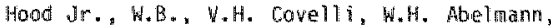
and J.C. Moman: Persistence of contractile behavior in acutely ischemic myocardium.

Cardlowasc. Res. 3: 249-260, 1969.

Hort, Wi: Makroskopische und mikrometrische Untersuchungen an Myokard Werschiedem stark gefuel ther linker Kafmern.

Anch. Path. Anat. Physiol, 333: 523, 1960.

Hough, F.S. and W. Gevers: Catecholamine release as riediator of intracellular enzyme activation in ischemic perfused rat hearts.

S. Afr. Med. J. 49: 538-543, 1975.

Huistan, R.M., G. Elzinga, $\mathbb{N}_{\text {. Westerhof, and }}$ P. Sipkema: Measurement of left ventricular wall stress.

Cardrowasc. Res. 14:142-153, 1980.

Helelsmanin. W.E.: Coronary wasodilatation by fatty acids.

Sastic Res. Cardiol. 71: 179-182, 1976.

Hunneman, D.H., C. Schwelckhardt, M.M. Gebhard, C.u. Prelusse, and H.J. Bretschnetder: Intramyocardial FFA cancentration after treatment ith verapanil.

Pfluegers Arch. Suppl. 301: R12, 1981 (abstract).

Ichinara, K. and \%. Abiko: Differences between andocardial and epicardial utillization of glycogem in the ischemtc heart.

Ar. J. Physiol. 229: 1585-1589, 1975.

lchithara, $K_{*}$ and $Y$. Abtho: Inhibition of endo- and epicardial glycogenolysis by propramollot in ischemic hearts.

Am. J. Physioll. 232: H349-H353, 1977.

Ithihara, K., M. IChinara, and $Y$. Abtho: Possible role of betamadrenergic receptors in myocardial metabolic response to ischemia.

Int: Perspectives in cardiovascular research, wol 3. Ischemic myocardium and antianginal drugs (eds.: M. W. Winbury, Y. Abiko). Rawen Press, Wew York, 1979, pp. 17-28.
Idell-Wenger, U.A., L.W. Grotgohat, and J. Neely: Coenzyme $x$ and cartitine distribution in nomal ard ischetsic hearts.

3. Biol, Chem. 253 : $4310-4319,1978$.

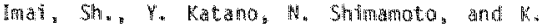
Sakai: Energy metabolis in ischemic myociandiun as studied in the isolated perfused guinea pig heart.

In: Perspectimes in cardiovascular research. ischemic myocarditum and antianginal drugs (eds.: M.M. Hinbury, $Y$, Abiko). Raved

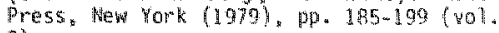
3).

lngels, N.B., G.T. Daughters, and S.R. Mo. vies: Stereo photogrammetric stuties on the dymantc geomet $r y$ of the canine laft wentricum lar epicandiugn.

1 Biomech. 4: $541-550,191$.

Irisawa, H., $A_{n} P$. Greer, and R.F. Rushomer: Changes in the dimenstons of the vena cava. Ant. J. Physiol. 196: 741-744, 1959.

Jageneau, A.H.M., W. van Gerwen, R. Kruget" H. van Belle, and R.S. Rememan: An improwed arilatal model for studying the effect of drugs on myocardial metabol ism during ischenta.

Recent Ady. Stud. Candiac struct. Metab. 10: $331-341,1975$

Jansen, H.: Lipolytic activities ip postheparin serum.

Ph. D-thesis, Medical Facullty, Rotterdam, The Netherlands (1975).

Jedeikin, L.A.: Regional distribution of glycogen and phosphorylase in the ventricles of the theart.

Circulation 45: 202-210, 1964

Jennings, R.B. and C.E. Ganate: Hitochondry al structure and function in acute myacandliat ischentic injury.

Circ. Res. 38 (suppl. 1): 80-89, 1975.

Jennings, R.B., H.K. Hawkins, J.E. Lowe, M.L. Hill, S. Klotman, and K.A. Reimer: Relation between high energy phosphate and lethal infury th mocoardat schenta in the dog.

An. J. Pathol. 92: 187'-215, 1978.

Jennings, A.B., K.A. Reinier, H.L. Hilli, artid S.E. Mayer: Total lschemia in dog heartis in vitiro. 1. Comparisom of high-energy phosphate production, utilltation and depletion and of adenine nucleotide catabolism in total ischemia in witro ws. severe ischenta in wivo. Circ. Res. 819: 880-900, 1981.

Jesmok, G.J., D.C. Warltter, G.J. Gross, and H.F. Hardman. Tramsmural triglycerides in acute mocardial fschemia.

Cardovasc. Res. 12:659-666, 197\%,

Jones, C.E. J. Jo Thomes, J.C. Parker, and M.E. Parker: Acute changes in high energy phosphates "nucleotide deriwatives, and contractile force in ischerilc and nonm is chemic canine myocardium following conomary acclusion.

Cardiovasc. Res. 110; 275-282, 1976.

Jong, J.H. de, and S. Goldstafn: Changes in coronary venous inosine concentrat ion and myocardial wall thickening during regional 


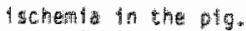

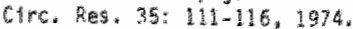

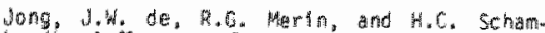

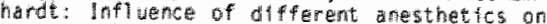

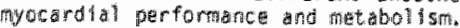

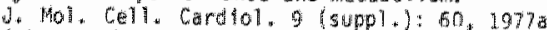
(abseriction)

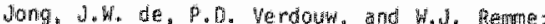
Myocardial fucleostate and carbohydrate metr boil is gitom and reperfistion af pig caronary artary. d. Hol. rell, cardul, 9: 297-312, $197 \mathrm{~b}$.

Uange, da: Inleiding tat de medische stitisHek. Deel II, G53. Ned. lmst. voor Prew. Geneesk., letaten, 3964.

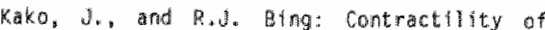
act In mostin bards preparated from norma

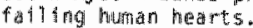

9. Clin. Invest. 974 465-470, 1558 .

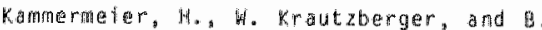
Karmermeler: Hyocardial hith energy phosphates as linfluenced by catachalamines and pressure load.

pluegers arch. 349: $325-335,1974$

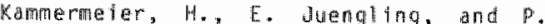
Schmidt: Hopotic fatione energy defichency or E-m-tecoup lngn

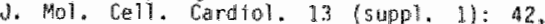
1981 (abstact).

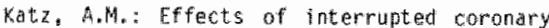
fow upor myocardial netalbolism amd contrac titity.

Prog. Cardtowasc. Dis. 10:450-465, 1968.

katz, A.M., and J.l. Hawell: Action from heart muscle: sul phydry groups.

cire. Pes. 14: $345-350,1964$

Katz, H.M. and H.H. Hecht: The early "pump" fallure of the fschenic heart.

An. J. Med. 47: 1497-1592, 1960

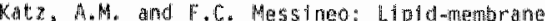
interactlons and the pothogenesis of isctemic

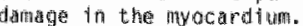

Cr. Kes. $48: 1-17,1961$.

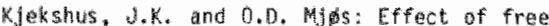
fatty acias on myocandial function and mets

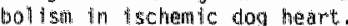

J. Clin. Invest. 51 : 1767.1776, 1972.

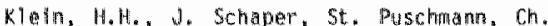
Whaber, H, Kreuker, and ho Schaper: Lass of canine rivocardial mícotimamido aderine dinucleotides deterintes the transtion from mewarsible to irreverstble ischenlc damage of thyocindal cellys.

Bas 10. Res, Card101, 76: 612-621, 1981.

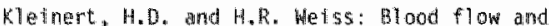
high-enargy phosphates in microregions af left ventriculam subendocardiut.

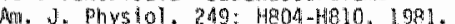

klocke, F.u. E. Bratumald, d Ross: Oxygen cost of electrical act iwation af the heart.

circ. Res. 18: $357-365,1966$.

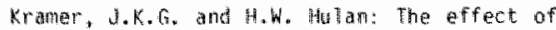

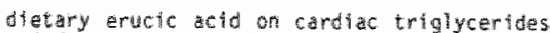
a

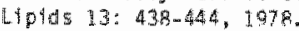

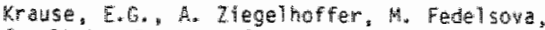

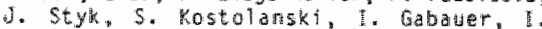

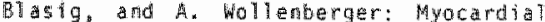
cyctic nucleotide levels tollowing coronary artery ligation.

Ady. Cardiol, 25: 119-130, 1977 .

Kuebler, H. and P.G. Spieckemanr: Regulaton of glycolysis in the ischemic and the anoxic myocidín.

W. Mol, Ge11. Cardiol. 1: $351-37 \%$, 1970.

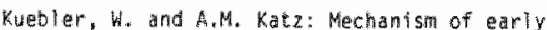
Dump futlitue of ischemic heart. Possible role of detemsine ipriphospltate depletion and finorabulc phos thate accural at han.

Ans. J. Cardiol. $40: 467-471,1277$.

Kumlen, $\forall, A_{\text {w }}$ and niwer, M.F.: Serum tree tatty acids after acte myocardial hifarction and cerebral vascular occlusion.

The Lancet if: $122-127,1966$.

Lab, Maj, and K. V. Wollard: Momophasio action potenthats, electrocardiograms anc

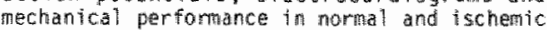
epicardial segatents of the pig vemuricle in sitit.

Candionase. Res. 12. 555-566, 978.

Lampracht, W. and I. Trautschald: Deteminam tion of aderosine triphosphate.

In: Pethods of anzymatic andysis. H. U. Bergneyer, Ed. Acadanic press, New rork,

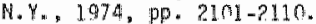

Lamprecht, H. P. Stein, F. Helnz, and $H$ he isser: neternination of creatine phospmate. In: Methods of enzymatic analysis. H.U. Bergineyer, Ed., Academic Pless, Hew York. M.Y., 1974, pp. $1777-1781$.

Lea, M. H. and G. Heber: Role of emzymes in homeostasis. VI 1. Inhibition of the act tuty of olycolytic enzymer by free fatty acids.

J. $610 \%$. Chem. $243: 1096 m 110 \%, 1968$.

Leints, J, de, L.H, Opte, and H. Latbbe: Effect of free fatty acid and encyme release in experimenta? glocose on myocardial infarction.

Nature $253: 746-747,1975$

Leiris, d. de and L.H. Npent: Effect of substrates and of coronary artery ligation an tachanical performance and on reieasie of $1 \mathrm{ac}$ thte dehydrogemase and creatinue phosphokinasie in isollated morking rat hearts.

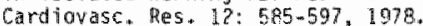

Liedthe, A. H.: A terations of caroohydrate

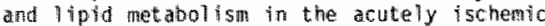
hearit.

Prog. Cardiovase, Dis. 23:32l-336, 1981.

Liedthe, A.J., 5. Nellis, and U.R. Heely: Effects of exeess free fatty acids on mechanical and metabolito function in nomal and ischeritic mocotedium in swine. Circ. Ras. 43: 652-62, 1978.

Liedtke, A.J., H.C. Hughes, amd J.R. theely: An experimental model for studying nyocardia? 
ischemia. Correlation of hemodynamic perform marce and metabolism in the working swine heart.

J. Thorac. Cardiowase. Surg. 69: 203-211, 1975 .

Lochner, A., A.C. M. Kotze, Aud.S. Benade, and Navers: Mitochondrial oxidative phosphory. lation in low-flow hypoxia: Role of free fatily acids.

N. Mol. Cell. Cardion, 10:857-875, 1978.

Lundsgaard-Hansen, P., C. Meyer, H. Riedwyl, E. Ehrengruber, E. Sitreit, and U. Schreiber: Transmural gradients of glycolytic enzyme activities in left ventricular myocardiun. I. The normal state.

prluegers Arch. 297; $89-1106,1067$.

Marcus, M.L., R.E. Kerber, U. Ehrhardt, and F.M. Abboud: Three-dinensional geometry of acutely ischemic myacardium.

circulation 52: $254 \times 263,1975$.

Marcus, M.L., R.E. Kerber, 3. Emmardt, F.M. Abboud, $M$. Schrader, $D$. Panther, and 0 . Lim: Effects of time on wolume and distribution of coronary collateral flow.

Am. a. Physioll. 230: 279m285, $1976 \mathrm{~m}$

Marsboam, R.A., D. Verstraete, D. Thienpont, and $D$. Phat theevws: The use of halo-anisone and fentanyl for neuroleptanalgesia in dogs. $\mathrm{Br}$. Vet. J. 120: 466-468, 1964.

Marzili1, M., H. H. Sabbah, and P.D. Stein: Supply-demand balance of subendocardial whuscle. Estimation from intramyocardial pres sure.

d. Tharac. Cardiovasc. Surg. 79: 80934809, 1980.

Marzilli, M. P. Carmici, H. Sabbah, P.D. Stein, and $F$. Ursini: Indirect evidence of regional differences of oxygen need within the left ventmicle.

4. Mol. Cell. Cardiol. 13 (suppl. I): 55, 1981. (abstract).

McHale, P.A., and J.C. Greenfleid: Evaluation of several geometric podels for astimation of left ventricular chrcumferemtial wall stress. circ. Res. 33: 303i-312, 1973 .

Hckever, W.P., D.E. Gregh, and P.C. Canney: Oxygen uptake of the nomworking left wentri. cle..

Clrc. Res. 6: 612-623, 1958.

Meduski, 3. W., B.C. Abtott, and J.0. Meduskf: Phystological aspects of the differences in the ability of mammatian cytomembranes to interact with molecular oxygen (abstract). Fed. Proc. 36: 567, $197 \%$.

Meer, Ju. wani der, and R.S. Reneman: An improved technique to induce a standardized functional stenosits of a coronary artery.

Eur. Surgl. Res. 4: 407-418, 1972.

Meer, J.u. van der, M.M.M. Jageneau, G. Elzinga, R. van Grondell, and R. S. Reneman: Changes in myacardial wall thickness (Mkt) in open-chest dogs.

Pluegers Arch. 340: $35-50,1973$.

Mishlin, 5., L. Stein, 2. Gatmatan, ard 1. Am
Arias: the bothing of fatcy acids to cytom plasmic proteins: binding to z-protein in liver and other tissues of the rat.

Biochem. Brophys. Kes. Contun. 1972.

Mos, 0.0.: Effect of free fatty acids on myocardial function and axygen corstumbution in intert dags.

3. Cinf. Invest. $50: 1386-1389,197^{\circ}$.

Mjos, 0.0.: Free fatty actios and oxygen consumption in dogs.

Scand, 4. clin. Lab. Imvest, 28: 121-125, 1971.

Mohrman, D.E. and E.A. Felgl: Competition betheen sympatheutic yasoconstriction and metabolic vasodilatation in camine coronary circulation,

Circ. Res. 42:79-86, 1978 .

Morgan, H.E., P.J. Randle, and 0.M. Regen: Regulation of glucose uptake by muscle. 3 . The effects of insulin, anoxis, salicate and 2:4adinturophenol on membrane transport and intraceliular phosphorylation of glucose in the isolated heart.

Biochen. J. 73: $573-579,1959$.

Most, A.Sin, R.d Capone, P. Szydlth, C.A. Brino and T.S. DeVonat Fallure of free fatty acids to influence the degree of myocandial injury following acute caronary anter'y occlu. sion in pigs.

cardiology 59: $201-21$, 1974 .

Nakamura, M, H. Matsuguchi, A, Mitsutake, ${ }^{\prime}$. Kikuchi, M. Takeshita, and 0 . Makagaki: Effect of graded caronary stenosis on myocardial blood flow and left ventrlcular wall motion.

Cardiology $72: 479-491,1977$.

Nayser, W. Bu: The role of calcilum in the i schemic myocardium.

At. d. Pathol. 102: 262-27n, 1981.

Nawer, W.G., P.A. poolemblison, and A. Hilltams: Hypoxia and calchum.

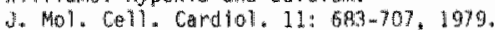

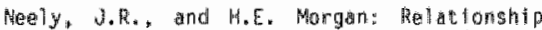
between carbohydrate and 11 pid metaboll 4 sm and the energy batince of heart muscle.

Aruth. Rev. Phys iol, 36:413-459, 1074 .

Neely, J.R., J.I. Whttmer, and M.J. Howetto: Effects of coronary blod fllow on glycolycic flux ant intracellicilar pH in lsolated rat hearts.

Circ. Res: 37: 733-741, 1975.

Nelson, 9.G.: Fire fatty actds and cardiec arrhythmias.

The lincet i: $783,1970^{\circ}$.

Nelson, P.G.: Effect of hepritin on serum free fatty actids, plasma catecholamines, and the incidence of arringthintos following acute

myocardial infarction.
Br. Med. J.: $3: 735-737,1970^{b}$.

Obeiti, A. H. Smlyen "R. Gilbert, and n. H. Eich: Regional ratetabolic changes in the myocardium following cororary artery ligatlon in dogs. 


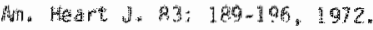

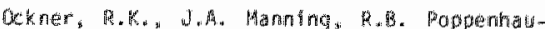

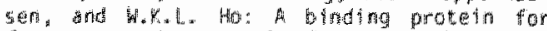

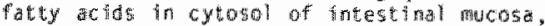
II wer" "myowardim, and other tisibes.

Sc fence $177: 56-58,1972$.

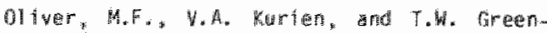

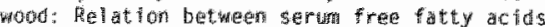

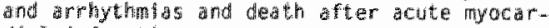

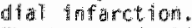

The Lamed i: $710-715$, $195 \mathrm{a}$.

DItuer, M. and P.A. rates: Induction of

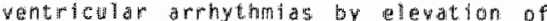
artertal frea fatty acids fin experimental

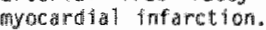

Cardiology 56: $399-364,1971$

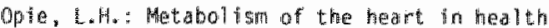
arud ifsease, Part I.

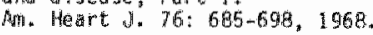

Ople, L.H.: Substrate atilization and glycolysis in the heart.

Cardiology $56: 2-21,1971 / 1972$.

Ophe, L.H:: Effects of regionat ischemia on metabolism of glucose and fatty acids.

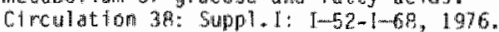

Ople, LuH. and K.R.L. Mansford: The wat we of lactate and pyruwate measurements in the os5essfrent of the redox state of free ricotinamide gdenilne dinacheots de in the cytoplasna of perfusied rat heart.

Eur. d. Clin. Invest. 1: 295-306, 1971 .

Opie, L.H., P.Thomas, P. Owen, R. W. Norris, A. J: Holland, and $S$. Van Noorden: Fallure of high concentrations of clloculating free fatty actols to provoke arrhythmias in experimental myocardial infarction.

The Lancet 1: $818-822,1971$.

opte, L.H. M. Thomas, P. Cwen and G. Shulland Increased coronary venous inorganic phosphate comcentrations during experimental myocardial Ischemla.

An: J. Cardial, 30:503-1513, 1972.

Dip, L.H. P. Owen, and R.M. Rlemersma: Reltue rates of oxtdation of glucose and free fatcy actas by ischente and nonischentic myocard"lube after cononary artery ligation in the dog.

cur. a. C14n, Inwest, 3: 419-435, 1973

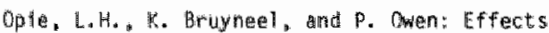
of glucos ansulin and potassidin theston on

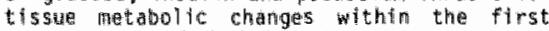
houm of myocardial infarction in the baboon. Circilation $5 ?: 49-57,1975$.

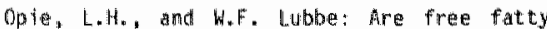
acids arthythnogentic

j. Mol, Cel1. Cardiol, 7: 155-159, 1975:

Ophes 1. H. and P. Owen; Effect of glucose.

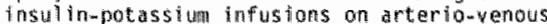
d) fremences of glucose and of free fatty acids on ts ske metabolic changes in dogs

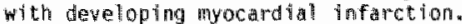

An. J. Cardiol. $39: 310-321,1976$.

Opye, L.H., P. Wen, and W. Lubbe; Est trated

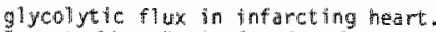

pecent Ads. Stut, Gardiac Struct, kntab. 7 $249-255 * 1975$ :

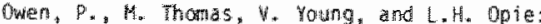
Comparisom between metabilic changes in loca wenous and corondry sinus hlood a axperifatent conomary arterial occlusion. Ass. J. Cardiol. 25: 562-570, 1970 ;

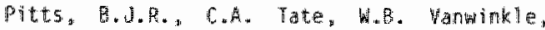
H. J. Wood, and M.L. Entman: Pallitulcarnutine intibition of calcium pump in cardiac sarcophasmic reticulun. Possible robe in myocar. dial ischemiat.

Life Sch. 23: $390-403,197 \mathrm{~B}$.

Phibbs, Ratt. and L. Dong: Momuff form distributior of microspheres in bood fllowing through a medium-size artery.

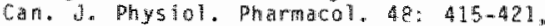
1970 .

Poolemilisan, P.A.: Is early decline of cardiac fumetion in ischemia due to carbon dibxide retenter

Lancet ?: $1285-1287,1975$

Poole-wison, P.A. and G.A. La her: The effect of acidosis and manganese on calcum exchange in the rayocardium of the rabbit.

ง. Physiol. $265: 20-21,1975$.

Pressman, B.C. and H.A. hardy" Effect of active agents on the latent ATPase of mitochondria.

Bicochim. Blophys. Acta 21 : 458-466, 1956.

Prokap, E.k. H. H. Strauss, J. shaw, B. pitt. and it. Whagner ir. : Comparison of regional 畔ycardial perfusion deterinined by ionic potassium 43 to that determimed by microspheres.

eyculation 50: $978-984,1974$.

Ramadoss, C.S., K. Uyeda, and W.H. Johnston: Studies on the fatty acid lpiactivation of phosphofructok inase.

J.Biol. Whem. 251: $98-107,1976$.

Randle, P.J., E.A. Newsholme, and P.B. Garm land: Pequlation of glucose wptake by miscle. 3. Effiects of fatty actds ketom bodies and pyruvate, and of alloxan-dlabetes and starvation, on the wotake and metabollic fate of lucose in mat heart and diaphagh muscle. 6rochen. a. $93: 652-665,9954$.

R日, E. E., K. I, Shine, and G, Langer: Potassiula sochanige and mecharical perfomance in anoxic mamal lian myocarditum.

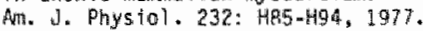

Rau, E.E. and G. L. Langer. Dissociation af emergetic state and potasiul los from anox ic myocardium.

An. J. Physiol. 235: $1537-4543,1979$.

Redding, $V_{\text {... J }}$ and J.R. Rees: Early changes in collateral flow following comonary artery ligation: the role of the sympathetic mervous systetern.

Cardiavasc. Res. 3: 219-225, 1968.

Regan, T.J.y H.A. Dldewurte?, and P.0. Ettinger: Regional coranary blood flow during ischemia or epinephrine: relation to myocar- 
dial potassium and triglyceride.

In: Myocardial blood flow in man. Methow's and significance in coronary distease (ed.: $A$. Haseri). Minerva Medica, Torino, Italy (1972), p. 424-434.

Retiner, K. A, M. H. Rasmussen, and R. B. Jenmings: Reduction by propranotol of myocardial necrosis folllowing temporary coronamy artery occlusion in dogs.

Cire. Res. 33: $353-353,1973$.

Reviner, H.A., R.Q. Jennings, and M.L, Mill: Total ischemila in dog hearts in vitro. 2. High-energy phosphate depletion and assoclated effects in energy metabolism, cell wol hme regulation, and sarcolental integrity. Circ. Res. 49: 9n1-911, 1981.

Reneman, R.5., A.M.M. Jageneau, W. van Gerven, d. Dory, and $P$. Beirniert: The radioactive microsphere method for the assessment of regional myocardial blood flow after coronary artery occlusion.

Pelluegers Arch. 353: 337-347, 1975.

Reneman, R.5, and A. verheyen: The radioac. tive microsphere method.

Bibl. Anat: 15: 15-19, 1977.

Reneman R. S., A. Werheyen, W. van Gerwem, L. Stijnem and A.H.M. Jageneau: The importance of size and diameter distribution of the microspheres for accurate detemination of regianal myocardial blood flow (MBF).

Bibl. Anat. 15: 30-34, 1977.

Reneman, R.S., A. Verheyen, W. van Gerven, L. Stijmem, and M.H.M. Jageneau: The importance of size and dialmeter distribution of the microspheres for accurate determination of regional myocardial blood flow (MBF).

Bibl. Anat. 15: 30-3i4, 1979.

Reneman, R.S., D.W. Slate, L, Lindborn, G.J. Tangelder, and $K_{n}-E$. Arfors: Muscle blood flow disturbances produced by simultaneously elevated wenous and total nuscle tissue pressure.

Microvasc. Res. 20: $307-318,1980$.

Rlemersma, R.A., R.L. Logan, M.F. Russe]1, and M.F. Ollwer: Heparin, free fatty acids and mycardial infarction in man.

J. Mal. Cell. Cardlol. 9 (suppl.): 45, 1977.

Remersma, R.A., RuL. Logam, and H.F. Ollver: Intrallpidheparin in metabolic studtes and in vitro llipolysts.

J. Mol, Cell. "Cardiol. 9 (suppl.): 45-46. 1977 .

Riemersma, R.A. and W.F. aliver: Raised plasma free fatty acids (FFA). ischemic myocardial metabolism and arrhythmias.

J. Mol. Cell. Cardiol. 11 (suppl, 2)" 48 , 1979.

Rivas, F., F.R. Cobb, R.J. Bache, and J.C. G. reenfield: Relationship between blood flow to ischemic regions and extent of myacardial infarction. Serial measurienents of blood flow to 5 shemic regions in dogs.

Circ. Res. $38: 439-447,1976$

Rognomi. F, and V. Vigano: Experimental research on metabolic effects of heparin and mocardial activity.

Artery 3. $180-187,1977$.

Ross. M.A. and D.0. Streeter Jr.: Nomulnifom subendocartital fiber ortentation in the nomal maca que left ventricle.

Eur. J. Cardiol. 3: 229-24\%, 1975.

Rothin, R.E, and R.u. Bing: Extraction art release of individual free fatty actos by the heart and fat depots.

3. clitu. Invest. 40: 1380-1386, 1661 .

Rouleat, A., L.E. Boenboon, A. Surjathana, and J.I.E. Hoffinat The role of autoregulation and tissue diastolic pressures in the transmural distribution of left weretricular blood flow in anesthet laed dogs.

Circ. Res. 45: 804-815, 1979

Rovetto, M.j.: Energy metabolisin in the ischemic hearti

Tex. Rep. Biol. Med. 39: 397-409, 1979

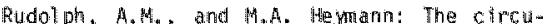
lation of the fetus in uitero. Methods for studying distribution of blood flow, cardiac output and organ blood flow.

Circ. Res. 21: 163-184, 1967

Rushner, R.F., D.L. Frankl औn, and R.M. Fllis: Left ventricular dimensions recorded by sanacard lometry.

Circ. Res. 34: 1-8, 1956.

Rubio, $R_{*}$, and R.M. Berne: Release of adenosime by the nombl myocardiun in dogs and its relationship to the regulation of coranary resistance.

Circ. Res. $25: 407-415,1969$

Russo, J.W., S. Margolis, C.C. Friestinger, and R.S. Ross: Heparin and ventricular arm rhythmias after myocardial infarction.

The Lancet 11: 1271-1275, 1970.

Rutenberg, H., J.C. Pamintuan, and L.A. Solaff: Serum free fatty acids and their relation to complications after acute myocardial infarction.

The Lallicet $\|$ 1: 559-564, 1969.

Schamhardt, H.C.: Reglonal nyocardit perw fus for and perfomance.

ph. D. - thesis, Erasmus Untwerstiy, Rotuterdath (1980).

Schamherdt, H.C., P.D. Verdoww. T.M. Wan der Hek, and P.R. Saxena: Reglonal myocandla 1 perfusian and wall thickness and arteriovenous shunting after ergotamine administration to pigs with a fixed coronary stienosis. d. Cardiovasc. Phamacol. 1: 673-687, 1979.

Schaper: W., The phystology of the collateral circulation in the nomal and hypoxic myocardium.

In: Rev, Phystal. Bfacheria Exp. Pharitacol. (eds.: E. Helmetch et al). Springer Verlag, Berlin-Heldelberg-New Varll. pp. 102-1445 1971: (chapter 63 ).

Schaper H., (ed.): The collateral circulattion of the heart. Horth-Hollaud Publ, Co., Amsterdam-Landon-New Yorlis (1971.6).

Schaper, W., P. Lewf, and A.H.M. dagenesat: 


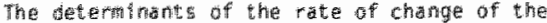
lieft ventricallar pressurg (dP/ot).

Arch pretsidufiorsch. 46: 27-41, 1965.

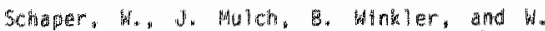
schaper: bltrastructural functorat and biccheralcil eriterte for astimation of reversibility of ischemie irijuty: a study on the

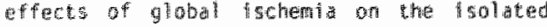
doy the thet.

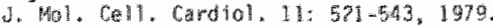

Scheler, $A$, and $5 . h$. Stezosth: Protective role of increased myocardal gilycagen stores An cardisa anoxla in the rat. circ. Fes. 27: $835-849,1970$.

Schosser, R. "K.-E. Mrfors "and K. Hessmer: M1C-11: a program for the wetermination of cardtac output, arterta-venous shunt and reglorit blood flow using the radloactive micrasuhere method.

Comput. Progir. Btomed. 9: 19-39, 1979.

Segra: G. Radial particle displacements in polseutlle flow of susperstions.

Nature 189: 209-210, 1961.

Shug, A.L., W. H. Themsen, J.D. Folts, N. flittar, M.I, Klein, J,R. Koke, P.l. Huth: Changes in is isue levels of carntine and other metabolttes during myocardial ischemia and amaxid:

Arch. Hoctien. Hophys. 187:25-33, 1978.

Snoeckx, L.M., s.L. Verheyer. A. wan de Water, P. Lewi, and R.S. Renemam: On-line computation of cardiac output with the thermodilution method using a digital miniconm puter.

Candiovasc. Res. 10: 556-564, 1976

Sobel - B.E., P.B. Corr, A.K. Robinson, R.A.

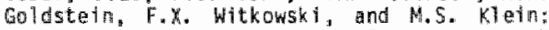
Accumulation of lysophosphoriycemides with arrhythmogentic properties in ischertic nvocarditump.

3. Cl1n, Invest. $62: 546.553,1978$

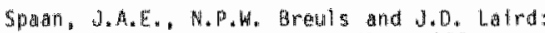
Ditatalla systolic coronary flow differences are calused bu intranyocardial pump action in tithe anesthetized doc.

Circ. Res. 49: 584-597, 1981 .

Sptra, D. and E.H. Sanmenbllck: The structum ral biasts of the contractille process in heart muscle under phystologlcal and pathological conditions.

Progr. Cardlowasc. 045. 7: 295, 1965.

Sphter, Nodu: Effect of lactate infusion on cantme mocardital free fatty actid metabolism tin vivo.

A4. J, Physial. 226:213-217, 1974 .

Stam, H. and W.C. Hel smarm: Release of IipoIytic products from rat heart. Hormonal stimulation, intracardiac origin and pharmacological modificotiom.

Biachem. Inter. 2: 477 48 $4,1982$.

Stegal, J.F., M.R. Kardon, H.L. Stone, and H.S. Bishop: A portable, simple sononicrometer.

1. Appl. Physiol, 23: 299-293, 1967.

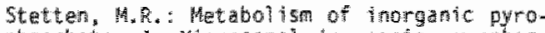
phosphate. 1 . Hicrosonal horganic pyrophosoh ate phosphotrangferase of rat liver.

3. Biol, Chen. 239: $3575-3583,1954$.

Streeter Jo, 0.0. H.H. Spotnitz, 0.P. Patel, 3. Ross Hr., and E. H. Samenbitek: Fiber orientation in the can a ne left ventricle guring diastole ardet systole.

Cinc. Res. $24: 339-347,1969$.

Streeter Jr.; D.D., R. H. Vaishanow, D.j. Patell, H.R. Spotntuz, J. Ross ar. and E.H. sonnenblick: Stress distribution in the cartine left wentricle during distole and systale.

giophy. d. 10: 345-363, 1070 .

Streeter dr., 0.0. and W. Thema: Engineering mechamics for successive states in canthe left ventricular myocandiua . II Fiber angle anof sarcomere length.

Clirc. Res. 33: 656-664, 1973.

Takano, 5.: Cenet ic stuches on the arrhythmia in acute myocardial infarction with special reference to seruth free fatty acto level. spr. Circ. U. 40:287-297, 1976.

Takenaka, $F$, and h. Higucht: High-energy phosphate contents of subeptcardum and stabendocardiun in the rat treated with isoprotereral and some other drugrs.

ل. Hol, Cell. Cardiol, 6: 123-135, 1974.

Tatooles, C.u. and W.t. Rand 11: Local ventricular bulging after acute coronary occlusion.

Am. J. Physiol, 201: 451-455, 1961

Tennant, R. and $\mathrm{C} . \mathrm{J}$. Wiggers: The erfect of coromary occlusion on myocardial contraction. An. J. Physiol, 112: 351-361, 1935.

Ten Velder, G.H.M.: Heat production of the canine left ventricle.

ph. D. -thesis, Free University. Amsterdan (19182).

Tein welden, G.H.M. "G. Elzthga, and M. Wes. terhof: Left ventelcular energetics: heat loss and temperature distribution of canine rinyociordium.

C1re. Res. 50:63-73, 1082.

Theroux, P., D. Franki in, J. Ross JP , and H.S. Kemper: Regiomal myocardial function durling acute corramary artery occlustan and it:s modification by phamacologic agents in the don.

Gite. Pes. 35: 806-909, 4974.

Therouk, P., J. Ross JP., D. Franklin, W.S. Kemper, and Sh. Sasayana: Regional myocardial function in the consclous dag during acute coronary acclusion and responses to marphine, onopianolol, ntroglycerin, and lidocitne. circulation 53: $302-314,1976$.

Theroux, P., J. Ros's Jr. D. Franklin. J.W. Covell, C.M. Bloor and 5 . Sasayama: Regional myocardial function and dimensions early and late after myocardial infarction in the unanesthetized dog.

Circ. Res. 40: 158-165, 1977.

Torrent-Guasp, F.: The cardiac muscle. Juan 
Manch Foundation, Madid (1973).

Tripe, M.R., S. Enetig, J.J. Leonard, A, Gerasch, C.R. Swaze, H.D. Manuel and Hod. Fox: Recem develorments if the measurement

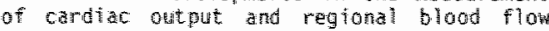
using inclocyanine green and microspheres. Med. Inst rua, 11: 160-165, 1977.

Irump, B. W. Mergner, M. Won Kahng, and A. Saladino: Studies on the subcellutar pathophysiology of ischentia.

Circulation 1: 17-26, 1976.

Tyberg, U.W., J.S. Forrester, H.L. hyatt, S.d. Goldrer, H.W. Parmley, and H.J.C. Swan? An analysis of segmental ischemic dysfunction utillizing the pressuremength loop.

Cinculation 49: $748-754,1974$.

Ut ley, J. E.L. Carl son, a. L.E. Hoftran; H.M. Martinez, and G.D. Buckberg: Total and regional Fyocardial blood flow measurements with $25 \mathrm{~m}, 15 \mathrm{~m}, 9$ and fittered $1-10 \mathrm{~m}$ diameter microspheres and antipyrine in dogs and sheep.

circ. Res. 34: $391-405,197$.

Vary, T.C., D.K. Reibel, and J.R. Heely: Control of energy metabalism of heart muscle. Ann. Rev. Phystol. 43, 419-430, 1981.

Vary. T.C. E.T. Angelakos and S.H. Schaffer: Relationship between adentne nucleotide metabolism and irreversible ischemic tissue damage in isolated perfiused rat heart.

Circ. Res. 45: 218. 225, 1979.

Vasdev, S.C., G.P. Bira, R. Marbaitz, K.J. Kako: Membrane changes induced by early myocardial ischemia in the dog.

Can. J.Bfochen, 58: 1112-1119, 1980.

Verdouw, P.D., H.C. Schamhardt, W.d. Reme,

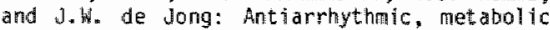
and hemodynamic effects of org 6001 (3al faamino 5 al fa -androstan-2bet-0L-17-one-hydrochloride) after coronary fiow reduction in pigs.

J. Pharmacoll, Exp. Ther, 204: 634-644, 1978.

Verclous, P.O., W. Beme, J.W. de Jong, amd H.A.P. Breeman: Myocardial substrate utillzation and hemodynamles following repeated coronary flow peduction in pigs.

Basic Res. Cardiol. 74: 477-493, 1979.

Vik-Mo, H., R.A. Riemersma, O.D. Njos, and M.F. Oliver: Effect of myocardial ischemia and antilipolytic agents on 14 polysis and fatty acid metabolism in the in sttu dog heart.

Sciand. J. Clin. Lab. Invest 39: $559-569$, 1979.

Vilk-Mo, Ha and 0.D. Mits: Influence of fire fatty actis on myocardial oxygen consumption and ischemic injury.

Am. 3. Cardiol. 48: 361 -365: 1981.

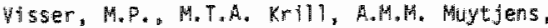
G.M. Willems, and W.Th. Hermens: Df stribution of enzymes in dog heart and liver. signtfi. cance for assessment of tissue damage from data on plasma enzyme activities.

C7 in. Chem. 27, 1845-11850, 1981 .

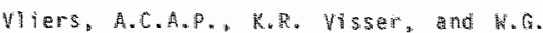

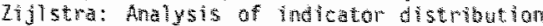

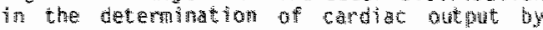

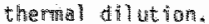

Condiograc. Res. $7: 125-132$, 1973

Vusce, G. W. van dar: Ane free fath actis harmful for the heartin

๖. Ding Res - 000-00n, 1082 .

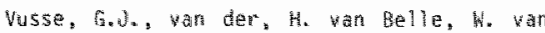
Gerwem, R. Kruger, and R.S. Rememan: Acude effect of fentany an henodymantes and mo-

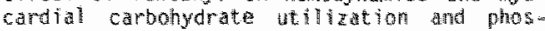
phate release duking ischemia.

Br. d. thesth. 51: $927.935,1979$.

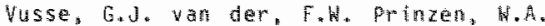
coumans, R. Kruger. C. Werlaan, and R.S. Reneman: Assessment of myocantial ischemla usting hemodynamic and biochentical variablas with specta reference to elevaled arterlal free fatty abd concentration by hamarim.

Adw. Clin. Cardtol. I: 407-420, 1980.

Vusse. G. Renaman: Assessment of fatty acids in don left verstricular mocardi wm.

BHochiti. Blophys. Acta 617 ; $347-352,1960$ b.

Wusse, G.u. van der, F. Pr. Prinen, and R. Rememan: Myocardial substrate uptake,

Bubl. Arat. 20: 497-502, 1981a

Wusse, G.J. van der" Th.H. H, Ponem, fi, Prinzen, and 胘.5. Reneman: The concentration of non-esteriffed fatty acids im biopstes

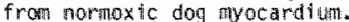

Hastc Res. Candiol, 76: 399-393, $1981 \mathrm{~b}$.

Vusse, G.J. van der, and R.S. Renenan: Glycagen apd 11 pids (endogenous substretes)

inn Cardiac metabolism. (eds. M. I.M. Noble and $A_{*}$ J. Orake, aublushed by john witey ard Sons Ltd, Chichester, England, 1982)

Wusse, G.J. van der, Th.H.M. Roemem, T. W. Prinzen, H.A. Counans, and R. S. Rememam; uptake and tissue content of fatty acilds in dog myocardifun umer normoxtc und ischemh conditions.

Cfrc. Res. 5n: noo-noo, 1902.

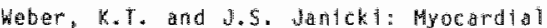
oxygen consumptiofi "the role of well force and shortentmi.

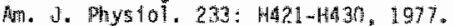

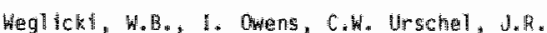
Serur, and E.H. Sonnenblick: Hydousts of myocarilal lipids during actdosts and ischem 洞 13 :

Recent. Adr, Stud. Cardlac Struct. Hetab. 3: $781-793,197.3 \%$

We latraub. H.S., S. Hateor, J.B. Agarmal,

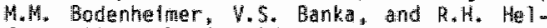
famt: The relationsh p betwen myocedrol bilood flow and contraction by myocardial layen the cantine left ventricite during sichemia.

Circ Re $5.48: 430-438,1901$.

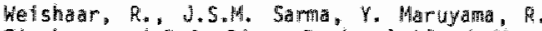
fischer, and R. B. Bing: Reglonit blood fiot. contrantilty and metabolism in araly mut cardial infarction. 
Carylalugy $62: 2-20,197 \%$

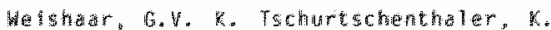

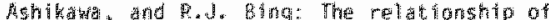
regional comanary blowd frow to witochondrial function durifor repertuston of the ischemic

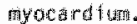

Curdology $64: 350-455,1979$.

Weiss, H. H.: Effect of coronary artery occluston on regional arterfal and wenous a saturation, $0_{2}$ extraction, blood fiow and $0_{2}^{2}$ consumption if the dog heart.

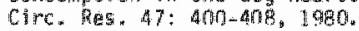

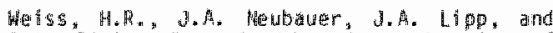
A.K. Slaha: Quantitative determination of reglonal oxymen consulipition in the dog heart. Clirc. Res. 42: $394-402,1978$.

Whitruer, J.T., J.A. Idell-benger, M.J. Povet-

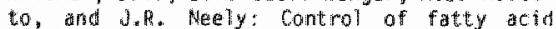
metrabolism in ischemic and hipoxic hearts.

3. Btol. Chem. 25. 4305-48ng, 1978.

Williangon, J. R.: Glycolytic control mechanisms. WI. Kinetics of intermediate changes durlag the arobic- anowic transtition in perfused rat theart.

J. B101. them. 241: 5026\%5036. 1966.

Whllamson, J.R.: Wnetic studies of epinephir ine effects in the perfused heart.

Pharmacal. Rev. 18: 205-21n, 1966.

Wi114ansom, J.R. "S.4. Sichaffer, A. Ford, and B. Safer: The cellular basis of ischemia and infarction, comtribution of tissue actuosis to ischentic anjury tin the perfused rat heart. circullation 53 , suppl. I: $1-3-1-14,1976$.

Hilson, M.F., W.M. CaldwelT, J.M. Gibsor, and S.J. Cho: Gauging systems to measure internal organ dimensions.

An: N. Med. Elctron. 2: 328-334, 1963

Winbury, M.M., B.B. Howe: Stenosis: regional ischemia and reserve.

In: Perspectiwes in cardiovascular mesearch wal. 3. lschemic myocardf un and antianginal drugs. Eds. M.M. Winbury and $\%$ Ablka, Raven Press. Naw york, N.H., 1979. pp. $55-76$

Wollenterger, A. anch L. Shathab: Anoxte-irdis. cad relogse of moradrenalthe from the isola. ted perfused hearnt.

Nature 207: $88-89,1965$.

Wollenberger, A. and E. G. Krause: Metalbolic controi chatucteristics of acutely ischemic myoca ard tum.

An. J. Cardilol. 22: 349-359, 1969.

Wisesten, B., 0.D. Buss, H, Dellst, and $W$. Schaper: Dllatory capacity of the coronary chrculation and its correlation to the arterlal wasculature in the canine left wentricle.

Bastc Res. Cardiol. 72, 635-650, 197\%,

Wyatt, H.L., J.S. Forrester, J.y. Tyberg, S. Goldner. S.E. Logan, H. h. Parmtey, and H.J.C. Swam: Effect of graded reductions in regional coromary perfusion om regional and total cardiac function.

Apr. J. Candiol, 36: 185-192, 1975.

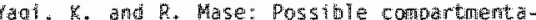
thon of adenine nucheotides in a complet reaction system composed of Factoryosinadenosinetriphosiphatase and creache kinase.

In: Molecular biology of rastiscular biology $0^{\frac{7}{3}}$ muscular contraction (eds.: 5. Ebasht, $F$. Osawa, Felkine and $\%$. Tonomur a). risevier pudi. Co., Amsterdan, 1965 , pp. $109-123$.

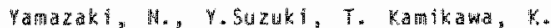

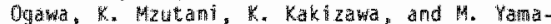
moto: Armythmogenic effects of acute free fatty ardid mobilization on 1 schemic heart. Recent Adv. Stud. Gadiac seruct. Metab 12 : $271-277,1978$

Mipintsol, T. W.A. Dobbs, P.D. Scanlon, T.u. knopp, aind J.B. Eassingthwaighte: Regional distribution of diffustible traces and carbonized microspheres in the left ventricle of isclated dog hearts.

Circ. Res. 33: 573-587, 1973.

Woran, $c$. J. Wowell and J. Ross: Structural basts for the ascending limb of left ventricular function.

circ. Res. 32: 297-303, 1973.

Zucker, I.H. and J.P. Gilmore: Atrial recepon tor disicharge dluring acute coronary occlusion in the dorg.

An. J. Physiol, 227: $360-363,1974$, 
NAWOORD

De studie, die aan dit proefschrift ten grondslag ligt, is begonnen als een prajekt binnen de werkgemeenschap hartfunktie van de Stichting voor Medisch Wetenschappelijk Onderzoek (FUNGO), met als projektleider prof. dr. R.S. Reneman. Het onderzoek is uitgevaerd a an de Rijksuniversiteit Limburg, binnen het kader wan het deelprajekt Myocard onder leiding van prof. dr. R.S. Rememan.

Een proefschrift staat op naam van een persoon, maar bijdragen zijn geleverd door velen. Al diegenen, die op enige wijze een bijdrage geleverd hebben aan de tot stand koming wan dit werkstuk wil ik hierbij hartelijk danken. Zonder daarbij iemand te kort te willen doen, wil ik een aantal met name noemen.

Het uitwoeren van dit anderzaek, waarbij verschillende facetten bestudeerd zijn van de drie-eenheid doorbloeding-metabolismemechanica van de hartspier, was alleen mogelijk dankzij grondige woorbereiding door, en goede samenwerking met Rob Reneman, Ger van der Vusse en Theo Arts.

Mijn dank gaat tevens uit naar Jasper Scholte, Mark Noble, Gijs Elzinga en Foppe ten Hoor, die met hun kritische kommentaren een wardevolle bijdrage geleverd hebben aan de totstandkoming van dit proefschrift.

WiT Coumans, Theo Roemen, Mat Rousch en Peter Will lensen hebben met grote nauwkeurigheid de chemische bepallingen werricht, en hebben geassisteerd bij de experimenten.

Het slagen wan deze experimenten is woor een belangrijk deel te danken aan de biotechnische bijstand van Inger Simons-Achterberg, Ruud Kruger, Cees Verlaan en Theo van de Nagel.

Els Geurts heeft het leeuwendee 1 van het typwerk verricht. Ik ben haar dankbaar voor de grote snelheid warmee zij steeds weer wijzigen aanbracht in tekst, en regel-en tabelindelingen. Even dankbiar ben ik voor de hulp van Bea Leliveld en Erik van der veen bij het toch nog tijdig voltooien van dit proefschrift. 


\section{LEVENSBERICHT}

2 Juli 1954 geboren te Hilversugh *

1966-1972 gymastum b gevolgd aam het Commentus College te Hilversum.

1972-1978 biologite gestudeerd aan de Rijksuniversiteit Utrecht.

$$
\begin{aligned}
& \text { kandidaatsexamen } \mathrm{B}_{5}{ }^{*} \text { ("medische biolo- } \\
& \text { gie"). } \\
& \text { doctoraalexamen met als hoofdrakken } \\
& \text { fysiolgie, klinische immunologie en } \\
& \text { bijvak histologie/celbiologie. }
\end{aligned}
$$

1 mei 1978 In dienst getreden als wetenschappelijk ambtenaar bij de Nederlandse Organisatie voor Zuiver Wetenschappelijk Onderzoek (ZWO), gestationeerd bij de capaciteitsgroep Fysiologie van de Rijksuniversiteit Limburg.

1 jan 1982 In dienst getreden als wetenschappelijk medewerker van de capaciteitsgroep Fysiologie, Rijksuniversiteit Limburg. 